\title{
Early (micro)circulatory haemodynamic changes in type I diabetes mellitus
}

\author{
Citation for published version (APA):
}

Houben, A. J. H. M. (1993). Early (micro)circulatory haemodynamic changes in type I diabetes mellitus. [Doctoral Thesis, Maastricht University]. Datawyse / Universitaire Pers Maastricht. https://doi.org/10.26481/dis.19931202ah

Document status and date:

Published: 01/01/1993

DOI:

10.26481/dis.19931202ah

Document Version:

Publisher's PDF, also known as Version of record

\section{Please check the document version of this publication:}

- A submitted manuscript is the version of the article upon submission and before peer-review. There can be important differences between the submitted version and the official published version of record.

People interested in the research are advised to contact the author for the final version of the publication, or visit the DOI to the publisher's website.

- The final author version and the galley proof are versions of the publication after peer review.

- The final published version features the final layout of the paper including the volume, issue and page numbers.

Link to publication

\footnotetext{
General rights rights.

- You may freely distribute the URL identifying the publication in the public portal. please follow below link for the End User Agreement:

www.umlib.nl/taverne-license

Take down policy

If you believe that this document breaches copyright please contact us at:

repository@maastrichtuniversity.nl

providing details and we will investigate your claim.
}

Copyright and moral rights for the publications made accessible in the public portal are retained by the authors and/or other copyright owners and it is a condition of accessing publications that users recognise and abide by the legal requirements associated with these

- Users may download and print one copy of any publication from the public portal for the purpose of private study or research.

- You may not further distribute the material or use it for any profit-making activity or commercial gain

If the publication is distributed under the terms of Article $25 \mathrm{fa}$ of the Dutch Copyright Act, indicated by the "Taverne" license above, 


\section{Early (micro)circulatory haemodynamic changes in type I diabetes mellitus}




\section{Early (micro)circulatory haemodynamic changes in type I diabetes mellitus}

\section{PROEFSCHRIFT}

ter verkrijging van de graad van doctor aan de Rijksuniversiteit Limburg te Maastricht, op gezag van de Rector Magnificus, Prof. dr. H. Philipsen, volgens het besluit van het College van Dekanen, in het openbaar te verdedigen op donderdag, 2 december 1993 om 14.00 uur

door

Alfonsius Josephus Hubertus Mathias Houben

geboren te Heerlen op 5 maart 1963 
Promotor:

Co-promotores:

Beoordelingscommissie:
Prof. dr. A.C. Nieuwenhuijzen Kruseman

Dr. N.C. Schaper

Dr. D.W. Slaaf

Prof. dr. P.J.E.H.M. Kitslaar (voorzitter)

Dr. M. Daemen

Prof. dr. R.S. Reneman

Prof. dr. H.A.J. Struijker Boudier

Prof. dr. J.E. Tooke (University of Exeter, UK)

\section{CIP-DATA KONINKLIJKE BIBLIOTHEEK, DEN HAAG}

Houben, Alfonsius Josephus Hubertus Mathias

Early (micro) circulatory haemodynamic changes in type I diabetes mellitus / Alfonsius Josephus Hubertus Mathias Houben. - Maastricht: University Pers Maastricht. - III. Thesis Maastricht. - With ref. - With summary in Dutch. ISBN 90-5278-103-6 Subject headings: diabetes mellitus / haemodynamics / (micro) circulatory blood flow.

\section{- 1993 A.J.H.M. Houben, Maastricht.}

Cover: author's finger nailfold capillaries.

Production: Datawyse Maastricht.

Financial support by the Netherlands Heart Foundation and the Scientific DurrerFund Foundation (ICIN) for the publication of this thesis is gratefully acknowledged. Furthermore this edition and promotion is supported by Novo Nordisk Pharma B.V., Hoechst Holland N.V. Pharma, Hemocue-Benelux, and Servier Nederland B.V.. 
"Only by experimenting......can we build up the majestic pile of factual information from wich our understanding of the natural world will grow."

Sir Peter Medawar in "Advise to a young scientist".

"De mensheid heeft in de loop van de tijd van de kant van de wetenschap twee grote aanslagen te verduren gekregen op haar naïve eigenliefde. De eerste keer was toen zij moest leren beseffen dat onze aarde niet het middelpunt van het heelal is, maar slechts een nietigheidje in een stelsel waarvan de grootheid nauwelijks voorstelbaar is.... De tweede keer was toen biologisch onderzoek de mens beroofde van het bijzondere privilege dat hij een speciaal schepsel zou zijn en hem degradeerde tot een afstammeling uit de wereld der dieren."

Sigmund Freud.

Veur Pa en Ma

en

veur Ineke en Joep 


\section{Contents}

Chapter 1

General introduction

1.1 Introduction 10

1.2 Aim of the thesis $\quad 10$

Chapter 2 Early haemodynamic changes in IDDM patients

and the pathophysiological mechanisms involved.

An overview.

2.1 Introduction 14

2.2 Pathogenesis of diabetic microangiopathy 14

2.3 Regulation of (micro)vascular blood flow $\quad 16$

2.4 Hyperperfusion early in the course of

IDDM. Pathophysiological mechanisms 18

2.4.1 Sympathetic neuropathy 18

2.4.2 Circulating vasodilator/vasoconstrictor hormones 18

2.4.3 Circulating metabolites 21

2.4.4 Endothelial vasodilator/vasoconstrictors $\quad 21$

2.4.5 Vascular smooth muscle function 23

2.4.6 Other factors 24

2.5 The role of glucose 25

2.6 Summary 28

$\begin{array}{lll}\text { Chapter } 3 & \text { Subjects and methods } & 41\end{array}$

3.1 Subjects $\quad 42$

3.2 Protocol $\quad 42$

3.3 Capillaroscopy $\quad 42$

3.4 Laser-Doppler $\quad 45$

3.5 Plethysmography $\quad 47$

3.6 Skin temperature $\quad 48$

3.7 Blood pressure and heart rate 49

3.8 Statistical analysis $\quad 49$

Chapter 4 Diurnal variations in total forearm and skin microcirculatory blood flow in man 51

4.1 Abstract 52

4.2 Introduction $\quad 52$

4.3 Subjects and methods 53

4.4 Results 54

4.5 Discussion $\quad 58$

Chapter 5 Skin blood cell flux in insulin-dependent diabetic subjects in relation to retinopathy or incipient nephropathy

5.1 Abstract 64

5.2 Introduction 64

5.3 Patients and methods 65 
5.4 Results 67

5.5 Discussion 69

Chapter 6 Venous distensibility and the venodilatory effect of nitroglycerin in insulin-dependent diabetic patients with and without early nephropathy 75

6.1 Abstract $\quad 76$

6.2 Introduction 76

6.3 Subjects and methods $\quad 77$

6.4 Results 79

6.5 Discussion 80

Chapter 7 Peripheral macro- and microcirculation in shortterm insulin-dependent diabetes mellitus: the role of prostaglandins in early haemodynamic changes $\quad 87$

7.1 Abstract $\quad 88$

7.2 Introduction $\quad 88$

7.3 Patients and methods $\quad 89$

7.4 Results 91

7.5 Discussion 93

Chapter 8 Acute effects of local hyperglycaemia on peripheral blood flow in man $\quad 99$

8.1 Abstract 100

8.2 Introduction $\quad 100$

8.3 Subjects and methods $\quad 100$

8.4 Results 102

8.5 Discussion 105

Chapter $9 \quad$ The effects of 7-hour local hyperglycemia on forearm macro- and microcirculatory blood flow and vascular reactivity in healthy man 109

9.1 Abstract 110

9.2 Introduction $\quad 110$

9.3 Subjects and methods 111

9.4 Results 115

9.5 Discussion $\quad 121$

$\begin{array}{lll}\text { Chapter } 10 & \text { Summary and conclusions } & 127\end{array}$

10.1 Summary ' 128

10.2 Conclusions 132

$\begin{array}{lr}\text { Samenvatting } & 135\end{array}$

$\begin{array}{ll}\text { Tenslotte } & 140\end{array}$

List of publications $\quad I 42$

$\begin{array}{ll}\text { Curriculum vitae } & 144\end{array}$ 


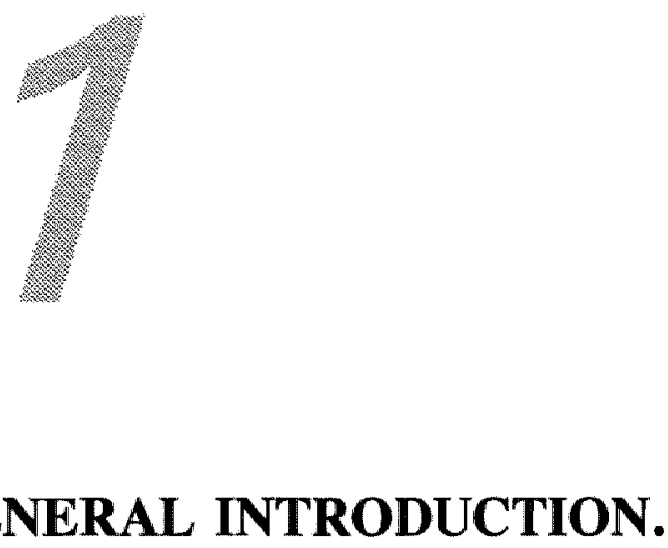

GENERAL INTRODUCTION. 


\subsection{INTRODUCTION}

Many subjects with insulin-dependent diabetes mellitus (IDDM) will develop, in the course of their disease, late complications like retinopathy, nephropathy, and neuropathy. These late -microvascular-complications have great impact on morbidity and mortality. One of the models explaining the development of these late complications is the haemodynamic hypothesis. According to this hypothesis, early functional haemodynamic changes contribute to the development of structural vascular changes: increased blood flow and capillary pressure contributes to the development of (micro)vascular sclerosis, which results in impaired (maximal) tissue perfusion and loss of autoregulation. Based on the various stages in the haemodynamic hypothesis, one may distinguish several subgroups of IDDM patients: short-term IDDM patients (stage of early functional changes); long-term IDDM patients without complications (stage of functional and/or structural changes); long-term IDDM patients with complications (stage of impaired (maximal) perfusion and loss of autoregulation). This thesis will focus, in particular, on the haemodynamic changes in IDDM patients and the possible pathophysiological mechanisms involved, that occur in the first years after diagnosis of the disease and early in the course of the development of diabetic nephropathy. Several mechanisms may be involved in the (micro)circulatory hyperperfusion (and hypertension) observed in many tissues early in the course of the IDDM: 1) subclinical sympathetic neuropathy; 2) increased levels of circulating vasodilator hormones like insulin and ANP; 3) endothelial dysfunction, leading to an imbalance of locally produced vasodilator/constrictor factors; 4) changes in vascular smooth muscle reactivity; 5) hyperglycaemia; 6) diminished oxygen dissociation from haemoglobin leading to relative hypoxia.

\subsection{AIM QF THE THESIS}

This thesis is divided into three major parts:

1. In the first part, the methods are described that were used to assess skin microcirculatory blood flow, forearm (predominantly muscle) blood flow, and venous compliance (chapter 3). Since some of the following studies were conducted over a period of several hours, we studied the possible diurnal variations in total forearm blood flow and skin nutritive and thermoregulatory blood flow in man during day-time (chapter 4).

2. In the second part, functional haemodynamic changes are described of the skin microvasculature in short-term and long-term IDDM subjects without complications and in long-term IDDM subjects with retinopathy or incipient nephropathy (chapter 5). One of the outcomes of this study was that IDDM subjects with incipient nephropathy revealed deterioration of microcirculato- 
ry (arteriolar) haemodynamics. To assess a possible relationship between the attenuated arteriolar haemodynamics and venous wall visco-elastic properties, we studied venous compliance of the peripheral venous system and the venodilatory effect of nitroglycerin in long-term IDDM subjects with and without early nephropathy (chapter 6).

3. In the third part of this thesis, studies are described to address some of the possible pathophysiological mechanisms leading to the haemodynamic changes early in the course of IDDM. The role of vasodilator prostaglandins in the early haemodynamic changes in short-term IDDM subjects was studied in chapter 7. In addition, we studied the acute effects of local hyperglycaemia (chapter 8) and the effects of 7-hour locall hyperglycaemia (chapter 9) on forearm (micro)circulatory blood flow and vasoreactivity to noradrenaline in healthy man.

This thesis starts with an overview of the current literature on the early haemodynamic changes in IDDM patients, and the possible pathophysiological mechanisms involved, in particular the role of glucose (chapter 2). 


-




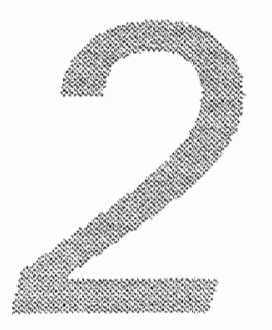

EARLY HAEMODYNAMIC CHANGES IN IDDM PATIENTS AND THE PATHOPHYSIOLOGICAL MECHANISMS INVOLVED. AN OVERVIEW. 


\subsection{INTRODUCTION}

Insulin-dependent (or type D) diabetes mellitus (IDDM) is an endocrine disorder, caused by a destruction of the pancreatic b-cells, resulting in insulin deficiency. The pathogenesis of this disease is probably a combination of genetic susceptibility and environmental factors, leading to an autoimmune attack on the B-cells. This systemic disease is characterized by hyperglycaemia and hypoinsulinaemia. To prevent lethal ketoacidosis and to reduce blood glucose levels, daily insulin injections are required.

Many IDDM patients develop chronic complications in the course of the disease, which have a great impact on morbidity and mortality. Besides autonomic and somatic neuropathy, and complications of the cardiovascular system, microangiopathic disorders like retinopathy and nephropathy develop in many diabetic patients. In their terminal stages, these latter complications lead to blindness and kidney insufficiency. After 30 to 40 years of diabetes, proliferative retinopathy has been estimated to develop in approximately $50 \%(1,2)$ and renal disease in about $40 \%$ of the patients (1). Renal failure has been estimated to be responsible for about $30 \%$ of the mortality rate (3). Many studies suggest that chronic hyperglycaemia is an important determinant in the development of diabetic retinopathy, nephropathy, and neuropathy. However, individual susceptibility and modulating factors (e.g. diet, smoking) also play a role in the development of diabetic complications.

\subsection{PATHOGENESIS OF DIABETIC MICROANGIOPATHY}

The pathogenesis of diabetic microangiopathic lesions like retinopathy, nephropathy, and to a lesser extent neuropathy, is probably multifactorial. One of the main hypotheses in the model explaining this pathogenesis is the Haemodynamic Hypothesis $(4,5,6)$, which is also the basic assumption of this thesis. This hypothesis (fig. 2.1) states that early in the course of the disease functional changes lead to structural vascular changes. A decrease in arteriolar resistance leads to increased arteriolar and capillary blood flow and pressure. This may induce physical injury to the vessel wall leading to thickening of the basement membrane. In addition, increased extravasation of macromolecules and their deposition in the vessel wall may be induced, eventually resulting in microvascular sclerosis (structural change). Ultimately, this leads to impaired (maximal) tissue perfusion and loss of autoregulation.

Many data from the literature support this hypothesis:

- In the first years after the onset of diabetes, blood flow has been found to be increased in several organs and tissues like retina, kidney, skeletal muscle, and fat (713), suggesting a generalized arteriolar vasodilation. In this phase of the disease, some studies found an increased cardiac output, which may be secondary to the increased peripheral blood flow $(14,15)$. 


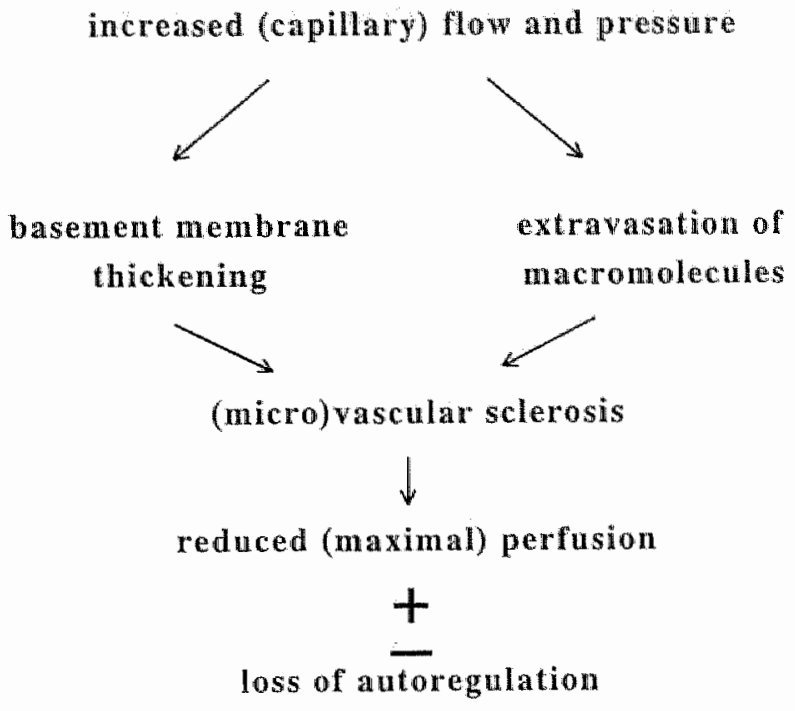

Figure 2.1: Scheme of the haemodynamic hypothesis.

Recently, the first direct evidence of increased capillary pressure became available from nailfold capillaries of short-term IDDM patients (16), which had already been demonstrated in the diabetic rat glomerulus (17). Furthermore, the veno-arteriolar reflex (which is an axon reflex that prevents capillary hypertension and hyperfiltration, when a limb is placed below heart level and thus venous pressure is increased, by precapillary vasoconstriction) has been found to be disturbed already shortly after the onset of IDDM (18). Increased capillary pressure could be one of the important factors in the increased vascular permeability, frequently observed in IDDM patients (19-22). Although increased capillary pressure in short-term IDDM patients has only been demonstrated in the skin, it seems likely that in other organs/tissues the increased blood flow is accompanied by a rise in capillary pressure as well. These early haemodynamic changes (increased flow and pressure) are functional rather than structural as they can be (nearly) normalized by improvement of metabolic control $(14,16)$.

- Increased capillary pressure and blood flow may induce secondary (micro)vascular changes, like endothelial injury, basement membrane thickening, and possibly vessel wall abnormalities, representing the second step in the development of diabetic microangiopathy. Capillary basement membrane thickening, often called the ultrastructural hallmark of diabetic microangiopathy, contributes to narrowing of the vascular lumen and (micro)vascular sclerosis $(23,24)$. In uncomplicated IDDM patients, who had diabetes for less than 10 years, increased thickness of muscle capillary basement membrane has been demonstrated, and this appeared to be related to long-term gly- 
caemic control $(25,26)$. The clinical relevance of basement membrane thickening is, however, not yet clear.

- The progression of these (micro)vascular abnormalities finally results in disturbed autoregulation and limited perfusion capacity. Autoregulation (which is the ability of an organ to maintain a relatively constant blood flow during changes in perfusion pressure) appears also impaired in the retina and kidney in IDDM patients with retinopathy and nephropathy, respectively $(27,28)$. In subcutaneous tissue impaired autoregulation was related to microvascular sclerosis $(29,30)$. With the progression of diabetic microangiopathy a limitation of the perfusion capacity can be demonstrated in retina, kidney, and nerves (31-33). Even a decreased density of capillaries, due to capillary closure as a result of endothelial proliferation, has been demonstrated in the conjunctiva and nerves $(33,34)$, but not in the skin $(35,36)$. These data should, however, be interpreted with caution, as only erythrocyte filled capillaries were studied and not the total number of capillaries. At present, there is only little information on the role of microvascular rarefaction in the pathophysiology of diabetic clinical microangiopathy.

The above described changes in microcirculatory haemodynamics are only one of the mechanisms responsible for the induction and progression of diabetic microangiopathy. Parallel to the haemodynamic changes other processes/mechanisms, like intracellular effects of glucose, non-enzymatic glycosylation, and oxidative stress, are involved in the pathogenesis of diabetic microangiopathy. Furthermore, these mechanisms may even induce the early hyperperfusion in IDDM, as will be discussed later. Also several environmental and genetic factors could play a role in the progression of (clinical) microangiopathy. Important examples of genetic factors, which might result in a predisposition for the development of diabetic nephropathy, are altered cellular sodium-lithium counter transport and vessel wall heparan-sulphate metabolism $(37,38)$. These factors, which seem to be more important in the later phase of progression of diabetic microangiopathy, fall outside the scope of this review.

In this thesis the focus will be on early haemodynamic changes in IDDM and the possible pathophysiological mechanisms involved. After a short overview of the regulation of microvascular blood flow, the pathophysiological mechanisms of, in particular, the peripheral hyperperfusion in IDDM patients will be discussed.

\subsection{REGULATION OF (MICRO)VASCULAR BLOOD FLOW}

Each tissue has its own characteristic (micro)vascular structure. Roughly, one can discern large and small arterioles, which control blood flow through the various parts of a tissue by their degree of contraction or dilatation. The small arterioles branch into capillaries, where the exchange of nutrients and waste products takes place. The capillaries terminate in small venules, which transport the blood via 
larger wenules and veins back to the heart. Venules and veins also play an important role in storage of blood and thus the amount of circulating wolume (39).

Blood flow through the (micro)vascular bed is determined by a balance of vasodilator and vasoconstrictor mechanisms, both central (neural and humoral) and local (autoregulatory) (40). In addition, the theological properties of blood influence microvascular perfusion, e.g. by changing shear-stress, which influences the endothelum. Blood flow control varies from organ to organ. As the haemodynamic measurements presented in this thesis were performed on muscle and skin, the control of blood flow through these tissues is discussed primarily $(41,42)$.

Neural control of arteriolar resistance is under the influence of sympathetic adrenergic vasoconstrictor nerves (this does not apply for the retina), through the action of noradrenaline. Also sympathetic cholinergic vasodilator nerves are suggested to be present in human skeletal muscle, but their role in vascular control is questionable $(41,43)$. Skin blood flow is determined by both central neural control and local axon reflexes (44). Due to the skin's thermoregulatory function, the relative contribution of both control mechanisms is determined by the prevailing core and skin temperature (45-47). Furthermore, many humoral factors, like catecholamines, vasopressin, angiotensin, histamine, acetylcholine, bradykinin, insulin, and glucocorticoids influence the (micro)vascular blood flow control. In addition, chemical agents like oxygen, carbondioxyde, adenosine, hydrogen, calcium, and potassium are potential vasoactive substances (48).

Local autoregulatory mechanisms are usually direct responses of vascular smooth muscle to local metabolites or physical changes like stretch (endothelium and neural independent) $(49,50)$, change in transmural pressure (endothelium dependent) $(51,52)$, change in flow (endothelium independent) $(53,54)$ and shear stress (endothelium dependent) $(55,56)$. As indicated, several of these mechanisms are dependent on the presence of the endothelium, which is situated at the interface between flowing blood and the vessel wall. The endothelum produces various vasoactive agents, like the vasodilators Endothelium Derived Relaxing Factor (EDRF, which is probably nitric oxide), prostaglandins, and Endothelium Derived Hyperpolarizing Factor (EDHF). In small blood vessels (arterioles, capillaries, and venules) the vasodilator prostaglandins $\mathrm{PGI}_{2}$ and $\mathrm{PGE}_{2}$ seem to contribute to a larger extent to basal vascular tone than EDRF. In larger blood vessels (arteries and veins), however, EDRF seems to be more important in the regulation of vascular tone than prostaglandins (57-60). Furthermore, the endothelium produces vasoconstrictor prostanoids, Endothelium Derived Constriction Factor ( $\bar{E} \bar{C} \bar{C})$, and the potent vasoconstrictor peptide endothelin (61-64). These vasoactive substances have a direct effect on vascular smooth muscle cells. 


\subsection{HYPERPERFUSION EARLY IN THE COURSE OF IDDM. PATHOPHYSIOLOGICAL MECHANISMS}

The metabolic and hormonal dearrangements that occur in IDDM probably influence the various control mechanisms of (micro)vascular blood flow, as improvement of metabolic control, usually by intensifying the insulin regime, (near) normalizes the early haemodynamic changes. Poor metabolic control results in severe hyperglycaemia and hypoinsulinaemia, while good metabolic control results in very mild hyperglycaemia to (near) normoglycaemia and peripheral hyperinsulinaemia. Until now it is unclear if a general hormonal/metabolic dearrangement is responsible for the early haemodynamic changes, or if different mechanisms are operant in various target tissues of diabetic microangiopathy. Several major factors/mechanisms involved in the early microvascular hyperperfusion and hypertension are discussed below. It should be noted, however, that this overview is not complete, given the multitude of hormonal/metabolic abnormalities that occur in IDDM patients during moderate or poor metabolic control.

\subsubsection{Sympathetic neuropathy}

The sympathetic nervous system plays a pivotal role in the regulation of peripheral vascular tone. In IDDM patients with clinical diabetic neuropathy an increased skin blood flow (both capillary (65) and shunt flow (65-67)) of the foot was demonstrated. The finding of an increased venous partial oxygen pressure in IDDM subjects with neuropathy, supports the presence of arterio-venous shunting (i.e. increased skin blood flow) (68). Deterioration of autonomic, motor, and sensory nerve function seems to be related to the level $(69,70)$ and the duration $(71)$ of hyperglycaemia. Sympathetic denervation of blood vessels may induce hyperperfusion, particularly in the skin, and opening of arterio-venous shunts. Already early in diabetes a subclinical form of sympathetic neuropathy has been suggested (72-74). Even a few weeks after the onset of IDDM, autonomic nerve dysfunction is demonstrable (75). Furthermore, a severe polyneuropathy may develop within the first few years of IDDM (76). Hence, sympathetic nerve dysfunction may play an important role in the onset of hyperperfusion early in IDDM. It remains to be demonstrated whether subclinical neuropathy in the first years of diabetes, is responsible for the early haemodynamic changes. Furthermore, it should be noted that blood flow in the retina is not under neurogenic control (77). Thus, other processes than sympathetic neuropathy are responsible for the haemodynamic changes in the retina, as will be discussed below.

\subsubsection{Circulating vasodilator/vasoconstrictor hormones}

Besides changes in sympathetic tone, an altered balance in the circulating levels of vasodilator and vasoconstrictor hormones is a plausible explanation of the hyperperfusion in some tissues in IDDM. 
Numerous studies have revealed that insulin, besides its possible stimulatory effect on the development of hypertension (which will not be discussed), has haemodynamic effects favouring vasodilatation. The haemodynamic effects of insulin are, however, complex. Relative hyperinsulinaemia, as present in IDDM patients with good metabolic control, results in both systemic and local effects. Hyperinsulinaemia produces sympathetic activation leading to increased muscle sympathetic nerve activity (78) and increased plasma catecholamine levels, as suggested by both animal and human studies (79-82). This systemic effect leading to peripheral vasoconstriction is usually counteracted or even overridden by local vasodilator action of insulin, as systemic (euglycaemic) hyperinsulinaemia in normal man leads to an increase in renal blood flow (83), and an increase or no change in skeletal muscle blood flow $(80,84,85)$. Furthermore, in IDDM patients with neuropathy euglycaemic hyperinsulinaemia results in an increased forearm blood flow and a drop in blood pressure, while there is no such an effect in patients without neuropathy (86). These results support the influence of insulin on the sympathetic nervous system (87). As mentioned above, the local effects of insulin result in vasodilatation and increased vascular permeability (88), possibly as a result of stimulation of the $\mathrm{Na}^{+}-\mathrm{K}^{+}$pump activity in the vessel wall (89). In addition, animal studies suggest that the vasoreactivity to norepinephrine and angiotensin II is reduced by insulin (90). Interestingly, Tooke et al (91) found in long-term uncomplicated IDDM patients an increased skin thermoregulatory blood flow and an improvement of postocclusive reactive hyperaemic blood flow of the skin capillaries during systemic hyperinsulinaemia. This indicates that insulin may also influence the local distribution of (micro)circulatory blood flow. However, the effects of local (intraarterial) insulin infusion (avoiding the systemic effects of insulin and glucose) on forearm haemodynamics are less clear. Some authors have demonstrated an increase in forearm blood flow (92-94), while other authors could not find any change in forearm blood flow during local hyperinsulinaemia $(89,95,96)$. These studies are difficult to compare due to differences in level and duration of local hyperinsulinaemia and/or methodological differences. Insulin lack, as present in IDDM patients with poor metabolic control, may favour peripheral hyperperfusion as well. Hypoinsulinaemia results in an increase in vasodilator prostaglandin $\left(\mathrm{PGI}_{2}\right)$ production $(97,98)$ leading to peripheral vasodilatation $(14)$.

Proinsulin is split into insulin and C-peptide in the $\mathrm{B}$-cells. Until recently, Cpeptide was thought to be biologically inactive. However, in recent studies vasoactive properties of $\mathrm{C}$-peptide were reported. In long-term uncomplicated IDDM subjects C-peptide infusion results in increased renal plasma flow, and restores a decreased forearm blood flow and capillary diffusion capacity during exercise to normal values $(99,100)$. In healthy volunteers C-peptide infusion has no effect on forearm blood flow (100). The C-peptide deficiency in IDDM patients possibly contributes to the impaired (exercise-induced) maximal perfusion capacity, and is probably of no relevance for the early hyperperfusion in diabetes.

It has been demonstrated in both IDDM and healthy subjects that systemic infusion of growth hormone leads to an increase in glomerular filtration rate and renal 
plasma flow $(101,102)$. Furthermore, local (intraarterialy infusion of physiological amounts of growth hormone increases forearm blood flow in healthy man, indicating direct vasodilator effects of growth hormone (103). Since in IDDM subjects with poor or moderate metabolic control growth hormone levels are increased (104), this might be one of the factors contributing to the hyperperfusion early in diabetes.

Besides growth hormone, systemic glucagon infusions induce increased glomerular filtrations and renal plasma flow in IDDM and healthy subjects as well $(105,106)$. Furthermore, glucagon may act as a potent vasodilator in the splanchnic region and, as has been demonstrated in rats, in other tissues like skeletal muscle and skin $(107,108)$. Glucagon injected subcutaneously, induces an intense local hyperaemic response (109). Braatvedt et al (110), however, demonstrated recently that these vasodilator effects of glucagon are probably a result of supraphysiological glucagon levels. Therefore, it seems to be unlikely that the relatively increased glucagon levels in IDDM (111) contribute to the peripheral hyperperfusion in IDDM.

Increased plasma levels of atrial natriuretic peptide (ANP) might be one of the hormonal mechanisms possibly responsible for the raised peripheral blood flow in diabetes, as it has been demonstrated to have vasodilator capacity. Infusion of physiological amounts of ANP into the brachial artery of healthy man, results in an increase in forearm blood flow (112). In IDDM patients without complications plasma ANP levels are significantly elevated, which may be related to the relative peripheral hyperinsulinaemia (113). These increased levels of ANP may therefore induce peripheral hyperperfusion. On the other hand, recent studies suggested that the forearm vasodilator response to intraarterial ANP infusion is impaired in long-term IDDM patients (114). This could neutralize the possible vasodilation induced by increased plasma ANP levels. Therefore, ANP could be an important factor involved in the early hyperperfusion in IDDM patients, however, this remains to be further investigated.

As stated above, both histamine and bradykinin are potent vasodilator factors. In long-term IDDM patients elevated plasma levels of histamine have been reported (115), which might contribute to increased flow and vascular permeability in these patients. It is, however, not clear whether plasma histamine levels are increased shortly after the onset of IDDM and thus whether they are involved in the early haemodynamic changes observed in these patients. Whether or not bradykinin levels are increased in short-term IDDM patients is not clear. Animal studies suggest, however, that hyperfiltration and hyperperfusion of the kidney in early IDDM is not dependent on bradykinin synthesis (116). The possible role of bradykinin in hyperperfusion of other tissues than kidney remains to be clarified.

Besides increased plasma levels of vasodilator hormones, decreased levels of vasoconstrictor hormones may facilitate vasodilatation. Under stable metabolic conditions, plasma and urinary levels of catecholamines, angiotensin II, plasma renin, and aldosterone are usually normal in IDDM subjects (117). Moreover, forearm vascular reactivity to infusion of angiotensin II and noradrenaline is unaltered in 
uncomplicated IDDM patients $(9,11)$ (see below). Hence, these factors are probably not involved in the development of early haemodynamic changes in IDDM.

In conclusion, in diabetic subjects with poor or good metabolic control, the vasodilatory effects of insulin lack or hyperinsulinaemia may contribute to the peripheral hyperperfusion in some tissues, like kidney, muscle, and skin. Furthermore, increased plasma levels of growth hormone and ANP may play a role in the early diabetic hyperperfusion.

\subsubsection{Circulating metabolites}

Changes in circulating metabolites (e.g. glucose, ketone bodies, fatty acids) may also play a role in the early hyperperfusion. A great body of evidence exist suggesting the haemodynamic effects of glucose. This is discussed in paragraph 2.5.

Ketone bodies have been demonstrated to exert haemodynamic effects. An acute increase in ketone body levels or lactic acid levels, comparable to those found in poorly controlled IDDM patients, induces renal hyperperfusion and hyperfiltration in both short-term IDDM and healthy subjects $(118,119)$. Hence, in situations of poor metabolic control, increased levels of ketone bodies may contribute to the hyperperfusion observed in several tissues in short-term IDDM patients.

An increase in fatty acid concentrations and a lowering of $\mathrm{pH}$ induces an inhibition of vascular prostacyclin synthesis in animals, whereas ketone bodies have no significant effect on prostacyclin production (98). These phenomena may occur in early diabetes, however they would result in hypo- instead of hyperperfusion.

\subsubsection{Endothelial vasodilators/vasoconstrictors}

A dysregulation of endothelial cell function leading to increased production of vasodilator factors and/or decreased production of vasoconstrictor factors, might be responsible for the early diabetes-induced haemodynamic changes. Animal studies on endothelial function in early diabetes reveal, however, conflicting data. Some animal studies suggest that increased blood flow and vascular permeability is related to increased nitric oxide (EDRF) production (120). In addition, endothelium-dependent vascular relaxation was found to be increased shortly after the induction of diabetes, suggesting an increased EDRF production as well (121). On the other hand, several other studies reported an impaired endothelium-dependent relaxation in various vascular beds (122-127). Interpretation of the animal data should, however, be considered with caution, as such experiments are often characterized by extreme hyperglycaemia and hypoinsulinaemia when compared to the situation in the diabetic patient. Moreover, the glucose concentration and the presence or absence of for instance L-arginine (the precursor of EDRF) in the incubation medium used in in vitro studies, greatly influence vascular reactivity $(128,129)$.

Human data on endothelial function in early diabetes do not favour the concept of increased EDRF production. Calver et al (9) recently studied the endothelium 
(in)dependent vasodilation of the forearm vasculature in short-term uncomplicated IDDM patients. They demonstrated that inhibition of basal endothelial EDRF (nitric oxide) production, by L-NMMA (a L-arginine analogue) infusion into the brachial artery, was less effective in reducing forearm blood flow in the diabetic patients than in healthy subjects. This impaired vasoconstriction to L-NMMA suggests that basal EDRF production is decreased early in diabetes, notwithstanding the fact that basal forearm blood flow was higher in the diabetic patients than in the healthy subjects. In contrast, stimulated endothelium-dependent vasodilatation following acetylcholine infusion, was similar in both patients and controls. These data suggest that basal and stimulated EDRF production may possibly be two different mechanisms. The decreased availability of basal nitric oxide might be the result of a masked normal production of endothelial nitric oxide by an increased destruction by oxygen-derived free radicals (130) or advanced glycosylation products (131). At present it is not (yet) possible to assess the local production of EDRF. Despite the fact that animal studies suggest the importance of increased EDRF production resulting in hyperperfusion, it remains to be elucidated whether in short-term IDDM patients the EDRF production is increased, normal, or decreased.

Also in long-term IDDM patients without any signs of diabetic complications, intraarterial infusion of carbachol (an acetylcholine analog) resulted in a normal forearm vasodilatation $(11,132)$. However, in long-term IDDM patients with incipient nephropathy both basal and carbachol stimulated EDRF production seems to be decreased compared to normoalbuminuric patients and healthy controls, despite a normal forearm blood flow (133). These data suggest the development of a general endothelial dysregulation parallel to the development of diabetic nephropathy, although it is uncertain whether these acetylcholine analogues induce vasodilatation via
EDRF release.

In both animal and human studies conflicting data have been reported on endothelial prostacyclin production in diabetes (134). Some animal studies suggest an increased production of this vasodilator prostaglandin, particularly in the kidney $(98,135-137)$, while others found normal or decreased prostaglandin production (138-141). In patients with IDDM (both short- and long-term), an increased vasodilator prostaglandin production has been suggested in the kidney, as well (141-143).
However, unchanged prostaglandin production was reported also in the kidney
$(144,145)$ and in other tissue (146,147). In addition, a dereas $(144,145)$ and in other tissue $(146,147)$. In addition, a decrease in circulating 6-keto
PGF la $_{\text {la }}$ (the stable end-product of prostacyclin) levels was reported in long-term IDDM patients $(148,149)$. The differences found between human and animal studies and within human studies are probably related to duration of disease, severity of hyperglycaemia, and the way prostacyclin was assessed. Direct measurement of plasma $\mathrm{PGF}_{1 \alpha}$ levels is rather disputable due to 1 ) nonspecific interference in the assay $(150), 2)$ the inability to discriminate at what location the prostacyclin production is increased, and 3) prostacyclin is produced locally in very small amounts and its half life is very short, resulting in very low plasma levels. Therefore, the possible 
role of prostaglandins in the early haemodynamic changes in diabetes is still a matter of debate.

As stated above, hyperperfusion can be induced by a decrease in endothelial vasoconstrictor factors. Indeed, decreased plasma endothelin levels were observed in uncomplicated long-term IDDM patients compared to age-matched healthy subjects (151). Whether these findings represent the situation in short-term IDDM patients remains to be investigated. Furthermore, interpretation of plasma levels of endothelium-derived vasoactive agents is precarious, as these agents are produced locally in very little amounts and have predominantly a direct local effect.

In long-term IDDM patients with signs of early nephropathy plasma endothelin levels are increased (152), which was also found in diabetic rats (153). Also vasoconstrictor prostaglandin production has been found to be increased in diabetic rats (154). These findings favour hypoperfusion, and probably represent a later phase in the haemodynamic hypothesis.

\subsubsection{Vascular smooth muscle function}

Parallel to changes in endothelial cell function, diabetes-induced changes in vascular smooth muscle reactivity may play an important role in the early hyperperfusion. Alterations in smooth muscle reactivity can result in vasodilatation (but also constriction) despite unchanged levels of neural, humoral, or endothelium-derived vasoactive factors.

According to many animal studies, the endothelium-independent vascular smooth muscle reactivity is changed in diabetes, favouring both vasodilatation and vasoconstriction (155-163). The conflicting data are probably a result of differences in duration of experimental diabetes (161) or the type of blood vessel that was studied.

In short-term uncomplicated IDDM patients with good metabolic control (mean $\mathrm{HbA}_{1 \mathrm{c}} 6.7 \pm 0.5 \%$ ), the vascular smooth muscle reactivity to sodium nitroprusside (SNIP, which is an exogenous nitric oxide donor) was reported to be decreased, which seemed to be a specific SNIP-related effect as the reactivity to the $\mathrm{Ca}^{2+}$-antagonist verapamil was unchanged (9). In long-term uncomplicated IDDM patients with a normal or rather poor metabolic control (mean $\mathrm{HbA}_{\mathrm{lc}} 9.2 \pm 0.9 \%$ ) the reactivity to sodium nitroprusside was unchanged $(11,132)$. Hence, it seems apparent that in the first years after the development of diabetes, a temporary impairment of SNIP-induced vasodilatation occurs.

In both short- and long-term uncomplicated IDDM patients no change in the forearm vasoreactivity to local administration of noradrenaline or angiotensin II could be demonstrated $(9,11)$. However, vascular reactivity may change when diabetic complications develop. In patients with retinopathy the vasopressor response to systemically infused noradrenaline and angiotensin II is increased (164). In patients with symptomatic autonomic neuropathy, the noradrenaline reactivity of the dorsal hand vein is increased, which might be secondary to the neuropathy (165). On the other hand, the noradrenaline reactivity of the dorsal hand vein in patients with incipient 
nephropathy is increased as well, compared to normoalbuminuric patients and healthy controls (166). These findings in long-term IDDM patients with complications favour hypoperfusion and fit in with a diminished (maximal) perfusion, as suggested to occur in the later phase of the haemodynamic hypothesis.

Similar to the biochemical endothelial changes, as will be described in paragraph 2.5 , changes in the intracellular milieu of vascular smooth muscle cells in diabetes may contribute to the above described increased vasoconstrictor responses. Experimental diabetes has been found to induce a decrease in 1,2-diacylglycerol content (167) and a decrease in $\mathrm{Na}^{+}-\mathrm{K}^{+}$-ATPase activity (168) with subsequent rise in intracellular $\mathrm{Ca}^{2+}(169)$ of vascular smooth muscle, favouring vasoconstriction. In addition, a decrease in basal cGMP levels has been suggested (170) thereby hindering vasodilation, although Harris et al (171) could not demonstrate a decrease in CGMP.

In conclusion, several changes in vascular smooth muscle cells and vasoconstrictor reactivity have been observed in both experimental and human diabetes. However, these changes seem to occur when complications like retinopathy or nephropathy have developed, and can not account for the hyperperfusion as observed in early diabetes.

\subsubsection{Other factors}

In addition to the above described factors affecting the regulation of peripheral vascular tone, other factors/mechanisms may be involved in the early hyperperfusion in diabetes.

In the retina blood flow is not under neurogenic control, but depends on the local oxygen pressure (77). The hyperperfusion observed in the retina and other tissues in early diabetes might be a compensation for the reduced oxygen dissociation from haemoglobin as described in diabetes $(172,173)$, leading to relative hypoxia. In addition, nerve function has been found to be diminished as a result of decreased oxygen availability (174), which might facilitate peripheral hyperperfusion.

In the skin of diabetic subjects increased arterio-venous shuntflow may partly be a result of increased metabolic rate (174), as there will be an increased need for heat dissipation.

In the kidney of diabetic rats early glycosylation products (Amadori products) induce an increased glomerular plasma flow and glomerular hyperfiltration by a decrease in afferent glomerular resistance (176). These products may therefore be involved in the increased flow and vascular permeability observed in early diabetes. This interesting hypothesis warrants further investigation in human subjects. The formation of advanced (non-enzymatic) glycosylation end products (AGE) in diabetes, however, plays an important role in the pathophysiology of advanced vascular complications and will be discussed later.

Changes in blood rheology have been described in diabetes mellitus (for review see 177). Increased plasma and whole blood viscosity have been reported in many 
studies. Also decreased red and white cell deformability, and increased red cell aggregation were found in diabetic patients, resulting in increased viscosity. It has been speculated that increased blood platelet aggregation contributes to the development of diabetic vascular complications (178). However, others could not demonstrate such a relation $(179,180)$. Such abnormal blood rheologic factors may hinder perfusion of small arterioles and capillaries. On the other hand, these abnormalities may also increase shear stress, which leads to enhanced EDRF/vasodilator prostaglandins release $(55,56)$, thereby theoretically contributing to the peripheral vasodilatation in diabetes.

Abnormalities of plasma lipid and lipoprotein concentrations, as observed in diabetes mellitus, may also contribute to the development of diabetic vascular disease by their atherogenic properties (181). They are probably involved in the later stages of the haemodynamic hypothesis and not in the early hyperperfusion.

\subsection{THE ROLE OF GLUCOSE}

One of the main features of diabetes mellitus is hyperglycaemia. It probably plays a dominant role in the development of diabetic complications. The early haemodynamic changes observed in IDDM patients are strongly related to the level of hyperglycaemia. Normalization of blood glucose levels in short-term diabetic patients results in a (near) normalization of increased blood flow to the kidney $(8)$, muscle $(10,15)$, retina (182), and a reduction in cardiac output $(14,15,183)$ and capillary pressure (16). Blood flow in the macula (183) or autoregulation of subcutaneous blood flow (30) was, however, not influenced by changes in blood glucose levels. In addition, a normalization of blood glucose levels leads to improved blood rheology (185), decreased platelet thromboxane production (186), and a decrease in total body energy expenditure (175). All these changes lead to a near normalization of hyperperfusion and hyperfiltration.

Besides the effects of normalization of blood glucose levels on early haemodynamic changes, long-term establishment of reasonably good metabolic control $\left(\mathrm{HbA}_{1 \mathrm{c}}\right.$ $<7.5-8.0 \%$ ) seems to have a clear beneficial influence on the development and progression of diabetic microvascular complications. For instance, the development of microalbuminuria is decreased as a result of good metabolic control (187). Moreover, near-normoglycaemia for several years reduces urinary albumin excretion in patients with incipient nephropathy, suggesting that the progression of (early) diabetic nephropathy is related to the mean level of glucose control (188). However, not all patients are equally "vulnerable" to long-term hyperglycaemia, which indicates that other factors like genetic predisposition are involved as well (189).

The evolution of diabetic neuropathy is influenced by poor glycaemic control too. During the first 5 years after diagnosis of IDDM mean nerve conduction velocity, heart rate variation, and thermal discrimination are significantly impaired in IDDM 
patients with poor compared to good glycaemic control (190). In addition, strict metabolic control may improve motor nerve conduction velocities (191).

There is little doubt that there is a strong association between long-term hyperglycaemia and the development and progression of diabetic retinopathy. However, in contrast to diabetic nephropathy and neuropathy, improved glycaemic control for several years does not seem to stop or reverse the progression of retinopathy, but retards it substantially (192). In summary, these studies suggest that long-term hyperglycaemia clearly contributes to the development and to a lesser extent to the progression of diabetic microangiopathic complications.

A confounding factor in the above described studies may be the changes in insulin levels to induce changes in blood glucose levels. Hence, the observed haemodynamic changes may partly be due to changes in insulin levels. However, several lines of evidence suggest that hyperglycaemia could be one of the main factors responsible for the early haemodynamic changes. In vitro studies have shown that endothelial cells are very susceptible to the "toxic" effects of glucose. Endothelial cells cultured in hyperglycaemic media show a disturbed DNA function, delayed replication, and accelerated death $(193,194)$. Recently, it was demonstrated in animals that the impaired endothelium-dependent relaxation in diabetic aorta or normal aorta exposed to high glucose levels is mediated by free radicals, like superoxide anion, oxygen-derived free radicals, and hydroxyl radicals (195), which is possibly a result of increased cyclooxygenase activity (196).

The group of Williamson (St. Louis, USA) has proposed a model of glucose- and diabetes-induced intracellular changes which may lead to increased blood flow and vascular permeability (197). This model is predominantly based on (in vivo) studies on the effects of systemic hyperglycaemia and of topical application of glucose on the microcirculation in normal animals, or the presence of diabetes. These studies contradict various other animal studies (using isolated blood vessels), which favour vasoconstriction rather than vasodilation (see above). The model involves the following: 1) Hyperglycaemia leads via the polyol pathway (fig. 2.2) to intracellular accumulation of sorbitol and fructose (198-201), due to increased aldose reductase activity, which is partly a result of increased aldose reductase mRNA expression (202). Sorbitol accumulation may induce tissue damage by osmotic effects, while fructose accumulation increases non-enzymatic fructosylation of tissue resulting in protein cross-linking (203) 2) Secondary to the polyol pathway activity an impaired myo-inositol uptake occurs $(168,204)$. A decreased level of myo-inositol may contribute to decreased $\mathrm{Na}^{+}-\mathrm{K}^{+}$-ATPase activity in endothelium $(205,206)$ and vascular smooth muscle $(204,207)$. Decreased levels of myo-inositol and decreased $\mathrm{Na}^{+}-\mathrm{K}^{+}$ATPase activity were associated with diabetes- or glucose-induced hyperperfusion/hyperfiltration $(208,209)$. It should, however, be noted that other authors suggested a relation between decreased $\mathrm{Na}^{+}-\mathrm{K}^{+}$-ATPase activity and a decreased EDRF production (207). Furthermore, a decrease in $\mathrm{Na}^{+}-\mathrm{K}^{+}$-ATPase activity may induce changes in cellular growth, differentiation, and vascular smooth muscle contraction (210). 3) Increased metabolism of glucose via the sorbitol pathway results in 
an increased NADH/N.AD ${ }^{+}$ratio (211), which facilitates diacylglycerol (DAG) production, production of tissue triose phosphate (a highly reactive nonenzymatic glycating agent), and impairs myo-inositol synthesis. 4) Hyperglycaemia also increases DAG synthesis directly (212), which activates protein kinase $C(205,212,213)$. De novo synthesis of DAG from dihydroxyacetone phosphate (DHAP) is possibly a result from DHAP reduction by NADH to glycerol-3-phosphate, which is then acylated to lysophosphatidic acid and via phosphatic acid dephosphorylated to DAG. The accumulation of DAG may induce increased blood flow via protein kinase C (in)dependent mechanisms, while microvascular permeability to albumin seems to be related to both protein kinase $C$ activation and DAG accumulation (212). Furthermore, some studies suggest that protein kinase $C$ activates the endothelial production of nitric oxide, which induces vasodilatation $(214,215)$.

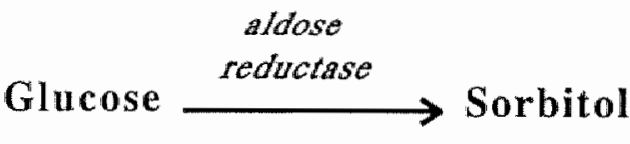

NADPH/NADP+

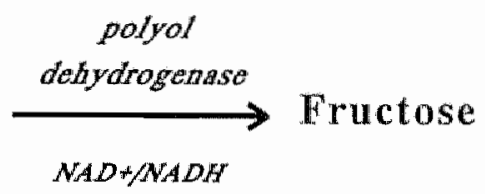

Figure 2.2: Scheme representing the polyol pathway.

In summary, the above described intracellular changes, like impaired myo-inositol uptake and $\mathrm{Na}^{+}-\mathrm{K}^{+}$-ATPase activity, increased DAG production and protein kinase $\mathrm{C}$ activity, related to the polyol pathway and induced by both hyperglycaemia and experimental diabetes, results in endothelial and/or vascular smooth muscle dysfunction. This vascular dysfunction can result in arteriolar vasodilation (216), increased blood flow and albumin permeation $(201,208,217)$, as observed early in experimental diabetes. Despite this enormous body of animal data indicating the significance of the polyol pathway and its related intracellular changes, the clinical relevance of this pathway in the pathogenesis of microvascular complications in IDDM patients is still controversial (218-225), and warrants further investigation.

Besides the polyol pathway glucose is involved in other biochemical processes like non-enzymatic glycosylation and autoxidation. Accumulation of advanced glycation end products (AGE) in vessel wall tissue leads to increased vascular permeability, basement membrane thickening, inelastic thickened vessel wall, and finally to vessel lumen narrowing and occlusion (226). In addition, vascular complications in IDDM are associated with increased chemical modifications of proteins (e.g. collagen) and lipids due to oxidative stress (227), contributing to alterations in function of such proteins. Increased levels of superoxide (228), lipid peroxides, and hydrogen peroxi- 
de may lead, through the formation of hydroxyl radicals, to oxidation, cross-linking, and fragmentation of proteins and lipids (227), resulting in inelastic thickened vessel walls. These processes characterize accelerated chemical aging of diabetic vessel wall tissue (229), and are probably involved in later phases of the haemodynamic hypothesis.

Little data are available on the direct haemodynamic effects of glucose in healthy man. Bülow et al (230) could not demonstrate changes in forearm or skin blood flow after an oral glucose load. The increase in subcutaneous adipose tissue blood flow they observed, was hypothesized to be secondary to metabolic events connected to glucose uptake and energy deposition in adipose tissue. In contrast, Quaade et al (231) demonstrated a decrease in adipose tissue blood flow after an oral glucose load. Short-term intravenous glucose infusion leads to an increased leg (232) but not renal (233) blood flow. However, during somatostatin-induced insulinopenia leg blood flow does not change during systemic hyperglycaemia (234). Hence, the increase in leg blood flow during systemic hyperglycaemia is probably induced by a rise in plasma insulin levels secondary to the systemic hyperglycaemia, as was demonstrated recently (78). Furthermore, intravenous glucose infusion does not influence blood pressure or plasma norepinephrine levels, while oral glucose loading decreases blood pressure, probably mediated by insulin-dependent gastrointestinal factors (235). As the previous studies indicate, systemic elevation of blood glucose levels results in secondary hormonal changes (i.e. insulin), which may induce haemodynamic changes themselves. Therefore, no conclusions can be drawn from the above mentioned studies.

\subsection{SUMMARY}

As stated in the Haemodynamic Hypothesis, hyperperfusion in several organs and tissues throughout the body early in the course of IDDM may be one of the initiating mechanisms in the development of microangiopathic lesions. Numerous studies revealed several possible pathological mechanisms contributing to the early hyperperfusion in IDDM. However, many hypotheses are based on animal studies, and are discordant with human studies. The marked differences often observed between studies on IDDM subjects and the diabetic rat model may often be explained by extremely high glucose levels $(25-40 \mathrm{mmol} / \mathrm{l})$ in diabetic animals in combination with lack of insulin, inducing a metabolic/hormonal milieu which does not seem to be relevant for the diabetic patient. Furthermore, most of the findings in animal studies on endothelial function and vascular reactivity seem to reflect later phases of the haemodynamic hypothesis, as they resemble findings in long-term IDDM patients
with complications.

Based on the available human studies, several potential pathological mechanisms can be revealed that are involved in the early hyperperfusion in IDDM patients. Some mechanisms may only be relevant for one specific tissue, while others may be 
relevant for several tissues. 1) Subclinical sympathetic neuropathy may induce peripheral hyperperfusion, particularly in muscle and skin. 2) Systemic infusion of insulin leads to vasodilatation in healthy volunteers. Local infusion of insulin leads in some studies to vasodilatation as well, while other studies could not demonstrate such an effect. Hence, the possible local vasodilator effect of insulin remains to be elucidated. In IDDM patients relatively high insulin levels in the systemic circulation (during good metabolic control), may facilitate hyperperfusion. In addition, increased plasma levels of ANP, growth hormone, and possibly histamine may contribute to the early hyperperfusion. 3) Many animal studies suggest that hyperglycaemia induces vasodilatation and increases vascular permeability, probably by acting on the vascular endothelium. Indeed, moderate metabolic control (i.e. hyperglycaemia) in IDDM patients is associated with hyperperfusion in several tissues, which (near)normalizes parallel to the improvement of metabolic control. However, this hyperperfusion may be related to secondary hormonal changes occurring during systemic hyperglycaemia as well. 4a) Despite the enormous body of evidence from animal studies on the induction of endothelial dysfunction by hyperglycaemia/diabetes, such a relation has not yet convincingly been demonstrated in humans. Stimulated endothelium-dependent vasodilation is unchanged in short-term IDDM patients. But although blood flow is increased in these patients, there is some indirect evidence suggesting that their basal EDRF production is decreased and not increased. Although some animal studies suggest that the early hyperperfusion in diabetes could be related to increased EDRF production, there are no data presently available that such a mechanisms is operant in short-term IDDM patients. Impaired endothelin production is an alternative hypothesis, which remains to be investigated. 4 b) The human data on vascular prostaglandin production are conflicting. Although some authors report an increased vasodilator prostaglandin production, particularly in the kidney, others find a decreased or unchanged prostaglandin production. 5) Changes in vascular smooth muscle reactivity, or circulating levels of vasoconstrictor hormones are likely not involved in the early hyperperfusion. 6) In particular in the retina, the early hyperperfusion may be related to a relative hypoxia, due to a diminished oxygen dissociation from haemoglobin in IDDM.

Other processes, like non-enzymatic glycosylation, endothelial damage/loss, and oxidative stress, are probably involved in a later phase of the haemodynamic pathogenesis of diabetic microvascular lesions, leading to hypoperfusion.

The aims of this thesis were distilled from the available aforementioned information and led to the following questions:

- to what extend are the functional haemodynamics of the skin microvasculature changed in IDDM subjects, in relation to the duration of disease and the presence of complications?

what is the possible relation between deterioration of peripheral arteriolar haemodynamics, as observed in IDDM subjects with incipient nephropathy, and possible changes in peripheral venous compliance? 
- do vasodilator prostaglandins play a role in the peripheral hyperperfusion in shortterm IDDM subjects?

- what are the effects of acute ( 1 hour) local hyperglycaemia on basal forearm and skin blood flow in healthy man?

- what are the effects of prolonged (7 hour) local hyperglycaemia on basal forearm and skin blood flow and on forearm vasoreactivity to noradrenaline in healthy man?

\section{REFERENCES}

1. Anderson AF, Sandahl-Christiansen J, Anderson JK, Kreiner S, Deckert T. Diabetic nephropathy in type I (insulin-dependent) diabetes: an epidemiological study. Diabetologia $1983 ; 25 ; 496-501$.

2. Klein $R$, Klein BEK, Moss SE. Visual impairment in diabetes. Ophthalmology 1984;91;1-9.

3. Deckert $T$, Poulsen JE, Larsen M. Prognosis of diabetics with diabetes onset before the age of thirty-one. Diabetologia 1978;14;363-370.

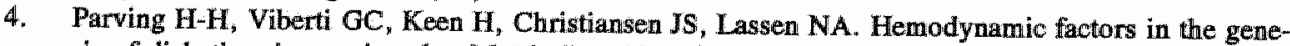
sis of diabetic microangiopathy. Metabolism 1983;32;943-949.

5. Zatz R, Brenner BM. Pathogenesis of diabetic microangiopathy. The hemodynamic view. Am J Med 1986;80;443-453.

6. Tooke JE. Microvascular haemodynamics in diabetes mellitus. Clin Sci 1986;70;119-125.

7. Kohner EM, Hamilton AM, Saunders SI, Sutcliffe BA, Bulpitt CJ. The retinal blood flow in diabetes. Diabetologia $1975 ; 11 ; 27-33$.

8. Christiansen JS, Gammelgaard J, Tronier B, Swendsen PA, Parving HH. Kidney function and size in diabetics before and during initial insulin treatment. Kidney Int 1982;21;683-688.

9. Calver A, Collier J, Vallance P. Inhibition and stimulation of nitric oxide synthesis in the human forearm arterial bed of patients with insulin-dependent diabetes. J Clin Invest 1992;90;2548-2554.

1.0. Christensen NJ. A reversible vascular abnormality associated with diabetic ketosis. Clin Sci 1970;39;539-548.

11. Halkin A, Benjamin N, Doktor HS, Todd SD, Viberti G, Ritter JM. Vascular responsiveness and cation exchange in insulin-dependent diabetes. Clin Sci $1991 ; 81 ; 223-232$.

12. Gundersen HJG. Peripheral blood flow and metabolic control in juvenile diabetes. Diabetologia $1974 ; 10: 225-231$.

13. Haggendlal $\mathbf{E}$, Steen $B$, swanborg A. Blood flow in subcutaneous fat tissue in patients with diabetes mellitus. Acta Med Scand 1970; 187;49-53.

14. Mathiesen ER, Hilsted J, Feldt-Rasmussen B, Bonde-Petersen F, Christensen NJ, Parving HH. The effect of metabolic control on hemodynamics in short-term insulin-dependent diabetic patients.

15. Thuesen L, Sandahl-Christiansen J, Schmitz O, Christensen NJ, Orskov H, Henningsen P. Increased myocardial performance following acute hyperglycaemia in insulin-dependent diabetic patients. A consequence of increased peripheral blood flow? Scand J Clin Lab Invest 1987;47;571-579.

16. Sandeman DD, Shore AC, Tooke JE. Relation of skin capillary pressure in patients with insulindependent diabetes mellitus to complications and metabolic control. New Eng I Med 1992;327;760-

17. Jensen PK, Blaehr H. Sandahl-Christiansen KS, Parving HH. The effect of strict metabolic control on renal function in short-term streptozotocin diabetic rats. Diabetologia 1984;27;249 (abstract
$249 \mathrm{~A}$ ).

18. Tooke JE, Lins PE, Ostergren J, Fagrell B. Skin microvascular autoregulatory responses in type I diabetes: the influence of duration and control. Int J Microcire Clin Exp 1985;4;249-256.

19. Parving HH, Noer I, Deckert T, Evrin PE, Nielsen SL, Lyngsoe J, Mogensen CE, Rorth M, Svendsen PA, Trap-Jensen J, Lassen NA. The effect of metabolic regulation on microvascular 
permeability to small and large molecules in short-term juvenile diabetios. Diabetologia $1976 ; 12 ; 161-166$.

20. O'Hare JA, Ferriss JB, Twomey B, O'Sullivan Df. Poor metabolic control, hypertensiom, and microangiopathy independently increase the transcapillary eseape rate of albumin in diabetes. Diabetologia $1983 ; 25 ; 260-263$.

21. Bollinger A, Frey J, Jager K, Furrer J, Seglias J, Siegenthaler W. Patterns of diffusion through skin capillaries in patients with long-term diabetes. New Eng J Med 1982;307;1305-1310.

22. Jaap AJ, Shore AC, Gartside IB, Gamble J, Tooke JE. Increased microvascullar fluid permeability in young type I (insulin-dependent) diabetic patients. Diabetologia 1993;36;648-652.

23. Williamson JR, Kilo C. Current status of capillary basement-membrane disease in diabetes mellitus. Diabetes $1977 ; 26 ; 65-73$.

24. Vracko R, Benditt EP. Capillary basal lamina thickening. Its relationship to endothelial aell death and replacement. J Cell Biol 1970;47;281-285.

25. Sosenko JM, Miettinen OS, Williamson JR, Gabbay KH. Muscle capillary basentent-membrane thickness and long-term glycemia in type I diabetes mellitus. New Eng J Med 1984;311;694-698.

26. Rogers DG, White NH, Santiago JV, Miller JP, Weldon VV, Kilo C, Williamson JR. Glycemic control and bone age are indepently associated with muscle capillary basement membrane width in diabetic children after puberty. Diab Care $1986 ; 9 ; 453-459$.

27. Sinclair SH, Grunwald JE, Riva CE, Braunstein SN, Nichols CW, Schwartz SS. Retinal vascular autoregulation in diabetes mellitus. Ophthalmol 1982;89;748-750.

28. Parving HH, Kastrup $J_{2}$ Smidt UM, Andersen AR, Feldt-Rasmussem B, Sandahl-Christiansen J. Impaired autoregulation of glomerular filtration rate in type I (insulin-dependent) diabetic patients with nephropathy. Diabetologia $1984 ; 27 ; 547-552$.

29. Kastrup J, Norgaard T, Parving HH, Henriksen O, Lassen NA. Impaired autoregullation of blood flow in subcutaneous tissue of long-term Type I (insulin-dependent) diabetic patients with microangiopathy: an index of arteriolar dysfunction. Diabetologia 1985;28;711-717.

30. Kastrup J, Mathiesen ER, Saurbrey N, Norgaard T, Parving HH, Lassen NA. Effect of strict metabolic control on regulation of subcutaneous blood flow in insulin-dependent diabetic patients. diab med $1987 ; 4 ; 30-36$.

31. Mogensen CE, Christensen CK, Vittinghus E. The stages in diabetic renal disease. Diabetes $1983 ; 32$ suppl2; 64-78.

32. Bresnick GH, de Venecia $G$, Myers EL, .. Retinal ischaemia in diabetic retinopathy. Arch Ophthalmol 1975;93;1300-1310.

33. Malik RA, Newrick PG, Sharma AK, Jennings A, Ah-See AK, Mayhew TM, Jakubowski I, Boulton AJM, Ward JD. Microangiopathy in human diabetic neuropathy: relationship between capillary abnormalities and the severity of neuropathy. Diabetologia $1989 ; 32 ; 92-102$.

34. Fenton BM, Zweifach BW, Worthen DM. Quantitative morphometry of conjunctiwal microcircualtion in diabetes mellitus. Microvasc Res 1979;18;153-166.

35. Trapp RG, Soler NG, Spencer-Green G. Nailfold capillaroscopy in type I diabetics with vasculopathy and limited joint mobility. I Rheumatol 1986;13;917-920.

36. Malik RA, Metcalfe J, Sharma AK, Day JL, Rayman G. Skin epidermal thickness and wascular density in type I diabetes. Diab Med 1992;9;263-267.

37. Viberti GC, Yüp-Messent J, Morocutti A. Diabetic mephropathy. Future avenue. Diab Care $1992 ; 15 ; 1216-1225$.

38. Deckert $T$, Feldt-Rasmussen B, Borch-Johnsen K, Jensen T, Kofoed-Enevoldsen A. Albuminuria eflects widespread vascular damage. The Steno hypothesis. Diabetologia 1989;32;219-226.

39. Guyton AC. Textbook of medical physiology. 6th ed. WB Saunders Company, Philadelphia, 1981 .

40. Kaley B, Altura BM (eds.). Microcirculation. Voll II. University Park Press, Baltimore, 1978.

41. Hudlicka O. Regulation of muscle blood flow. Clin Physiol 1985;5;201-229.

42. Johnson JM, Brengelmann GL, Hales JRS, Vanhoutte PM, Wenger CB. Regulation of the cutane ous circulation. Fed Proc 1986;45;2841-2850.

43. Rosell S. Nervous control of the microcirculation. In: Microcirculation. Vol II. Kaley $\mathbb{B}_{3}$ Altura BM (eds.). University Park Press, Baltimore, 1978. 
44. Lindblad LE, Ekenvall L, KLingsted $C$. Neural regulation of vascular tone and cold induced vasoconstriculion in human finger skin. J Aut Nerv System 1990;30;169-174.

45. Hornyak ME, Nayer HK, Rydenhage B, Wallin BG. Sympathetic activity influences the wascular axon reflex in the skin. Acta Physiol scand 1990;139;77-84.

46. Oberle $\mathrm{J}$, Elatin M, Karlason T, Wallin BG. Temperature-dependent interaction between vasoconstrictor and vasodilator mechanisms in human skin. Aeta Physiol Scand 1988;132;459-469.

47. Freadman RR, Sabharwal SC, Moten M, Migaly P. Local temperature modulates $\alpha$ - and $\alpha 2$-adremergic vasoconstriction in men. Am J Physiol 1992;263;H1197-H1200.

48. Alura BM. Humoral, hornonal, and myogenic mechanismis in milcrocirculatory regulation. In: Microcirculation. Vol II. Kaley B, Altura BM (eds.). University Park Press, Baltimore, 1978.

49. Hwa JJ, Bevan JA. Stretch-dependent (myogenic) tone in rabbit ear resistance arteries. Am J Physiol $1986 ; 250 ; \mathrm{H} 87-\mathrm{H} 95$.

50. Mangiarua EI, Joyce EH, Bevan JA. Denervation increases myogenic tone in a resistance artery in the growing rabbit ear. Am I Physiol 1986;250; H889-H891.

51. Halpern WL, Osol $R$, Osol $G$. Activation induces moygenic-like diameter responses to dynamic pressure changes in isolated and pressureized mesenteric arteries of the rat. In: Vascilar neuroeffect mechanisms. Bevan JA, Majewski H, Maxwell RA, Story DF (eds.). Washington DC, IRL, 1988.

52. Harder, DR. Pressure-induced myogenic activation of cat cerebral aretries is dependent on intact endothelium. Circ Res 1987;60;102-107.

53. Bevan JA, Joyce EH. Flow dependent dilation in myograph mounted resistance artery segments. Blood Vessels 1988;25;101-104.

54. Bevan JA, Joyce EH, Wellman GC. Flow-dependent dillation in a resitance artery still occurs after endothelium removall. Circ Res 1988;63;980-985.

55. Davies PF, Triputhi SC. Mechanical stress mechanisms and the cell. An endothelitum paradigm. Circ Res 1993;72:239-245.

56. Koller A, Sun D, Kaley G. Role of shear stress and endothelial prostaglandins in flow- and viscosity-induced dilation of arterioles in vitro. Circ Res $1993 ; 72 ; 1276-1284$.

57. Koller $A$, Kaley $G$. Prostaglandins mediate arteriolar dilation to incremsed blood flow velocity in skeletal muscle microcirculation. Circ Res 1990;67,529-534.

58. Rubanyi GM, Romero JC, Vanhoutte PM. Flow induced release of endothelium derived relaxing factor. Am J Physiol 1986;250; H1 145-H1149.

59. Forstermann U, Warmuth $G$, Dudel $C$, Alheid U. Formation and functional importance of endothelium derived realxing factor (EDRF) and prostaglandins in the microcirculation. Z Kardiol 1989;78suppl $6 ; 85.91$.

60. Gerritsen ME. Functional heterogeneity of wascular endothelial cells. Biochem Pharmacol $1987 ; 36 ; 2701-2711$.

61. Furchgott RF. Role of endothellium in responses of vascular smooth muscle. Circ Res 1983;53;557573 .

62. Brenner BM, Troy JL, Ballermann BJ. Endothelium-dependent vascular responses. Mediators and mechanism. J Clin Invest 1989;84;1373-1378.

63. Luscher TF. The endothellum. Target and promotor of hypertension? Hypertension 1990;15;482485.

64. Kontunek 5J, Pawlik W. Physiology and pharmacology of prostaglandins. Dig Dis Sci 1986;31suppl; 6 s- $19 \mathrm{~s}$.

65. Flyn MD, Edmonds ME, Tooke JE, Watkins PJ. Direct measurement of capillary blood flow in the diabetic neuropathic foot. Diabetologia $1988 ; 31,652-656$.

66. Rayman G, Hassian A, Tooke JE. Blood flow in the skin of the foot related to posture in diabetes mellitus. Br Med J 1986;292;87-90.

67. Archer $A G$, Roberts VC, Watkins PJ. Blood flow patterns in painful diabetic neuropathy. Diabetologia $1984 ; 27 ; 563-567$.

68. Boulton AMM, Scarpello JHB, Ward JD. Venous oxygenation in the diabetic neuropathic foot: evidence of arteriovenons shunting. Diabetologia $1981 ; 22 ; 6-8$. 
69. Gregersen $G$. Variations in motor conduction velocity produced by acute changes of the metabolic state in diabetic patients. Diabetologia 1968;4;273-277.

70. Young RJ, Macintyre CCA, Martyn CN, Prescott RJ, Ewing DJ, Smith AF, Viberti G, Clarke BF. Progression of subclinical polyneuropathy in young patients with type I (insulin-dependent) diabetes: associations with glycaemic control and microangiopathy (microvascular complications). Diabetologia 1986;29;156-161.

71. Saenz de Tejada $I_{y}$ Goldstein $I_{n}$ Azadzoi $K$, Krame $R J$, Cohen RA. Impaired meurogenic and endothelium-mediated relaxation of penile smooth muscle from diabetic men with impotence. New Eng I Med 1989;320;1025-1030.

72. Watkins PJ, Edmonds ME. Sympathetic nerve failure in diabetes. Diabetologia $1983 ; 25 ; 73-77$.

73. Fagius J. Microneurographic findings in diabetic polyneuropathy with special reference to sympathetic merve activity. Diabetologia $1982 ; 23 ; 415-420$.

74. Mueller SM, Mueller TM, Ertel PJ. Sympathetic and vascular dysfunction in early experimental juvenile diabetes mellitus. Am J Physiol 1982;243;H139-H144.

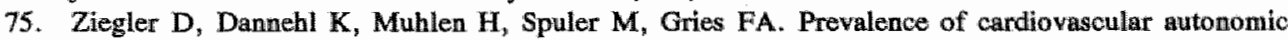
dysfunction assessed by spectral analysis and standard tests of heart-rate variation in newly diagnosed IDDM patients. Diab Care 1992;15;908-911.

76. Said $G$, Goulon-Goeau $C$, Slama $G$, Tchobroutsky $G$. Severe early-onset polyneuropathy in insulindependent diabetes mellitus. A Clinical and pathological study. New Eng J Med 1992;326;12571263.

77. Bulpitt CJ, Kohner EM, Dollery CT. Autoregulation in the retinal microcirculation. In: microcirculatory approaches to current therapeutic problems. Ditzel J, Lewis DH (eds) Basel: Karger 1971.

78. Vollenweider P, Tappy L, Randin D, Schneiter P, Jequeir E, Nicod P, Scherrer U. Differential effects of hyperinsulinemia and carbohydrate metabolism on sympathetic nerve activity and muscle blood flow in humans. J Clin Invest 1993;92;147-154.

79. Liang CS, Doherty JU, Faillace R, Maekawa K, Arnold S, Gavras H, Hood WB. Insullin infusion in comscious dogs. Effects on systemic and coronary hemodynamics, regional blood flows, and plasma catecholamines. I Clin Invest 1982;69;1321-1336.

80. Anderson EA, Hoffman RP, Balon TW, Sinkley CA, Mark AL. Hyperinsulinemia produces both sympathetic neural activation and vasodilation in normal humans. J Clin Invest 1991;87;2246-2252.

81. Rowe JW, Young JB, Minaker KL, Stevens AL, Pallotta J, Landsberg L. Effect of insulin and glucose infusions on sympathetic nervous system activity in normal man. Diabetes $1981 ; 30 ; 219$ 225.

82. Berne $\mathrm{C}$, Fagius $\mathrm{J}$, Pollare $T_{y}$ Hjemdahl P. The sympathetic response to euglycaemic hyperinsullinaemia. Diabetologia 1992;35;873-879.

83. Stenvinkel $\mathbb{P}$, Blinder $J$, Alvestramd $A$. Effects of insulin on renal haemodynamics and the proximal and distal tubular sodium handling in healthy subjects. Diabetologia $1992 ; 35 ; 1042-1048$.

84. Laakso M, Edelman SV, Brechtel G, Baron AD. Decreased effect of insulin to stimulate skeletal muscle blood flow in obese man. $\mathrm{J}$ Clin Invest $1990 ; 85 ; 1844-1852$.

85. Yki-Jarvinen H, Young AA, Lamkin C, Foley JE. Kinetics of glucose disposal in whole body and across the forearm in man. J Clin Invest 1987;79;1713-1719.

86. Takata $S$. Yamamoto $M$, Yagi $S$, Noto $Y$, lkeda $T$, Hattori $N$. Peripheral circulatory effects of insulin in diabetes. Angiology $1985 ; 36 ; 110-115$.

87. Pocellati $F$, Fanelli $C$, Bottini $P$, Epifano $L$, Rambotti AM, Lalli $C$, Pampanelli $S_{\text {, }}$ Scionti $L$, Santeusamio F, Brunetti P, Hilsted J, Bolli GB. Mechanisms of arterial hypotension after therapeutic dose of subcutaneous insulin in diabetic autonomic newropathy. Diabetes $1993 ; 42 ; 1055-1064$.

88. Nestler JE, Barlascini CO, Tetrault GA, Fratkin MJ, Clore JN, Blackard WG. Increased transcapillary escape rate of albumin in nondiabetic men in response to hyperinsulinemia. Diabetes $1990 ; 39 ; 1212-1217$.

89. Ferrannini $E$, Taddei $S$, Santoro $D$, Natali $A$, Boni $C$, Del Chiaro D, Buzzigoli G. Independent stimulation of glucose metabolism and $\mathrm{Na}+-\mathrm{K}+$ exchnage by insulin in the human forearm. Am $J$ Physiol 1988;255;E953-E958. 
90. Yagi $\$$, Takata $\$$, Kiyokawa $H$, Yamamoto $M$, Noto $Y$, Ikeda $T$, Hattori $N$. Effects of insulin on vasoconstricitve responses to norepinephrine and angiotensin II in rabbit femoral artery and vein. Diabetes $1988 ; 37 ; 1064-1067$.

91. Tooke JE, Lins PE, Ostergren J, Adamson U, Fagrell B. The effects of intrawenous insulin infusion on skin microcirculatory flow in type I diabetes. Int I Microcirc Clin Exp. 1985;4;69-83.

92. Creager MA, Liang CS, Coffman JD. Beta adrenergic-mediated vasodilator response to insulin in the human forearm. I Pharmacol Exp Ther 1985;235;709-714.

93. Louard RU, Fryburg DA, Gelfand RA, Barrett EJ. Insulin sensitivity of protein and glucose metabolism in human forearm skeletal muscle. J Clin Invest $1992 ; 90 ; 2348-2354$.

94. Smits P, Tack CJV, Thien Th, Lutterman JA. Insulin attenuates the vasoconstrictor response to noradrenaline in the human forearm. Diabetologia 1993;36 suppl 1;A124.

95. Natali A, Buzzigoli $G$, Taddei $S$, Santoro D, Cerri M, Pedrinelli R, Ferrannini E. Diabetes $1990 ; 39 ; 490-500$.

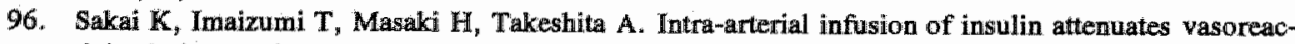
tivity in human forearm. Hypertension $1993 ; 22 ; 67-73$.

97. Axelrod L. Insulin, prostaglandins, and the pathogenesis of hypertension. Diabetes $1991 ; 40 ; 1223$ 1227.

98. Jeremy JY, Mikhailidis DP; Dandona $\mathbb{P}$. Simulating the diabetic enwironment modifies in vitro prostacyclin synthesis. Diabetes 1983;32:217-21.

99. Johansson $\mathrm{BL}$, Sjōberg $\mathrm{S}$, Wahren J. The influence of human $\mathrm{C}$-peptide on renal function and glucose utilization in type I (insulin-dependent) diabetic patients. Diabetologia 1992;35;121-128.

100. Johansson BL, Linde B, Wahren J. Effects of C-peptide on blood flow, capillary diffusion capacity and glucose utilization in the exercising forearm of type I (insulin-dependent) diabetic patients. Diabetologia 1992;35;1151-1158.

101. Christiansen JS, Gammelgaard J, Frandsen M, Orskov H, Parving HH. Kidney function and size in type I (insulin-dependent) diabetic patients before and during growth hormone administration for one week. Diabetologia $1982 ; 22 ; 333-337$.

102. Christiansen JS, Gammelgaard J, Orskov H, Andersen AR, Telmer S, Parving HH. Kidney function and size in normal subjects before and during growth hormone administration for ome week. Eur J Clin Invest $1981 ; 11 ; 487-490$.

103. Fryburg DA, Gelfand RA, Barrett EJ. Growth hormone acutely stimulates forearm muscle protein synthesis in normal humans. Am I Physiol 1991;260;E499-E504. 104. Schaper NC. Growth hormone secretion in type I diabetes: a review. Acta Endocrimol (Copenh)
$1990 ; 122 ; 7-12$.

105. Parving $\mathrm{HH}$, Noer $\mathrm{I}$, Kehler $\mathrm{H}_{\text {, }}$ et al. The effect of short-term glucagon infusion on kidney function in normal man. Diabetologia $1977 ; 13 ; 323-325$.

106. Parving HH, Christiansen JS, Noer I, Tronier B, Mogensen CE. The effect of glucagon infusion on kidney function in short-term insulin-dependent jwvenile diabetics. Diabetologia 1980;19;350-354. 107. Parmley WW, Glick G, Sonnenblick EH. Cardiovascular effects of glucagon in man. N Eng J Med
$1968 ; 279 ; 12-17$.

108. Nichols AJ, Hiley CR. Comparison of the effects of intravenous and intrasplenic infusions of glucagon on cardiac output and its distribution in the rat. Naunyn Schmiedebergs Arch Pharmacol $1987 ; 335 ; 344-350$.

109. Simmons KL, Williams G. Attempts to accelerate glucagon absorption: effects of adding a vasodilator and of injection using a 'sprinkler' needle. Eur J Clin Invest 1989;22;434-437.

110. Braadvedt GD, Stanners A, Newrick PG, Halliwell $M$, Corrall RJM. Evidence against a putative role for glucagon as a physiological splanchnic vasodilator in man. Clin Sci $1993 ; 84 ; 193-199$.

111. Unger RH. Diabetes and the alpha cell. Diabetes $1976 ; 25 ; 136-151$.

112. Bolli P, Muller FB, Linder $L$, Raine AEG, Resink TJ, Erne P, Kiowski W, Rilz R, Buhler FR. The vasodilator potency of atrial natriuretic peptide in man. Circulation 1987;75;221-228.

113. Trevisan R, Fioretto P, Semplicini A, Opocher G, Mantero F, Rocco S, Remuzzi G, Morocutti A, Zanette G, Donadon V, Perico $N$, Giorato $C$, Nosadini R. Role of insulin and atrial matriuretio 
peptide in sodium retention in insulin-treated IDDM patients during isotonic volume expansion. Diabetes 1990;39;289-298.

114. Smits $P$, Hersbach $F$, Jansen $T$, Lutterman $J$, Thien $T$. Impaired vasodilator response to atrial natriuretic factor in insulin-dependent (type 1) diabetes mellitus. Proceedings of the th thuropean meeting on Hypertension, Milan june 1993; abstract 710.

115. Gill DS, Barradas MA, Fonseca VA, Dandona P. Plasma histamine concentrations are elevated in patients with diabetes mellitus and peripheral vascullar disease. Metabolism 1989;38;243-247.

116. Bank N, Laborra MAG, Aynedjian HS, Schlondorff D. Vasoregulatory hormones and the hyperfiltration of diabetes. Am J Physiol 1988;254;F202-F209.

117. Weidmann P, Beretta-Piccoll C, Trst BN. Pressor factors and responsiveness in hypertension accompanying diabetes mellitus. Hypertension 1985;7-suppl $\mathrm{II} ; \mathrm{II}-33$ - III-42.

118. Fioretto $P$, Trevisan $R$, Velussi M, Cernigoi A, De Riva C, Bressan M, Doria A, Pauletto N, Angeli $\mathbf{P}$, De Dona $C$, Nosadini $R$. Glomerular filtration rate is increased in man by the infusion of both D,L-3-Hydroxybutyric acid and sodium D,L-3-hydroxybutyrate. J Clin Endocrinol Metab $1987 ; 65 ; 331-338$.

119. Trevisan $\mathbf{R}_{\mathrm{s}}$ Nosadini R, Fioretto $P$, Velussi M, Avogaro A, Duner E Iori E, Doria A, Merkel C, Valerio A, Crepaldi G. Metaboli control of kidney hemodynamics in normal and insulin-dependent diabetic subjects. Effects of acetoacetic, lactic, and acetic acids. Diabetes 1987;36;1073-1081.

120. Tilton RG, Chang K, Hasan KS, Smith SR, Petrash M, Misko TP, Moore WM, Currie MG, Corbett JA, McDaniel ML, Williamson JR. Prevention of diabetic vascular dysfunction by guanidines. Diabetes $1993 ; 42 ; 221-232$.

121. Altan VM. Karasu C, Ozuari A. The effects of type-1 and type-2 diabetes on endothelium-dependent relaxation in rat aorta. Pharmacol Biochem Behav $1989 ; 33 ; 519-522$.

122. Oyama $Y$, Kawasaki $H$, Hattori $Y$, Kanno $M$. Attenuation of endothelium-dependent relaxation in aorta from diabetic rats. Eur I Pharmacol 1986;131;75-78.

123. Meraji S, Jayakody L, Senaratne MPJ, Thomson ABR, Kappagoda T. Endothelium-dependent relaxation in aorta of BB rat. Diabetes 1987;36;978-981.

124. Mayhan WG. Impairment of endothelium-dependent dilatation of the basilar artery during diabetes mellitus. Brain Res 1992;580;297-302.

125. Miyata N, Tsuchida K, Okuyama S, Otomo S, Kamata K, Kasuya $\mathbf{Y}$. Age-related changes in endothelium-dependent relaxation in aorta from genetically diabetic WBN/Kob rats. Am J Physiol $1992 ; 262 ; \mathrm{H1} 104-\mathrm{H} 1109$.

126. Mayhan WG. Impairment of endothelium-dependent dilatation of cerebral arterioles during diabetes mellitus. Am J Physiol 1989;256;H621-H625.

127. Cameron NE, Cotter MA. Impaited contraction and relaxation in worta from streptozotocin-diabetic rats: role of polyol pathway. Diabetologia 1992;35;1011-1019.

128. Heesen Br, Ido $Y$, Williamson JR, Wolffenbuttel BHR. Vasoreactivity of aortic rings from diabetic rats is dependent on diabetes duration and glucose concentration. Diabetologia 1992;35; $\mathrm{A} 9$.

129. Baydoun AR. Emery PW, Pearson JD, Mann GE. Substrate-dependent regulation of intracellular amino acid concentrations in culltured bovine aortic endothelial cells. Biochem Biophys Res Comm $1990 ; 173 ; 940-948$.

130. Langenstroer $P$, Pieper GM. Regulation of spontaneous EDRF release in diabetic rat aorta by oxygen free radicals. Am J Physiol $1992 ; 263 ; \mathrm{H} 257-\mathrm{H} 263$.

131. Bucala $R$, Tracey $\mathrm{KJ}$, Cerami A. Adwanced glycosylation products quench nitric oxide and mediate defective endothelium-dependent vasodilatation in experimental diabetes. J Clin Invest 1991;87;432438.

132. Smits P, Kapma JA, Jacobs MC, Lutterman J, Thien T. Endothelium-dependent vascular relaxation in patients with type I diabetes. Diabetes $1993 ; 42 ; 148-153$.

133. Elliott TG, Cockcroft JR, Groop PH, Earle K, Morocutti A, Viberti GC, Ritter JM. Vascular responses in the forearm of microalbuminuric type $I$ (insulin-dependent) diabetic patients: evidence of altered nitric oxide biosynthesis. Diabetologia 1992;35;A19. 
134. Colwell JA, Lopes-Virella MF, Winocour PD, Halushka PV. New concepts about the pathogenesis of atherosclerosis in diabetes mellitus. In: The diabetic foot. Levin ME, O'Neall LW (eds). St. Louis: CV Mosby Company, 1988.

135. Craven PA, DeRubertis FR. Sorbinil suppresses prostaglandin production in the streptozotocin diabetic rat. Metabolism 1989;38:649-54.

136. Chang WP, Dimitriadis $E_{\text {, Allen }} T$, Dunlop ME; Cooper $M$, Larkins $R G$. The effect of aldose reductase inhibitors on glomenular prostaglandin prodiction and urinary albumin excretion in experimental diabetes mellitus. Diabetologia 1991;34:225-31.

137. Jensen PK, Steven $\mathrm{K}$, Blaehr $\mathrm{H}_{*}$ Christiansen JS, Parwing HH. Effects of indomethacin on glomerular hemodynamics in experimental diabetes. Kidney Int $1986 ; 29 ; 490-495$.

138. Jeremy JY, Thompson CS, Mikhailidis DP, Dandona P. Experimental diabetes mellitus inhibits prostacyclin synthesis by the rat penis: pathological implications. Diabetologia $1985 ; 28 ; 365-368$.

139. Harrison HE, Reece AF, Johnson M. Decreased vascular prostacyclin in experimental diabetes. Life Sci $1978 ; 23 ; 351-356$.

140. Carreras LO, Chamone DAF, Klerckx P, Vernylen J. Decreased vascular prostacyclin (PGI2) in diabetic rats. Stimulation of PGI2 release in normal and diabetic rats by the antithrombrotic compound BAY g 6575. Thromb Res 1980;19;663-670.

141. Fíretto P, Sambataro M, Cipollina MG, Duner E, Giorato $C_{3}$ Morocutti A, Mollo F, Ben GP, Carraro A, Sacerdoti E, Brocco E, Opocher E, Nosadini R. Impaired response to angiotensin II in type 1 (insulin-dependent) diabetes mellitus. Role of prostaglandins and sodium-lithium countertransport activity. Diabetologia 1991;34:595-603.

142. Gambardella S, Andreani D, Cancelli A, Di Mario U, Cardamone I, Stirati G, Cinotti GA, Pugliese $F$. Renal hemodynamies and urinary excretion of 6-keto-prostaglandin $F_{l a}$ and thromboxane $B_{2}$ in newly diagnosed type I diabetic patients. Diabetes 1988;37:1044-8.

143. Berg v.d. BW, Nieuwenhuijzen Kruseman AC, Geel v. JLC, Cornelissen P, Mulder AW. Effect of short-term inhibition of prostaglandin synthesis on glomerular filtration rate and microalbuminuria in patients with incipient diabetic nephropahty. Neth $I$ Med 1988;33:106-12.

144. Jenkins DAS, Craig K, Collier A, Watson ML, Clarke BF. Evidence against a role for prostaglandins in sustaining remal hyperfiltration in type I diabetes mellitus. Diab Med 1989;6;502-505.

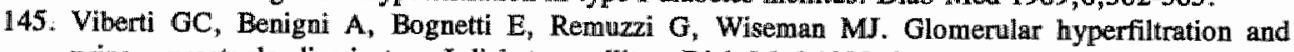
urinary prostaglandins in type I diabetes mellitus. Diab Med 1989;6;219-223.

146. Davis TME, Brown E, Finch DR. In vitro prostacyclin production, plasma 6-keto prostaglandin $\mathrm{F}_{\text {ialphas }}$ concentrations and diabetic retinopathy. Br Med J 1981;282:1259-62.

147. Mourits-Andersen T, Jensen IW, Nohr Jensen P, Ditzel J, Dyerberg J. Plasma 6-keto-PGF1 $\alpha$, thromboxane $B 2$ and $P G E 2$ in type $I$ (insulin-dependent) diabetic patients during exercise. Diabetologia $1987 ; 30 ; 460-463$.

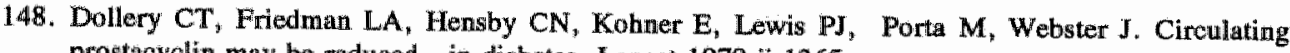
prostacyclin may be reduced in diabetes. Lancet $1979 ;$;ii; 1365 .

149. Silberbauer K, Schernthaner G. Sinzinger H. Piza-Katzer H, Winter M. Decreased vascular prostacyclin in juvenile-onset diabetes. New Eng $\mathbb{N}$ Med 1979;300;366-367.

150. Greaves $\mathrm{M}_{7}$ Preston FE. 6-keto-prostaglandin $\mathrm{F}_{\mathrm{i \alpha}}$ fact or fiction? Thromb Res $1982 ; 26 ; 145-157$.

151. Smulders $\mathrm{RA}_{4}$ Stehouwer $\mathrm{CDA}$, Olthof $\mathrm{CG}$, Van Kamp GJ, Donker AJM. Plasma endothelin levels and vascular effects of $\mathbb{L}$-arginine in type $I$ (insulin-dependent) diabetes. Diabetologia 1992;35 [suppl 1];A19.

152. Takahashi $\mathrm{k}$, Ghatei MA, Lam HC, O'Halloran DJ, Bloom SR. Elevated plasma endothelin in patients with diabetes mellitus. Diabetologia 1990;33;306-310.

153. Tukeda ' $Y$, Miyamori $I$, Yoneda $T$, Takeda $R$. Production of endothelin-1 from the mesenteric arteries of streptozotocin-induced diabetic rats. Life Sci 1991;48;2553-2556. 154. Tesfamariam B, Jakubowski JA, Cohen RA. Contraction of diabetic rabbit aorta caused by endothe-
lium-derived PGH2-TxA2. Am J Physiol 1989;257; H1327-H1333.

155. Fulton DJR, Hlodgson WC, Sikorski BW, King RG. Attemuated responses to endothelin-1, KCL and $\mathrm{CaCl} 2$, but not noradrenaline, of aortae from rats with streptozotocin-induced diabetes mellitus. $\mathrm{Br}$ J Pharmacol 1991;104;928-932. 


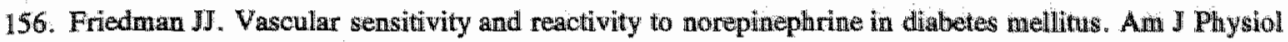
$1989 ; 256 ; \mathrm{H1} 134-\mathrm{H} 1138$.

157. White RE, Carrier GO. Enhanced vascular $\alpha$-adrenergic meuroeffector system in diabetes: importance of calcium. Am J Physiol 1988;255;H1036-H1042.

158. Agrawal DK, Bhimji $\mathrm{S}$, McNeill JH. Effect of chronic experimental diabetes on vascular snooth muscle function in rabbit carotid artery. J Cardiovasc Pharmacol 1987;9;584-593.

159. Scarborough NL, Carrier GO. Nifedipine and alpha adrenoceptors in rat aorta. II. Role of extracellular calcium in enhanced alpha-2 adrenoceptor-mediated contractio in diabetes. I Pharmacol Exp Ther $1984 ; 231 ; 603-609$.

160. Mulhern M, Docherty JR. Effects of experimental diabetes on the responsiveness of rat aorta. Br J Pharmacol 1987;97;1007-1012.

161. Morff RJ. Microvascular reactivity to norepinephrine at different arteriolar levells and durations of streptozocin-induced diabetes. Diabetes 1990;39;354-360.

162. Hill MA, Larkins RG. Altered microvascular reactivity in streptozotocin-induced diabetes in rats. Am J Physiol 1989;257;H1438-H1445.

163. Mayhan WG, Simmons LK, Sharpe GM. Mechanism of impaired responses of cerebral arterioles during diabetes mellitus. Am J Physiol 1991;260; H319-H326.

164. Christlieb AR, Janka HU, Kraus B, Gleason RE, Icasas-Cabral EA, Aiello LM, Cabral BV, Solano A. Vascular reactivity to angiotensin II and to norepinephrine in diabetic subjects. Diabetes $1976 ; 25 ; 268-274$.

165. Eichler HG, Blaschke TF, Kraemer FB, Ford GA, Blochl-Daum B, Hoffman BB. Responsiveness of superficial hand veins to $\alpha$-adrenoceptor agonists in insulin-dependent diabetic patients. Clin Sci $1992 ; 82 ; 163-168$.

166. Bodmer CW, Patrick AW, How TV, Williams G. Exaggerated sensitivity to NE-induced vasoconstriction in IDDM patients with microalbuminuria. Diabetes $1992 ; 41 ; 209-214$.

167. Okumura K, Nishiura T, Awaji Y. Kondo J. Hashimoto H, Ito "T. 1,2-Diacylglycerol content and its fatty acid composition in thoracic aorta of diabetic rats. Diabetes 1991;40;820-824.

168. Simmons DA, Winegrad AI. Mechanisms in rabbit aorta for hyperglycaemia-induced alterations in angiotensin II and morepinephrine effects. Diabetologia 1992;35;725-729.

169. Ohara T, Sussman KE, Draznin B. Effect of diabetes on cytosolic free Ca2+ and Na+-K+-ATPase in rat aorta. Diabetes $1991 ; 40 ; 1560-1563$.

170. Kamata K, Miyata N, Kasuya Y. Impairment of endothelium-dependent relaxation ans changes in levels of cyclic GMP in aorta from streptozotocin-induced diabetic rats. Br J Pharmacol 1989;97;614-618.

171. Harris KH, MacLeod KM. Influence of the endothelium on contractile responses of arteries from diabetic rats. Eur J Pharmacol 1988; 153;55-64.

172. Ditzel $J_{n}$ Jaeger $\mathbf{P}$, Kjaergaard JJ. Haemoglobin Alo and red cell oxygen releasing capacity in relation to early microvascular responses in ambulatory diabetics. Adv Microcirc $1979 ; 8 ; 1-13$.

173. Ditzel $\mathbb{J}_{\text {. }}$ Changes in rheology and oxygen transport function of the erythrocytes in diabetes. In: Mi crocirculatory approaches to current therapeutic problems. Ditzel J and Lewis DH (eds.). Basel: Karger 1971.

174. Young MJ, Veves A, Walker MG, Boulton AM. Correlations between nerve function and tissue oxygenation in diabetic patients: further clues to the aetiology of diabetic neuropathy? Diabetologia $1992 ; 35 ; 1146-1150$.

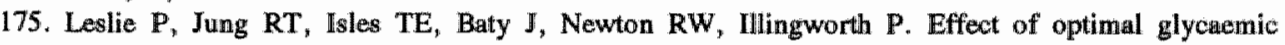
control with continuous subcutaneous insulin infusion on energy expenditure in type I diabetes mellitus. Br Med J 1986;293;1121-1126.

176. Sabbatini M, Sansone G, Uccelo F, Giliberti A, Conte G, Andreucci VE. Early glycosilation products induce glomerular hyperfiltration in normal rats. Kidney Int 1992;42;875-881.

177. MacRury SM, Lowe GDO. Blood rheology in diabetes mellitus. Diab Med 1990;7;285-291.

178. Hendra TJ, Yudhin JS. Spontaneous platelet aggregation in whole blood in diabetic patients with and without microvascular disease. Diab Med 1992;9;247-251. 


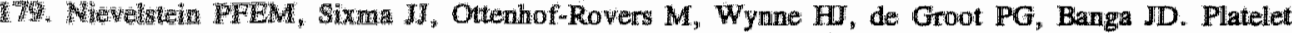

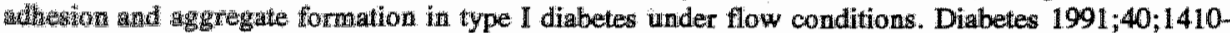
14⿻

130. Aless tes aldellows. New Eng I Med 1988;319;208-212.

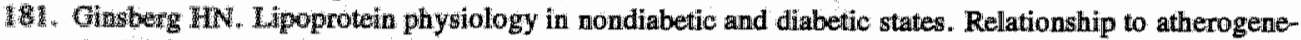
sig. Diab Care 1991; $; 4 ; 839-855$.

182. Gronwald IE, Brucker AJ, Schwartz SS, Braunstein SN, Baker L, Petrig BL, Riva CE. Diabetic gyemic control and retinal blood flow. Diabetes 1990;39;602-607.

183. Coldweit RS, Borer IS, Jovanovic LG, Drexler AJ, Hochreiter CA, Devereux RB, Peterson CM. acelation of hemoglobin A1 and blood glucose to candiac function in diabetes mellitus. Am $\mathrm{J}$ Cardiol $1985 ; 56 ; 642-646$.

184. Fillon T, sleightholm MA, Merrick C, Chahal P, Kohner EM. The effect of acute hyperglycaemia on flow velocity in the macular capillaries. Inwest Ophthalmol 1987;28;1027-1030.

185. Van Acker K, Xiang DZ, Rillaerts $E$, Wan Gaal L, De Leeuw I. Blood rheology during an intensified conventional insulin treatment (ICIT) in insulin-dependent diabetes. Diab Res Clin Pract 1989;6;259-264.

186. Collier A, Tymkewycz PM, Matthews DM, Jones RL, Clarke BF. Changes in some aspects of platelet function with improvement of glycaemic control over 6 months. Diab Res $1987 ; 5 ; 79-82$.

187. Mathiesen ER, Ronn B, Jensen $T$, Storm B, Deckert $T$. Relationship between blood pressure and urinary albumin excretion in development of microalbuminuria. Diabetes $1990 ; 39 ; 245-249$.

188. Dahl-Jorgensen K, Bjoro T, Kierulf P, Sandwik L, Bangstad HJ, Hanssen KF. The effect of long term strict glycemic control on kidney function in insulim-dependent diabetes mellitus: seven years result from the Osilo study. Kidney Int 1992;41;920-923.

189. Seaquist ER, Goetz FC, Rich S, Barbosa J. Familial clustering of diabetic kidney disease. Evidence for genetic susceptibility to diabetic nephropathy. New Eng J Med 1989;320;1161-1165.

190. Zjegler D, Mayer P, Muhlen H, Gries FA. The natural history of somatosensory and autonomic nerve dysfunction in relation to glycemic control during the first 5 years after diagnosis of type I (insulin-dependent) diabetes mellitus. Diabetologia 1991;34;822-829.

191. Ziegler D, Danneh! $K$, Wiefels $K$, Gries FA. Differential effects of near-normoglycaemia for 4 years on somatic nerve dysfunction and heart rate variation in type I diabetic patients. Diab Med $1992 ; 9 ; 622-629$.

192. Reichard P, Berglund B, Britz A, Cars I, Nilsson BY, Rosenquist U. Intensified conventional insulin treatment retards the microvascular complications of insulin dependent diabetes mellitus (IDDM): the Stockholm diabetes intervention study (SDIS) after five years. J Int Med $1991 ; 230 ; 101-108$.

193. Lorenzi $\mathrm{M}$, Cagliero $\mathrm{E}$, Toledo $\mathrm{S}$. Glucose toxicity for human endothelial cells in culture. Diabetes $1985 ; 34 ; 621-627$.

194. Lorenzi M, Montisano DF, Toledo S, Barrieux A. High glucose induces DNA damage in cultured human endothelial cells. J Clin Invest 1986;77;322-325.

195. Tesfamariam B, Cohen RA. Free radicals mediate endothelial cell dysfunction caused by elevated glucose. Am J Physiol 1992;263;H321-H326.

196. Tesfamariam B, Cohen RA. Role of superoxide anion and endothelium in vasocontrictor action of prostaglandin endoperoxide. Am J Physiol 1992;262;H1915-H1919.

197. Williamson JR, Kilo C, Tilton RG. Mechanisms of glucose- and diabetes-induced vascular dysfunction. In: Hypergllycemia, diabetes, and vascular disease. Ruderman N, Williamson JR, Brownlee $M$ (eds.). Oxford University Press, New York, 1992.

198. Dwornik D. Aldose reductase inhibition. An approach to the prevention of diabetic complications. Porte D (ed). McGraw-Hill, New York, 1987.

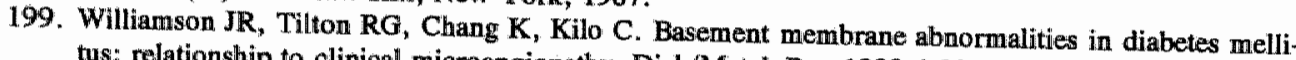
tus: relationship to clinical microangiopathy. Diab/Metab Rev 1988;4;339-370.

200. Greene DA, Lattimer SA, Sima AAF. Sorbitol, phosphoinositides, and sodium-potassium-ATPase in the pathogenesis of diabetic complications. New Eng J Med 1987;316;599-606. 
201. Williamson JR, Ostrow E, Eades D, Chang K, Allison W, Kilo $C_{\text {s }}$ Sherman WR. Glucose-induced microvascular functional changes in nondiabetic rats are stereospecifio and are prevented by an aldose reductase inhibitor. J Clin Invest $1990 ; 85 ; 1167-1172$.

202. Ohtaka $M$, Tawata $M$, Hosaka $Y$, Onaya $T$. Glucose modulation of alsdose reductase miRNA expression and its activity in cultured calf pulmonary artery endothelial cells. Diabetologia $1992 ; 35 ; 730-734$.

203. Larkins $\mathrm{RG}_{\mathrm{y}}$ Dunlop ME. The link between hyperglycaemia and diabetic nephropathy. Diabetologia $1992 ; 35 ; 499-504$.

204. Simmons DA, Winegrad AI. Mechanism of glucose-induced $\left(\mathrm{Na}^{+}, \mathrm{K}^{+}\right)$-ATPase inhibition in nortic wall of rabbits. Diabetologia $1989 ; 32 ; 402-408$.

205. Lee TS, MacGregor LC, Fluharty SJ, King GL. Differential regulation of protein kinase C and $(\mathrm{Na}, \mathrm{K})$-adenosine triphosphate activities by elevated glucose levels in retinal capillary endothelial cells. I Clin Invest 1989;83;90-94.

206. Yorek MA, Stefani MR, Moore SA. Acute and chronic exposure of mouse cerebral microvessel endothelial cells to increased concentrations of glucose and galactose: effect on myo-inositol metabolism, $\mathrm{PGE}_{2}$ synthesis, and $\mathrm{Na}^{+} / \mathrm{K}^{+}$-ATPase transport activity. Metabolism 1991;40;347-358.

207. Gupta S, Sussman I, McArthur CS, Tornheim K, Cohen RA, Ruderman NB. Endothelium-dependent inhibition of $\mathrm{Na}^{+}-\mathrm{K}^{+}$ATPase activity in rabbit aorta by hyperglycemia. I Clin Invest $1992 ; 90 ; 727-732$.

208. Tilton RG, Chang $\mathbb{K}$, Pugliese G, Eades DM, Province MA, Sherman WR, Kilo C, Williamson JR. Prevention of hemodynamic and vascular albumin filtration changes in diabetic rats by aldose reductase inhibitors. Diabetes $1989 ; 37 ; 1258-1270$.

209. Pugliese G, Tilton RG, Speedy A, Santarelli E, Eades DM, Province MA, Kilo C, Sherman WR, Williamson $\mathrm{JR}$. Modulation of hemodymamic and vascular filtration changes in diabetic rats by dietary myo-inositol. Diabetes 1990;39;312-322.

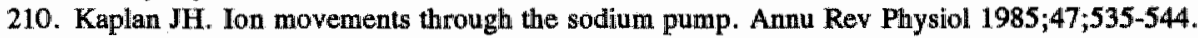

211. Lou MF, Dickerson JE, Garadi R, York BM. Glutathione depletion in the lens of galactosemic and diabetic rats. Exp Eye Res $1988 ; 46 ; 517-530$.

212. Wolf BA, Williamson JR, Easom RA, Chang K, Sherman WR, Turk J. Diacylglycerol accumulation and microvascular abnormalities induced by elevated glucose levels. J Clin Invest $1991 ; 87 ; 31$ 38.

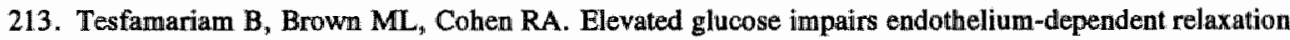
by activating protein kinase C. J Clin Invest $1991 ; 87 ; 1643-1648$.

214. Bredt DS, Hwang PM, Glatt CE, Lowenstein C, Reed RR, Snyder SH. Cloned and expressed nitric oxide synthase structurally resembles cytochrome P-450 reductase. Nature (Lond) 1991;351;714718.

215. Nakane M, Mitchell J, Forstermann W, Murad F. Phosphorylation by calcium calmodulin-dependent protein kinase II and protein kinase $C$ modulates the activity of nitric oxide synthase. Biochem Biophys Res Commun 1991;180;1396-1402.

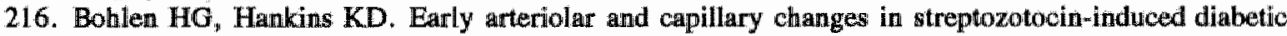
rats and intraperitoneal hyperglycaemic rats. Diabetologia $1982 ; 22 ; 344-348$.

217. Chakrabarti S, Prashar S, Sima AAF. Augmented polyol pathway activity and retinal pigment epithelial permeability in the diabetic BB rat. Diab Res Clin Pract 1990;8;1 12.

218. Fagius $J$, Jameson S. Effects of aldose reductase inhibitor treatment in diabetic polyneuropahty- a clinical and neurophysiological study. J Neurol Neurosurg Psych 1981;44;991-1001.

219. Judzewitsch RG, Jaspan JB, Polonsky KS, Weinberg CR, Halter JB, Halar E, Pfeifer MA, Vukadinovic C, Bernstein L, Schneider M, Liang KY, Gabbay KH, Rubenstein AH, Porte D. Aldose reductase inhibition improves nerve conduction velocity in diabetic patients. New Eng J Med $1983 ; 308 ; 119-125$.

220. Jennings PE, Nightingale $S$, Le Guen $C$, Lawson $N$, Williamson JR, Hoffman P, Barneth AH. Prolonged aldose reductase inhibition in chronic peripheral diabetic neuropathy: effects on microangiopathy. Diab Med 1990;7;63-68. 
221. Pedersen MM, Christiansen IS, Mogensen CE. Reduction of glomerular hyperfiltration in normoalbuminuric IDOM patients by 6 months of aldose reductase inhibition. Diabetes $1991 ; 40 ; 527-531$.

222. Ziegler $D$, Mayer $\mathbf{P}$, Rathmann $W$, Gries WF. One-year treatment with the aldose reductase inhibitor, ponalrestat, in diabetilic newropathy. Diab Res Clin Pract 1991;14;63-74.

223. Ramirez LC, Arauz C, Prumeda L, Hammon K, Rosenstock J, Raskin P. The effect of aldose reductase inhibition with ponslrestat on the width of the capillary basement membrane in diabetes mellítus. Diab Res Clin Pract 1991;11;73-80.

224. O'Hare IP, Morgan MH, Alden P, Chissel $S$, $O^{\prime}$ Brien IAD, Corrall RJM. Aldose reductase inhibition in diabetic neuropatthy: clinical and neurophysiological studies of one year's treatment with sorbinil. Diab Med 1988;5;537-542.

225. Martyn $\mathrm{CN}$, Reid W, Young RU, Ewing DJ, Clarke BF. Six-month treatment with sorbinil in asymptomatic diabetic neuropathy. Failure to improve abnormal nerve function. Diabetes $1987 ; 36 ; 987-990$.

226. Brownlee $\mathrm{M}_{*}$ Cerami $\mathrm{A}$, Vlassara $\mathrm{H}$. Advanced glycosylation end products in tissue and the biochemical basis of diabetic complications. New Eng J Med 1988;318;1315-1321 .

227. Baynes JW. Role of oxidative stress in development of complications in diabetes. Diabetes 1991;40;05-412.

228. Ceriello $A$, Giugliano $D$, Quatraro A et al. Metabolic control may influence the increased superoxide anion generation in diabetic serum. Diab Med 1991;8;540-542.

229. Dyer DG, Dunn JA, Thorpe SR, Baillie KE, Lyons TJ, MoCance DR, Baynes JW. Accumulation of Maillard reaction products in skin collagen in diabetes and aging. $J$ Clin Invest 1993;91;24632469.

230. Bülow J, Astrup A, Christensen NJ, Kastrup J: Blood flow in skin, subcutaneous adipose tissue and akeletal muscle in the forearm of normal man during an oral glucose load. Acta Physiol Scand $1987 ; 130 ; 657-661$.

231. Quaade F, Larsen OA, Lassen NA, Nielsen SL. Observations on the influence of glucose upon subcutaneous adipose tissue blood flow. Acta Med Scand 1967;suppl 476;85-90.

232. Laakso M, Edelman SV, Olefsky JM, Brechtel G, Wallace P, Baron AD: Kinetics of in vivo muscle insulin-mediated glucose uptake in human obesity. Diabetes 1990;39;965-974.

233. Christiansen JS, Frandsen M, Parving HH. Effect of intravenous glucose infusion on renal function in normal man and in insulin dependent diabetics. Diabetologia 1981;21;368-372.

234. Edelman SV, Laakso M, Wallace P, Brechtel G, Olefsky IM, Baron AD. Kinetics of insulin-mediated and non-insulin-mediated glucose uptake im humans. Diabetes 1990;39;955-964.

235. Jansen RWMM, Hoefnagels WHL. Influence of oral and intravenous glucose loading on blood pressure in normotensive and hypertensive elderly subjects. J Hyperten 1987;5 (suppl 5);s501-s503. 


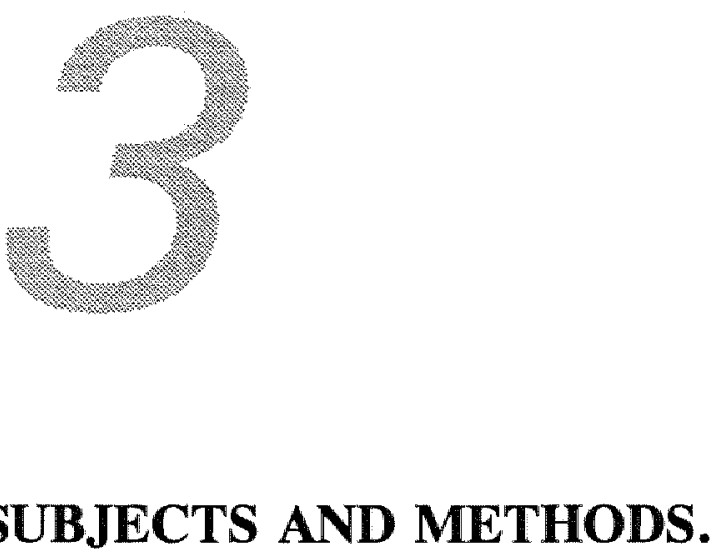




\subsection{SUBJECTS}

The studies described in this thesis were performed in subjects with insulin-dependent diabetes mellitus (IDDM) and healthy volunteers. Insulin-dependent diabetes mellitus was defined either as onset of disease before the age of 30 years and requiring insulin therapy within a few weeks from diagnosis, or as having had ketoacidosis. The IDDM subjects had no clinical signs of diabetic polyneuropathy, renal disease other than (micro)albuminuria, or cardiovascular disease. Some of the IDDM subjects who participated in the study described in chapter 5 had signs of autonomic neuropathy. Both IDDM subjects and healthy volunteers were normotensive (systolic blood pressure $<160$, diastolic blood pressure $<90 \mathrm{mmHg}$ ) and used no other medication than insulin. Further characteristics on the subjects are presented in the separate chapters.

\subsection{PROTOCOL}

All investigations were performed in a temperature controlled room $\left(23^{\circ}-25^{\circ} \mathrm{C}\right.$. $)$. Precautions were taken to minimize external disturbances during the measurements. The measurements of both macro and microcirculatory parameters were performed in supine position with the investigated arm at heart level, and started after at least a 30 minutes period of acclimatization. We did not perform measurements in subject's legs or feet, because of the possible haemodynamic disturbances due to asymptomatic macroangiopathic lesions, which can be present in diabetic patients in particular. In the experiments described in chapters $4,6,7,8,9$ subjects were studied in fasting state. They were asked to refrain from smoking, eating, and drinking (except for water) from 10 p.m. the night before the measurement until the end of the experiment. Besides, the IDDM subjects omitted their morning insulin injection. In the experiments described in chapter 5 subjects were asked to refrain from smoking and drinking caffeine or alcohol containing drinks on the day of measurement, but they were not fasting. The measurements were performed 2 hours after the meal. The experiments were postponed to another day if an IDDM subject suffered symptomatic hypoglycaemia or had a blood glucose level below 3.5 or above $15 \mathrm{mmol} / 1$.

\subsection{CAPILLAROSCOPY}

Nutritive skin blood flow was evaluated using intravital microscopy. Finger nailfold capillaries were visualized using a Wild-Leitz microscope and the images were recorded on videotape for off-line analysis (fig. 3.1). The microscope was equipped with a 20x objective (Leitz L20; numeric aperture 0.32). Incident illumination was performed using a Leitz Ploemopak system (tube factor $1 \mathrm{x}$ ) and a POL-cube (1). Light from a 100 Watt mercury arc passed through a heat absorption and a heat reflection filter, a polarizer and a $50 \%$ mirror, and through the objective lens to 
illuminate the object. A crossed analyzer was positioned above the $50 \%$ mirror in the image

pathway. Directly reflected light was cancelled by the analyzer and could not reach the video camera. A drop of paraffin oil was applied to the nailfold to diminish scattering, and improve skin transparency. Neutral density filters were used to adjust light intensities. Light that penetrates the skin is scattered, reflected multiple times, and depolarized. If no strong absorbing parts are present, the reflected light image will be homogeneously bright.

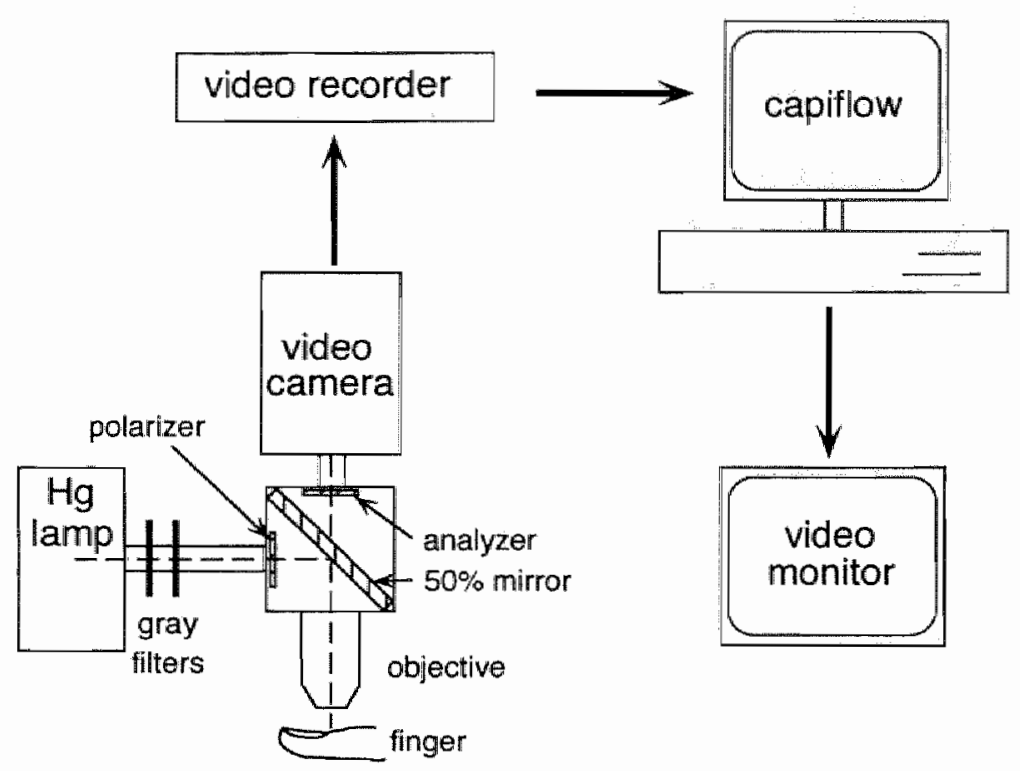

Figure 3.1: Schematic representation of the capillary microscopy system.

However, the 100 Watt mercury lamp has a peak in its emission spectrum about 420 $\mathrm{nm}$. This wavelength matches the haemoglobin absorption spectrum. Consequently, the red blood cells (RBC) appear dark in a bright background. Focusing of the image was performed by means of a stepping-motor, which was operated through a foot switch. The microscopic images were projected onto the sensitive surface of a video camera (Philips) positioned in the image plane of the objective lens. The images were videotaped (Sony, Betamax) for off-line analysis.

Capillary blood cell velocity was analyzed using the temporal correlation method (2), which is incorporated into the automated Capiflow software (3) (SIM, Kista, Sweden). Two photometric windows are positioned on the capillary (fig. 3.2). Blood cells and plasma gaps passing through the capillary modulate the light intensity in the two windows. The fluctuations - often with clearly recognizable peaks and 
throughs - in the upstream window appear after some delay (and with some changes) in the downstream window. The delay equals the time needed for the RBCs to travel the distance between the windows. The time delay between the two signals was assessed by cross-correlation of the two signals. The velocity is the ratio of the preset distance between the two windows and the time delay. The two windows were positioned on the arterial limb of the capillary.

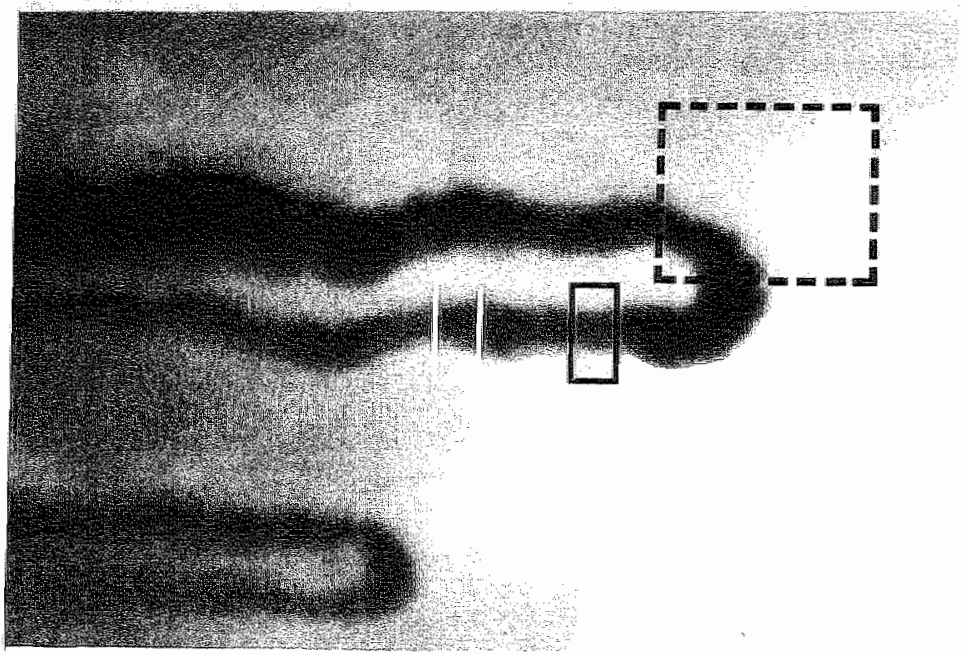

Figure 3.2: Microscopic image of a capillary in the finger nailfold. The white and black rectangle represent the upstream and downstream cross-carrelation window, respectively, as generated by Capiflow. The large dotted rectangle represents the wirdow for movement correction, as generated by Capiflow.

Usually, the width of the windows was about the width of the capillary and the height of the windows was about twice the width of the capillary. The distance between the windows is to be varied with the RBC velocity. At low velocities (approximately $0.1 \mathrm{~mm} / \mathrm{s}$ ) we used a interwindow distance of about $20 \mu \mathrm{m}$, and at higher velocities (approximately $1.0-1.5 \mathrm{~mm} / \mathrm{s}$ ) we used a distance of $30-40 \mu \mathrm{m}$. The width, height, and distance of the windows was adjusted for every CBV recording to obtain an optimal cross-correlation figure (2).

With incident polarized light microscopy the capillary wall can not be visualized. The RBCs appear black in a white background. Our capillary diameter data actually represent the width of the red blood cell column, which is common for capillaroscopy. Moneta and co-workers (4) demonstrated that the RBC column comprises about $70 \%$ of the capillary diameter. The width of the RBC column ("capillary diameter") was determined using the random line length option of the Capiflow software. A line can be drawn on the video screen corresponding to the RBC column width. The 
length of this line is calculated by the program. RBC column width of the arterial limb was determined at the position of velocity measurement. The width of the venous limb was determined at a similar distance from the apex as in the arterial limb.

\section{Reproducibility}

The instrumental variability of the CBV measurement with Capiflow was evaluated by calculating the coefficient of variation (CV) for two CBV measurements of the same recording using exactly the same windlow (size and distance) settings: $\mathrm{CV}=$ $6 \%(\mathrm{n}=11)$. The variability is caused by a different starting point for the correlation process. The quality of the correlation procedure depends on the length of the two windows and their separation (2). Therefore, we compared CBV of the same recording using different window size and distance settings, but still resulting in optimal cross-correlation, which resulted in a CV of $15 \%(n=11)$. This indicates the importance of an optimal setting of window size and separation. The temporal variability of CBV was assessed by comparing two consecutive CBV measurements, with a 60 minutes interval. The $\mathrm{CV}$ was $31 \%(\mathrm{n}=9)$. The mean $\mathrm{CV}$ of CBV measurements in the same subject (and the same capillaries) on two separate days (with an interval of approximately two weeks) is $30 \%(\mathrm{n}=8)$. The physiological variability with time clearly exceeds that of the instrument.

\subsection{LASER-DOPPLER}

Skin thermoregulatory blood flow was determined using laser-Doppler fluxmetry. The light $(632.8 \mathrm{~nm})$ of the He-Ne laser in the laser-Doppler device (Periflux PF3, Perimed, Sweden) is reflected and scattered in the skin tissues and moving red blood cells (fig. 3.3). The light beams scattered by moving RBCs undergo a frequency shift according to the Doppler effect. This frequency shift is a measure of RBC flux (red cell velocity times concentration) and equalls red blood cell flow. Since, the thaematocrit is not likely to change within one experiment, the LDF signal is proportional to volume flow (5). In addition, comparison of LDF with other techniques like heat clearance (6) or isotope clearance (7) results in strong correlations, indicating that the LDF signal is proportional to blood flow. All measurements were performed at ambient skin temperature using the standard probe PF 308, filter setting: $12 \mathrm{kHz}$ ('wide band'), and time constant: $0.2 \mathrm{~s}$. LDF measurements were recorded on a chart recorder with a paper speed of $6 \mathrm{~cm} /$ minute (chapters $5,7,8$ ), or on disc using our computerized data acquisition system (chapters 4 and 9). The recordings were analyzed off-line. RBC flux is expressed as (arbitrary) perfusion units (PU), calibrated to the Periflux Motility Standard. The biological zero value (8), which is represented by the LDF signal in a "no flow" situation (obtained after at least 3 minutes of arterial occlusion), was subtracted from all LDF values (except for chapter 8, where no arterial occlusion of the forearm was performed). He-Ne laser light penetrates the skin to a depth of about $1 \mathrm{~mm}$. The measuring volume depends on the 
separation of the emitting and receiving fibres. The volume "seen' by each of the fibres is approximately a hemisphere with a radius of about $1 \mathrm{~mm}$ (9). Therefore, the flux values include signals from capillaries, arterioles, venous plexus, and A-V shunts.

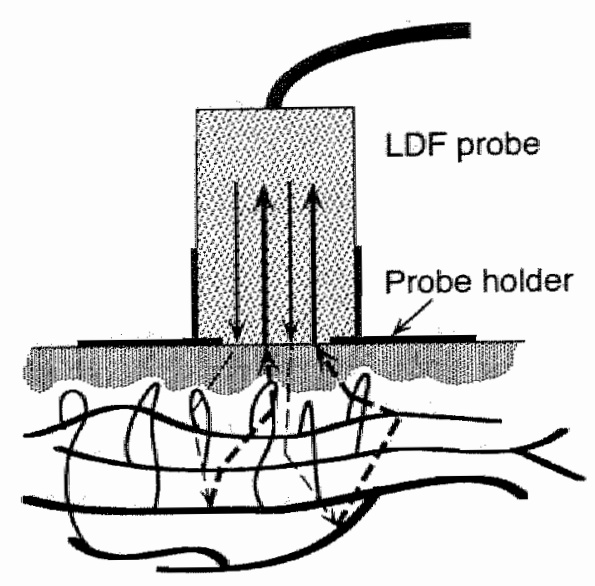

Figure 3.3: Schematic representation of the emission and scattering of laser light in the skin.

The efficacy of the laser light is low in the skin layer where the capillaries are situated (50 - $400 \mu \mathrm{m}$ from the outside of the skin) and maximal in the deeper skin layer where the arterioles, venous plexus and $\mathrm{A}-\mathrm{V}$ shunts are situated (around $600 \mu \mathrm{m}$ ). Moreover, the contribution of the capillaries in this signal has been found to be approximately $5-10 \%$ (10). Hence, the laser-Doppler flux (LDF) values represent predominantly skin thermoregulatory perfusion $(9,11)$. In the regions where we measured (the dorsal aspect of the finger and the ventral side of the forearm) A-V shunts are relatively scarce (12). Therefore, the largest contribution to the LDF signal was probably derived from the venous plexus.

Human skin blood flow shows both spatial and temporal variations. Displacement or rotation of the laser-Doppler probe results in different flux readings, due to asymmetry of the probe configuration $(13,14)$. Therefore, the probe remained in the same position during the experiments and rotation was avoided by securing the probe with adhesive tape to the probeholder.

- Resting LDF values were calculated as the mean value during one minute (prior to occlusion; chapter 5) or two minutes (chapters $4,7,8,9$ ) recording.

- The variables determined after arterial and venous occlusion are described in chapter 5. 


\section{Reproducibility}

The physiological variability of two consecutive LDF measurements on the same spot, with a 30 minutes interval, is represented by the coefficient of variation ( $\mathrm{CV}$ ) of $16 \%(n=12)$ comparing the mean LDF value of both measurements, which is in agreement with others (13). The mean CV of LDF measurements in the same subject on two separate days (with an interval of approximately two weeks) is $27 \%$ $(\mathrm{n}=20)$, which is lower than found by others $(15,16)$. The increase of CV from $16 \%$ to $27 \%$ includes the variability with position of the probe.

\subsection{PLETHYSMOGRAPHY}

\section{Flow measurements}

Forearm blood flow (FBF) was determined using mercury in silastic strain gauge venous occlusion plethysmography as described by Whitney (17). Venous congestion ( $50 \mathrm{mmhg}$ ) of the upperarm for a few heartbeats, by means of a rapid cuff inflator, results in a cumulative increase of forearm volume, which is measured by the mercury strain gauges placed around the forearm. This strain gauge was positioned on the proximal part of the forearm, around the widest circumference of the muscle. Change of the length of the strain gauge, i.e. the circumference of the arm, results in a change in resistance. The increase in forearm volume is assumed to represent the volume of arterial blood that enters the forearm during those few heartbeats and pools in the veins. The plethysmographically determined volume variations (FBF) in this position correlate well $(r=0.99)$ with electromagnetic flowmeter measurements (18). FBF is represented as $\mathrm{ml} / 100 \mathrm{ml}$ forearm/minute. As the blood flow through the hand is rather variable, predominantly due to the $A-V$ shunt flow, hand flow was excluded during the FBF measurements, starting one minute before the actual measurement, by means of a paediatric cuff around the wrist inflated to $200 \mathrm{mmhg}$ (19). FBF represents predominantly forearm muscle blood flow. The contribution of skin blood flow is approximately $19-27 \%$ in the FBF ranges we measured (20). The volume of the forearm compartment in which FBF was determined (from wrist to elbow), was measured using water displacement. Forearm vascular resistance was calculated as the ratio of mean arterial pressure (MAP) and FBF.

Two different plethysmographs were used in the studies described in this thesis. In chapter 7 we used a Hokanson EC4 plethysmograph (Hokanson, USA). A flow curve lasted 10 seconds, of which during 5 seconds venous occlusion was applied. Therefore, 6 inflow curves per minute were determined. The flow was recorded using a chart recorder with a paper speed of $6 \mathrm{~cm} /$ minute. Three FBF measurements of two minutes each were performed, with an interval of 10 minutes. The mean of the 3 measurements was used for calculations.

In chapters 4,8 , and 9 we used an ECG-triggered Periflow plethysmograph (Jansen Scientific Instruments, Belgium). A flow curve lasted 5 heartbeats, of which during 3 beats venous occlusion was applied. Therefore, on average 12 inflow curves per minute were determined. FBF measurements were recorded on a chart recorder with 
a paper speed of $6 \mathrm{~cm} /$ minute (chapters 7,8 ), or on disc using our computerized data acquisition system (chapters 4,9 ). The recordings were analyzed off-line. Baseline FBF was measured during four minutes. The mean of the last two minutes was used for calculations.

\section{Reproducibility}

The mean $\mathrm{CV}$ for two consecutive FBF measurements (10 minutes apart) with the Hokanson EC4 plethysmograph is $11 \%(n=16)$ and for the Periflow plethysmograph $14 \%(n=14)$ ( 30 minutes interval between the two measurements). Comparing FBF measurements on two separate days (with an interval of approximately two weeks) resulted in a mean CV for the Hokanson EC4 of $22 \%(n=8)$, and $23 \%$ for the Periflow plethysmograph $(n=14)$. The results obtained with both plethysmographs do not differ.

\section{Venous compliance measurements}

Venous compliance, representing venous visco-elastic properties, is defined as the slope of the relationship of intravenous volume and pressure changes. It was determined using the Hokanson EC4 plethysmograph. The volume changes, as measured with the plethysmograph were related to intravenous pressures. A 20 gauge catheter was inserted in a vein of the right forearm for intravenous pressure measurements. A pressure transducer was placed $5 \mathrm{~cm}$ below the sternal angle and connected to a HP $78205 \mathrm{C}$ pressure monitor (HP, Böblingen, Germany) for intravenous pressure measurements. The cuff for venous occlusion was placed just above the elbow. A mercury strain gauge was placed around the forearm, $5-8 \mathrm{~cm}$ distal to the lateral humeral epicondyl. Changes in forearm volume and intravenous pressure were measured during the following cuff pressures: $25-30-35-40-50 \mathrm{mmhg}$. The duration of each pressure step was 3 minutes, followed by a 2 minute interval of deflation of the cuff. The changes in volume and intravenous pressure during each cuff pressure step were obtained from the values measured just before and after deflation of the cuff. Venous volume-pressure curves were constructed by plotting changes of forearm volume (Dv: $\mathrm{ml} / 100 \mathrm{ml}$ forearm) against corresponding changes in intravenous pressure (dP: mmhg) during the 5 pressure steps. The slope of this Dv/Dp curve, calculated by linear regression analysis, is a measure of forearm venous distensibility.

\section{Reproducibility}

The coefficient of variation of the venous compliance measurements is $8.7 \%$ for two consecutive measurements ( 30 min interval), and $11.4 \%$ for two measurements on different days (more than 5 weeks between 2 measurements) (21).

\subsection{SKIN TEMPERATURE}

Skin temperature was measured proximal to the laser-Doppler probe on the dorsum of the same finger, using a Hewlett Packard 78214 C monitor (HP, Germany). 


\subsection{BLOOD PRESSURE AND HEART RATE}

Blood pressure was determined non-invasively in chapters 4-7, and intraarterially in chapters 8 and 9. The Finapres blood pressure monitor (Ohmeda, USA) measures non-invasively both digital artery blood pressure and heart rate. Digital artery blood pressure is determined, beat to beat, using the technique described by Penàz (22). A cuff around the finger is inflated to a pressure equal to the pressure in the digital artery, till the artery is just about to collapse (which is determined with a photoplethysmograph in the cuff). Hence, the transmural pressure is almost zero. The cuff pressure, which is dynamically adjusted by a servo system, represents the pressure in the digital artery. Blood pressure values recorded with the Finapres monitor correlate very well in absolute terms with blood pressure recordings in the brachial artery in rest (23). Blood pressure was determined on the third finger of the contralateral arm. The mean of a one minute recording was used for calculations.

In chapters 8 and 9 blood pressure was measured in the brachial artery using a pressure dome positioned at right atrium level $(5 \mathrm{~cm}$ below the sternal angle), which was connected to a Hewlett Packard $78205 \mathrm{C}$ monitor (HP, Germany). Heart rate was determined from the ECG.

\subsection{STATISTICAL ANALYSIS}

All data were collected and analyzed by the same investigator. Data are expressed as mean \pm standard deviation (SD) when their distribution was normal. In all other cases median and interquartile ranges are given. Nonparametric statistical tests were used for analysis: two-tailed Wilcoxon for two related samples; two-tailed MannWhitney U for two unrelated samples. When appropriate, the Bonferroni correction was used to correct for multiple comparisons. The Friedman (nonparametric twoway ANOVA) test was used for multiple related samples (within group comparison); Kruskal-Wallis (nonparametric one-way ANOVA) for multiple unrelated samples (between groups comparison). P values below 0.05 were considered to be statistically significant. 


\section{REFERENCES}

1. Slaaf DW, Tangelder GJ, Reneman RS, Jager K, Bollinger A. A versatile incident illuminator for intravital microscopy. Int I Microcirc Clin Exp 1987;6;391-397.

2. Slaaf DW, Arts $T$, Jeurens TJM, Tangelder GI, Rememan RS. Electronic measurements of red blood cell velocity and wolume flow in microvessels. In: Imvestigative microtechniques in medicine and biology. Vol. 1, Chayen $J$ and Bitensky L (eds.). New York: Marcel Dekker, Inc., 1984;327364.

3. Pries AR, Eriksson SE, Jepsen H. Real-time oriented image analysis in microcirculatory research. SPIE (Int Soc for Optical Eng) proceedings, vol 1357, 1990.

4. Moneta $G$, Brulisauer $M$, Jager $K$, Bollinger A. Infrared fluorescence videomicroscopy of skin capillaries with indocyanine green. Int I Microcirc Clin Exp 1987,6;25-34.

5. Driesgen $G$, Rutten $W$, Inhoffen $W$, Scheidt $H$, Heidtmann $H$. Is the Iaser doppler flow signal a measure of microcirculatory cell flux? Int J Microcire Clin Exp 1990;9;141-161.

6. Saumet $\mathrm{J}$, Ditmar A, Leftheriotis $\mathrm{G}$. Non-invasive measurement of skin blood flow: comparison between plethysmography, laser-doppler flowmetry and heat thermal clearance method. Int I Microcirc Clin Exp 1986;5;73-83.

7. Holloway GA, Watkins DW. Laser doppler measurements of cutaneous blood flow. J Invest Derm $1977 ; 69 ; 306-309$.

8. Caspary $L$, Creutzig A, Alexander K. Biological zero in laser Doppler fluxmetry. Int J Microcirc Chin Exp 1988;7;367-371.

9. Nilsson GE, Tenland T, Oberg BA. Evaluation of a laser Doppler flowmeter for measurement of tissue blood flow. IEEE Trans Biomed Eng 1980;BME 27;597-604.

10. Fagrell B. The relationship between macro- and microcirculation. Clinical aspects. Acta Pharmacol Toxicol 1986;58: suppl 6;67.

11. Tooke JE, Ostergren $\mathbf{J}$, Fagrell B. Synchronous assessment of human skin microcirculation by laser Doppler flowmetry and dynamic capillaroscopy. Int J Microcirc Clim Exp 1983;2;277-284.

12. Smith Jf, Kampine JP. Circulatory physiology: the essentials. Baltimore, Williams + Wilkins, 1980.

13. Tenland T, Salerud EG, Nilsson GE, Oberg PA. Spatial and temporal variations in human skin blood flow. Int J Microcirc Clin Exp 1983;2;81-90.

14. Bongard O, Fagrell B. Variations in laser Doppler flux and flow motion patterns in the dorsal skin of the human foot. Microvase Res 1990;39;212-222.

15. Sundberg S. Acute effects and long-term wariations in skin blood flow measured with laser Doppler flowmetry. Scand J Clin Lab Invest $1984 ; 44 ; 341-345$.

16. Lukkari-Rautiarinen E, Lepantalo M, Pietila $\mathbf{J}_{\mathrm{*}}$ Reproducebility of skin blood flow, perfusion pressure and oxygen tension measurements in advanced lower limb ischaemia. Eur $\mathrm{J}$ Vasc Surg $1989 ; 3 ; 345-350$.

17. Whitney RJ. The measurement of volume changes in human limbs. I Physiol 1953;121;1-27.

18. Jageneau AHM. Noninwasive methods on cardiovascular haemodynamics. North-Holland biomedical press, Amsterdam, 1981.

19. Lenders J, Janssen GJ, Smits $\mathbb{P}$, Thien $T$. Role of the wrist cuff in forearm plethysmography. Clin Soi $1991 ; 80 ; 413-417$.

20. Cooper KE, Edholm OQ, Mottram RF. The blood flow in skin and muscle of the human forearm. J Physiol (Lond) $1955 ; 128 ; 258$.

21. Kooman JP, Wijnen JAG, Draajer P, van Bortel LMAB, Glad-ziwa U, Peltenburg HG, StruykerBoudier HAJ, van Hooff JP, Leunissen KML. Compliance and reactivity of the peripheral venous system in chronic intermittent hemodialysis. Kidney Int 1992;41;1041-1048.

22. Pendz J. Photoeleetric measurement of blood pressure, volume and flow in the finger. Digest 10th Int Conf Medl Biol Engng 104, Dresden 1973.

23. Imholz BPM, van Montfrans GA, Settels JJ, van der Hoeven GMA, Karemaker JM, Wieling W. Continuous noninvasive blood pressure monitoring; reliability of Finapres device during the Valsalva manoeuvre. Cardiovase Res $1988 ; 22 ; 390-397$. 


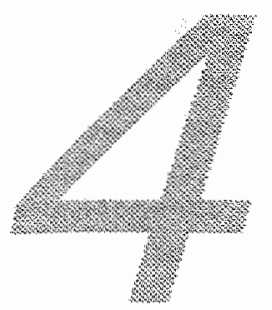

\section{DIURNAL VARIATIONS IN TOTAL FOREARM AND SKIN MICROCIRCULATORY BLOOD FLOW IN MAN.}

A.J.H.M. Houben, D.W. Slaaf, F.C. Huvers, P.W. de Leeuw, A.C. Nieuwenhuijzen Kruseman, N.C. Schaper.

Submitted for publication. 


\subsection{ABSTRACT}

The aim of the present study was to determine diurnal variations in total forearm and skin microcirculatory blood flow in healthy man. At six time points between 08.00 and 18.00 hours was measured: blood pressure, forearm blood flow (FBF; strain gauge plethysmography), skin thermoregulatory blood flow (LDF; laser-Doppler fluxmetry), and skin nutritive blood flow (CBV; intravital capillary microscopy) in 15 healthy, fasting, and resting men. FBF increased gradually from 2.8 in the morning to $4.3 \mathrm{ml} / 100 \mathrm{ml} / \mathrm{min}$ in the afternoon ( $P<0.001$ ). In contrast, LDF decreased, predominantly in the morning, from 18.3 at $09.00 \mathrm{~h}$ to 13.1 at $12.00 \mathrm{~h}$ and to 12.1 perfusion units at $17.30 \mathrm{~h}(\mathbb{P}<0.001)$. However, performing the same protocol starting in the afternoon resulted in a similar initial decrease in LDF, suggesting an acclimatization phenomenon. Although not statistically significant, the decrease in CBV showed a similar pattern as compared to LDF. Blood pressure did not change. In conclusion, forearm blood flow increased during the day, probably due to diurnal variation in muscle flow. The initial decrease we observed in skin thermoregulatory blood flow is probably not related to diurnal variation but due to long-term acclimatization to the experimental conditions. These data suggest different regulatory mechanisms for the different vascular beds studied. Measurements of forearm blood flow should preferably be performed at the same time of day, and skin microcirculatory haemodynamic measurements should be performed after a standard period of acclimatization.

\subsection{INTRODUCTION}

Diurnal rhythms have a profound influence on many regulatory systems throughout the human body, including haemodynamics. Blood pressure (1) and heart rate (2) are higher early in the morning than late in the afternoon. This may partly be due to variations in sympathetic outflow and/or circulating plasma catecholamine levels which are also higher in the morning than in the afternoon $(3,4)$. As a result, higher morning peripheral vascular resistance attenuates forearm blood flow as compared to that in the afternoon $(5,6)$. In studies regarding peripheral haemodynamics, changes are often difficult to interpret because of these circadian variations. At present, no data are available concerning possible diurnal rhythms in peripheral microcirculation, or whether such rhythms are similar in different peripheral vascular beds. In general, haemodynamic measurements are performed between 9 a.m. and 6 p.m. Therefore, the aim of present study was to determine whether the diurnal variation in total forearm blood flow is paralleled by variations in skin thermoregulatory blood flow, and skin nutritive blood flow (microcirculation), and whether possible variations are similar in the different vascular beds studied. 


\subsection{SUBJECTS AND METHODS}

Experiments were performed in 15 healthy male volunteers, with a mean age of 21.7 \pm 2.1 (SD) years and a body mass index of $23.6 \pm 2.3$ (SD) $\mathrm{kg} / \mathrm{m}^{2}$. Forearm volume was measured by water displacement. Three subjects were smokers (their results did not differ from the nonsmokers). All participants gave written informed consent and the study was approved by the hospital's medical-ethical committee.

\section{Methods}

Except for blood pressure and heart rate, all measurements were performed on the non-dominant arm. Forearm blood flow was measured on both arms.

Capillary blood cell velocity (CBV; representing skin nutritive blood flow) was monitored during two minutes in two distal capillaries of the fourth finger nailfold using epi-POL microscopy (7), with a $20 \mathrm{x}$ lens (numeric aperture: 0.32 ). Images were videotaped for off-line analysis. The same two capillaries were studied during each subsequent measurement. Mean CBV of the two capillaries was used for calculations (with a CV of $19 \%$ comparing the first minute with the second), which was evaluated off-line using the temporal correlation technique (8) incorporated in CAPIFLOW software (SIM, Kista, Sweden). In six subjects CBV was not evaluable on all timepoints throughout the day.

Thermoregulatory skin perfusion (9) was determined using laser-Doppler fluxmetry (LDF; Periflux PF3, Perimed, Järfälla, Sweden), with probe PF 308, wide band (12 Khz) mode, and time constant $0.2 \mathrm{~s}$. The probe was placed on the dorsum of the interphalanx of the same finger where CBV was monitored. This probe remained in the same position during the experiment. The mean value of two minutes recording was used for calculations (with a $\mathrm{CV}$ of $8.1 \%$ comparing the first with the second minute). Flux values are expressed as arbitrary, but calibrated Perfusion Units (PU). Biological zero values (mean: $3.8 \pm 1.4$ (SD) PU), obtained during arterial occlusion, were subtracted from the measured LDF levels (10). Skin temperature was measured at the same site using a Hewlett Packard $78214 \mathrm{C}$ monitor (HP, Böblingen, Germany).

Blood pressure and heart rate were measured during one minute on the third finger of the dominant arm using the Finapres blood pressure monitor (Ohmeda, Englewood, CO, USA).

Total forearm blood flow (FBF) was determined using ECG-triggered strain gauge venous occlusion plethysmography (Periflow, JSI, Beerse, Belgium) (11). The hand circulation was excluded by inflating a wrist cuff to suprasystolic pressure starting one minute before each FBF measurement. Hence, FBF represents predominantly muscle blood flow, determined by arteriolar tone. FBF was measured during four minutes. The mean of the last two minutes was used for calculations (with a $\mathrm{CV}$ of $11.7 \%$ comparing the third with the fourth minute). A flow curve lasted 5 heartbeats, of which during 3 beats venous occlusion $(50 \mathrm{mmhg}$ ) was applied. Therefore, on the average 12 inflow curves per minute were determined. 
Day-time protocol

All experiments started at $8 \mathrm{a} . \mathrm{m}$. and were performed in a quiet, temperature controlled room (mean temp. $24.9 \pm 0.4$ (SD) ${ }^{\circ} \mathrm{C}$.). Precautions were taken to minimize external disturbances. Subjects were studied in supine position. They remained in bed during the experiment. Between the measurements they were allowed to sit upright (by placing the bed's head in vertical position), but 15 minutes before each measurement they were placed supine again. Subjects were not allowed to smoke, eat, or drink (except for water) from $10 \mathrm{p} . \mathrm{m}$. the night before the experiment till the end of the experiment. Measurements started after a 60 minute period of acclimatization, and were performed at six time points during the day: $9.00 ; 10.30 ; 12.00$; $13.30 ; 16.30$; and 17.30 hours. During each measurement were monitored, in the following order: CBV, LDF, skin temperature, blood pressure and heart rate, and FBF. Forearm vascular resistance (FVR) was calculated as the ratio of mean arterial pressure (MAP) and FBF.

\section{Afternoon protocol}

To determine whether the observed changes in microcirculatory blood flow were due to a diurnal rhythm or to any kind of acclimatization, an additional set of experiments was performed in five healthy males (mean age $25.4 \pm 5.4$ (SD) years). The protocol of the morning, as described above, was shifted 5 hours to the afternoon. The subjects were allowed to use a light breakfast at $08.00 \mathrm{~h}$. but were not allowed to smoke or take caffeine or alcohol containing drinks on the day of study. The protocol started at $13.00 \mathrm{~h}$. and measurements were performed at 14.00, 15.30, and 17.00 hours.

\section{Statistical analysis}

All data are presented as median values with interquartile ranges unless otherwise indicated. The Friedman test (nonparametric two-way ANOVA) was used for analysis of multiple related samples and Wilcoxon for paired analysis. $\mathrm{P}$ values below 0.05 were considered to be statistically significant. Nonlinear curvefitting was performed using SYSTAT V5.0. The residual of sum-of-squares was tested (F-test) with that of the linear curve to determine the $P$ value.

\subsection{RESULTS}

\section{Macrocirculation and forearm blood flow}

Median volume of the non-dominant arm (from wrist to elbow) was 1203 (11101313) and that of the dominant arm was 1258 (1184-1332) ml (Wilcoxon, $\mathbf{P}=0.014$ ). Mean arterial pressure (MAP) and heart rate did not change significantly during the day (table 4.1), although there seemed to be a little increase in blood pressure late in the afternoon. In contrast, forearm blood flow (FBF) in both arms showed a gradual increase of $58 \%$ during the day (Friedman, $\mathrm{P}<0.001$ ) (fig. 4.1). 
FOREARM BLOOD FLOW

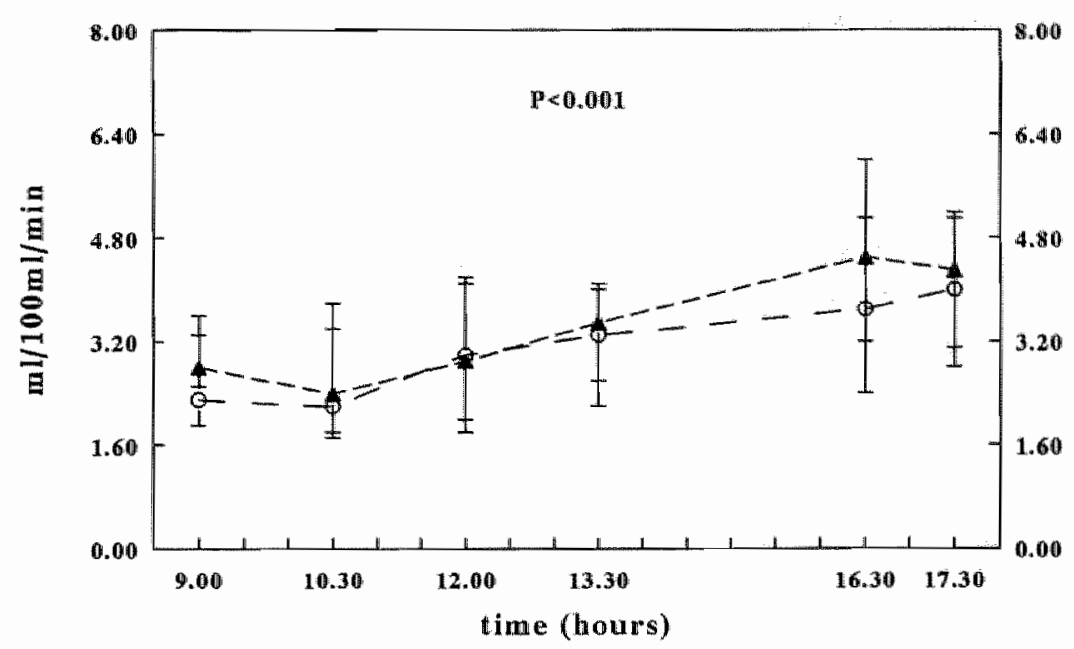

Figure 4. 1: Basal forearm blood flow of both the nom-dominant ( 4 ) and the dominant arm (o) measured at six timepoints during the doy. Data are represented as median and interquartile range $(n=15)$. P-value indicates level of significance (similar for both arms); Friedman two-way ANOVA comparing FBF at the six timepoints.

FBF decreased in one and remained unchanged in two subjects. The curve through the medians during the day (of the non-dominant arm) was best fitted by a linear equation $\left(R^{2}=0.88\right)$. FBF in the non-dominant arm was not different from FBF in the dominant arm (fig. 4.1). The FBF ratio (non-dominant/dominant) did not change during the day (table 4.1). As FBF increased and MAP did not change, forearm vascular resistance decreased significantly during the day. No correlation was found between FBF and skin temperature (median correlation coefficient $-0.23 ; \mathrm{P}=0.50$ ) during the day. FBF and skin thermoregulatory flow (LDF) did not correlate either during the day (median correlation coefficient $-0.25 ; \mathrm{P}=0.07$ ).

\section{Microcirculation}

The width of the erythrocyte column (representing the capillary diameter) did not change during the day (median $10 \mu \mathrm{m}$ at 9.00 and $17.30 \mathrm{~h}$ ). Hence, capillary blood cell velocity (CBV) values represent capillary blood flow. CBV did not change significantly during the day (Friedman, $P=0.12$; fig. 4.2), although the $C B V$ pattern during the day resembled that of the skin thermoregulatory flow. 
Table 4.1: Basal values of skin temperature, ratio in foream blood flow (FBF) of non-dominant (ind) and dominant (d) arm, mean arterial pressure (MAP), and hean rate at six moments during the day. Data represented as median (interq. range) P-walies from Friedman test comparing sit moments.

\begin{tabular}{llllllll}
\hline & $9.00 \mathrm{~h}$ & $10.30 \mathrm{~h}$ & $12.00 \mathrm{~h}$ & $13.30 \mathrm{~h}$ & $16.30 \mathrm{~h}$ & $17.30 \mathrm{~h}$ & P-level \\
\hline Skin temp & 32.9 & 32.0 & 32.5 & 32.2 & 32.4 & 32.4 & 0.01 \\
$\left({ }^{\circ} \mathrm{C}\right)$ & $(32.3-33.5)$ & $(30.9-32.9)$ & $(30.4-32.9)$ & $(30.9-33.0)$ & $(31.4-33.3)$ & $(31.2-33.0)$ & \\
Ratio & 1.13 & 1.04 & 1.00 & 1.06 & 1.22 & 1.09 & 0.14 \\
PBF-nd/FBF-d & $(0.92-1.57)$ & $(0.91-1.25)$ & $(0.83-1.26)$ & $(0.88-1.37)$ & $(0.99-1.43)$ & $(0.80-1.58)$ & \\
MAP (mimhig) & 83 & 86 & 83 & 88 & 86 & 90 & 0.14 \\
& $(78-87)$ & $(81-88)$ & $(79-87)$ & $(79-92)$ & $(80-92)$ & $(85-96)$ & \\
Heart rate & 56 & 55 & 56 & 56 & 56 & 59 & 0.07 \\
$($ (min) & $(52-64)$ & $(50-61)$ & $(50-61)$ & $(49-58)$ & $(51-64)$ & $(53-66)$ & \\
\hline
\end{tabular}

\section{CAPILLARY BLOOD CELL VELOCITY}

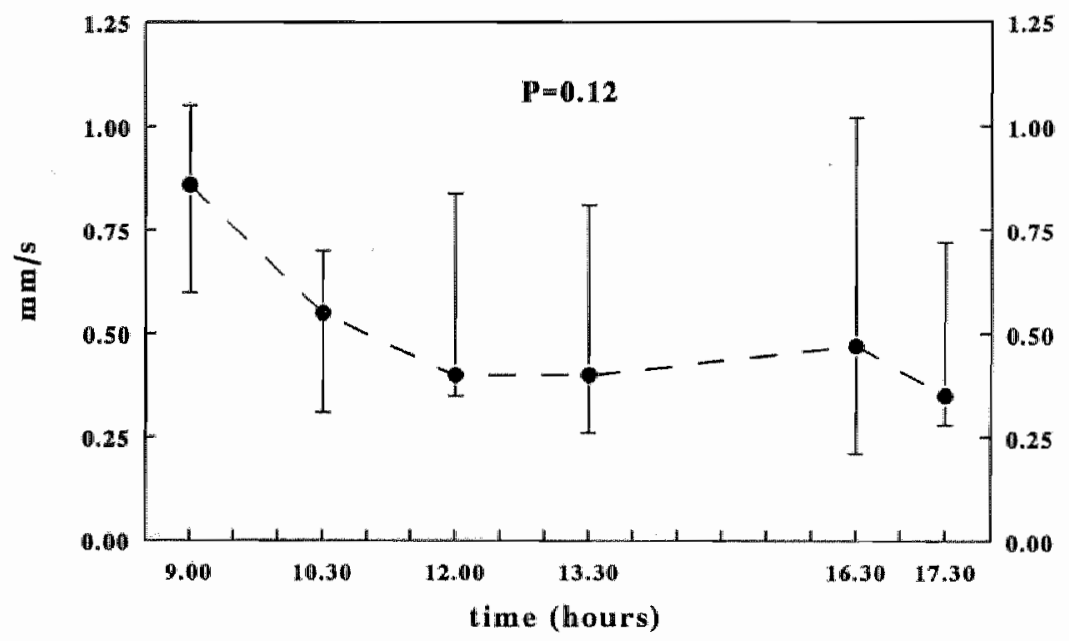

Figure 4.2: Basal capillary blood cell velocity (representing nutritive skin blood flow) measured at six timepoints during the day. Data are derived from the mean CBV of the same two capillaries during the day. Data are represented as median and interquartile range $(n=9)$. P-walue indicates level of significance; Friedman two-way ANOVA comparing $C B V$ at the six timepoints.

The CBV coefficient of variation (CV) for two repeated measurements (one hour apart) in the afternoon (the stable period after acclimatization) is $31 \%$. The thermoregulatory flow (LDF) showed a mean decrease of $27 \%$, predominantly in the mor- 
ning, from 18.3 in the morning to $13.1 \mathrm{PU}$ at $12.00 \mathrm{~h}$ (Friedman, $\mathrm{P}<0.002$ ) and from 14.6 at $13.30 \mathrm{~h}$ to $12.1 \mathrm{PU}$ in the late afternoon (Friedman, $\mathrm{P}=0.77$ ) (fig. 4.3). However, the nonlinear curve fit (inverse logarithm; $R^{2}=0.83$ ) through these data was not significantly different from a linear equation $\left(R^{2}=0.60\right)$. LDF increased in one and remained unchanged in two subjects. The LDF CV for two repeated measurements in the afternoon is $18 \%$. Skin temperature did also show a decrease during the day (Friedman, $\mathrm{P}<0.01$; table 4.1 ). A positive correlation was found between $\mathrm{CBV}$ and skin temperature during the day, with a median correlation coefficient of 0.49 (slope 1.67 ), $\mathrm{P}<0.01$. LDF and skin temperature were also positively correlated, with a median correlation coefficient of 0.58 (slope 0.1 ), $\mathrm{P}<0.01$. No correlation was found between skin nutritive and thermoregulatory flow (median correlation coefficient $0.41 ; \mathrm{P}=0.58$ ).

\section{LASER-DOPPLER FLUXMETRY}

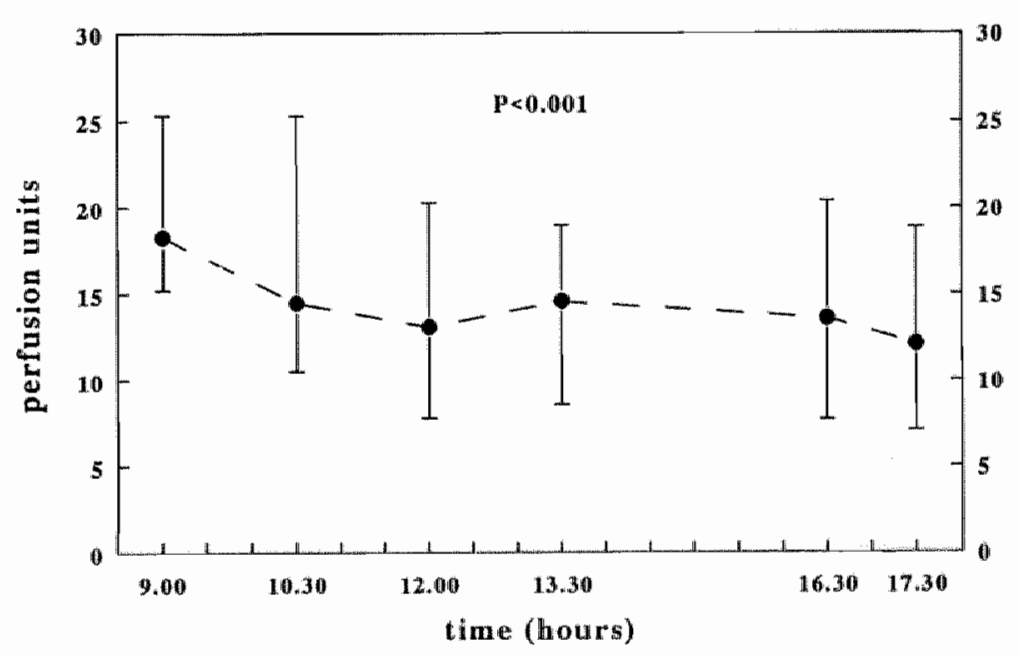

Figure 4.3: Basal laser-Doppler flucomerry (represening thermoregulatory skin blood flow) measured at six timepoints during the day. Data are represensed as median and interquartile range $(n=15)$. P-value indicates level of significance; Friedman two-way ANOVA comparing LDF at the six timepoints.

\section{Afternoon protocol}

Blood pressure and heart rate did not change during these experiments (data not shown). In four out of five cases, FBF increased in both arms (table 4.2) similar to the increase observed in the afternoon as described above (fig. 4.1). However, LDF showed a large decrease from 14.00 to 17.00 hours (table 4.2 ), comparable to the large decrease in LDF observed in the morning (fig. 4.3). In addition, CBV (table 
4.2) and skin temperature (not shown) showed a decrease similar to that observed in the morning (fig. 4.2).

Table 4.2: Individual blood flow values of the afternoon protocol. Capillary blood cell velocity (CBV), skin laser-Doppler fluxmetry (LDF), and forearm blood flow (FBF) of the nondominant (nd) arm in five healthy males.

\begin{tabular}{lllll}
\hline & subject no, & $14.00 \mathrm{~h}$ & $15.30 \mathrm{~h}$ & $17.00 \mathrm{~h}$ \\
\hline CBV (mm/s) & 1 & 0.43 & 0.47 & 0.37 \\
& 2 & 0.64 & 0.56 & 0.63 \\
& 3 & 1.00 & 0.94 & 0.71 \\
& 4 & 0.67 & 0.40 & 0.35 \\
& 5 & 0.69 & 0.97 & 1.44 \\
LDF (PU) & 1 & 43 & 26 & 21 \\
& 2 & 17 & 12 & 10 \\
& 3 & 24 & 13 & 13 \\
& 4 & 43 & 26 & 23 \\
FBF-nd & 5 & 8 & 12 & 26 \\
(ml/d//min) & 1 & 3.6 & 3.9 & 4.1 \\
& 2 & 2.3 & 3.5 & 9.0 \\
& 3 & 7.9 & 6.0 & 5.8 \\
& 4 & 1.8 & 2.1 & 2.2 \\
& 5 & 1.7 & 2.1 & 3.3 \\
\hline
\end{tabular}

\subsection{DISCUSSION}

The results of the present study demonstrate diurnal variation in total forearm (muscle) blood flow (FBF) in fasting healthy men. FBF showed a gradual increase during the day. In contrast, skin (thermoregulatory) microcirculation (LDF) showed a decrease, particularly in the first three hours, which is probably independent of the time of day, as the same pattern was observed in both the day-time and afternoon protocol.

\section{Forearm blood flow}

The mean increase of total forearm blood flow (FBF) during the day was $58 \%$. As skin blood flow (LDF) showed a decrease, the increase in FBF represents predominantly an increase in muscle blood flow. Changes in FBF were similar in both arms. 
Blood pressure did not change significantly during the day, probably due to the fact that the subjects were physically inactive and were studied in supine position (12). As a result of the aforementioned two observations, vascular resistance (FVR = MAP/FBF) decreased during the day. Several mechanisms may explain the increase in FBF. A 48-hour fast leads to an increase in forearm blood flow, possibly induced by reduced plasma noradrenaline levels (13). However, Bennett et al (14) found no changes in blood pressure or FBF after a 12-hour fast. Moreover, our observations are in line with those of Panza et al (6), in that study subjects were allowed to eat and walk around. Hence, our experimental conditions (fasting and resting) do not seem to have had a major influence on the circadian variation in resting forearm muscle blood flow. The pattern of FBF was indeed similar in the day-time and afternoon protocol. The observed decrease in peripheral vascular tone from the early morning till the afternoon could be due to an increased $\alpha$-sympathetic vasoconstrictor activity in the morning as compared to the afternoon (6). However, increased plasma catecholamine levels in the morning $(3,4)$ or increased postsynaptic sensitivity to vasoconstrictor factors in the morning could also play a role in the variations in vascular tone.

\section{Skin microcirculation}

Nutritive skin blood flow (CBV) exhibited no significant changes, although there was a tendency to a decrease especially in the morning. Thermoregulatory skin blood flow (LDF) did show a significant decrease, predominantly in the morning. However, performing the experiments in the afternoon, resulted in a similar pattern of decrease in CBV and LDF as observed in the morning. Skin temperature, which is positively correlated with laser-Doppler flux, as shown by the present data and a previous study (15), showed a parallel decrease. These data suggest that this decrease in microcirculatory blood flow is not of diurnal origin but due to long-term acclimatization, which might mask a possible diurnal rhythm. This long-term acclimatization is probably related to the physical inactivity during the experiments. When no heat is produced by lack of muscle activity (central and regional) no heat has to be lost and thus thermoregulatory blood flow may fall. Indeed, Sundberg (16) could not demonstrate a significant change in forearm skin perfusion between 08.00 and 14.00 hours using laser-Doppler fluxmetry. In Sundberg's study the subjects were studied in 'active state', coming directly from sedentary indoor work.

In our view skin temperature is determined predominantly by the skin thermoregulatory blood flow, as supported by the observed correlation between these parameters. The positive correlation between skin temperature and skin nutritive blood flow is possibly due to an increased skin metabolic rate at higher skin temperatures, demanding increased amounts of nutrients. The lack of statistically significant correlation between CBV and LDF is probably related to the fact that these methods record flow in different components of the microcirculation (9). CBV represents blood flow in the skin nutritive capillaries, which may be regulated separately by precapillary sphincters (17). The CBV coefficient of variation (CV) we found for two repeated measurements after acclimatization is $31 \%$. Thus, only larger changes in CBV will 
be detected due to the variations in CBV recordings, which are likely to be the result of vasomotion of the feeding arterioles. LDF determines blood flow predominantly in the venous plexus and $\mathrm{A}-\mathrm{V}$ shunts. The contribution of capillary blood flow to the LDF signal is only 5-10\% (18). The LDF CV for repeated measurements in the afternoon is $18 \%$, which makes this technique more suitable for detecting changes in skin perfusion. In cross-sectional studies, comparing different groups of subjects, skin microcirculatory haemodynamics should be performed after a standard period of acclimatization. However, when studying possible effects of an acute intervention, a 3 hour period of acclimatization should be taken into account.

The discrepancy between changes in forearm muscle blood flow and skin blood flow are probably due to differences in flow regulating mechanisms for these two vascular beds. Skin thermoregulatory flow is predominantly influenced by thermoregulatory mechanisms which act through local axon reflexes $(19,20)$. These local axon reflexes prevail over the central sympathetic control (21). Therefore, a decreased $\alpha$-sympathetic vasoconstrictor activity during the day, possibly responsible for decreased forearm vascular resistance (Panza et al, 1991), may not have a major effect on skin thermoregulatory flow.

In conclusion, the results of the present study demonstrate diurnal variation in total forearm blood flow but not in skin microcirculation in resting and fasting man. Forearm (muscle) blood flow increased during the day. In contrast, skin (thermoregulatory) blood flow decreased, predominantly in the first three hours. The observed decrease in skin blood flow is probably related to the subject's physical inactivity, and might mask a possible diurnal rhythm. The divergency in flow pattern between forearm (muscle) and skin blood flow suggests different regulatory mechanisms for the vascular beds studied. Measurements of forearm blood flow should preferably be performed on the same time of day. Skin microcirculatory haemodynamic measurements, in a cross-sectional study design, should be performed after a standard period of acclimatization, while such measurements in a longitudinal design should be performed after a $2-3$ hour period of acclimatization.

\section{ACKNOWLEDGMENTS}

This study was supported by a grant from the Diabetes Fonds Nederland. We would like to thank Mr. Piet Claessens for excellent technical support. 


\section{REFERENCES}

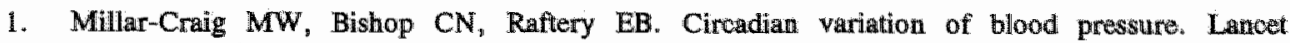
$1978 ; 1 ; 795-797$.

2. Malpas SC, Purdie GL. Circadian variation of heart rate variability. Cardiowaso Res $1990 ; 24 ; 210-$ 213.

3. Tofler GH, Brezinsid DA, Schafer AI, Czeisler CA, Rutherford JD, Willich SN, Glesson RE, Williams GH, Muller JE. Concurrent moming increase in platelet aggregability and the risk of myocardial infarction and sudden cardiac death. N Eng J Med 1987;316;1514-1518.

4. Linsell CR, Lightman SL, Mullen PE, Brown MJ, Causon RC. Circadian rhythms of epinephrine and norepinephrine in mam. J Clin Endocrin Metab 1985;60;1210-1215.

5. Kaneko M, Zechman FW, Smith RE. Circadian variation in human peripheral blood flow levels and exercise responses. J Appl Physiol 1968;25;109-114.

6. Panza JA, Epstein SE, Quyyumi AA. Circadian wariation in vascular tone and its relation to $\alpha$ sympathetic wasoconstrictor activity. N Eng J Med 1991;325;986-990.

7. Slaaf $\mathrm{DW}$, Tangelder GJ, Reneman RS, Jäger $\mathrm{K}$, Bollinger $\mathrm{A}$. A versatile incident illuminator for intravital microscopy. Int J Microcirc Clin Exp 1987;6;391-397.

8. Slaaf DW, Arts $T_{n}$ Jeurens TJM, Tangelder GJ, Reneman RS. Electronic measurement of red blood cell velocity and volume flow in microvessels. In: Investigative microtechniques in medicine and biology. Vol. 1, Chayen J and Bitensky L (eds.). New York: Marcel Dekker, Inc., 1984;327-364.

9. Tooke JE, Ostergren J, Fagrell B. Synchronous assessment of human skin microcirculation by laser Doppler flowmetry and dynamic capillaroscopy. Int J Microcire Clin Exp 1983;2;277-284.

10. Caspary L, Creutzig A, Alexander K. Biological zero in laser Doppler fluxmetry. Int J Microcirc Clin Exp 1988;7;367-371.

11. Whitney $\mathbf{R J}$. The measurement of volume changes in human limbs. J Physiol 1959;121,1-27.

12. Mann $\mathrm{S}_{1}$ Millar-Craig MW, Melwille DI, Balasubramanian V, Raftery EB. Physical activity and the circadian rhythm of blood pressure: Clin Sci $1979 ; 57 ; 291 \mathrm{~S}-294 \mathrm{~S}$.

13. Gallen IW, MacDonald IA, Mansell PI. The effect of a 48 h fast on the physiological responses to food ingestion in normal-weight women. Br J Nutrit 1990;63;53-64.

14. Bennett $T$, Macdonald $I A$, Sainsbury $R$. The influence of acute starvation on the cardiovascular responses to lower body subatmospheric pressure or to standing in man. Clin Sci 1984;66;141-146.

15. Houben AJHM, Schaper NC, Slaaf DW, Tangelder GJ, Nieuwentuijzen Kruseman AC. Skin blood cell flux in insulin-dependent diabetic subjects in relation to retinopathy or incipient nephropathy. Eur J Clin Invest 1992;22;67-72.

16. Sundberg S. Acute effects and long-term variations in skin blood flow measured with laser Doppler flowmetry. Scand J Clin Lab Invest 1984;44;341-345.

17. Flynn MD, Hassan AAK, Tooke JE. Effect of postural change and thermoregulatory stress on the capillary microcirculation of the human toe. Clin Soi 1989;76;231-236.

18. Fagrell $B$. The relationship between macro- and microcirculation. Clinical aspects. Acta Pharmacol Toxicol 1986;58-suppll 6;67.

19. Lindblad LE, Ekenvall $\mathbf{L}$, Klingstedt $C$. Neural regulation of vascular tone and cold induced vasoconstriction in human finger skin. J Aut Nerv Syst 1990;30;169-174.

20. Johnson JM, Brengelmann GL, Hales JRS, Vanhowitte PM, Wenger CB. Regulation of the cuttaneous circulation. Fed Proc 1986;45;2841-2850.

21. Hornyak ME, Naver HK, Rydenhag B, Wallin BG. Sympathetic activity influences the vascular axon reflex in skin. Acta Physiol Scand 1990;139;77-84. 
ב__ 


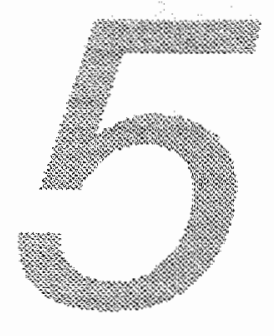

\section{SKIN BLOOD CELL FLUX IN INSULIN- DEPENDENT DIABETIC SUBJECTS IN RELATION TO RETINOPATHY OR INCIPIENT NEPHROPATHY.}

A.J.H.M. Houben, N.C. Schaper, D.W. Slaaf, G.J. Tangelder, A.C. Nieuwenhuijzen Kruseman.

Published in: European Journal of Clinical Investigation 1992;22;6772. 


\subsection{ABSTRACT}

We studied the relationship of retinal and/or renal microvascular complications and duration of disease with altered finger skin microcirculation in insulin-dependent diabetic (IDDM) subjects. Short-term and long-term IDDM subjects without complications or either with proliferative retinopathy or incipient nephropathy were investigated with laser-Doppler fluxmetry. An increased resting flux in skin microcirculation was found in short-term (median: 34 perfusion units, PU) and uncomplicated long-term IDDM subjects (25 PU) as compared to age-matched healthy controls (18 PU), which suggests a generalized dilatation of the microcirculation throughout the body. In long-term IDDM subjects with retinopathy we also observed an increased resting flux (37 PU), but in subjects with incipient nephropathy resting flux was decreased (17 PU) relative to the other diabetic subjects, to a level not different from the healthy control group. Postocclusive hyperaemic peak flux was decreased in patients with incipient nephropathy relative to the other diabetic patients, which suggests a defect in maximal arteriolar vasodilatation. Between the groups no differences were found in the veno-arteriolar reflex during venous occlusion. In conclusion: IDDM patients demonstrated increased red blood cell flux. However, with the occurrence of incipient nephropathy the resting flux and the maximal postocclusive vasodilatation decreased, which suggest that development of nephropathic changes in diabetes is representative of a more generalized alteration of microvascular flow regulation. Local neurogenic microvascular control appears not affected in these patients.

\subsection{INTRODUCTION}

Diabetic microangiopathy is one of the main causes of increased morbidity and mortality in subjects with insulin-dependent diabetes mellitus (IDDM). Several investigators $(1,2)$ have postulated that functional haemodynamic changes as increased blood flow and capillary pressure contribute to the development of structural changes in the microcirculation, leading to increased permeability and vascular sclerosis with eventually loss of autoregulation and decrease of organ perfusion. A number of studies have indeed demonstrated increased blood flow in kidney, retina, skin, fat tissue and skeletal muscle in short-term diabetic subjects, which appeared to be reversible by improwement of metabolic control (3-7). Low peripheral vascular resistance with cardiac hyperfunction has been found in poorly controlled IDDM subjects developing microvascular complications $(8,9)$.

Several studies on skin microcirculation have revealed that these haemodynamic changes may be related to both impaired neurogenic vascular control and alteration of arteriolar myogenic responsiveness (10-12). Aforementioned alterations are already demonstrable in short-term diabetes, but are more marked when the so called long-term diabetic microvascular complications are present. The (clinically) most important long-term microvascular complications are retinopathy and nephropathy. 
From the current literature it is not clear whether microvascular changes in the skin are associated with retinopathy and/or nephropathy in particular, or whether they are merely an expression of a generalized vascular disease. The studies which evaluated skin microcirculation, reported only on subjects with retinopathy or neuropathy, but not with nephropathy $(7,10-12)$. Moreover, these studies investigated the microcirculation at various sites of either the hand or the foot, which is a confounding factor for comparison of findings.

The present study was undertaken to further substantiate a possible relationship of altered skin microcirculation in IDDM subjects with renal and/or retinal microvascular complications. To this end four groups of IDDM subjects were studied: shortterm; long-term without complications or with either proliferative retinopathy or incipient nephropathy. For comparison age-matched healthy volunteers were included in this study. Laser-Doppler fluxmetry was employed to assess the perfusion of the finger skin microcirculation. Postischaemic hyperaemic responses were studied to detect alterations in arteriolar myogenic responsiveness. Skin flux during venous congestion was studied for determination of changes in the local neurogenic control of the microcirculation (veno-arteriolar reflex). In addition, the possible influence of autonomic neuropathy was investigated.

\subsection{PATIENTS AND METHODS}

Fourty-eight insulin-dependent (type I) diabetic subjects and 15 age-matched healthy volunteers were studied. Four groups of 12 diabetic subjects each were selected from the clinic population:

1. short-term diabetes; no microvascular complications (ST)

2. long-term diabetes; no microvascular complications (R-M-)

3. long-term diabetes with proliferative retinopathy but without (incipient) nephropathy $(\mathrm{R}+)$

4. long-term diabetes with incipient nephropathy (microalbuminuria) $(\mathbf{M}+)$.

Clinical characteristics are shown in table 5.1. Mean arterial pressure (MAP) was higher in $M+$ subjects compared with ST, R-M-, $R+$ and $C$ subjects $(P<0.05)$. In $M+$ subjects mean $\mathrm{HbAlc}$ level was higher compared with $S T$ subjects $(\mathrm{P}<0.05)$, but not compared with R-M- and R+. Type 1 diabetes was defined either as onset of disease before the age of 30 years and requiring insulin therapy within a few weeks from the diagnosis, or as having ketoacidosis. Short-term diabetes was defined as duration of disease less than 2 years, and long-term more than 10 years. Retinopathy was assessed by an ophthalmologist using direct and indirect ophthalmoscopy and fundus photography. Patients without retinopathy revealed no microaneurysms, haemorrhages or exudates. Incipient nephropathy was defined as an albumin/ creatinine ratio greater than $3 \mathrm{mg} / \mathrm{mmol}$ in 2 out of 3 first morning urine samples (13). Urinary albumin excretion was measured by an immunoturbidimetric method. Autonomic 
neuropathy was assessed by heart rate and blood pressure tests as described by Ewing and Clarke (14).

Table 5.1: Characteristics of the healthy wolwhteers and IDDM subjects grouped according ro durathor of disectse and compllcations.

\begin{tabular}{|c|c|c|c|c|c|}
\hline & Control & ST & R-M- & $\mathbf{R}+$ & $M+$ \\
\hline Male/female & $10 / 5$ & $9 / 3$ & $7 / 5$ & $5 / 7$ & $4 / 8$ \\
\hline Age (years) & $33 \pm 1.9$ & $29 \pm 2.3$ & $37 \pm 3.3$ & $44 \pm 3.9$ & $31 \pm 3.7$ \\
\hline $\begin{array}{l}\text { Duration diabetes } \\
\text { (years) }\end{array}$ & & 1.3 & 17 & 22 & 15 \\
\hline Glucose (mmol/l) & & $6.6 \pm 0.6$ & $8.5 \pm 1.1$ & $9.0 \pm 0.9$ & $10.6 \pm 1.4$ \\
\hline $\mathrm{HbAl}_{\sigma}(\%)$ & & $7.5 \pm 0.3$ & $8.1 \pm 0.5$ & $8.5 \pm 0.2$ & $9.0 \pm 0.4^{2}$ \\
\hline Haematocrit (\%) & & $43 \pm 1$ & $41 \pm 1$ & $40 \pm 1$ & $42 \pm 1$ \\
\hline MAP (mmHg) & $79 \pm 3$ & $75 \pm 2$ & $76 \pm 3$ & $79 \pm 3$ & $89 \pm 3^{b}$ \\
\hline $\begin{array}{l}\text { Albumin/creatinin } \\
\text { (mg/mmol) }\end{array}$ & & $<3$ & $<3$ & $<3$ & $10.4 \pm 2.3$ \\
\hline $\begin{array}{l}\text { Autonomic neuro- } \\
\text { pathy }\end{array}$ & & 1 early & 2 early & $\begin{array}{l}3 \text { early } \\
2 \text { definite } \\
2 \text { severe }\end{array}$ & $\begin{array}{l}6 \text { early } \\
\text { 1. definite }\end{array}$ \\
\hline
\end{tabular}

ST: short-term diabetes; $\mathbf{R}-\mathbf{M}-:$ long-term diabetes without microvascular complications; $\mathbf{R}+:$ long-term diabetes with retinopathy; $M+:$ long-term diabetes with microalbuminuria (incipient nephropathy). Data as mean $\pm \mathrm{SEM}$; a) $\mathrm{p}<0.05$ ws $\mathrm{ST}$; b) $\mathrm{p}<0.05$ versus other groups $(\mathrm{C} / \mathrm{ST} / \mathrm{R}-\mathrm{M}-/ \mathrm{R}+$ ). "Autonomic neuropathy classification according to Ewing and Clarke (14).

Blood glucose concentration was measured by the hexokinase method on the Cobas Bio analyzer (Hoffman Laroche, Basel, Switzerland), HbA1c by HPLC (Diamat, Bio-Rad Laboratories, Richmond, Ca, USA). Digital blood pressure was measured noninvasively using the Finapres blood pressure monitor (Ohmeda, Englewood, CO, USA). None of the diabetic subjects used any other medication than insulin, or had evidence of macrovascular disease.

The study protocol was approved by the ethics committee of the hospital and informed consent was obtained from all subjects. All subjects were asked to refrain from smoking and drinks containing caffeine or alcohol on the day of measurement. All measurements were performed after 30 minutes of acclimatization, the subject lying supine in a room with a constant temperature (mean: $23.8^{\circ} \mathrm{C} \pm 0.9 \mathrm{SD}$ ). At the start of the study blood glucose, HbAlc and haematocrit were determined. If a subject suffered symptomatic hypoglycaemia or had a blood glucose concentration below 3.5 or above $15 \mathrm{mmol} / \mathrm{l}$, the measurements were postponed.

Red blood cell flux in the superficial skin microvessels on the dorsum of the fourth finger of the right hand was measured at heart level, using laser-Doppler flux- 
metry (Periflux PF3, Perimed, Stockholm, Sweden). Red blood cell flux was expressed as perfusion units (PU); calibrated to the Periflux motility standard. Perfusion units are determined by red blood cell concentration and velocity. Flux data are presented with the corresponding biological zero subtracted. The biological zero was considered the mean laser-Doppler flux signal at the end of an arterial occlusion. No differences were found in biological zero between the groups (median: 3 PU; interquartile range: $2-3$ ).

In each subject 5 venous and 5 arterial occlusions were performed, using a small cuff at the base of the finger. The interval between occlusions was 10 minutes. The median of the 5 values of venous or arterial occlusions respectively, were used for calculations. Resting flux was calculated as the mean flux during the last minute before each occlusion. For arterial occlusion cuff pressure was maintained at 200 $\mathrm{mmHg}$ for 4 minutes. The following parameters were determined during the postocclusive reactive hyperaemia: peak flux, delta peak flux (peak flux minus resting flux), \% Postocclusive Reactive Hyperaemia (\%PRH) ([delta peak flux / resting flux] x 100), time-to-peak flux following release of occlusion and duration of hyperaemia. For venous congestion cuff pressure was maintained at $50 \mathrm{mmHg}$ for $1 \mathrm{~min}$ ute. During venous congestion flux was measured and the mean value of the last 50 seconds was taken as the flux during venous congestion. The percentage flux reduction was defined relative to the preocclusion resting flux ([(resting flux-occlusion flux)/resting flux] $\times 100 \%$ ). During the measurements skin temperature was measured continuously by an electronic thermometer (Hewlett Packard, USA).

Statistical analysis was performed using nonparametric tests. The Kruskal-Wallis test was used for multiple group comparison and the Mann-Whitney $U$ test for two group comparison. Correlations were performed with the Spearman rank test. Statistical significance was considered as $\mathrm{P}<0.05$.

\section{$5.4 \quad$ RESULTS}

Table 5.2 shows that in comparison with healthy volunteers resting flux was increased in the subjects with short-term diabetes (ST), and long-term diabetes without complications $(\mathrm{R}-\mathrm{M}-)$ or with retinopathy $(\mathrm{R}+)(\mathrm{P}<0.01)$. In the diabetic subjects with incipient nephropathy $(M+)$, resting flux was not different from the healthy volunteers, but appeared to be decreased compared with ST, R-M-, and R+ subjects $(p=0.059)$. Skin temperature was also higher in ST and $R-M-$ subjects compared with healthy volunteers $(P=0.02)$, but not in the $R+$ and $M+$ subjects (table 5.2). Taken together all 63 subjects, a positive correlation existed between skin temperature and resting flux $(\mathrm{R}=0.67 ; \mathrm{P}<0.001 ; \mathrm{Y}=30 \mathrm{X}-905$ ( $\mathrm{Y}=$ rest flux, $\mathrm{X}=$ skin temperature)). Compared with the healthy volunteers, the peak flux, representing the maximal arteriolar flux carrying capacity after arterial occlusion, was increased in the $S T$ and $R+$ subjects $(\mathrm{P}<0.05)$. In $\mathrm{R}-\mathrm{M}$ - subjects peak flux appeared unchanged (table 5.2). In the diabetic subjects with incipient nephropathy $(M+)$, peak flux was decreased relative to all the other diabetic subjects $(S T, R-M-$, and $R+; P<0.05$ ). 
Table 5.2: Resting cutanieus blood flux and haemodymamic responses to 4 mimutes arterial acclusion or I minute wenous occlusion in healthy control and IDDM subjects.

\begin{tabular}{|c|c|c|c|c|c|}
\hline & Control & $\mathrm{sT}$ & R-M- & $\mathrm{R}+$ & $\mathbb{M}+$ \\
\hline $\begin{array}{l}\text { Skin temperature } \\
\left({ }^{\circ} \mathrm{C}\right)\end{array}$ & $\begin{array}{l}30.3 \\
(29.1-32.9)\end{array}$ & $\begin{array}{l}32.6^{*} \\
(31.6-33.1)\end{array}$ & $\begin{array}{l}32.3^{2} \\
(30.9-32.6)\end{array}$ & $\begin{array}{l}31.0 \\
(29.7 \times 32.2)\end{array}$ & $\begin{array}{l}30.4 \\
(28.3-32.0)\end{array}$ \\
\hline Resting flux (PU) & $\begin{array}{l}18 \\
(7 \cdot 24)\end{array}$ & $\begin{array}{l}34^{b} \\
(24-34)\end{array}$ & $\begin{array}{l}25^{5} \\
(21-34)\end{array}$ & $\begin{array}{l}37^{6} \\
(20-43)\end{array}$ & $\begin{array}{l}17 \\
(7-26)\end{array}$ \\
\hline \multicolumn{6}{|l|}{ Arterial occlusion } \\
\hline Peak flux (PU) & $\begin{array}{l}76 \\
(60-90)\end{array}$ & $\begin{array}{l}101^{c} \\
(92-135)\end{array}$ & $\begin{array}{l}77 \\
(62-98)\end{array}$ & $\begin{array}{l}110^{\circ} \\
(83-135)\end{array}$ & $\begin{array}{l}44^{d} \\
(31-116)\end{array}$ \\
\hline $\begin{array}{l}\text { Delta-peakflux } \\
\text { (PU) }\end{array}$ & $\begin{array}{l}62 \\
(38-72)\end{array}$ & $\begin{array}{l}67 \\
(57-99)\end{array}$ & $\begin{array}{l}63 \\
(39-71)\end{array}$ & $\begin{array}{l}73 \\
(42-96)\end{array}$ & $\begin{array}{l}32 \\
(21-85)\end{array}$ \\
\hline$\%$ PRH & $\begin{array}{l}344 \\
(225-794)\end{array}$ & $\begin{array}{l}238 \\
(173-263)\end{array}$ & $\begin{array}{l}219 \\
(157-331)\end{array}$ & $\begin{array}{l}215 \\
(151-308)\end{array}$ & $\begin{array}{l}210 \\
(177-420)\end{array}$ \\
\hline $\begin{array}{l}\text { Duration hype- } \\
\text { raemial (s) }\end{array}$ & $\begin{array}{l}185 \\
(140-240)\end{array}$ & $\begin{array}{l}128 \\
(93-225)\end{array}$ & $\begin{array}{l}229 \\
(173-280)\end{array}$ & $\begin{array}{l}206 \\
(163-233)\end{array}$ & $\begin{array}{l}218 \\
(156-255)\end{array}$ \\
\hline $\begin{array}{l}\text { time to peak hype- } \\
\text { raemia }(\mathrm{s})\end{array}$ & $\begin{array}{l}13 \\
(10-37)\end{array}$ & $\begin{array}{l}24 \\
(10-34)\end{array}$ & $\begin{array}{l}22 \\
(11-40)\end{array}$ & $\begin{array}{l}29 \\
(21-48)\end{array}$ & $\begin{array}{l}36 \\
(31-41)\end{array}$ \\
\hline \multicolumn{6}{|l|}{ Venous ocdusion } \\
\hline flux (PC) & $\begin{array}{l}11 \\
(4-15)\end{array}$ & $\begin{array}{l}13 \\
(9-16)\end{array}$ & $\begin{array}{l}12 \\
(8-15)\end{array}$ & $\begin{array}{l}12 \\
(7-22)\end{array}$ & $\begin{array}{l}5^{\circ} \\
(4-9)\end{array}$ \\
\hline \% flux reduction & $\begin{array}{l}51 \\
(34-62)\end{array}$ & $\begin{array}{l}70 \\
(58-76)\end{array}$ & $\begin{array}{l}60 \\
(41-73)\end{array}$ & $\begin{array}{l}51 \\
(45-76)\end{array}$ & $\begin{array}{l}53 \\
(39-73)\end{array}$ \\
\hline
\end{tabular}

Data as median values (interquartile range); PU: perfusion units; a) $p<0.02$ ws $M+$, b) $p<0.01$ vs $C$, c) $\mathrm{p}<0.05$ vs $\mathrm{C}$, d) $\mathrm{p}<0.05$ vs ST, R-M- and $\mathrm{R}+$, e) $\mathrm{p}<0.05$ vs C/ST/R-M-/R+.

The delta peak flux, representing the maximal increase in flux after arterial occlusion, was not statistically different between diabetic and nondiabetic subjects, although the delta peak flux in the patients with incipient nephropathy $(M+)$ seemed to be decreased relative to the other four groups (ST, R-M-, $R+, C$ ). The relative increase in resting flux (\%PRH) was comparable in all the diabetic subjects, but tended to be higher in the healthy volunteers.

In all diabetic subjects time to peak hyperaemia appeared increased relative to healthy volunteers, but these differences were not statistically significant (table 5.2). Duration of post-occlusive hyperaemia was not different between the diabetic and nondiabetic subjects.

During venous congestion, laser-Doppler flux was not different between healthy control subjects and ST, R-M- and $\mathrm{R}+$ subjects. In $\mathrm{M}+$ subjects however, flux during venous congestion was decreased relative to the other subjects (C, ST, R-M-, $\mathrm{R}+$; $\mathrm{P}<0.05$; table 5.2 ). The percentage flux reduction during venous congestion 
relative to the pre-occlusion flux was however not different between groups of diabetic patients and healthy volunteers. The percentage flux reduction during venous congestion in $\mathrm{R}-\mathrm{M}$ - and $\mathrm{R}+$ subjects with autonomic neuropathy was increased $(\mathrm{p}<0.01)$ relative to the reduction in subjects without autonomic neuropathy (table $5.3)$.

Table 5.3: Flux reduction during $I$ minute venous occlusion in long-duration $R-M-$ and $R+1 D D M$ subjects with or without autonomic neuropathy.

\begin{tabular}{|c|c|c|}
\hline & \multicolumn{2}{|c|}{ NEUROPATHY } \\
\hline & $+(n=9)$ & $-(n=15)$ \\
\hline \multicolumn{3}{|l|}{ Venous oeclusion } \\
\hline Flux (PU) & $\begin{array}{l}7 \\
(6-12)\end{array}$ & $\begin{array}{l}14 \\
(10-18)\end{array}$ \\
\hline$\%$ flux reduction & $\begin{array}{l}71 \\
(48-80)\end{array}$ & $\begin{array}{l}51^{2} \\
(32-60)\end{array}$ \\
\hline
\end{tabular}

Data as median values (interquartile range); PU: perfusion units; a) $p<0,01$ vs Neuropathy + .

The presence of autonomic neuropathy had no effect on the hyperaemic response after arterial occlusion. No correlations were found between resting flux, or peak flux and HbAlc $(R=-0.11, P>0.1$; and $R=0.09, P>0.1$ respectively, $n=48)$. Neither were any correlations found between resting flux nor peak flux and albu$\mathrm{min} /$ creatinine ratio $(\mathrm{R}=-0.2, \mathrm{P}>0.1$; and $\mathrm{R}-0.14, \mathrm{P}>0.1, \mathrm{n}=12)$. Furthermore, no correlations were found between haemodynamic responses and resting flux on the one hand and age, blood glucose, haematocrit, and digital artery pressure on the other hand.

\subsection{DISCUSSION}

The present study demonstrates that, compared to healthy volunteers, resting skin blood flux is increased in short-term diabetic subjects, and long-term subjects with or without retinopathy. In comparison with patients without microalbuminuria skin blood flow seemed to be reduced in patients with incipient nephropathy. A similar pattern was observed in post-occlusive hyperaemic peak flux: this parameter was increased in short-term and long-term diabetes, irrespective of the presence of retinopathy, but was lower in diabetic subjects with incipient nephropathy compared with patients without incipient nephropathy. These findings suggest that in diabetic patients, irrespective of the duration of disease or the presence of retinopathy, skin blood flow is increased without change of maximal arteriolar dilating capacity. However, when incipient nephropathy has developed, the increased skin blood flow disappears, while maximal arteriolar dilating capacity decreases. Diabetic metabolic 
control does not seem to play a significant role in these changes in haemodynamic characteristics, as no correlation was found between these parameters. Furthermore, no correlation as observed between the degree of microalbuminuria and haemodynamic characteristics, but only a relative small number of patients was studied. In addition, local neurogenic vascular control was intact in all the patient groups we studied, as demonstrated by an unchanged percentage fall in flux during venous congestion. The presence of autonomic neuropathy even appeared to enhance the veno-arteriolar reflex in diabetic patients.

In the present study we used laser-Doppler fluxmetry to assess red blood cell flux in the skin microcirculation in the dorsum of the finger. With laser-Doppler fluxmetry no absolute values are obtained, but its perfusion units correlate well with blood flow measurements done with Xenon-washout and plethysmography $(15,16)$. In skin, laser-Doppler fluxmetry derives its signal mainly from thermoregulatory flow and to a lesser extend nutritional flow $(<10 \%)(17)$. Thermoregulatory flow may vary dramatically in areas in which arteriovenous shunts are abundant. This shunt flow is regulated by the sympathetic nervous system (18). However, in the dorsum of the finger, from which our readings were taken, arteriovenous anastomoses are scanty (19). Hence, our recordings showed less variability and represent predominantly flow in subpapillary plexuses and flow in nutritional capillaries $(<10 \%)$.

Our finding of increased resting skin flux in diabetic patients, except the patients with incipient nephropathy, suggests hyperperfusion in particular in the subpapillary (thermoregulatory) plexuses, because capillaroscopic studies demonstrated an unchanged nutritional flow in comparable patient groups $(7,20)$. This is supported by the positive correlation between resting flux and skin temperature. Increased shunt flow may also be a contributing factor. It has been hypothesized that increased blood flow, as suggested in the present study, is based on microvascular vasodilatation, and that this overperfusion is one of the initiating mechanisms in the pathogenesis of diabetic microangiopathy $(1,2)$.

The different parameters of reactive hyperaemia appeared not to be disturbed in short-term or long-term diabetic patients with or without retinopathy in comparison with healthy controls. Maximal arteriolar vasodilating capacity, represented by the peak flux, was unchanged or increased. Neither the maximal increase in flux (delta peak flux) nor the percentage increase in flux (\%PRH) after arterial occlusion was changed. These findings suggest that in these patients structural changes do not (yet) play an important role in skin microvascular flow regulation. The time-to-peak flux tended to be longer in all the diabetic patients, which is in agreement with a study on the finger nailfold capillaries of Tooke et al (7). They reported an increased postocclusive time-to-peak blood cell velocity, even within the first year of diabetic life. Reported was also that the time-to-peak hyperaemia in long-duration diabetes may not be different from control values in the presence of good glycaemic control. Therefore, the prolonged time-to-peak is probably based on functional vascular wall changes like altered viscoelastic properties (21), and/or haemorheological alterations. 
Once incipient nephropathy has developed in diabetic patients, skin microcirculation seems to change. In our studies resting skin blood flux was lower in patients with incipient nephropathy in comparison with normo-albuminuric patients, but was not different from healthy volunteers. Maximal peak flux showed the same pattern, it was decreased in the patients with incipient nephropathy in comparison with normo-albuminuric patients. Furthermore, the maximal increase in flux after arterial occlusion (delta peak flux) seemed to be impaired and time-to-peak flux tended to be prolonged (although both parameters were not statistically significant). These changes were observed despite a higher blood pressure in the micro-albuminuric patients, which was reported by others as well (22). This suggests that in diabetes the skin microvascular vasodilatation disappears and the maximal vasodilating capacity declines when microalbuminuria develops. A possible mechanism involved, is the development of structural vascular changes like increased wall thickness (23). As resting flux and peak flux in microalbuminuric patients were not different from healthy volunteers, no further conclusions can be drawn.

Our observation that with the development of incipient nephropathy but not retinopathy skin microcirculation alters, is in line with several observations that nephropathy but not retinopathy is accompanied by the development of extra-renal micro and macrovascular changes, which may involve skin abnormalities such as foot ulcerations as well $(24,25)$. Although in long-term diabetes the occurence of retinopathy usually parallels nephropathy, the pathogenesis of these microangiopathic changes are obviously different. Almost all diabetic subjects are susceptible to proliferative retinopathy, but in contrast, only a subset of in particular IDDM subjects appears susceptible to nephropathy (25).

Our finding that the veno-arteriolar reflex during venous congestion is not impaired in both short- and long-term diabetic subjects, irrespective of the presence of microvascular complications, is in contradiction with other reports, which revealed an impaired reflex in even first year diabetic subjects $(7,10)$. The veno-arteriolar reflex is a protective mechanism to prevent capillary hypertension when venous pressure is increased (e.g. increased hydrostatic load). This is probably a local axon reflex, which increases precapillary resistance (26). In the aforementioned studies, flow reduction during venous congestion was assessed in the nailfold area, while we performed our measurements more proximal at the dorsum of the finger. As shown by Winocour and coworkers (11), veno-arteriolar reflexes may vary at various sites of the hand, although this does not sufficiently explain the discrepancy between the observations. Our finding of even a more marked decrease of flux during venous congestion in long-duration IDDM subjects with autonomic neuropathy suggest that this autonomic neuropathy, as assessed by cardiovascular tests, is not necessarily associated with impaired local neurogenic control of vascular tone. In this situation the effects of local veno-arteriolar reflexes on skin microcirculation during venous congestion or, more naturally, limb dependency may even be more dominant.

In conclusion, we found an increased resting flux in skin microcirculation in short-term and long-term diabetic subjects, which is probably indicative of a generalized dilatation of the microcirculation throughout the body. This disturbance of 
microvascular flow regulation appears not to be located at the level of local neurogenic control mechanisms. The skin hyperperfusion, together with the maximal arteriolar vasodilating capacity regresses parallel to the occurrence of incipient nephropathy but not retinopathy. These data suggest that development of nephropathic changes in diabetes is representative of a more generalized alteration of microvascular flow regulation.

\section{ACKNOWLEDGMENTS}

The authors gratefully acknowledge Mr. Piet Claessens for excellent technical support.

\section{REFERENCES}

1. Parving H-H, Viberti GC, Keen $H$, Christiansen JS, Lassen NA. Hemodynamic factors in the genesis of diabetic microangiopathy. Metabolism 1983;32:943-949.

2. Tooke JE. Microvascular haemodynamics in diabetes mellitus. Clin Sci 1986; 70;119-125.

3. Mogensen $C E$. Glomerular filtration rate and renal plasma flow in short-term and long-term juvenile diabetes mellitus. Scand J Clin Lab Invest $1971 ; 28: 91-100$.

4. Gundersen HJG. Peripheral blood flow and metabolic controll in juvenile diabetes. Diabetologia 1974;10:225-231.

5. Kohner EM, Hamiliton AM, Saunders SJ, Sutcliffe BA, Bulpitt CJ. The retinal blood flow in diabetes. Diabetologia 1975; 11:27-33.

6. Christiansen JS, Gammelgatard $\mathrm{J}$, Tronier B, Svendsen PA, Parving H-H. Kidney function and size in diabetes before and during initial insulin treatment. Kidney Int 1982;21:683-688.

7. Tooke JE, Lins P.E, Ostergren J, Fagrell B. Skin microvascular autoregulatory responses in type I diabetes: the influence of duration and control. Int J Microcirc: Clin Exp 1985;4:249-256.

8. Mathiesen ER, Hilsted J, Feldt-Rasmussen B, Bonde-Petersen F, Christensen NJ, Parving H-H. The effect of metabolic control on hemodynamics in short-term insulin-dependent diabetic patients. Diabetes: 1985:74.13011-12ns

9. Thuesen L, Christiansen JS, Mogensen CE, Henningsen P. Cardiac hyperfunction in insulin-dependent diabetic patients developing microvascular complications. Diabetes 1988;37:851-856.

10. Tooke JE, Ostergren I, Lins PE, Fagrell B. Skin microvascular blood flow control in long duration diabetics: with and without complications. Diab Res: 1987;5:189-192.

11. Winocour PH, Mitchell WS, Gush RJ, Taylor LJ, Baker RD. Altered hand skin blood flow in type 1 (insulin-dependent) diabetes mellitus. Diab Med 1988;5:861-866.

12. Walmsley $\mathbf{D}$, Wiles $\mathbf{P G}$. Myogenic microvascular responses are impaired in long-duration type 1 diabetes. Diab Med 1990;7:222-227.

13. Nieuwenthuijzen Kruseman $\mathrm{AC}_{\text {, van }}$ den Berg BW, Degenaar CP, Wolffenbuttel BHR. Screening for microalbuminuria with Micro-Bumintest tablets and albumin/creatinine ratio in diabetes mellitus. Horm Metab Res (in press).

14. Ewing DJ, Clarke BF. Diagnosis and management of diabetic autonomic neuropathy. $\mathrm{Br}$ Med J 1982;285:916-918.

15. Holloway GA, Watkins DW. Laser doppler measurement of cutaneous blood flow. $\int$ Invest Derm $1977 ; 69: 306-309$. 
16. Saumet $\mathrm{JL}_{*}$ Dittmar $\mathrm{A}$, Leftheriotis $\mathrm{G}$. Non-invasive measurement of skin blood flow: Conparisou between plethysmography, laser-doppler flowmetry and heat clearance method. Int I Microcirc: Clin Exp 1986;5:73-83.

17. Tooke JE, Ostergren J, Fagrell B. Synchronous assessment of human skin micnocirculation by laser Doppler flowmetry and dynamic capillaroscopy. Int J Micnocirc: Clin Exp 1983;2:277-284.

18. Hales JRS, Fawcett AA, Bennett JW. Differential influences of core and superficial body temperatures in the partition of cutaneous blood flow between capillaries and arterio-venous ansstomoses. Plugers Arch 1975;361:105-106.

19. Smith JI, Kampine JP. Circulatory physiology: the essentials. Balltimore: Williams and Wilkins. 1980.

20. Fagrell B, Hermansson I-L, Karlander S-G, Ostergren $\mathbf{J}$. Vital capillary microscopy for assessment of skin viability and microangiopathy in patients with diabetes mellitus. Acta Med Scand $1984 ;$ suppl $687: 25-28$.

21. Wilkin JK. Cutaneous reactive hyperemia: viscoelasticity determines response. $\mathrm{J}$ Invest Dermatol $1987 ; 89: 197-200$.

22. Marshall SM, Alberti KGGM. Comparison of the prevalence and associated teatures of abnormal albumin excretion in insulin-dependent and non-insulin-dependent diabetes. Q J Med 1989;70:61-71.

23. Zatz $R$, Brenner BM. Pathogenesis of diabetic microangiopathy. The hemodynamic view. Am $J$ Med 1986;80:443-453.

24. Borch-Johnsen $K$, Kreiner $S$. Proteinuria-value as a predictor of cardiovascular mortality in insulin dependent diabetes mellitus. Br Med J 1987;294:1651-1654.

25. Krowlewski AS, Wassam JH, Raud LI, Kahn CR. Epidemiologic approach to the etiology of type 1 diabetes mellitus and its complications. New Eng J Med 1987;317:1390-1398.

26. Henriksen $O$. Local mervous mechanism in regulation of blood flow in human subcutaneous tissue. Acta Physiol Scand 1976;98;385-391. 


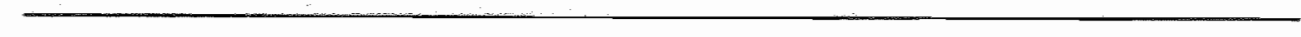




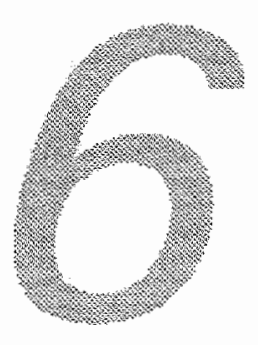

\section{VENOUS COMPLIANCE AND THE VENODILATORY EFFECT OF} NITROGLYCERIN IN INSULIN-DEPENDENT DIABETIC PATIENTS WITH AND WITHOUT (INCIPIENT) NEPHROPATHY.

N.C. Schaper, A.J.H.M. Houben, Y. Schoon, J.P. Kooman, F.C. Huvers, A.C. Nieuwenhuijzen Kruseman.

Submitted for publication. 


\subsection{ABSTRACT}

The venous system plays a pivotal role in volume and blood pressure homeostasis. We tested the hypothesis that the visco-elastic properties of the peripheral venous system are reduced in patients with (incipient) diabetic nephropathy. Twenty-two normotensive patients with long-term insulin-dependent diabetes mellitus (IDDM), 11 without and 11 with (incipient) nephropathy ( 8 microalbuminuria and 3 proteinuria, serum creatinin below $100 \mu \mathrm{mol} / \mathrm{l}$ ), and 14 healthy age/sex matched controls were studied. Forearm venous compliance (VENCOMP) was determined using strain gauge plethysmography and direct intravenous pressure measurements. Furthermore, the venodilatory effect of $0.4 \mathrm{mg}$ nitroglycerin sl. (NTG) was studied. In comparison with healthy controls, VENCOMP was decreased in patients without and with (incipient) nephropathy, without any differences between the two diabetic groups: 0.059 $(0.052-0.066), 0.044(0.038-0.059)$, and $0.049(0.046-0.058) \mathrm{ml} / 100 \mathrm{ml} / \mathrm{mmHg}$, respectively (medians and interq. ranges) $(\mathrm{P}<0.05)$. No differences in the increase of forearm volume after NTG were observed: $0.34(0.11-0.51), 0.37(0.19-0.50)$ and $0.39(0.20-0.55) \mathrm{ml} / 100 \mathrm{ml}$, respectively. In conclusion, the visco-elastic properties of the peripheral venous system are reduced in patients with long-term IDDM. This reduction is not related to the presence of nephropathy. No major differences were observed in NTG-induced venodilation between diabetic patients and healthy subjects.

\subsection{INTRODUCTION}

Loss of vascular elasticity is thought to be one of the consequences of long-term hyperglycaemia in patients with insulin-dependent diabetes mellitus (IDDM). Both animal and human studies suggest that non-enzymatic glycation of proteins in bloodvessels can result in altered biomechanical properties of the vessel wall $(1,2)$. Furthermore, non-enzymatic glycation is thought to play a central role in the development of diabetic (micro)vascular complications $(1,2)$. However, arterial compliance, a measure of arterial elasticity, has been reported as normal, increased, and decreased in IDDM patients (3-5). This discrepancy might be explained by factors like the duration of disease, the site of measurement, differences in neurohumoral factors affecting arterial compliance and the blood pressure. When the intraluminal pressure rises, the vessel wall diameter will increase passively with a subsequent decrease in compliance. Vice versa, a rise in (systolic) blood pressure can also be the result of a decrease in arterial compliance, as this will increase cardiac afterload (6).

Patients with diabetic nephropathy are markedly at risk for the development of hypertension. Furthermore, this rise of blood pressure, in which possibly both renal and extrarenal factors are involved, profoundly affects the course of the nephropathy $(7,8)$. In an earlier study we observed a decreased maximal hyperaemic response of the skin vasculature in normotensive patients with incipient nephropathy, relative to 
patients without this complication (9). These results suggested that at least in peripheral arterioles structural changes may occur early in the course of nephropathy.

In IDDM patients little attention has been paid to changes of the venous system, which is a low pressure system and which does not seem to be exposed to the raised blood pressure. The venous system, however, plays an pivotal role in volume and blood pressure homeostasis. Approximately $60-80 \%$ of the total blood volume is located within the venous system in healthy man (10). A major part of this blood volume is haemodynamically inactive ("unstressed volume"). Venous compliance is defined as the volume/pressure ratio of the stressed compartment and changes in venous compliance could affect volume and blood pressure control (11).

In parallel to peripheral arteriolar vascular changes, a loss of compliance of the peripheral venous system could be one of the extrarenal manifestations of early diabetic nephropathy. Therefore, the present study was undertaken to determine whether, in comparison to normoalbuminuric patients and healthy controls, venous compliance is decreased in normotensive IDDM patients with (incipient) nephropathy. Furthermore, to substantiate whether possible structural changes of the venous wall and/or changes in venous tone have consequences for the venodilatory efficacy of nitrates, the venodilatory effect of sublingual nitroglycerin was examined in the same subjects.

\subsection{SUBJECTS AND METHODS}

Twenty-two normotensive IDDM patients with a duration of disease $>10$ years were studied (for details see table 6.1). Eleven patients, 6 females and 5 males, had (incipient) nephropathy: 8 had microalbuminuria (median $24 \mathrm{~h}$ albumin excretion: 120 (109-165) (interquartile range) $\mathrm{mg}$ ) and $3 \mathrm{had}$ macroalbuminuria (24h protein excretion: $0.9(1.2-1.8) \mathrm{mg}$, respectively). Of these patients one had background and 5 had (pre)proliferative retinopathy. Eleven patients, 5 females and 6 males, without microalbuminuria (median $24 \mathrm{~h}$ albumin excretion: $9(7.5-12) \mathrm{mg}$ ) were also studied. Three of these patients had background and one had (pre)proliferative retinopathy. The median duration of diabetes in patients with and without (incipient) nephropathy was 26 (16-30) and 17 (13-25) years (NS), respectively. As a control group 14 healthy subjects, 5 femalles and 9 males, were studied. No subject used any medication other than insulin, suffered from renal disease other than (micro)albuminuria, had clinical signs of cardiovascular disease or diabetic neuropathy. All had palpable ankle and foot pulses. All participants gave written informed consent and the study was approved by the hospital"s medical-ethical committee.

\section{Methods}

All experiments started at $8 \mathrm{a} . \mathrm{m}$. and were performed in a temperature controlled room $\left(23-25^{\circ} \mathrm{C}\right)$. The subjects were fasting from $10 \mathrm{p} . \mathrm{m}$. the evening before the experiment, and were studied in supine position. The morning insulin injection was omitted in the diabetic patients. Venous compliance was determined as described by 
Kooman et al (12). A 20 gauge catheter was inserted in a deep vein of the right forearm, the arm being at heart level, for intravenous pressure measurements and for blood sampling. A pressure transducer was placed $5 \mathrm{~cm}$ below the sternal angle. Intravenous pressure was measured with a HP $78205 \mathrm{C}$ pressure monitor (HP, Böblingen, Germany). Forearm volume changes were measured using mercury strain gauge venous occlusion plethysmography (Hokanson EC4 plethysmograph, Hokanson, Issaquah, WA, USA). The cuff for venous occlusion was placed just above the elbow. A mercury stain gauge was placed around the forearm, $5-8 \mathrm{~cm}$ distal to the lateral humeral epicondyl. Measurements started 30 minutes after venapunction. First, the upper arm cuff was inflated to a cuff pressure of $25 \mathrm{mmHg}$ and was kept inflated during three minutes. This time interval was chosen to obtain stabilized values for arm volume and venous pressure. Thereafter, the cuff was deflated for two minutes to minimize accumulation of interstitial fluid due to capillary filtration. The changes in volume and intravenous pressure during each cuff pressure step were obtained from the values measured just before and after deflation of the cuff. Subsequently, the same procedures were followed to obtain volume/pressure ratios during cuff pressures of $30,35,40$ and 50 mmhg. Venous compliance was defined as the slope of the venous pressure (dP: mmhg) versus forearm volume $(\mathrm{dV}: \mathrm{ml} / 100 \mathrm{ml}$ forearm) measurements and was calculated by linear regression analysis. The intraand interday (more than 5 weeks between 2 measurements) coefficient of variation of the venous compliance measurements is 8.1 and $11.1 \%$, respectively (12). Two sets of measurements were performed in each subject with a 15 minute interval, the mean value of these measurements were used for calculations.

Table 6.1: Clinical characteristics and laboratory results of the healthy subjects (control), IDDM patients with (EN+) and without (EN-) (incipient) nephropathy.

\begin{tabular}{lccc}
\hline & Control & IDDM, EN - & IDDM, EN + \\
\hline Number & 14 & 11 & 11 \\
Age (years) & $36(29-42)$ & $34(29-44)$ & $35(26-42)$ \\
BMI $\left(\mathrm{kg} / \mathrm{m}^{2}\right)$ & $21.7(20.5-24.7)$ & $23.9(22.3-25.8)$ & $24.1(22.6-24.6)$ \\
MAP $(\mathrm{mmHg})$ & $94(85-105)$ & $96(90-104)$ & $94(82-112)$ \\
Glucose $(\mathrm{mmol} / \mathrm{l})$ & $4.4(4.1-4.7)$ & $12.3(8.3-14.9)$ & $11.1(9.3-13.3)$ \\
HbA1. $(\%)$ & $5.2(5.0-5.5)$ & $9.0(7.2-9.5)$ & $7.7(6.4-9.4)$ \\
Creatinin $(\mu$ mol//) & $74(69-85)$ & $73(68-80)$ & $79(70-88)$ \\
\hline
\end{tabular}

BMI $=$ body mass index; MAP $=$ mean arterial pressure. Data are expressed as medians with interquartile ranges.

To study the venodilatory effect of nitroglycerin, the increase in resting forearm volume after a $0.4 \mathrm{mg}$ sublingual dose of nitroglycerine (Nitrolingual spray) was determined 15 minutes after the end of the second set of measurements. As the swel- 
ling rate of an arm is elevated in long-term DDM patients during an increase in venous pressure, due to factors as increased capillary filtration and disturbed local haemodynamic control (13), the effect of nitroglycerin was determined without the prior application of venous occlusion. Blood pressure and heart rate were measured using the Finapres blood pressure monitor (Ohmeda, Englewood, $\mathrm{CO}$, USA).

Blood samples were drawn 15 minutes after venapunction for determination of glucose, $\mathrm{HbAlc}$, and serum creatinine. Two further samples were drawn for glucose determination, one between the two sets of measurements and one at the end of the experiment, blood glucose values are presented as the mean of these three measurements. In the two days preceding the experiment each subject collected 24-hours urine for determination of creatinine and, only in diabetic patients, microalbumin or total protein. Blood glucose concentration was measured by the glucoseoxydase method, HbAlc by HPLC, sodium by a ion selective electrode, microalbuminuria by a commercial assay using an immunoturbidometric method (Uni-Kit Albumin, Hoffman-LaRoche, Basel, Switzerland) and macroproteinuria by pyrogallol red-molybdate complex method. Microalbuminuria was defined as a $24 \mathrm{~h}$ albumin excretion of $25-250 \mathrm{mg}$.

Statistical analysis was performed using non-parametric tests (except linear regression analysis for pressure/volume relationships). The Kruskal-Wallis test was used for multiple group comparison and the Mann-Whitney $U$ test for two group comparison. Statistical significance is considered as $P<0.05$. All data are presented as median and interquartile ranges.

\subsection{RESULTS}

Blood glucose, HbAlc values and serum creatinin levels did not differ between the patients without and with (incipient) nephropathy, neither were any differences observed in blood pressure, or body mass index between the three groups studied (table 6.1). The median intravenous pressure/ forearm yolume ratios obtained at the five different occlusion pressures are depicted in figs. 6.1, 6.2, and 6.3. The median correlation coefficient of the individual delta volume/delta pressure relationships at different cuff pressures in the normoalbuminuric patients, the patients with (incipient) nephropathy and healthy subjects was: $0.99(0.98-0.99), 0.98(0.97-1.0)$ and $0.99(0.99-1.0)$, respectively (NS). Venous compliance was decreased in both normoalbuminuric and (incipient) nephropathy patients, in comparison with healthy control subjects: $0.44(0.38-0.59), 0.49(0.46-0.58), 0.59(0.52-0.66)$, Kruskal-Wallis: $\mathrm{P}<0.02$; Mann-Whitney $\mathrm{U}$ : control subjects vs normoalbuminuric patients $\mathrm{P}<0.01$, control subjects vs (incipient) nephropathy patients $P<0.05$. No difference in venous compliance could be observed between the two groups of diabetic patients $(P=0.45)$ (figure 6.4).

During the different occlusion pressures, the intravenous pressure was lower than the external pressure. For each individual the median difference between the five external and intravenous pressures was calculated. As this difference was similar in 
patients without and with (incipient) nephropathy, the data of both groups were combined. The median difference between external cuff pressures and intravenous pressures was increased in the diabetic patients $(\mathrm{n}=22)$ in comparison with the healthy controls: $10.6(7.6-12.4)$ vs $7.8(4.2-11.1)$ mmhg, $P<0.05$.

\section{CONTROL SUBJECTS}

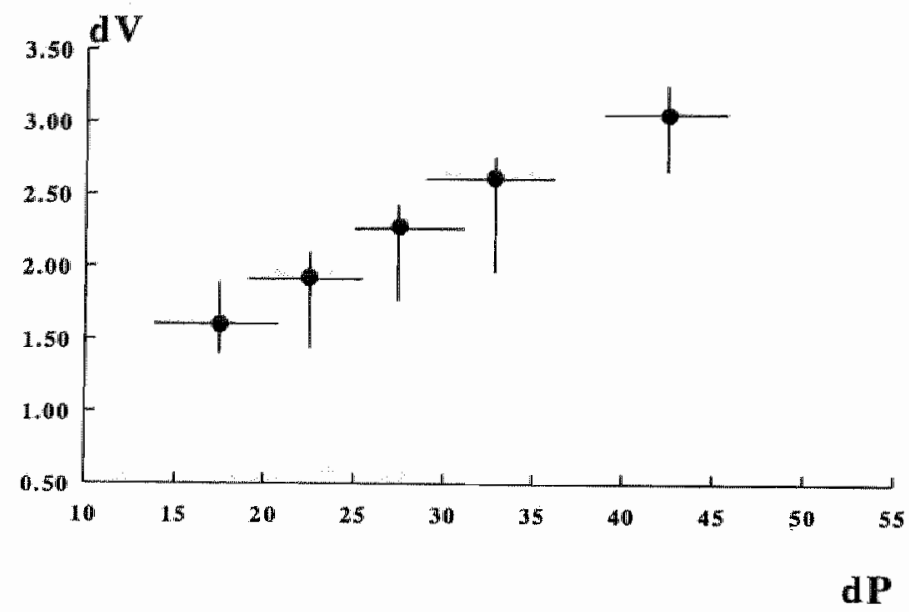

Figure 6.1: Medians and interquartile ranges of the change in intravenous pressure (dP, mmHg) and forearm wolume (dV, ml/100ml forearm) after occlusion of the cuff of the upperarm with external pressures: $25,30,35,40$ and $50 \mathrm{~mm} H \mathrm{~g}$ (see text for details) in healthy control subjects.

After nitroglycerin administration an increase in forearm volume was observed in all 3 groups $(\mathrm{P}<0.01)$. There were, however, no differences in the increase in forearm volume between the patients without and with (incipient) nephropathy and healthy controls: $\quad 0.34(0.11-0.51), 0.37(0.19-0.50)$, and $0.39(0.20-0.55$ $\mathrm{m} 1 / 100 \mathrm{ml})$, respectively $(\mathrm{P}=0.65)$. Intravenous pressure did not change in the patients with normoalbuminuria or (incipient) nephropathy nor in the healthy subjects (median change in pressure $0.0 \mathrm{mmHg}$ in the three groups). Furthermore, no changes were observed in blood pressure or heart rate (data not shown).

\subsection{DISCUSSION}

In the present study forearm venous compliance was reduced to a similar extent in normotensive IDDM patients with and without (incipient) nephropathy, relative to 
healthy subjects. In the diabetic patients the venodilatory effect of sublingual nitroglycerin was not changed.

Venous compliance was determined using strain gauge plethysmography and intravenous pressure measurements, as previously described by Kooman et al. (12).

\section{IDDM EN-}

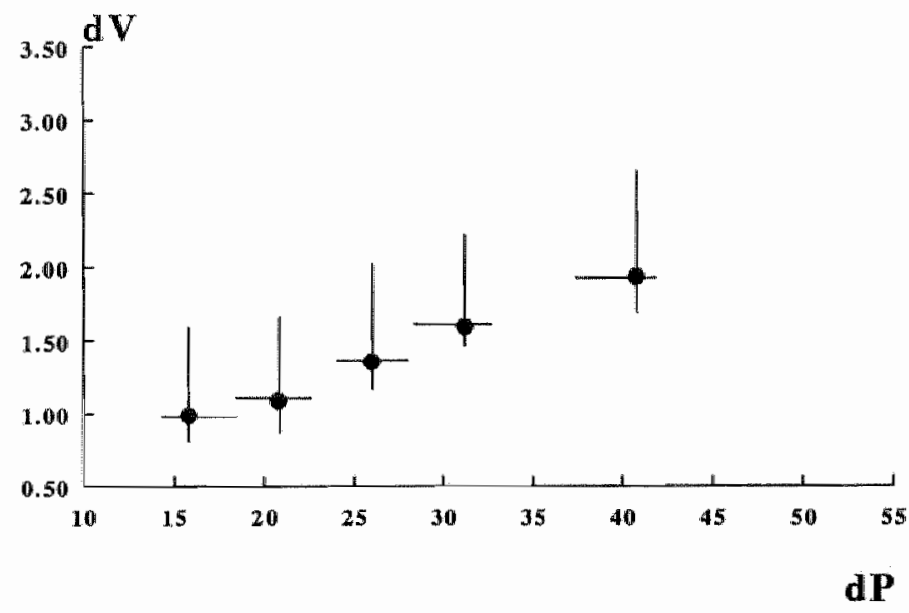

Figure 6.2: Medians and interquartile ranges of the change in intravenous pressure (dP, mmHg) and forearm volume $(d V, m l / 100 m i$ forearm) after occlusion of the cuff of the upperarm with extermal pressures. $25,30,35,40$ and 50 muntig (see text for details) in normoalbumimuric IDDM patients.

Venous compliance was studied in the linear part of the pressure/volume curve, which is thought to represent the visco-elastic characteristics of the venous wall (14). In the present study compliance of forearm venous vessels was studied, a vascular bed that plays only a minor role in volume and blood pressure homeostasis. Forearm venous compliance is, however, strongly and positively correlated to total effective compliance (15).

In diabetic patients the swelling rate of the forearm is increased after venous occlusion (13), which might confound the compliance measurements. In the present study the changes in volume were, however, measured after deflation of the cuff, to minimize the influence of factors like increased capillary filtration. In comparison with healthy subjects, a reduced increase in intravenous pressures were reached in the diabetic patients during inflation of the external cuff. These data suggest that, in addition to the decreased venous compliance, the compressibility of forearm tissues 
is decreased in IDDM patients with long-term diabetes. Whether this possible increased forearm stiffness also affects noninvasive arterial blood pressure measurements is uncertain.

\section{IDDM EN+}

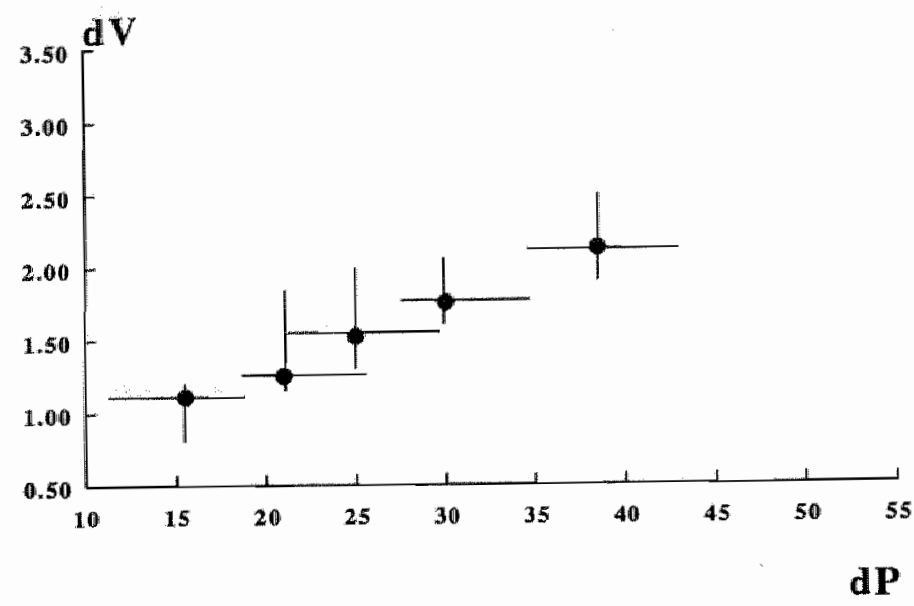

Figure 6.3: Medians and interquartile ranges of the change in intrawenous pressure (dP, mmLg) and forearm volume ( $d V$, mil/100ml forearm) after occlusion of the cuff of the upperarm with external pressures: $25,30,35,40$ and $50 \mathrm{mmHg}$ (see text for details) in IDDM patients with early nephropathy.

The observed impaired venous compliance in normoalbuminuric IDDM patients is in line with an earlier study of Bell et al (16). However, in this study, using technetium labelled erythrocytes, intravenous pressures were not measured and only relative compliance was determined.

In the present study no differences were observed in the compliance of the peripheral venous system between normoalbuminuric and (incipient) nephropathy patients. The maximal hyperaemic response of the skin vasculature is, however, impaired in normotensive patients with incipient nephropathy, relative to patients without this complication (9). The present data suggest that in contrast to early structural changes of peripheral (skin) arterioles, a loss of compliance of the peripheral venous system is not associated with the development of diabetic nephropathy.

The loss of visco-elastic properties of the venous wall in the IDDM patients could be explained by structural changes in the vessel wall. As a result of non-enzymatic glycosylation of collagen and other connective tissue proteins, advanced glycosylation end (AGE) products are formed, which can form irreversible cross-links be- 
tween ageing proteins, thereby altering their biomechanical properties $(1,2)$. Indeed, in a skin biopsy study of Monnier et al (17) a correlation was observed between collagen linked fluorescence, which is thought to be a measure of AGE products, and the visco-elastic properties of the aorta, measured by pulse wave velocity.

\section{VENOUS COMPLIANCE \\ slope of $d V / d P$ curve}

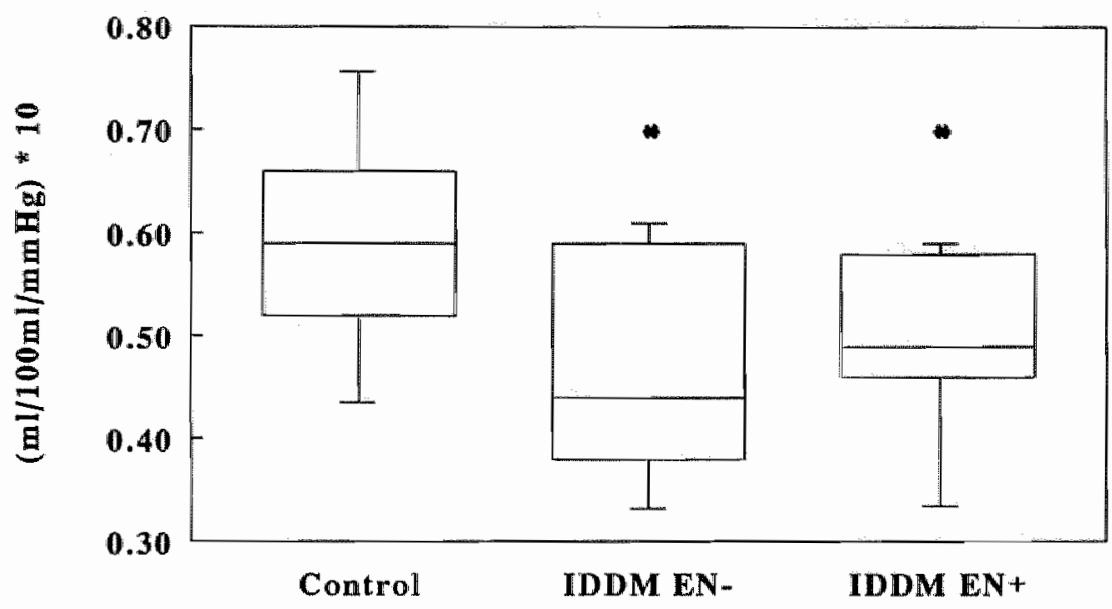

Fygure 6.4: Venous compliance of the forearm, expressed as the slope of the dV/dP curve (see text for details) in healihy subjects (control), IDDM patients without $(N-)$ and with $(N+)$ (incipiens) nephroparhy. Results are expressed as medion with interquartiles (box) and ranges. * $P<0.05$ us control (Mann-Whimey $U$ ).

On the other hand, an increase in venous tone could explain a decrease in venous compliance as well. Hand vein reactivity to local infusion of noradrenaline is increased in patients with incipient nephropathy or with clinical signs of diabetic polyneuropathy $(18,19)$, suggesting an increased venous tone. However, in patients without these complications the hand vein reactivity to noradrenaline is unchanged $(18,19)$, and sympathetic outflow and plasma levels of catecholamines and angiotensine II are normal or reduced (2). Furthermore, the present study indicates that the venodilatory effect of nitroglycerin is unchanged. These data suggest that venous tone is normal in long-term normoalbuminuric patients. Whether the decreased venous compliance in long-term IDDM patients, as found in the present study, is a result of structural vessel wall changes, warrants further investigation.

Changes in the venous system can have profound influences upon volume and blood pressure homeostasis. Venous compliance is decreased in non-diabetic patients 
with (borderline) hypertension and in their normotensive siblings $(11,22)$. Safar et al (11) suggested that a loss of venous compliance could be an important factor in the development of essential hypertension. A loss of venous compliance would "centrali$z \mathrm{e}^{\prime \prime}$ the blood volume and would raise cardiac output. However, in the present study venous compliance was reduced in normotensive normoalbuminuric patients, comparable to values observed in subjects with essential hypertension (medians: 0.44 and 0.51 , respectively, 12). We do not have follow-up data on the blood pressures of the normoalbuminuric patients, but, normoalbuminuric patients with long-term diabetes do not seem to be at risk for the development of hypertension (23). Therefore, the present study is not in concert with the hypothesis that a loss of venous compliance will result in a rise of the blood pressure.

The present results indicate that the venodilatory effect of nitroglycerin, administrated sublingually, is comparable in both patients and healthy control subjects. These findings indicate that despite a decreased venous compliance, the venodilator efficacy of nitrates is unchanged in long-term IDDM patients.

In conclusion, the present study indicates that venous compliance is decreased in normotensive IDDM patients with long-term diabetes, with and without (incipient) nephropathy. This loss of visco-elastic properties of peripheral veins is not related to the development of nephropathy. No major differences were observed in the response to sublingual nitroglycerin between patients and healthy subjects.

\section{ACKNOWLEDGMENTS}

This study was supported by ICI, The Netherlands.

\section{REFERENCES}

1. Brownlee M, Cerami A, Vlassara H. Adwanced glycosyllation end products in tissue and the biochemical basis of diabetic complications. N Eng Med 1988;318;1315-1321.

2. Dominiczak MH. The significance of the products of the Maillard (browning) reaction in diabetes. Diab Med 1991;8;505-516.

3. Christensen $T$, Neubauer B. Arterial wall stiffness in insulin dependent diabetes mellitus. Acta Radiol 1987;28;207-208.

4. Scarpello JHB, Martin TRP, Ward JD. Ultrasound measurements of pulse-wave velocity in the peripheral arteries of diabetic subjects. Clin Sci 1980;58;53-57.

5. Lehmann ED, Gosling RG, Sonksen PH. Arterial wall compliance in diabetes. Diab Med $1992 ; 9 ; 114-119$.

6. O'Rourke M. Arterial stiffness, systolic blood pressure, and logical treatment of arterial hypertension. Hypertension 1990;15;339-347.

7. Mogensen CE, Hansen KW, Osterby R, Damsgaard EM. Blood pressure elevation versus abnormal albuminuria in the genesis and prediction of renal disease in diabetes. Diab Care $1992 ; 15 ; 1192$. 1204.

8. Epstein M, Sowers JR. Diabetes mellitus and hypertension. Hypertension 1992;19;403-418. 
9. Houben AIHM, Schaper NC, Slaaf DW, Tangelder GJ, Nieuwenhuizen Kruseman AC. Skin blood cell flux in insulin-dependent diabetic subjects in relation to retioupathy or incipient nephropathy. Eur I Clin Imvest 1992;22;67-72.

10. Grenway CV, Lautt WW. Blood volume, the venous system, preload, and cardiac output. Cain I Physiol Pharmacol 1986;64;383-387.

11. Safar ME, London GM. Venous system in essential hypertension. Clin Sci 1985;69;497-504.

12. Kooman JP, Wijnen JAG, Draaijer P, van Bortel LMAB, Gladziwa U, Peltenburg HG, Struyker Boudier HAJ, van Hooff JP, Leunissen KML. Compliance and reactivity of the peripheral venous system in chronic intermittent hemodialysis. Kidney Int 1992;41;1041-1048.

13. Tooke JE. The microcirculation in diabetes. Diab Med $1987 ; 4 ; 1894196$.

14. Oberg $B$. The relationship between active venoconstriction and passive recoil at various distending pressures. Acta Physiol Scand 1967;71;233-247.

15. Safar MJ, London GM, Simon. JA, et al. Rapid dextran infusion in essential hypertension. Hypertension $1986 ; 8 ; 142-146$.

16. Bell D, Collier A, Nicoll JJ, Jackson M, Millar AM, Clarke BF, Muir AL. Reduced venous compliance and increased transcapillary escape of protein in insulin-dependent diabetic patients. Diab Med 1988;5;454-458.

17. Bodmer CW, Patrick AW, How TV, Williams G. Exaggerated sensitivity to NE-induced vasoconstriction in IDDM patients with microalbuminuria. Possible etiology and diagnostic implications. Diabetes $1992 ; 41 ; 209-214$.

18. Eichler HG, Blaschke TF, Kreamer FB, Ford GA, Blochl-Daum B, Hoffman BB. Responsiveness of superficial hand veins to alpha-adrenoceptor agonists in insulin dependent mellitus. Clin Science $1992 ; 82 ; 163-168$.

19. Monnier VM, Vishwanath V, Frank KE, Elmets GA, Dauchot P, Kohn RR. Relation between complications of type I diabetes mellitus and collagen-linked fluorescence. N Eng J Med $1986 ; 314 ; 403-408$.

20. Manyari DE, Malkinson TJ, Robinson V, Smith ER, Cooper KE. Acute changes in forearm venous volume and tone using radionuclide plethysmography. Am J Physiol 1988;255;H947-H952.

21. Calver $A$, Collier $J$, Vallance $P$. Inhibition and stimulation of nitric oxide synthesis in the human forearm arterial bed of patients with insulin-dependent diabetes. J Clin Invest 1992;90;2548-2554.

22. Ito $N$, Takeshita $A$, Higuchi $S$, Nakamura $M$. Venous abnormality in normotensive young mem with a family history of hypertension. Hypertension $1986 ; 8 ; 142-146$.

23. Norgard K, Feldt-Rasmussen B, Borch-Johnsen K, Saelan H, Deckert T. Prewalence of hypertension in type 1 (insulin dependent) diabetes mellitus. Diabetologia 1990;33;407-410. 


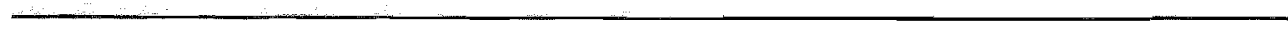




\section{PERIPHERAL MACRO- AND \\ MICROCIRCULATION IN SHORT-TERM \\ INSULIN-DEPENDENT DIABETES MELLITUS: \\ THE ROLE OF PROSTAGLANDINS IN EARLY HAEMODYNAMIC CHANGES.}

A.J.H.M. Houben, A.C. Nieuwenhuijzen Kruseman, E. Bouhouch, D.W. Slaaf, N.C. Schaper.

Published in: European Journal of Clinical Investigation (in press). 


\subsection{ABSTRACT}

To determine whether vasodilator prostaglandins are involved in the peripheral hyperperfusion observed in patients with short-term insulin-dependent diabetes mellitus (IDDM), forearm and skin blood flow was studied before and after cyclooxygenase inhibition. Skin nutritive (CBV: capillary blood-cell velocity) and thermoregulatory (LDF: laser-Doppler fluxmetry), and forearm (muscle) blood flow (FBF) were measured before and after $500 \mathrm{mg}$ acetylsalicylic acid (ASA) infused intravenously in 14 short-term IDDM patients and 22 healthy control subjects. In the IDDM patients, baseline LDF (median: 27 (19-35; interquartile range) vs 17 (15-23) pu) and FBF $(3.4(2.5-4.1)$ vs $2.6(2.2-2.9) \mathrm{ml} / 100 \mathrm{ml} / \mathrm{min})$ were increased, while CBV $(0.70(0.40-1.33)$ vs $0.69(0.41-0.96) \mathrm{mm} / \mathrm{s})$ was unchanged compared to healthy controls. ASA infusion had similar effects on baseline CBV, LDF, and FBF in patients and controls. In 8 of the control subjects the role of prostaglandins in the regulation of basal peripheral blood flow was studied before and after ASA and placebo infusion. The changes in baseline CBV, LDF, and FBF were similar after ASA and placebo infusion in healthy controls. In conclusion, in short-term IDDM patients, increased skin thermoregulatory and forearm (muscle) blood flow are probably not related to vasodilator prostaglandins. Furthermore, prostaglandins are not likely to be involved in regulating basal peripherall blood flow in healthy man.

\subsection{INTRODUCTION}

Haemodynamic changes may be one of the initiating mechanisms in the development of diabetic microangiopathy $(1,2)$. Shortly after the onset of insulin-dependent diabetes mellitus (IDDM), blood flow is increased in several tissues and organs throughout the body (3-5). Recently, we demonstrated increased skin blood flow in patients with short-term diabetes (6). Besides alterations in neurogenic vascular control, this increased flow may be caused by changes in endothelial release of vasoactive factors $(7,8)$, such as the vasodilator prostacyclin.

Increased levels of prostacyclin have been shown to induce skin hyperperfusion in man (9). In experimental and human diabetes, both increased and decreased endothelial production of prostacyclin have been reported (for review see 10). Several studies suggest that, particularly in short-term diabetes, prostacyclin production is increased (11-13).

The aim of the present study was to determine whether enhanced production of prostacyclin is involved in the increased peripheral blood flow in short-term IDDM patients. Total forearm, and skin nutritive and thermoregulatory blood flow were determined in short-term IDDM patients and healthy controlls, before and after the inhibition of prostaglandin production by infusion (i.v.) of the cyclooxygenase inhibitor acetylsalicylic acid (ASA). As the role of prostaglandins in the control of basal skin thermoregulatory and nutritive blood flow in normal man has not previously 
been reported, we also performed a randomized, double-blind, placebo-controlled study of ASA infusion in some of the healthy subjects.

\subsection{PATLETS AND METHODS}

Experiments were performed in 14 insulin-dependent diabetes mellitus patients (4 females, 10 males) with a mean age of $27.7 \pm 7.0$ (SD) years, a mean duration of disease of $34 \pm 17$ months, and a mean body mass index (BMI) of $23.1 \pm 2.2$ $\mathrm{kg} / \mathrm{m}^{2}$. All the patients had no symptoms of (autonomic) neuropathy, had normal ankle reflexes, and normal vibration sensation (tuning fork) at the great toe. The patients had no history of cardiovascular disease, and all foot pulses were palpable. The control group comprised 22 healthy volunteers ( 8 females, 14 males) with a mean age of $26.5 \pm 7.5$ years, and a mean BMI of $23.8 \pm 2.4 \mathrm{~kg} / \mathrm{m}^{2}$. All subjects were normotensive, and used no medication (particularly no aspirin for the last two weeks) except for insulin. None of the patients or controls had suffered from peptic ulcer, asthma, nasal polyps, or an allergic reaction to acetylsalicylic acid (ASA) in the past. The study protocol was approved by the hospital's ethical committee and written informed consent was obtained from all subjects.

\section{Methods}

Capillary blood cell velocity (CBV; representing skin nutritive blood flow) was determined using intravital microscopy, with a $20 \mathrm{x}$ objective (numeric aperture: 0.32) (14). Images were videotaped for off-line analyses. Recordings were made during two minutes in the finger nailfold of the fourth and the fifth finger, in two capillaries each. The same four capillaries were studied during each subsequent measurement. CBV was analyzed in the arterial limb (using temporal correlation (15) incorporated in CAPIFLOW software (SIM, Kista, Sweden)) together with capillary diameter measurements. Analysis of CBV was possible during 1 to 1.5 minute of each recording. The coefficient of variation for two repeated measurements (with an interval of 60 minutes) is $31 \%$. The CV for two repeated CBV measurements of the same recording is $6 \%$. In 4 patients and 4 controls, CBV measurements were not performed, and in 1 patient and 3 controls the CBV measurements could not be evaluated, due to inadequate image quality.

Thermoregulatory skin perfusion (LDF) was determined on the dorsum of the interphalanx of the fourth finger of the non-dominant hand using laser-Doppler fluxmetry (Periflux PF3; Perimed, Järfälla, Sweden) (12 kHz mode, time constant 0.2 s), as previously described (6). The mean value of two minutes recording was used for calculations. The CV for repeated measurements is $16 \%$. Skin temperature was measured at the same spot.

Forearm blood flow (FBF) was determined using mercury strain gauge venous occlusion plethysmography (Hokanson EC4, Issaquah, WA, USA). Hand circulation was excluded by inflating a wrist cuff to suprasystolic pressure, starting one minute before each FBF measurement. Hence, FBF represents predominantly muscle blood 
flow. A flow curve lasted 10 seconds, and comprised 5 seconds with venous occlusion $(50 \mathrm{mmHg}$ ), and 5 seconds without occlusion, 6 inflow curves per minute were therefore determined. Three FBF measurements of two minutes were performed, separated by an interval of 10 minutes. The mean of the 3 measurements was used for calculations. The $\mathrm{CV}$ for repeated measurements is $11 \%$.

Blood pressure and heart rate measurements were performed during one minute, using the Finapres blood pressure monitor (Ohmeda, Englewood, CO, USA).

Blood glucose concentration was measured at the start and the end of the experiment by the glucose oxidase method using the ESAT 6660 autoanalyzer (Eppendorf, Hamburg, Germany). HbAlc concentration (normal range 4.2-6.2\%) was measured by HPLC (Diamat, Bio-Rad Laboratories, Richmond, CA, USA).

\section{Protocol}

To study the effects of $500 \mathrm{mg}$ ASA infused intravenously on basal forearm and skin microcirculatory blood flow, 8 subjects of the control group were investigated in a (pilot) study, using a randomized, double-blind, placebo-controlled protocol, with an interval of two to three weeks between the first and the second experiment. The protocol is described below. Placebo infusion consisted of $\mathrm{NaCl} 0.9 \%$ (infusion rate: $90 \mathrm{ml} / \mathrm{h}$ ). To verify cyclooxygenase inhibition by ASA, platelet aggregation (in platelet-rich plasma) was measured in an absorptiometer during stimulation with arachidonic acid and ADP (16), and plasma thromboxane- $B_{2}$ content was determined by RIA (Du Pont, Dreieich, Germany) before and one hour after the ASA or placebo infusion.

To study the possible role of vasodilator prostaglandins in the early peripheral hyperperfusion in diabetes, a comparative study of cyclooxygenase inhibition on peripheral blood flow in IDDM patients and healthy controls was performed. CBV, LDF, and FBF were studied before and after cyclooxygenase inhibition (by $500 \mathrm{mg}$ ASA i.v.) in 14 short-term IDDM patients and 22 healthy controls. All experiments started at $8 \mathrm{a} . \mathrm{m}$. and were performed in a quiet, temperature-controlled room (mean temperature $24.6 \pm 0.4(\mathrm{SD}){ }^{\circ} \mathrm{C}$.). The subjects were not allowed to smoke, eat, or drink (except for water) from 10 p.m. the night before until the end of the experiment, and the diabetic patients omitted their morning insulin. The experiment was postponed to another day if an IDDM subject suffered symptomatic hypoglycaemia or had a blood glucose level below 3.5 or above $15 \mathrm{mmol} / \mathrm{l}$. The subjects were studied in the supine position. A catheter was inserted into the cubital vein of the dominant arm for blood sampling and infusion of ASA. This catheter was kept patent with $\mathrm{NaCl}(0.9 \%)$. Thirty minutes after insertion of the catheter, baseline flow measurements started in the following sequence: CBV, LDF, FBF. All measurements were performed on the non-dominant arm, except for blood pressure and heart rate, which were performed on the dominant arm. After the baseline flow measurements (as described above), $500 \mathrm{mg}$ acetylsalicylic acid (Aspégic; Lorex, Weesp, The Netherlands) in $30 \mathrm{ml} \mathrm{NaCl} 0.9 \%$ (infusion rate $90 \mathrm{ml} / \mathrm{h}$ ) was infused intravenously (i.v.) (17), to inhibit the vascular production of prostacyclin (18-20). During the infusion, the subjects were allowed to sit upright, but were placed supine again 
15 minutes before the second set of measurements. One hour after the start of the infusion, an identical set of flow measurements, as described above, was performed.

\section{Statistical analysis}

Blood flow data were tested for normality. LDF and CBV data were found to be not normally distributed. All data are presented as median values with interquartile ranges unless otherwise indicated. Nonparametric tests were used for paired and unpaired analysis (Wilcoxon and Mann-Whitney $U$, respectively). $P$ values less than 0.05 were considered to be statistically significant.

\section{$7.4 \quad$ RESULTS}

The mean blood glucose level of the diabetic patients at the time of study was $8.3 \pm$ $2.8 \mathrm{mmol} / \mathrm{l}$, and their mean $\mathrm{HbAlc}$ level was $7.5 \pm 1.0 \%$.

Table 7.1: Baseline blood flow walwes and percentage changes in baseline values after placebo (0.9\% $\mathrm{NaCl}$ ) or $500 \mathrm{mg} \mathrm{ASA}$ infusion in 8 healthy subjects.

\begin{tabular}{|c|c|c|c|c|}
\hline & \multicolumn{2}{|c|}{ PLACEBO } & \multicolumn{2}{|c|}{$500 \mathrm{mg} \mathrm{ASA}$} \\
\hline & basal & $\%$-change & basal & $\%$-change \\
\hline $\begin{array}{l}\mathrm{CBV} \\
(\mathrm{mm} / \mathrm{s})\end{array}$ & $\begin{array}{l}0.72 \\
(0.39-1.04)\end{array}$ & $\begin{array}{l}-39 \\
(-65--16)\end{array}$ & $\begin{array}{l}0.69 \\
(0.49-0.95)\end{array}$ & $\begin{array}{l}-26 \\
(-75-+4)\end{array}$ \\
\hline $\begin{array}{l}\text { LDF } \\
\text { (PU) }\end{array}$ & $\begin{array}{l}17.1 \\
(14.1-22.9)\end{array}$ & $\begin{array}{l}-39 \\
(-65--31)\end{array}$ & $\begin{array}{l}16.6 \\
(15.2-20.4)\end{array}$ & $\begin{array}{l}-26 \\
(-67-+7)\end{array}$ \\
\hline $\begin{array}{l}\text { FBF } \\
(\mathrm{mil} / 100 \mathrm{ml} / \mathrm{min})\end{array}$ & $\begin{array}{l}2.3 \\
(2.0-2.4)\end{array}$ & $\begin{array}{l}+12 \\
(+2-+26)\end{array}$ & $\begin{array}{l}2.2 \\
(1.8-2.5)\end{array}$ & $\begin{array}{l}+15 \\
(+1-+39)\end{array}$ \\
\hline
\end{tabular}

$+=$ increase; - = decrease. $\mathrm{CBV}=$ capillary blood cell velocity, LDF $=$ laser-Doppler fluxmetry, $\mathrm{FBF}=$ forearm blood flow, pu $=$ perfusion units. Data are represented as median and interquartile ranges.

The results of the placebo-controlled study on the effects of ASA on peripheral macro and microcirculation in 8 healthy control subjects are shown in table 7.1. No differences were observed in baseline values of CBV, LDF, or FBF (table 7.1), nor in erythrocyte column widths (representing capillary diameters), skin temperature, MAP, or heart rate (data not shown). The possible effects of placebo or ASA infusion are expressed as percentage change from baseline values. The percentage changes were not different between placebo and ASA infusion (table 7.1). However, the CBV data showed large variation. Following ASA infusion, platelet aggregation was inhibited in 7 cases, and after placebo infusion in 1 case (Wilcoxon, $P=0.03$ ). In one case platelet aggregation was already inhibited before ASA infusion. In our 
haematology lab 10-20\% of the healthy volunteers (who have not been using nonsteroidal anti-inflammatory drugs) demonstrate an inhibited platelet aggregation, even on repeated measurements (unpublished data). Plasma thromboxane- $\mathrm{B}_{2}$ levels decreased by $91 \%$ (83-93) after ASA infusion (baseline value: 541 (380-894); after ASA: $68(43-77) \mathrm{pg} / \mathrm{ml})$, and by $5 \%(-70-7)$ after placebo infusion (baseline value: 344 (182-450); after placebo: $395(195-650) \mathrm{pg} / \mathrm{ml}$ ) (Wilcoxon, $\mathrm{P}=0.02$ ).

\section{FOREARM BLOOD FLOW}

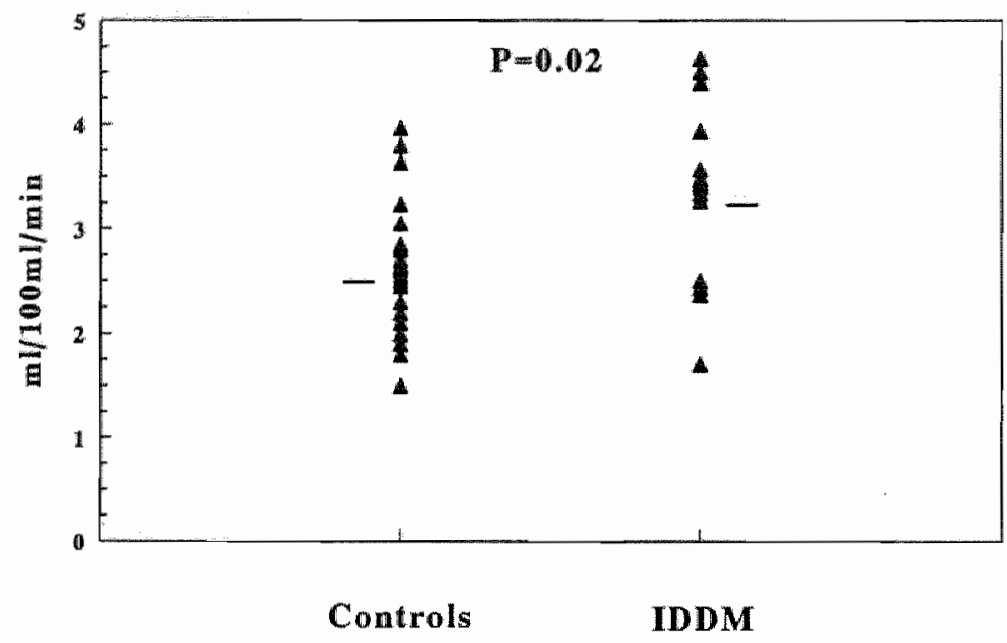

Figure 7.1: Baseline walues of forearm (muscle) blood flow (FBF; determined with venous occlusion plethysmography) in 22 healthy subjects and 14 IDDM patients. Horizontal bars indicate median wilues. $P$ value indicates level of significance derermined with Mann-Whitney $U$ test.

Baseline values of FBF and LDF were significantly higher in IDDM patients compared to the control subjects (fig. 7.1 and 7.2 respectively). No differences were observed in baseline values of CBV (fig. 7.3), the width of the erythrocyte column (representing the capillary diameter) of the arterial limb (control: 9.5 (9-11);IDDM: $9.5(8-11) \mu \mathrm{m}$ ), or the width of the venous limb (control: $11.5(10.5-13)$;IDDM: $11.5(10.5-12.5) \mu \mathrm{m})$ between patients and controls. Hence, calculated capillary blood flow (CBV x $\pi r^{2}$ ) was not different either between patients and controls (control: 51 (29-72);IDDM: $\left.55(27-89) 10^{3} \mu \mathrm{m}^{3} / \mathrm{s}\right)$. Neither were any differences observed in baseline skin temperature (control: 32.0 (30.1-32.8);IDDM: 32.0 (30.6-32.7) ${ }^{\circ} \mathrm{C}$ ), MAP (control: 90 (84-98);IDDM: $87(80-92) \mathrm{mmHg}$ ), or heart rate (control: 59 (55-62);IDDM: 61 (52-68) beats/min) between patients and controls. 


\section{LASER-DOPPLER FLUXMETRY}

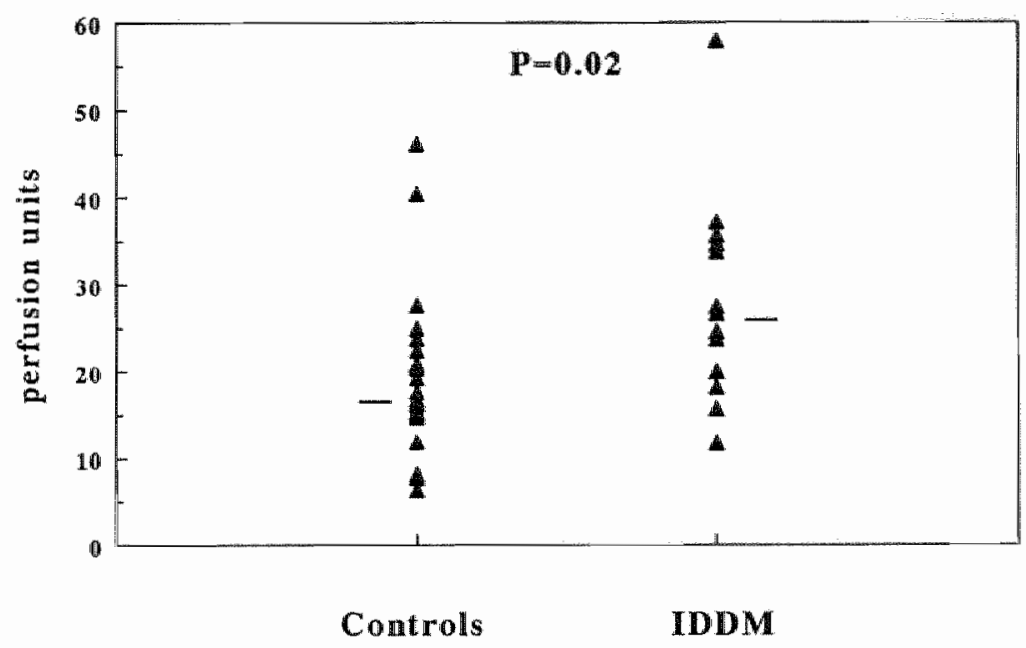

Figure 7.2; $\quad$ Baseline values of skin thermoregulatory blood flow (LDF; determined with laser-Doppler flucumetry) in 22 healthy subjects and 14 IDDM patients. Horizontal bars indicate median values. $P$ walue indicates level of significance determined with Mann-Whitney $U$ test.

The changes from baseline values of LDF and FBF after ASA infusion were not different between patients and controls (table 7.2). Neither were any differences found in changes in baseline CBV between patients and controls (table 7.2), however, these data showed large variation. Calculated capillary blood flow, skim temperature, MAP, and heart rate did not change statistically significant after ASA (data not shown).

\subsection{DISCUSSION}

In short-term IDDM patients, increased forearm muscle and skin thermoregulatory, but not skin nutritive blood flow was demonstrated. Inhibition of prostaglandin production had simillar effects on basal forearm and skin blood flow in healthy and diabetic subjects, suggesting that prostaglandins do not play a role in the peripheral hyperperfusion of IDDM. Furthermore, the results of the ASA/placebo studies suggest also no role for prostaglandins in the regulation of basal forearm and skin blood flow in healthy subjects. 
CAPILLARY BLOOD CELL VELOCITY

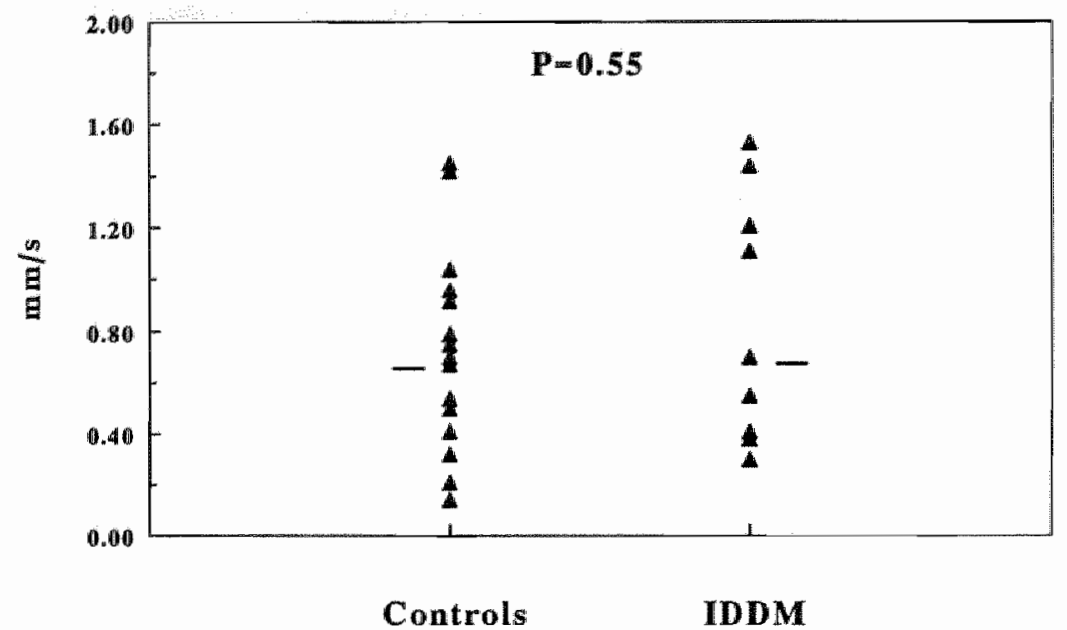

Figure 7.3: Baseline values of capillary blood cell velocity (CBV; determined with nailfold intrawial microscopy) representing skin nutritive blood flow in 15 healthy subjects and 9 IDDM parients. Horizontal bars indicate median values. $P$ value indicates level of significance determined with Mann-Whitney $U$ test.

ASA and placebo (saline) infusion had similar effects on FBF, LDF, and CBV in healthy volunteers, although the CBV data should be interpreted with caution, due to large variation. These data suggest that, in healthy subjects, prostaglandins are not involved in the local regulation of basal forearm (muscle), skin thermoregulatory, and skin nutritive blood flow. These findings are consistent with previous reports that have demonstrated no changes in basal forearm, or finger blood flow after prostacyclin inhibition $(21,22)$. On the other hand, it has been shown that vasodilator prostaglandins may be involved in the forearm muscle post-occlusive reactive hyperaemic blood flow (21), but not in the finger hyperaemic response (22). In addition, prostaglandins apparently play a role in the autoregulation of splanchnic and renal blood flow $(23,24)$, and possibly in the regulation of venous tone $(25)$.

The observed decrease in skin microcirculatory blood flow in patients and control subjects is probably related to long-term (approximately 3 hours) acclimatization to the experimental conditions (e.g. physical inactivity), as we demonstrated recently in a study on the diurnal variations in forearm macro- and microcirculation (26). The increase in forearm (muscle) blood flow is probably related to diurnal variation (27). The changes in peripheral blood flow after ASA were similar in patients and control subjects, suggesting that prostaglandins are not involved in the early diabetic hyper- 
perfusion. It seems unlikely that the variations in peripheral blood flow would obscure any ASA-related changes.

Table 7.2. Percentage changes in baseline blood flow walles, one hour after infusion of 500 mg ASA in 22 healthy controls and I4 IDDM patients.

\begin{tabular}{llll}
\hline & Control & IDDM & P-value \\
\hline$\%$ CBV & -24 & +18 & 0.11 \\
& $(-38-+39)$ & $(+7-+131)$ & \\
\% LDF & -11 & -11 & 0.84 \\
& $(-61-+37)$ & $(-46-+2)$ & \\
$\%$ FBF & +24 & +23 & 0.97 \\
& $(+1-+35)$ & $(-1-+50)$ & \\
\hline
\end{tabular}

$+=$ increase; - = decrease. CBV $=$ capillary blood cell velocity, LDF = laser-Doppler fluxmelty, $\mathrm{FBF}=$ forearm blood flow. Data are represented as median and interquartile ranges. $P$ values are determined with Mann-Whitney U test.

The lack of haemodynamic effects of ASA infusion in the present study could be due to incomplete inhibition of endothelial prostacyclin production. We did not measure plasma prostacyclin levels or its stable end-products because of the many uncertainties concerning these assays and the interpretation of their results. Prostacyclin is produced locally by vascular endothelial cells in very small amounts and it has a very short half life; circulating prostacyclin levels are therefore very low. Due to non-specific interference in the assay (28), measurement of circulating levels of prostacyclin's stable end product $\left(\mathrm{PGF}_{1 \alpha}\right)$ leads to conflicting results $(29,30)$. However, two hours after a single oral dose of $300 \mathrm{mg} \mathrm{ASA}, \mathrm{PGI}_{2}$ production by venous tissue is inhibited completely (18). Although the systemic bioavailability of aspirin is $50 \%$ after a single orall dose (20), prostacyclin production in aortic tissue is still reduced by $75 \%$, more than 10 hours after a single oral dose of $325 \mathrm{mg} \mathrm{ASA}$ (31). Hence, $500 \mathrm{mg}$ ASA infused intravenously (resulting.in a much greater bioavailability (20)) is very likely to inhibit endothelial prostaglandin production (near) completely after one hour. Moreover, the dosage used in the present study inhibited platelet aggregation and plasma $\mathrm{TxB}_{2}$ levels completely, confirming that cyclooxygenase was inhibited by ASA. We therefore consider it unlikely that our findings of no change in haemodynamics after ASA infusion can be explained by incomplete inhibition of endothelial cylooxygenase.

In short-term IDDM patients with good metabolic control, the present study demonstrates an increased forearm (muscle) blood flow, as previously described in moderately well regulated patients (4), and an increased skin thermoregulatory blood flow, as we have already demonstrated (6), as compared to healthy controls; this suggests arteriolar vasodilatation. However, skin nutritive capillary blood flow (CBV) and diameters were unchanged in these patients, suggesting an unchanged 
precapillary resistance. Also in long-term IDDM patients CBV has been reported unchanged (32). Sandeman et al (33), recently demonstrated an increased capillary pressure in short-term IDDM patients, which might be a result of precapillary vasodilation or postcapillary vasoconstriction. Unfortunately, they did not measure CBV, so we can not compare our data with theirs.

Cyclooxygenase inhibition did not decrease the peripheral hyperperfusion in the IDDM patients. The changes in blood flow after ASA infusion were similar in patients and healthy controls. The calculated power of the present study is that, with $\alpha=0.05$ and $B=0.10$, a difference of $11 \%$ in LDF and $25 \%$ in FBF can be detected. The changes in baseline CBV after ASA, however, should be interpreted with caution, due to the small sample sizes and wide variation in data. In short-term diabetes, renal hyperperfusion and hyperfiltration are partly due to elevated prostacyclin production $(13,34,35)$. We demonstrated previously that inhibition of prostaglandin synthesis reduces hyperfiltration (36). In contrast to the hyperperfusion/ filtration in the kidney, peripheral hyperperfusion is not normalized after prostaglandin inhibition. Hence, increased levels of prostacyclin are probably not involved in the observed diabetic peripheral hyperperfusion. Apart from increased prostacyclin levels, several other mechanisms might explain the early diabetic peripheral hyperperfusion, such as a subclinical form of (autonomic) neuropathy $(37,38)$. We did not perform autonomic function tests in the IDDM patients. However, in a previous study (6) we found normal autonomic functions, with increased skin blood flow, in a very similar patient group, and in long-term IDDM patients there was no correlation between hyperperfusion and abnormal autonomic functions. Based on the recent study of Calver et al (39), it seems less likely that increased levels of Endothelium-Derived Relaxing Factor (EDRF) are involved. Possibly, an increased basal metabolism is responsible for the hyperperfusion (particularly in the skin), as it will increase the need for heat dissipation $(40)$.

In conclusion, in short-term IDDM patients with good metabolic control, skin thermoregulatory and forearm muscle blood flow are increased compared with healthy control subjects, while skin nutritive blood flow seems unchanged. Inhibition of cyclooxygenase, by intravenous ASA, does not reduce this peripherall hyperperfusion. Therefore, increased levels of vascular prostacyclin are probably not involved in the diabetic peripheral hyperperfusion. In addition, prostaglandins are not likely to be involved in the local regulation of basal skin, and forearm (mainly muscle) blood flow in healthy subjects.

\section{ACKNOWLEDGMENTS}

This study was supported by grant 91.103 from the Diabetes Fonds Nederland. The authors are indebted to Mr. P. Claessens and Mr. N. Kessels for excellent technical and analytical support. 


\section{RETERENCES}

1. Parving HH, Viberti GC, Keen H, Christiansen IS, Lassen NA. Hemodynamic factors in the genesis of diabetic microamgiopathy. Metabolism 1983;32:943-949.

2. Tooke JE. Microvascular haemodynamics in diabetes mellitus. Clin Sci 1986;70:119-125.

3. Mogensen CE. Glomerular filtration rate and renall plasma flow in short-term and long-term juvenile diabetes mellitus. Scand J Clin Lab Invest 1971;28:91-100.

4. Christensen NJ. A reversible vascular abnormality associated with diabetic ketosis. Clin Sci 1970;39:539-548.

5. Kohner EM, Hamilton AM, Saunders SJ, Sutcliffe BA, Bulpitt CJ. The retinal blood flow in diabetes. Diabetologia 1975;11:27-33.

6. Houben AJHM, Schaper NC, Slaaf DW, Tangelder GJ , Nieuwenhuijzen Kruseman AC. Skin blood cell flux in insulin-dependent subjects in relation to retinopathy or incipient nephropathy. Eur $\mathrm{J}$ Clin Invest $1992 ; 22: 67-72$.

7. Lorenzi $\mathrm{M}$, Cagliero $\mathrm{E}$, Toledo $\mathrm{S}$. Glucose toxicity for human endothelial cells in culture. Delayed replication, disturbed cell cycle, and accelerated death. Diabetes 1985;34:621-627.

8. Bohlen HG, Hankins $\mathrm{KD}$. Early arteriolar and capillary changes in streptozotocin-induced diabetic rats and intraperitoneal hyperglycaemic rats. Diabetologia $1982 ; 22: 344-348$.

9. Wollersheim $\mathbb{H}$, Thien $T$. Hemodynamic effects of prostacyclin infusions in healthy volunteers. Angiology 1988;39:227-233.

10. Colwell JA, Lopes-Virella MF, Winocour PD, Halushka PV. New concepts about the pathogenesis of atherosclerosis in diabetes mellitus. In: The diabetic foot. Levin ME, O'Neal LW (eds). St. Louis: CV Mosby Company, 1988.

11. Chang WP, Dimitriadis E, Allen T, Dunlop ME, Cooper M, Larkins RG. The effect of aldose reductase inhibitors on glomerular prostaglandin production and urinary albumin excretion in experimental diabetes mellitus. Diabetologia 1991;34:225-231.

12. Jeremy JY, Mikhailidis DP, Dandona P. Simulating the diabetic environment modifies in vitro prostacyclin synthesis. Diabetes 1983;32:217-221.

13. Craven PA, DeRubertis FR. Sorbinil suppresses prostaglandin production in the streptozotocin diabetic rat. Metabolism 1989;38:649-654.

14. Slaaf DW, Tangelder GJ, Reneman RS, Jager $\mathbb{K}$, Bollinger A. A versatile incident illuminator for intravital microscopy. Int J Microcirc Clin Exp 1987;6:391-397.

15. Slat DW, Arts T, Jeurens TJM, Tangelder GS, Reneman RS. Electronic measurement of red blood cell velocity and volume flow in microwessels. In: Inwestigative microtechniques in medieine and biology. Vol. 1, Chayen J and Bitensky L (eds.). New York: Marcel Dekker, Inc., 1984.

16. Born GVR. Aggregation of blood platelets by adenosine diphosphate and its reversal. Nature $1962 ; 194 ; 927-929$.

17. Linder L, Kiowski W, Buhler FR, Luscher TF. Indirect evidence for release of endothelium-derived relaxing factor in human forearm circulation in viwo. Blunted response in essential hypertension. Circulation $1990 ; 81 ; 1762-1767$.

18. Preston FE, Whipps $\mathrm{S}$, Jackson CA, French $\mathrm{AJ}$, Wyld PJ, Stoddard CJ. Inhibition of prostacyclin and platelet thromboxane $A_{2}$ after low dose aspirin. New Eng J Med 1981;304:76-79.

19. Neri Serneri GG, Masotti $G$, Gensini GF, Poggesi $L$, Abbate $R$, Mannelli $M$. Prostacyclin and thromboxane $\mathrm{A}_{2}$ formation in response to adrenergic stimulation in humans: a mechanism for local control of vascular response to sympathetic activation? Cardiovase Res 1981;15:287-295.

20. Cerletti $C$, Gambino $M C$, Bucchi $F$, Gaetano $G$. Comparison of the effects of oral versus intravenous aspirin on platelet, vascular, and renal prostanoid generation. In: Adwances in prostaglandin, thromboxane, and leukotriene research. Vol. 17. Samuelsson B, Paolletti R, Ramwell PW (eds.). New York: Raven Press, 1987.

21. Kilbom A, Wennhalm A. Endogenous prostaglandins as local regulators of blood flow in man: effect of indomethacim on reactive and functional hyperaemia. J Physiol 1976;257;109-121. 


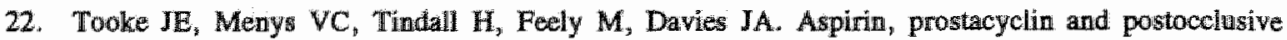
reactive hyperaemia in man. Prost Leukotr Med 1982;9;379-385.

23. Chou $C C$, Alemayehu $A$, Mangino M. Prostanoids in regulation of postprandial hyperemia and oxygen uptake. Am J Physiol 1989;257;G798-G808.

24. Chou SY, Ponsh JG, Faubert PF. Renall medullary circulation: hormonal control. Kidney Int $1990 ; 37 ; 1-13$.

25. Münzel T, Stewart DJ, Holtz J, Bassenge E. Preferential venoconstriction by cyclooxygenase inhibition in vivo without attentuation of nitroglyceria venodilation. Circulation 1988;78;407-415.

26. Houben AJHM, Slaaf DW, Huvers FC, de Leeuw PW, Nieuwenlhuijzen Kruseman AC, Schaper NC. Diumal variations in human total forearm and skin microcirculatory blood flow. (submitted for publication).

27. Panza JA, Epstein SE, Quyyumi AA. Circadian variation in vascular tone and its relation to $\alpha$ sympathetic vasoconstrictor activity. New Eng J Med 1991;325;986-990.

28. Greaves M, Preston FE. 6-keto-prostaglandin $\mathbb{F}_{\text {tos }}$ fact or fiction? Thromb Res 1982;26;145-157.

29. Davis TME, Brown $E$, Finch DR. In vitro prostacyclin production, plasma 6-keto-prostaglandin $F_{1 \text { iph }}$ concentrations and diabetic retinopathy. Br Med J 1981;282:1259-1262.

30. Dollery CT, Friedman LA, Hensby CN, Kohner E, Lewis PJ, Porta M, Webster J. Circulating prostacyclin may be reduced in diabetes. Lancet $1979 ;$ ii; $; 1365$.

31. Weksler BB, Pett SB, Alonso D, Richter RC, Stelzer P, Subramanian V, Tack-Goldman K, Gay WA. Differential inhibition by aspirin of wascular and platelet prostaglandin synthesis in atherosclerotic patients. New Eng J Med 1983;308;800-805.

32. Fagrell B, Hermansson IL, Karlander $\mathrm{SG}_{0}$ Ostergren J. Vital capillary microscopy for assessment of skin viability and microangiopathy in patients with diabetes mellitus. Acta Med Scand 1984;suppl.687; 25-28.

33. Sandeman DD, Shore AC, Tooke JE. Relation of skin capillary pressure in patients with insulindependent diabetes mellitus to complications and metabolic control. New Eng J Med 1992;327;760 764.

34. Fioretto P, Sambataro M, Cipollina MG, Duner E, Giorato C, Morocutti A, Mollo F, Ben GP, Carraro A, Sacerdoti E, Brocco E, Opocher E, Nosadini R. Impaired response to angiotensin II in type I (insulin-dependent) diabetes mellitus. Role of prostaglandins and sodium-lithium countertransport activity. Diabetologia 1991;34:595-603.

35. Gambardella S, Andreani D, Cancelli A, Di Mario U, Cardamone I, Stirati G, Cinotti GA, Pugliese F. Renal hemodynamics and urinary excretion of 6-keto-prostaglandin $F_{t a x}$ and thromboxane $B_{2}$ in newly diagnosed type I diabetic patients. Diabetes 1988;37:1044-1048.

36. van de Berg BW, Nieuwenhuijzen Kruseman AC, van Geel JLC, Cornelissen $P_{9}$, Mulder AW. Effect of short-term inhibition of prostaglandin synthesis on glomerular filtration rate and microalbuminuria in patients with incipient diabetic nephropahty. Neth J Med 1988;33:106-112.

37. Ziegler D, Dannehl K, Muhlen H, Spuler M. Gries FA. Prevalence of cardiowascular autonomic dysfunction assessed by spectral analysis and standard tests of heart-rate variation in mewly diagnosed IDDM patients. Diab Care 1992;15;908-911.

38. Rayman G, Hassan A, Tooke JE. Blood flow in the skin of the foot related to posture in diabetes mellitus. Br Med J 1986;292;87-90.

39. Calver $A$, Collier $J$, Vallance $P$. Inhibition and stimulation of nitric oxide synthesis in the human forearm arterial bed of patients with insulin-dependent diabetes. J Clin Invest 1992;90;2548-2554.

40. Leslie P, Jung RT, Isles TE, Baty L, Newtom RW, Illingworth P. Effect of optimal glycaemic control with continuous subcutaneous insulin infusion on evergy expenditure in type I diabetes mellitus. Br Med J 1986;293;1121-1126. 


\section{ACUTE EFFECTS OF LOCAL \\ HYPERGLYCAEMIA ON PERIPHERAL BLOOD FLOW IN MAN.}

A.J.H.M. Houben, N.C. Schaper, A.C. Nieuwenhuijzen Kruseman.

Published in: Diabetic Medicine 1993;10;39-43. 


\subsection{ABSTRACT}

To determine whether local hyperglycaemia affects peripheral blood flow in man, total forearm and skin microcirculatory blood flow were studied in healthy subjects before, during, and after a one-hour infusion of different concentrations of glucose or mannitol in the brachial artery. Mild or high forearm hyperglycaemia, induced by $5 \%$ glucose infusion ( $\approx 10 \mathrm{mmol} / 1$ and $\approx 18 \mathrm{mmol} / 1$ respectively) did not induce any changes in forearm muscle or skin blood flow. However, mild forearm hyperglycaemia ( $\approx 8 \mathrm{mmol} / \mathrm{l}$ ), induced by $20 \%$ glucose infusion, acutely increased forearm blood flow, decreased forearm vascular resistance, but did not change skin blood flow. 20\% Mannitol infusion, as an osmotic control, did not result in any changes. We conclude that intra-arterial administration of $5 \%$ glucose does not acutely affect peripheral blood flow. The glucose-related effect induced by $20 \%$ glucose infusion, is probably due to marked hyperglycaemia at the catheter tip.

\subsection{INTRODUCTION}

The pathogenesis of microangiopathy in patients with Type 1 diabetes is probably multifactorial. Early haemodynamic changes probably form one of the initiating mechanisms $(1,2)$. In a recent study we demonstrated an increased skin blood flow within the first two years of Type 1 diabetes (3). Several studies suggest that hyperglycaemia may be one of the causes of these early haemodynamic changes. In Type 1 diabetic patients cardiac output and forearm blood flow increase during poor metabolic control (4). In vitro studies suggest a direct "toxic" effect of D-glucose on vascular endothelial cells, which is absent when these cells are incubated in media containing L-glucose (5). Daily intravenous glucose infusions in animals leads to arteriollar vasodilatation (6), and even locally applied glucose results in vasodilatation $(7,8)$ suggesting a direct effect of glucose on the vascular wall resulting in arteriolar vasodilatation (8). At present no in vivo data are available, to our knowledge, of a direct effect of glucose on blood vessels in man.

The present study was undertaken to investigate the acute effects of a one-hour local hyperglycaemia on the total forearm and skin blood flow in healthy volunteers, by infusion of different concentrations of glucose into the brachial artery.

\subsection{SUBJECTS AND METHODS}

Twenty-three healthy volunteers participated in this study. Group I ( $20 \%$ glucose infusion) consisted of 3 females and 4 males with mean age of $22.9 \pm 0.6$ (SEM) years. All the females were studied in the follicular phase of the menstrual cycle. Group II (20\% mannitol infusion) consisted of 7 males with a mean age of $22.1 \pm$ 0.7 years. Group III (5\% glucose infusion) consisted of 7 males with am mean age of $20.9 \pm 0.3$ years. Group IV ( $5 \%$ glucose "HIGH" infusion) consisted of 6 males 
with a mean age of $21.7 \pm 1.1$ years. In four males two infusions were performed. All gave written informed consent and the protocol was approved by the hospital's medical-ethical committee.

Each experiment started at $8.00 \mathrm{a} . \mathrm{m}$. and was performed in a quiet room with constant temperature $\left(23.4 \pm 0.2^{\circ} \mathrm{C}\right.$.). Subjects had fasted overnight and were studied in supine position. Three catheters were inserted: one into the brachial artery in the cubital fossa of the nondominant arm, for infusion of glucose or mannitol, and one into the cubital veins of both arms, for blood sampling. These catheters were kept patent with saline $(\mathrm{NaCl} 0.9 \%)$.

Flow measurements were performed at heart level on the nondominant arm. Forearm blood flow (FBF) was determined by (ECG-triggered) mercury strain gauge venous occlusion plethysmography (Periflow, JSI, Beerse, Belgium). The hand circulation was excluded by inflating a cuff at the wrist to a suprasystolic level, starting one minute before each measurement. FBF was measured during four minutes of which the mean of the last two minutes were used for calculations. A flow curve lasted 5 heartbeats, of which during 3 beats venous occlusion was applied. Therefore, an average of 12 inflow curves per minute were determined. The coefficient of variation $(n=23)$ is $11.7 \%$ comparing the mean $F B F$ value of the third minute with that of the fourth minute.

Skin blood cell flux was assessed two minutes prior to FBF measurements on the ventral side of the forearm using laser-Doppler flowmetry (LDF), with a coefficient of variation $(n=23)$ of $8.1 \%$ comparing the mean LDF value of the first minute with that of the second minute (Periflux PF3, Perimed, Järfälla, Sweden).

Blood pressure and heart rate were measured during the last two minutes of the FBF measurements on the contralateral arm with the Finapres blood pressure monitor (Ohmeda, Englewood, CO, USA). Blood pressure values measured with Finapres correlate very well with blood pressure recordings in the brachial artery in rest (9).

After a period of acclimatization of 30 minutes, flow measurements were performed every 20 minutes until a steady state was reached $(t=-20$ minutes). At $t=0$ baseline measurements were performed and blood samples for blood glucose and serum insulin were drawn. These procedures were repeated every 20 minutes, after starting the intra-arterial infusions for one hour with either glucose or mannitol at $\mathrm{t}=0$ (immediately after the flow measurements), until the end of the experiment $(\mathrm{t}=120)$.

The first series of infusions were performed in random order with $20 \%$ glucose (infusion $\mathrm{I}, \mathrm{n}=7$ ), $20 \%$ mannitol as an osmotic control (infusion $\mathrm{II}, \mathrm{n}=7$ ), or $5 \%$ glucose (infusion III, $\mathrm{n}=7$ ). The rates of infusion were individually calculated using the FBF measurement at $t=-20$ and forearm volume, to raise forearm blood glucose or mannitol levels by about $5 \mathrm{mmol} / \mathrm{l}$. Consequently, infusion rates were higher during infusion III compared to infusion I and II. Additionally, a set of $5 \%$ glucose infusions were performed with rates to raise forearm blood glucose levels about 15 $\mathrm{mmol} / \mathrm{l}$ (infusion IV "HIGH", $\mathrm{n}=6$ ). The total amounts of infused glucose/mannitol were smail and induced no changes in systemic blood glucose or insulin levels (except for infusion IV, see results). As a controll for the infused amount of volume 
saline was administrated with the same infusion rates as the glucose or mannitol infusions from $t=-20$ to $t=0$, and from $t=60$ to $t=120$.

Blood glucose and total insulin were determined by the hexokinase method on the Cobas Bio analyzer (Hoffman Laroche, Basel, Switzerland), and by a commercial radioimmunoassay (Pharmacia, Uppsala, Sweden) respectively.

Data are expressed as mean \pm SEM or median (interquartile range) when the distribution was normal or not normal, respectively. Nonparametric two-way ANOVA test (Friedman, for multiple related samples) was used for statistical analysis within each group or Wilcoxon paired-sign test (for two related samples comparison). Between groups comparisons were made using the Kruskal-Wallis test (for multiple groups comparison).

Table 8.1: Skin blood flux $(L D F)$ at the start $(t=0)$ and after 20, 40,60 minutes of intraanterial glucose or mannitol infusions.

\begin{tabular}{lllll}
\hline & $\mathrm{t}=0$ & $\mathrm{t}=20$ & $\mathrm{t}=40$ & $\mathrm{t}=60$ \\
\hline $\begin{array}{l}\text { INFUSION I: } 20 \% \text { glucose } \\
(\mathrm{n}=7)\end{array}$ & 8.1 & 8.3 & 8.1 & 7.8 \\
INFUSION II: $20 \%$ mannitol & $(6.8-9.5)$ & $(5.9-10.8)$ & $(5.9-11.1)$ & $(6.5-14.6)$ \\
$(\mathrm{n}=7)$ & $(8.3-11.3)$ & 9.4 & 9.4 & 10.0 \\
INFUSION III: $5 \%$ glucose & 11.8 & $12.8-11.2)$ & $(8.0-9.8)$ & $(8.2-10.5)$ \\
$(\mathrm{n}=7)$ & $(10.1-26.4)$ & $(10.4-15.1)$ & 11.5 & 11.6 \\
INFUSION IV: $5 \%$ glucose & 9.3 & 8.3 & 8.1 & $8.13 .6)$ \\
"HIGH" (n=6) & $(5.9-10.7)$ & $(6.5-8.8)$ & $(6.0-9.7)$ & $(6.5-9.4)$ \\
\hline
\end{tabular}

Data are expressed as median and interquartile ranges, $\mathbb{P U}=$ perfusion units.

\subsection{RESULTS}

Infusion of saline at various infusion rates, prior to the glucose or mannitol infusions, did not change total forearm blood flow (FBF), nor any of the other measured parameters (data not shown). At $t=0$ no differences could be observed in FBF, skin blood cell flux (LDF), or mean arterial pressure (MAP) between the four different infusion groups (Kruskal-Wallis $\mathrm{P}=0.13 ; \mathrm{P}=0.09 ; \mathrm{P}=0.34$ respectively) (fig. 8.1 and table 8.1).

Figure 8.1: The effects of intraarterial glucose and mannitol infiusion on forearm blood flow. All infusions started at $t=0$ and lasted 60 minutes. $20 \%$ gitucose induced a local forearm hyperglycaemia of approximately 8 mmol/. $20 \%$ mannitol, as an osmotic control, was infused with similar infusion rates as $20 \%$ glucose. Infusion of $5 \%$ glucose and $5 \%$ glucose "HIGH" (with higher infusion rates) resulted in a local forearm hyperglycaemia of approximately 10 and $18 \mathrm{mmol} / \mathrm{l}$, respectively. Data are expressed as median and interquartile ranges. $P$-values indicate level of significance using Friedman test $t=0, t=20$, $t=40, t=60, t=120$. 

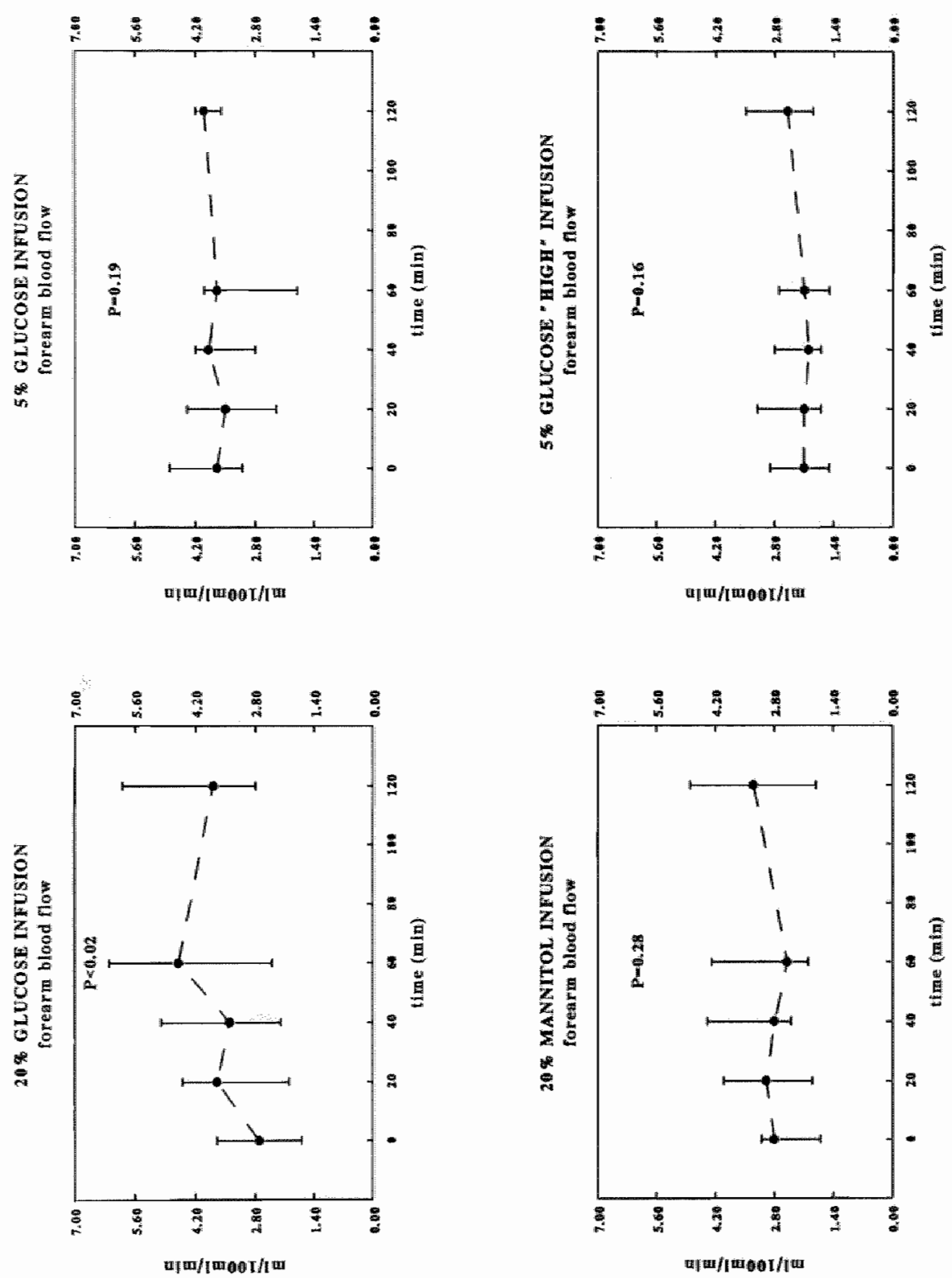
During infusion I (20\% glucose; rate: $13.4 \pm 1.6 \mathrm{ml} / \mathrm{h})$ FBF increased from median 2.7 at $t=0$ to median $4.6 \mathrm{ml} / 100 \mathrm{ml} / \mathrm{min}$ at $\mathrm{t}=60$, and remained increased at $\mathrm{t}=120$ minutes (median $3.8 \mathrm{ml} / 100 \mathrm{ml} / \mathrm{min}$; Friedman $\mathrm{t}=0, \mathrm{t}=20, \mathrm{t}=40, \mathrm{t}=60, \mathrm{t}=120$, $P<0.02$; Wilcoxon $t=0, t=120, P<0.03$ ) (fig. 8.1). An increase in FBF was observed in all 7 subjects. During this infusion callculated forearm vascular resistance (FVR $=$ MAP/FBF) decreased from median 36 at $t=0$ to median 25 $\mathrm{mmHg} / \mathrm{ml} / 100 \mathrm{ml} / \mathrm{min}$ at $\mathrm{t}=60$, and remained decreased at $\mathrm{t}=120$ minutes (median 24 (17-33) $\mathrm{mmH} / \mathrm{ml} / 100 \mathrm{ml} / \mathrm{min}$; Friedman $\mathrm{t}=0, \mathrm{t}=20, \mathrm{t}=40, \mathrm{t}=60, \mathrm{t}=120, \mathrm{P}<0.01$; Wilcoxon $t=0, t 120, P<0.03$ ). In contrast to the changes in $F B F$, no changes in LDF were observed (table 8.1). MAP did not change $(93(88-100)$ at $t=0 ; 92(90$ 104) $\mathrm{mmHg}$ at $\mathrm{t}=60$ ) either. The forearm blood glucose levels reached during the infusions are shown in table 8.2. No changes were observed in systemic glucose levels $(3.7 \pm 0.2$ at $\mathrm{t}=0 ; 3.9 \pm 0.2 \mathrm{mmol} / 1$ at $\mathrm{t}=60)$ or systemic insulin levels $(5.0$ \pm 1.4 at $\mathrm{t}=0 ; 5.4 \pm 1.6 \mathrm{mU} / 1$ at $\mathrm{t}=60$ ).

During infusion II ( $20 \%$ mannitol; rate: $14.3 \pm 2.5 \mathrm{ml} / \mathrm{h})$, no changes were observed in FBF (fig. 8.1), FVR (data not shown), LDF (table 8.1), or MAP (82 (73$87)$ at $t=0 ; 85(79-95) \mathrm{mmHg}$ at $t=60)$. As aspected, blood glucose levels in the infusion arm (table 2) and systemic blood glucose levels did not change.

During infusion III ( $5 \%$ glucose; rate: $70.4 \pm 9.6 \mathrm{ml} / \mathrm{h})$, no changes were observed in FBF (fig. 8.1), FVR (data not shown), LDF (table 8.1), or MAP (88 (73116) at $\mathrm{t}=0 ; 93(87-111) \mathrm{mmHg}$ at $\mathrm{t}=60$ ). Forearm blood glucose levels rose to approximately $10 \mathrm{mmol} / \mathbb{1}$ (table 8.2 ). Systemic glucose levels $(4.4 \pm 0.4$ at $\mathrm{t}=0 ; 4.5$ $\pm 0.6 \mathrm{mmol} / 1$ at $\mathrm{t}=60)$ and systemic insulin levels $(6.6 \pm 0.5$ at $\mathrm{t}=0 ; 6.8 \pm 0.5$ $\mathrm{mU} / \mathrm{l}$ at $\mathrm{t}=60$ ) did not change during this infusion.

During infusion IV ( $5 \%$ glucose "HIGH"; rate: $142 \pm 23 \mathrm{ml} / \mathrm{h}$ ) again no changes were observed in FBF (fig. 8.1), FVR (data not shown), LDF (table 8.1), or MAP $(87(85-95)$ at $\mathrm{t}=0 ; 88(80-95) \mathrm{mmHg}$ at $\mathrm{t}=60)$. During this infusion forearm blood glucose levels rose to approximately $18 \mathrm{mmol} / 1$ (table 8.2 ). Systemic blood glucose levels showed a statistically significant increase $(\mathrm{t}=0: 3.8 \pm 0.1 ; \mathrm{t}=20: 4.2 \pm 0.1$; $\mathrm{t}=40: 4.3 \pm 0.1 ; \mathrm{t}=60: 4.5 \pm 0.2 \mathrm{mmol} / \mathrm{l} ; \mathrm{P}<0.02$, Friedman $\mathrm{t}=0, \mathrm{t}=20, \mathrm{t}=40$, $\mathrm{t}=60)$. Systemic insulin levels did not change $(5.3 \pm 0.4$ at $\mathrm{t}=0 ; 6.9 \pm 0.6 \mathrm{mU} / \mathrm{l}$ at $t=60$ ). Heart rate (data not shown) did not change during any of the experiments.

Both infusion I ( $20 \%$ glucose) and III ( $5 \%$ glucose) were calculated to raise forearm blood glucose levels by about $5 \mathrm{mmol} / \mathrm{l}$. The actual levels of forearm blood glucose measured in the venous effluent was lower during infusion I compared with infusion III, probably because FBF increased during infusion I and not during infusion III. 


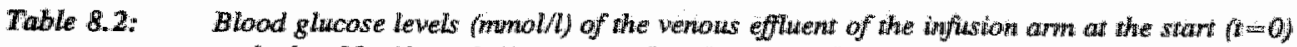
and after 20,40 , and 60 minutes of intraarterial glucose or manuitol imfiusions.

\begin{tabular}{lllll}
\hline & $t=0$ & $t=20$ & $t=40$ & $t=60$ \\
\hline $\begin{array}{l}\text { INFUSION I: } 20 \% \text { glucose } \\
(\mathrm{n}=7)\end{array}$ & $4.1 \pm 0.4$ & $7.0 \pm 1.2$ & $7.4 \pm 1.4$ & $7.6 \pm 2.5 \quad \mathrm{a}$ \\
$\begin{array}{l}\text { INFUSION II: } 20 \% \text { mannitol } \\
(\mathrm{n}=7)\end{array}$ & $3.8 \pm 0.2$ & $3.9 \pm 0.3$ & $3.8 \pm 0.2$ & $3.8 \pm 0.2$ \\
$\begin{array}{l}\text { INFUSION III: 5\% glucose } \\
(\mathrm{n}=7)\end{array}$ & $4.0 \pm 0.2$ & $10.4 \pm 1.4$ & $9.0 \pm 0.7$ & $10.9 \pm 1.5 \mathrm{~b}$ \\
$\begin{array}{l}\text { INFUSION IV: 5\% glucose } \\
\text { "HIGH" }(\mathrm{n}=6)\end{array}$ & $3.6 \pm 0.1$ & $15.8 \pm 2.7$ & $18.4 \pm 3.7$ & $17.9 \pm 2.9 \mathrm{c}$ \\
\hline
\end{tabular}

Data are expressed as mean \pm SEM. a: $\mathrm{P}<0.05 ;$ b: $\mathrm{P}<0.02 ; \mathrm{c}: \mathrm{P}<0.01$; Friedman test: $t=0, t=20, t=40, t=60$.

\subsection{DISCUSSION}

In the present study the effects of local hyperglycaemia on peripheral blood flow were determined. Mild $(\approx 10 \mathrm{mmol} / \mathrm{l})$ or even high $(\approx 18 \mathrm{mmol} / \mathrm{l})$ forearm hyperglycaemia induced by infusion of $5 \%$ glucose into the brachial artery, did not acutely induce any changes in forearm muscle or skin blood flow. It has been suggested that increased peripheral blood flow in Type 1 diabetic patients is related to hyperglycaemia (4). However, conflicting data have been reported on the effects of systemic hyperglycaemia on peripheral blood flow in non-diabetic men. Both an increase and no change of forearm or leg blood flow have been reported $(10,11)$. The latter studies are difficult to compare with the present study as secondary (hormonal) changes occur during systemic hyperglycaemia, which could influence peripheral blood flow. The present study evaluates the effects of local hyperglycaemia in the isolated forearm on peripheral blood flow, without changes in systemic blood glucose (except for infusion IV) or systemic insulin levels. Possibly, the blood vessels in the eye or kidney are more susceptible for local effects of hyperglycaemia than blood vessels of the forearm. However, increased forearm muscle $(4,12)$ and skin blood flow (3) has been demonstrated in Type I diabetic patients, shortly after the onset of diabetes, which seems to be related to the level of metabolic control $(4,12)$. In the present study moderate and high levels of local hyperglycaemia were induced. Higher blood glucose levels ( $>20 \mathrm{mmol} / \mathrm{l}$ ) could possibly acutely affect peripheral blood flow. Such high levels, however, are not relevant for the average diabetic patient. Several mechanisms, like the polyol pathway (8), non-enzymatic glycosylation (13), or synthesis of diacylglycerol and protein kinase C activation (14), may be responsible for hyperglycaemia-induced haemodynamic changes. According to the present results, the time needed to induce these changes will be longer than one 
hour. Therefore, a possible effect of long-term moderate local hyperglycaemia on peripheral blood flow is not excluded by the present data.

In contrast to the $5 \%$ glucose infusions, total forearm blood flow (FBF) increased acutely during infusion of $20 \%$ glucose resulting in a mild local hyperglycaemia $(\approx$ $8 \mathrm{mmol} / \mathrm{l}$ ), and remained increased one hour after the end of the infusion. The $20 \%$ glucose infusions did not induce any changes in systemic blood glucose or insulin levels. Forearm vascular resistance (FVR) decreased during this infusion. Skin blood flow (LDF) did not change. Hence, this increased FBF probably represents predominantly increased muscle flow. As intra-arterial infusion of $20 \%$ mannitol did not change FBF or FVR, it is not likely that the observed vasodilatation is due to blood hyperosmolarity. The only differences between the $5 \%$ glucose and $20 \%$ glucose infusions were i) a lower infusion rate during $20 \%$ glucose infusion, and ii) different glucose concentrations at the catheter tip. Similar infusion rates during saline or $20 \%$ mannitol did not induce any changes in FBF or FVR. Therefore, the observed differences in FBF and FVR are possibly related to the higher glucose concentration at the catheter tip during the $20 \%$ glucose infusion relative to the $5 \%$ glucose infusion. The calculated glucose concentration of a $20 \%$ glucose solution is approximately $1100 \mathrm{mmol} / 1$, and that of a $5 \%$ glucose solution is approximately $280 \mathrm{mmol} / 1$. Possibly, the marked hyperglycaemia at the catheter tip during $20 \%$ glucose administration acutely affected surrounding endothelial cells and/or smooth muscle cells of the artery, resulting in a vasodilation.

In conclusion, local forearm hyperglycaemia induced by $5 \%$ glucose does not acutely change forearm or skin blood flow. However, intra-arterial administration of $20 \%$ glucose, resulting in similar local hyperglycaemia, acutely increased forearm blood flow, but not skin microcirculatory blood flow, possibly due to the very high local arterial glucose concentrations.

\section{ACENOWLEDGMANTS}

The authors would like to thank Mr. F. Jungbauer for excellent experimental assistance and Mr. P. Claessens for excellent technical assistance.

\section{REFERENCES}

1. Tooke JE. Microvascullar haemodynamics in diabetes mellitus. Clin Sci 1986;70:119-125.

2. Zatz R, Brenner BM. Pathogenesis of diabetic microangiopathy. The hemodynamic view. Am J Med 1986;80:443-453.

3. Houben AJHM, Schaper NC, Slaaf DW, Tangelder GJ, Nieuwenhuijzen Kruseman AC. Skin blood cell flux in insulin-dependent diabetic subjects in relation to retinopathy or incipient nephropahty. Eur J Clin Invest 1992; 22:67-72.

4. Mathiesen ER, Hilsted J, Feldt-Rasmussen B, Bonde-Petersen F, Christensen NJ, Parving H-H. The effect of metabolic control on hemodynamics in short-term insulin-dependent diabetic patients. Diabetes 1985;34:1301-1305. 
5. Lorenzi $M$, Cagliero $E_{y}$ Toledo $S$. Glucose toxicity for human endothelial cells in cultures. Delayed replication, disturbed cell cycle, and accelerated death. Diabetes 1985; 34:621-627.

6. Bohlen $\mathrm{HG}$, Hankins $\mathrm{KD}$. Early arteriolar and capillary changes in streptozotocin-induced diabetie rats and intraperitoneal hyperglycaemic rats. Diabetologia 1982; 22:344-348.

7. Woods LL, Mizelle HL, Hall JE. Control of renal hemodynamics in hyperglycemia: possible role of tubuloglomerular feedback. Am J Physiol 1987; 252:F65-F73.

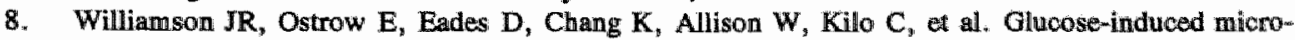
vascular functional changes in nondiabetic rats are stereospecific and are prevented by an aldose reductase inhibitor. I Clin Invest 1990; 85:1167-1172.

9. Imholx BPM, van Montfrans GA, Settels JJ, van der Hoeven GMA, Karemaker JM, Wieling W. Continuous noninvasive blood pressure monitoring; reliability of Finapres device during the Valisalva manoeuvre. Cardiovase Res $1988 ; 22: 390-397$.

10. Bülow J, Astrup A, Christensen NJ, Kastrup J. Blood flow in skin, subcutaneous adipose tissue and skeletal muscle in the forearm of normal man during an oral glucose load. Acta Physiol Scand $1987 ; 130: 657-661$.

11. Laakso M, Edelman SV, Olefsky JM, Brechtell G, Wallace P, Baron AD. Kinetics of in vivo muscle insulin-mediated glucose uptake in human obesity. Diabetes 1990; 39:965-974.

12. Gundersen HUG. Peripheral blood flow and metabolic control in juvenile diabetes. Diabetologia 1974;10:225-231.

13. Brownlee M, Cerami A, Vlassara H. Advanced glycosylation end products in tissue and the biochemical basis of diabetic complications. New Eng J Med 1988;318:1315-1321.

14. Larkins RG, Dunlop ME. The link between hyperglycaemia and diabetic nephropathy. Diabetologia $1992 ; 35: 499-504$. 


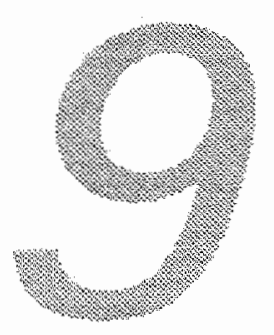

\section{THE EFFECTS OF 7-HOUR LOCAL} HYPERGLYCEMIA ON FOREARM MACRO AND MICROCIRCULATORY BLOOD FLOW AND VASCULAR REACTIVITY IN HEALTHY MAN.

A.J.H.M. Houben, N.C. Schaper, C.H.A. de Haan, F.C. Huvers, D.W. Slaaf, P.W. de Leeuw, A.C. Nieuwenhuijzen Kruseman.

Submitted for publication. 


\subsection{ABSTRACT}

Animal studies suggest that hyperglycaemia directly affects local blood flow and vascular reactivity. We studied the effects of local forearm hyperglycaemia, for 7 hours, on forearm (muscle) and skin microcirculatory blood flow in 12 healthy men. Furthermore, the effects of this local hyperglycaemia on forearm vasoreactivity to noradrenaline were studied. Using the perfused forearm technique, a local hyperglycaemia of approximately $16 \mathrm{mmol} / 1$ was induced by continuous intraarterial infusion of $5 \%$ glucose, without inducing major systemic metabolic changes. All subjects received both glucose and placebo $(0.9 \% \mathrm{NaCl}$ ) infusions (on two different occasions), in random order and single blind. Forearm (muscle) blood flow (FBF) and vascular reactivity to noradrenaline were measured using venous occlusion plethysmography. Skin microcirculatory blood flow was evaluated using intravital capillary microscopy (CBV; nutritive flow) and laser-Doppler fluxmetry (LDF; thermoregulatory flow). Measurements were performed at baseline and after 4 and 7 hours of intraarterial glucose or placebo infusion. The (diurnal) changes in FBF and LDF ratio (infused:contralateral arm), as well as the change in CBV were not different between glucose and placebo experiments. Noradrenaline produced similar reductions in FBF ratio during glucose and placebo experiments. We conclude that in contrast to animal studies, local hyperglycaemia $(\approx 16 \mathrm{mmol} / \mathrm{l})$ for 7 hours does not affect forearm macro and microcirculatory blood flow or vascular reactivity to noradrenaline in man.

\subsection{INTRODUCTION}

One of the main causes of morbidity and mortality in patients with insulin-dependent diabetes mellitus (IDDM) is microangiopathy. Early haemodynamic changes are probably an important initiating mechanism in the development of this microangiopathy $(1,2)$. Already shortly after the onset of IDDM haemodynamic changes can be observed in several organs and tissues, as was demonstrated recently for forearm muscle $(3,4)$ and skin $(4,5)$. In addition, cardiac output $(6)$, blood flow to the kidneys $(7)$ and retina (8), and skin capillary pressures (9) have been found to be increased in early IDDM. Most of these parameters normalize parallel to normalization of metabolic control, which suggests that hyperglycaemia plays an important role in the development of these haemodynamic changes. Indeed, local injection or application of glucose in healthy animals results in arteriolar vasodilation (10), increased blood flow $(11,12)$, and disturbed autoregulation (12). Some of these effects are already observed a few hours after induction of local hyperglycaemia.

Besides changes in endothelium (in)dependent vasodilation $(3,10)$, diabetes induces changes in vasoconstrictor reactivity. Both in vitro and in vivo animal studies have shown an increased sensitivity and reactivity to noradrenaline $(13,14)$. In IDDM patients an increased reactivity to noradrenaline was demonstrated as well $(15,16)$. 
We demonstrated recently, that a one hour local (forearm) moderate hyperglycaemia did not change forearm (muscle) blood flow (FBF) (17). Only unphysiologically high local glucose concentrations resulted in an increase in FBF. These findings in combination with those of aforementioned animal studies suggest that several hours of local hyperglycaemia are required to induce haemodynanic changes. The present study was undertaken to determine the effects of a 7-hour local (forearm) hyperglycaemia, induced by intraarterial infusion of glucose, on basal forearm blood flow, and on skin thermoregulatory and nutritive microcirculatory blood flow in healthy men. Furthermore, the effects of this local hyperglycaemia on forearm vasoreactivity to noradrenaline, a physiological endogenous vasoconstrictior, was evaluated. LDF and FBF were measured in both arms to compare the infused arm with the contralateral (control) arm, as forearm blood flow increases and skin microcirculatory blood flow decreases during the day $(18,19)$. To correct for possible systemic effects of local glucose infusion and possible diumal variations in vasoconstrictor response to noradrenaline, the experiments were placebo controlled.

\subsection{SUBJECTS AND METHODS}

Experiments were performed in 12 healthy male volunteers (recruited from a student population), with a mean age of $23.6 \pm 3.1$ (SD) years and a body mass index of $23.0 \pm 3.1$ (SD) $\mathrm{kg} / \mathrm{m}^{2}$. The number of subjects was based on earlier studies $(17,18)$. Forearm volume was measured by water displacement. Mean forearm volume (from elbow to wrist) of the nondominant arm was $1226 \pm 225$ (SD) $\mathrm{ml}$, and volume of the dominant arm was $1304 \pm 226 \mathrm{ml}$. Three subjects were smokers (their results were similar to the nonsmoker's results). All participants gave written informed consent and the study was approved by the hospital's medical-ethical committee.

\section{Protocol}

The subjects received both glucose and placebo infusions, in random order and single-blind, with an interval of two to three weeks. All experiments started at 8.00 a.m. and were performed in a quiet, temperature controlled room (mean temperature $24.9 \pm 0.2$ (SD) ${ }^{\circ} \mathrm{C}$.). Precautions were taken to minimize external disturbances. Subjects were studied in supine position. They remained in bed during the experiment. Between the measurements they were allowed to sit upright (by raising the bed's head to the vertical position), but 15 minutes before each measurement they were placed supine again. Subjects were not allowed to smoke, eat, or drink (except for water) from 22.00 hours the night before the experiment till the end of the experiment. At $8.30 \mathrm{~h}$ three catheters were inserted: a 20 -gauge catheter into the brachial artery (retrogradely) in the cubital fossa of the nondominant arm, for infusion of glucose/placebo and noradrenaline, and in both arms a catheter into the antecubital vein (anterogradely), for blood sampling. Venous blood from the infused arm was drawn to determine local glucose levels (at $10.15 \mathrm{am}$, and every 30 minutes after the 
start of the glucose infusion; during the placebo experiments at 10.15, 12.30, 14.30, and $17.30 \mathrm{~h}_{*}$ ), pyruvate and lactate levels (at $10.15,14.30$ and $17.30 \mathrm{~h}$ ), and adrenaline and noradrenaline levels (at 10.15 and $17.30 \mathrm{~h}$.). Insulin, C-peptide (at 10.15 , $12.30,14.30$, and 17.30 h.), and "systemic" blood glucose levels (at the same moments as local glucose levels) were determined in venous blood from the contrallaterall arm. The catheters were kept patent with saline $(\mathrm{NaCl} 0.9 \%)$.

Baseline measurements of (micro)circulatory blood flow started at 10.15 a.m., and were performed in the following order: CBV (measured in nailfold capillaries of the fourth finger of the infused arm), LDF (measured on the dorsum of the fourth finger of both hands), FBF (measured on both arms). FBF was measured before and during 3 cumulative doses of noradrenaline (Centrafarm, Etten-Leur, The Netherlands): $0.025,0.1$, and $0.4 \mu \mathrm{g} / \mathrm{min}$. Each dose was infused for 3 minutes (the doses and duration of infusion were based on a pilot study, unpublished data). After these measurements $(10.30 \mathrm{a} . \mathrm{m}$.) the intraarterial infusion of $5 \%$ glucose or placebo $(0.9 \% \mathrm{NaCl})$ started. The rates of infusion were individually calculated using the basal FBF measurement and forearm volume, to raise forearm blood glucose levels by about $12 \mathrm{mmol} / \mathrm{l}$. The same calculations for infusion rate were used for placebo infusion. The mean infusion rate was $126 \pm 48$ (SD) $\mathrm{ml} / \mathrm{h}$. At $14.30 \mathrm{~h}$ (after 4 hours) and at $17.30 \mathrm{~h}$ (after 7 hours of local forearm hyperglycaemia), another set of haemodynamic measurements was performed.

\section{Methods}

Capillary blood cell velocity (CBV; representing skin nutritive blood flow) was monitored using epi-POL videomicroscopy (20), with a Leitz L $20 x$ lens (numeric aperture: 0.32). Images of 2 capillaries in the distal row of the fourth finger nailfold of the infused arm were recorded during two minutes. The images were videotaped for off-line analysis. The same two capillaries were studied during each subsequent measurement. Mean CBV of the two capillaries was used for calculations (with a coefficient of variation (CV) of $19 \%$ comparing the CBV of the first minute with that of the second), which was evaluated off-line using the temporal correlation technique (21) incorporated in CAPIFLOW software (SIM, Kista, Sweden). Capillary diameter was measured as the width of the red blood cell column in the arteriolar and venular limb. In 5 subjects image quality was not sufficient to determine CBV at all time points throughout both experiments. CBV was not studied in the contralateral arm, due to immobility of the equipment.

Thermoregulatory skin perfusion was determined using laser-Doppler fluxmetry (LDF; Periflux PF3, Perimed, Järfalla, Sweden), with two probes PF 308, wide band $(12 \mathrm{Khz})$ mode, and time constant $0.2 \mathrm{~s}$. The probes were placed on the dorsum of the interphalanx of the fourth finger of both hands. These probes remained in the same position throughout the experiment. The mean value of two minutes recording was used for calculations (with a CV of $8 \%$ comparing mean LDF of the first with that of the second minute). Flux values are expressed as arbitrary Perfusion Units (PU), calibrated against an external standard. Biological zero values, obtained 
during arterial occlusion, were subtracted from the measured LDF levels (22). Mean biological zero value (pooled for all measurements) was $4.5 \pm 1.7$ PU. Skin temperature was measured at the same site (infused arm) using a Hewlett Packard 78214C monitor (HP, Böblingen, Germany).

Forearm blood flow (FBF) was determined in both arms simultaneously using ECG-triggered strain gauge venous occlusion plethysmography (23) (Periflow, ISI, Beerse, Belgium). The hand circulation was excluded during the FBF measurement by inflating a wrist cuff to suprasystolic pressure, starting one minute before each FBF measurement. Hence, FBF measurements represent predominantly muscle blood flow (24). FBF was measured during eleven minutes: two minutes of baseline FBF and during 3 doses of noradrenaline infusion (each dose for 3 minutes). The mean value of the last minute of each period was used for calculations. The CV of baseline FBF measurement is $12 \%$ (comparing the mean FBF of the first with that of the second minute). The $\mathrm{CV}$ of repeated measures of the vasoconstrictor response to the highest dose of noradrenaline $(0.4 \mu \mathrm{g} / \mathrm{min})$ during the day is $13 \%$. A flow curve lasted 5 heartbeats, with venous occlusion $(50 \mathrm{mmHg})$ applied during three beats. Therefore, on the average 12 inflow curves per minute were determined.

Blood pressure was measured intraarterially using a Hewlett Packard $78205 \mathrm{C}$ monitor (HP, Böblingen, Germany). Heart rate was recorded from the ECG.

Blood glucose was determined by the glucoseoxidase method on the ESAT 6660 analyzer (Eppendorf, Hamburg, Germany). Total insulin and C-peptide were determined by a commercial radioimmunoassay (Pharmacia, Uppsala, Sweden, and BykSangtec, Dietzenbach, Germany, respectively). Lactate was determined by the lactateoxidase method, and pyruvate by the lactic dehydrogenase method. Both plasma adrenaline and noradrenaline were determined by HPLC according to the method of Van der Hoorn (25).

\section{Statistics and calculations}

All data are presented as median values with interquartile ranges unless otherwise indicated. For each measurement period the ratio for LDF and FBF was calculated (infused arm divided by the contralateral arm). This calculated ratio corrects for all systemic factors that affect the regulation of blood flow in both arms (e.g. changes in blood pressure, level of arousal, hormonal changes etc.), and ensures that only the direct effects of locally infused substances on forearm blood flow are taken into account (26). In a earlier study on diumal variations of forearm macro and microcirculation, the FBF ratio was demonstrated to be stable during the day (18). The experiments were placebo controlled to correct for possible glucose-induced systemic effects, which would affect blood flow in both arms. 
Table 9.1: Mean blood gilucose, insulin, C-peptide, pyruvate, and lactate levels during the glucose and placebo experiments.

\begin{tabular}{|c|c|c|c|c|c|}
\hline & $10.15 \mathrm{~h}$ & $12.30 \mathrm{~h}$ & $14.30 \mathrm{~h}$ & $17.30 \mathrm{~h}$ & P-lewel \\
\hline \multicolumn{6}{|l|}{ PLACEBO } \\
\hline Glucose (1) mmol/l & $4.3 \pm 0.4$ & $4.2 \pm 0.5$ & $4.1 \pm 0.4$ & $4.1 \pm 0.4$ & 0.14 \\
\hline Insulin (cl) mU/1 & $4.4 \pm 1.2$ & $3.9 \pm 1.3$ & $3.7 \pm 1.0$ & $3.3 \pm 0.6$ & 0.016 \\
\hline $\begin{array}{l}\text { C-peptide (cl) } \\
\text { numol/I }\end{array}$ & $0.38 \pm 0.12$ & $0.35 \pm 0.11$ & $0.29 \pm 0.06$ & $0.25 \pm 0.08$ & 0.0001 \\
\hline Pyruvate (i) $\mu \mathrm{mol} / \mathrm{l}$ & $70 \pm 23$ & $\cdots$ & $60 \pm 13$ & $57 \pm 15$ & 0.33 \\
\hline Lactate (i) mmol/l & $0.62 \pm 0.25$ & --- & $0.56 \pm 0.12$ & $0.60 \pm 0.16$ & 0.65 \\
\hline \multicolumn{6}{|l|}{ GLUCOSE } \\
\hline Glucose (cl) $\mathrm{mmol} / \mathrm{l}$ & $4.6 \pm 0.4$ & $5.3 \pm 0.7 *$ & $4.7 \pm 0.6$ & $5.0 \pm 0.6 *$ & 0.009 \\
\hline Insulin (cl) mU/1 & $4.3 \pm 1.2$ & $7.7 \pm 2.7 *$ & $5.4 \pm 1.2 *$ & $6.2 \pm 2.0$ & 0.23 \\
\hline $\begin{array}{l}\text { C-peptide (cl) } \\
\text { nmol/ll }\end{array}$ & $0.44 \pm 0.14$ & $0.80 \pm 0.16 *$ & $0.56 \pm 0.12 *$ & $0.65 \pm 0.12 *$ & 0.003 \\
\hline Pyruvate (i) $\mu \mathrm{mol} / 1$ & $74 \pm 23$ & -..-- & $71 \pm 12 *$ & $67 \pm 14$ & 0.15 \\
\hline Lactate (i) mmol/l & $0.64 \pm 0.25$ & $\ldots$ & $0.58 \pm 0.17$ & $0.59 \pm 0.14$ & 0.92 \\
\hline
\end{tabular}

The blood glucose levels (cl) during the glucose infusion are a summary of the data presented in figure 9.1. $\mathrm{i}=$ infused arm; $\mathrm{cl}=$ contralateral arm. P-level from Friedman test comparing the repeated measurements during the day. * indicates significant difference compared with placebo values (Wilcoxon; $\mathrm{P}<0.05$ with Bonferroni). Data represented as mean $\pm \mathrm{SD}$.

The effects of local glucose infusion on CBV, LDF ratio, and FBF ratio were compared with the effects of local placebo $(\mathrm{NaCl} 0.9 \%)$ infusion after 4 and 7 hours. For each dose of noradrenaline the percentage change in FBF ratio (relative to preinfusion values) was calculated at baseline $(10.15 \mathrm{a} . \mathrm{m}$.$) , after 4-(14.30 \mathrm{~h}$.$) , and after$ 7-hour glucose/placebo infusion $(17.30 \mathrm{~h}$.) using the formula:

$$
\left(\frac{\left(F B F_{(0)(n a)} \times F B F_{(c)(s a)}\right)}{\left(F B F_{(c)(n a)} \times F B F_{(i)(s a l)}\right)}-1\right) \times 100
$$

(i) = infused $\operatorname{arm} ;(\mathrm{c})=$ contralateral $\mathrm{arm} ;(\mathrm{na})=$ during noradrenaline infusion and (sal) $=$ during saline infusion into the infused arm. 
The percentage change in FBF ratio for each dose of noradrenaline, before and during the glucose infusion was compared with those of the placebo experiments.

As the distribution of the CBV, LDF, and FBF data was not normal, the Friedman test (nonparametric two-way ANOVA) was used for analysis of multiple related samples and Wilcoxon paired sign test for paired analysis. When appropriate, the Bonferroni correction was used for multiple comparisons. $P$ values below 0.05 were considered statistically significant.

\subsection{RESULTS}

\section{Metabolic effects}

At baseline (10.15 a.m.) no differences were found in "systemic" glucose, insulin, and C-peptide levels between the glucose and placebo experiments, while during 7 hours local glucose infusion these levels were significantly higher as compared to the placebo experiments (table 9.1). During the intraarterial infusion of glucose in the nondominant arm, forearm venous blood glucose levels increased to a level of approximately $16 \mathrm{mmol} / 1$ (figure 9.1 ). Venous blood glucose levels in the contralateral arm ("systemic" glucose levels) showed a small increase during the local glucose infusions $(\mathrm{P}<0.01)$, but did not reach a hyperglycaemic level (fig. $9.1 ;$ table 9.1 ). As shown in table 9.1, C-peptide levels also showed a small but statistically significant increase during the local glucose infusion. Probably, as a result of insulin extraction by the liver we did not measure a significant increase in insulin levels during local glucose infusions. In contrast, during the placebo $(\mathrm{NaCl} 0.9 \%)$ infusions insulin, and C-peptide levels showed a small decrease during the day, whereas blood glucose did not change (table 9.1). In both glucose and placebo experiments no changes were observed in lactate and pyruvate levels (table 9.1).

\section{Baseline haemodynamics}

Baseline values of central and forearm haemodynamics are summarized in table 9.2 and figs 9.2, 9.3, and 9.4. No differences were observed in baseline values before the start of glucose or placebo infusions. Plasma levels of both adrenaline (glucose: 120 (90-185); placebo: $140(70-150) \mathrm{pmol} / \mathrm{l})$ and noradrenaline (glucose: 0.55 (0.45-0.89); placebo: $0.56(0.43-0.78) \mathrm{nmol} / \mathrm{l})$ were not different at baseline. Also no differences in skin temperature or the baseline width of the erythrocyte columns (representing the capillary diameter) could be observed between the glucose or placebo experiments (data not shown). The percentage change in FBF ratio during the three cumulative doses noradrenaline were similar before the start of glucose or placebo infusion (fig. 9.5), also when they were expressed as percentage change in FVR ratio (data not shown; Forearm Vascular Resistance (FVR) $=$ MAP/FBF). 


\section{BLOOD GLUCOSE LEVELS}

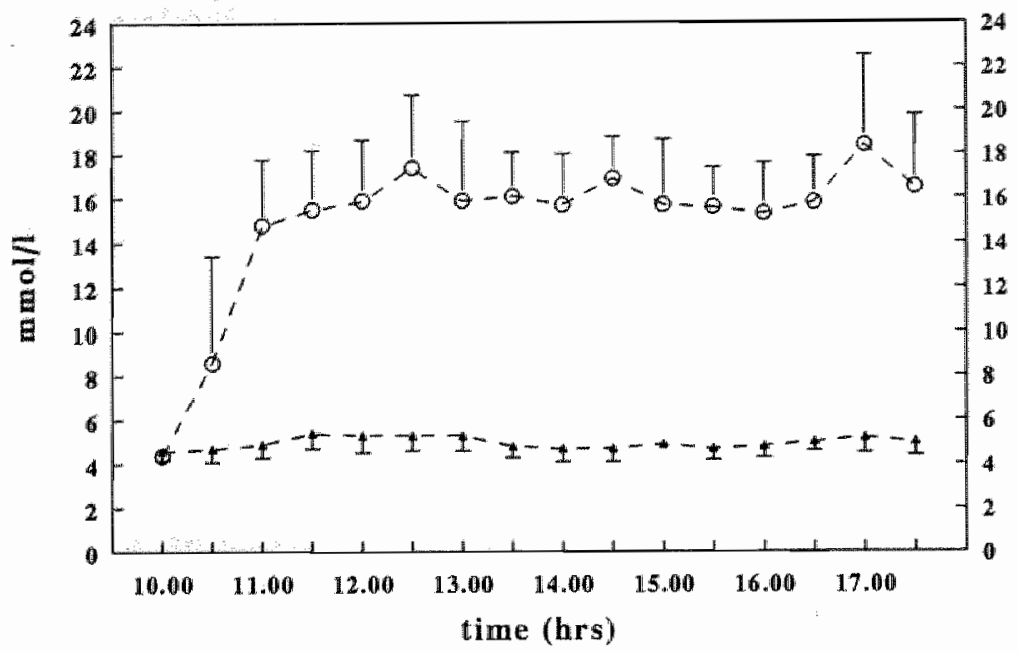

Figure 9.1: Mean venous blood glucose levels of the infused arm (o) and the contralateral arm (A ; representing the "systemic" blood glucose levels) during the intraarterial infusion of glucose. During the local infusion of glucose, the systemic blood glucose levels showed a small increase $(P<0,001$, Friedman). Data represented as mean $\pm S D$.

Haemodynamic effects of local hyperglycaemia

Blood pressure (MAP) increased during the glucose experiments (median change: 3 (1-6) $\mathrm{mmHg}$ after 7 hours, (Friedman; $\mathbb{P}<0.05$ )), whereas no statistically significant changes in MAP were observed during placebo experiments (median change: -1 ( -2 +1) $\mathrm{mmHg}$ (Friedman;NS)). Comparing the change in MAP during glucose and placebo resulted in $\mathrm{P}=0.01$ (Wilcoxon). Plasma adrenaline and noradrenaline levels were not changed after $7 \mathrm{~h}$. glucose or placebo infusions (ADRENALINE: glucose: 105 (72-192); placebo: 120 (100-190) pmol/1; and NORADRENALINE: glucose: $0.58(0.45-0.71)$; placebo: $0.48(0.44-0.71) \mathrm{nmol} / \mathrm{l})$. Also heart rate did not change during glucose or placebo experiments, except after 4 hours of infusion there was a difference in heart rate between glucose and placebo (table 9.2). The effects of the 7-hour local hyperglycaemia on forearm macro and microcirculation are depicted in figures $9.2,9.3$ and 9.4 , and table 9.2. 
FOREARM BLOOD FLOW
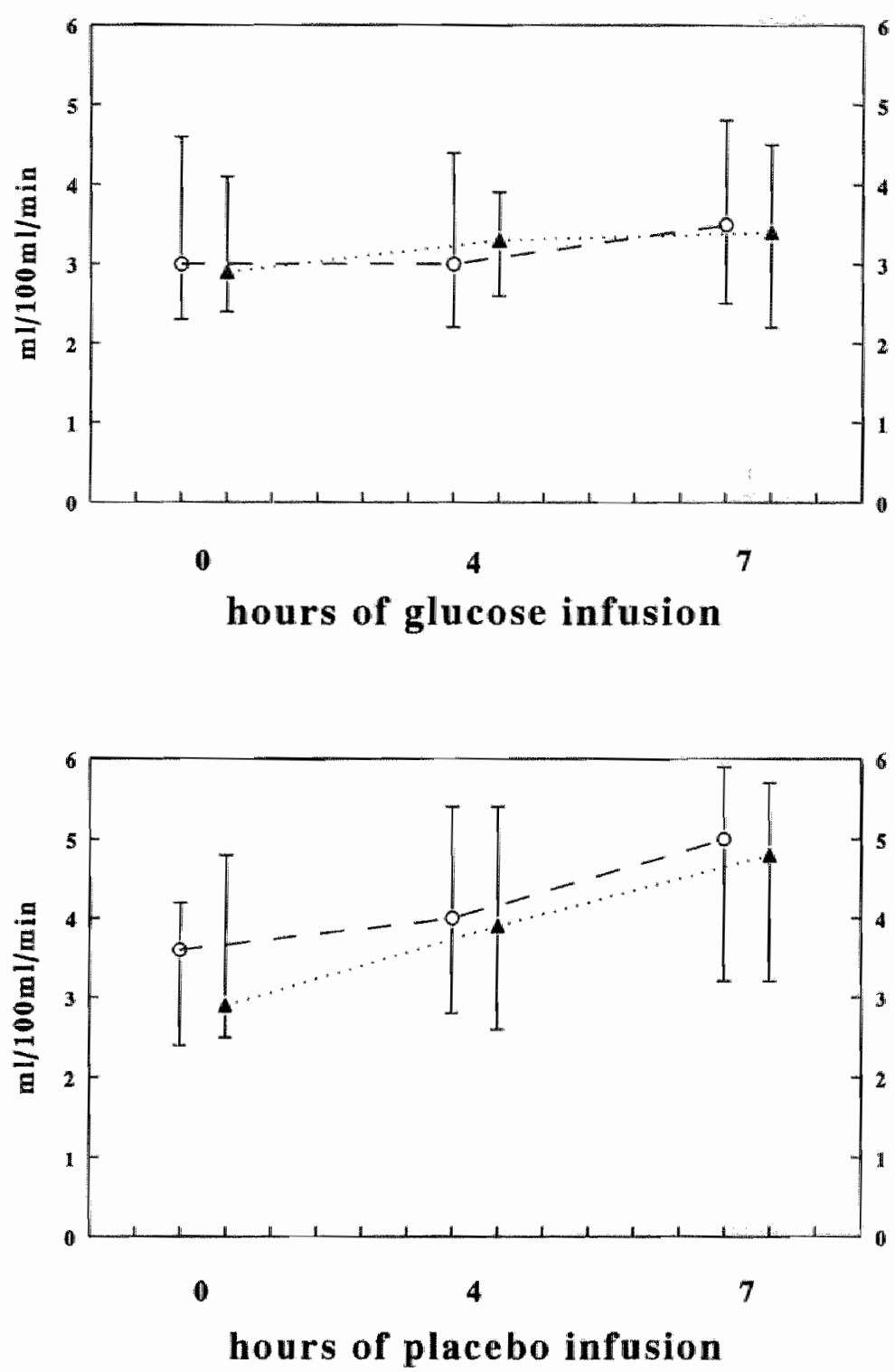

Figure 9.2: $\quad$ Median (and interquartile range) forearm blood flow (FBF) walues ( $n=12$ ) of the infused arm (o) and the contralateral arm ( 4 ) before and after 4 and 7 hours of intraarterial infusion of $5 \%$ glucase (panel A) and placebo (saline; panel B). 


\section{LASER-DOPPLER FLUXMETRY}
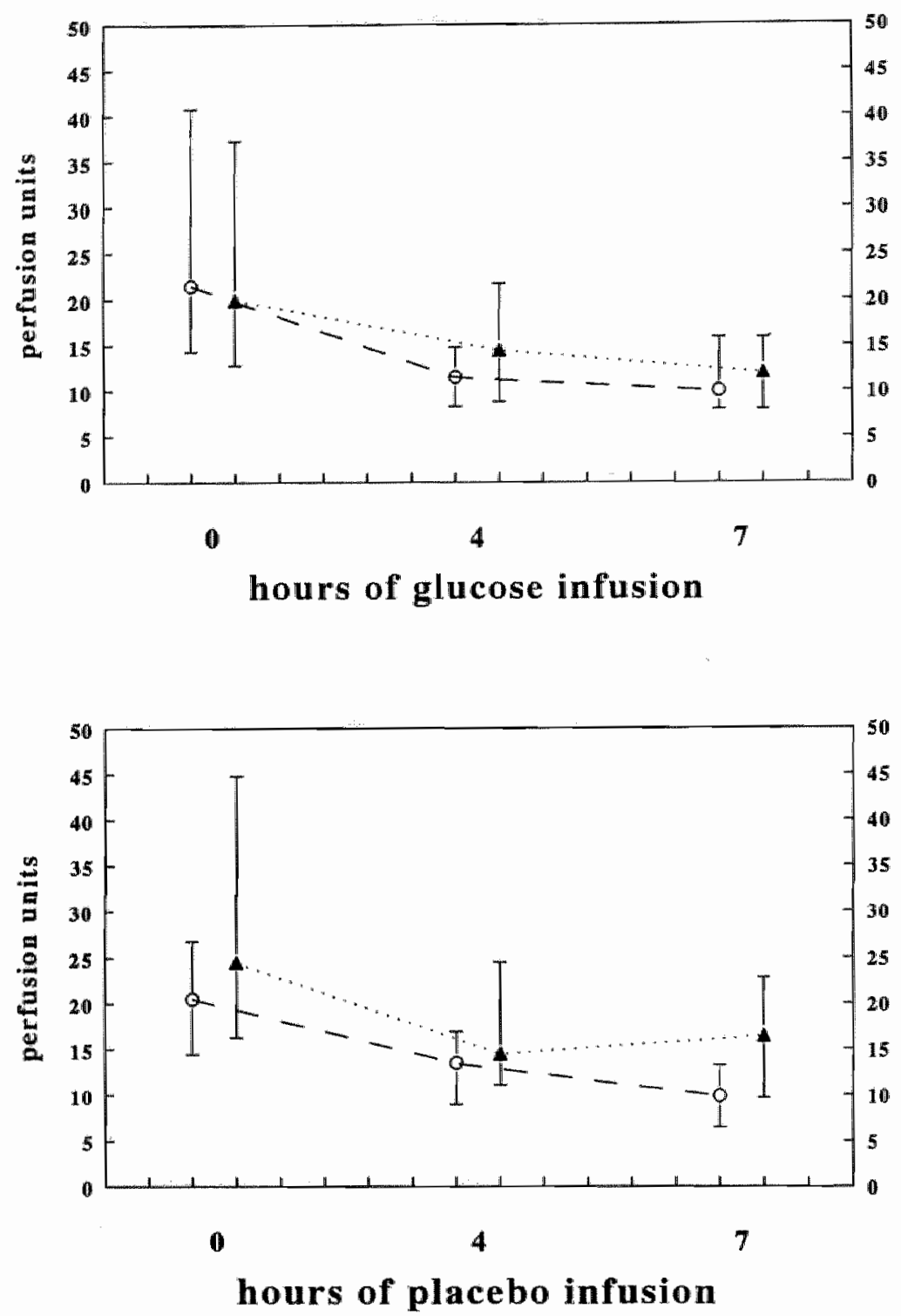

Figure 9.3: Median (and interquartile range) laser-Doppler fiurmetry (LDF) values $(m=12)$ of the infused arm ( $O$ ) and the contralateral arm ( $A$ ) before and after 4 and 7 hours of intratarterial infusion of 5\% glucose (panel A) and placebo (saline; panel B). 


\section{CAPILLARY BLOOD CELL VELOCITY}

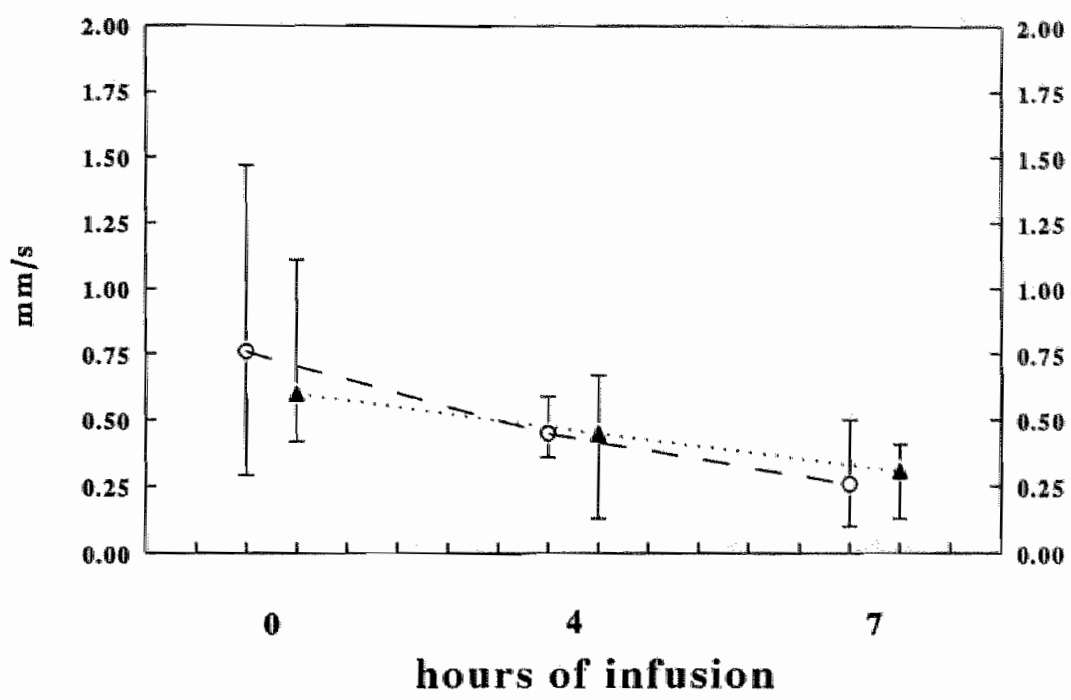

Figure 9.4: Median (and interquartile range) capillary blood cell velocity (CBV) walues $(n=7)$ of the infused arm before and after 4 and 7 hours of intraarrerial infusion of $5 \%$ glucose (o) and placebo (saline) ( 4 ).

The FBF ratios (infused:contralateral arm), FVR ratios (data not shown), and LDF ratios did not change during 7 hours of glucose or placebo infusion (within group comparison; table 9.2). Comparison of FBF ratios, LDF ratios, and CBV between the glucose and placebo experiments (between group comparison) at baseline $(0 \mathrm{~h})$ and after 4 and 7 hours of infusion revealed no differences (except for LDF ratio after $7 \mathrm{~h}$, see further). These data suggest no local effect of hyperglycaemia on forearm macro and microcirculation (table 9.2). As can been seen in figure 9.3 and table 9.2, the difference in LDF ratio after 7 hours glucose or placebo infusion is probably a result of a relative increase in LDF of the contralateral arm in the placebo group, instead of a local effect of glucose on the infused arm. Although the FBF ratios were not different between glucose and placebo (table 9.2), the increase in absolute FBF values of both separate arms was much less during the glucose experiments than during the placebo experiments (figure 9.2), which may imply a systemic effect during the glucose experiments. During 7 hours of placebo infusions FBF increased in the infused arm $58(23-101) \%$ and in the contralateral arm $23(10-90)$ $\%$, whereas during glucose infusions this increase was $2(-25-+56) \%$ in the infused arm and $5(-11-+24) \%$ in the contralateral arm (infused arm: glucose vs placebo $\mathrm{P}=0.03$, contralateral arm: glucose vs placebo $\mathrm{P}=0.02$ ). 
Table 9.2* Ratios (infused:contralateral arm) of Laser-Doppler Fluamesry (LDF) and Forearm Blood Flow (FBF), and absolute volues of Capillary bload cell velocity (CBV). Mean arterial pressure (MAP), and Heart rate at baseline (O hours), after 4 hours, and after 7 hours. of the glucose or placebo infusion.

\begin{tabular}{|c|c|c|c|}
\hline & \multicolumn{3}{|c|}{ HOURS OF INFUSIION } \\
\hline & $\mathrm{Oh}$ & $4 \mathrm{~h}$ & $7 \mathrm{~h}$ \\
\hline $\begin{array}{l}\text { CBV glucose } \\
(\mathrm{mm} / \mathrm{s})\end{array}$ & $0.76(0.29-1.47)$ & $0.45(0.36-0.59)$ & $0.26(0.01-0.50)$ \\
\hline $\begin{array}{l}\text { CBV placebo } \\
(\text { min/s) }\end{array}$ & $0.60(0.42-1.10)$ & $0.45(0.13-0.67)$ & $0.31(0.13-0.41)$ \\
\hline LDF-ratio glucose & $0.80(0.63-2.27)$ & $0.77(0.46-1.66)$ & $1.20(0.59-1.67)$ \\
\hline LDFFratio placebo & $0.77(0.54-1.37)$ & $0.82(0.48-1.17)$ & $0.56(0.41-1.30)$ \\
\hline FBF-ratio glucose & $1.03(0.89-1.18)$ & $1.12(0.93-1.18)$ & $1.03(0.96-1.48)$ \\
\hline FBF-ratio placebo & $1.10(0.85-1.15)$ & $1.13(0.96-1.31)$ & $1.09(0.97-1.32)$ \\
\hline $\begin{array}{l}\text { MAP glucose } \\
(\mathrm{mmHg})\end{array}$ & $79(73-83)$ & $79(74-84)$ & $82(74-87)$ \\
\hline $\begin{array}{l}\text { MAP placebo } \\
(\mathrm{mmHg})\end{array}$ & $81(76-85)$ & $79(74-82)$ & $80(77-82)$ \\
\hline $\begin{array}{l}\text { Heart rate glucose } \\
\left(\mathrm{min}^{-1}\right)\end{array}$ & $54(50-56)$ & $50(48-55)$ & $54(51-56)$ \\
\hline $\begin{array}{l}\text { Heart rate placebo } \\
\left(\mathrm{min}^{-1}\right)\end{array}$ & $55(53-58)$ & $54(50-59) *$ & $55(53-61)$ \\
\hline
\end{tabular}

* indicate significant difference compared with glucose values (Wilcoxon with Bonferronni correction; $P<0.05$ ). Data represented as medians and interquartile ranges.

FVR showed similar changes in both arms (data not shown). No differences were observed in the changes in skin temperature between glucose and placebo (data not shown). The width of the erythrocyte columns was not changed after 7-hours glucose or placebo infusion (data not shown).

Figure 9.5 depicts the percentages change in FBF ratio to $0.025,0.1$, and 0.4 $\mu \mathrm{g} / \mathrm{min}$ noradrenaline before and during glucose and placebo experiments. The reactivity to noradrenaline did not change during the glucose or placebo experiments (within group comparison), neither were any differences in reactivity observed between glucose and placebo infusions (between group comparison). 


\section{VASCULAR REACTIVITY TO NORADRENALINE}

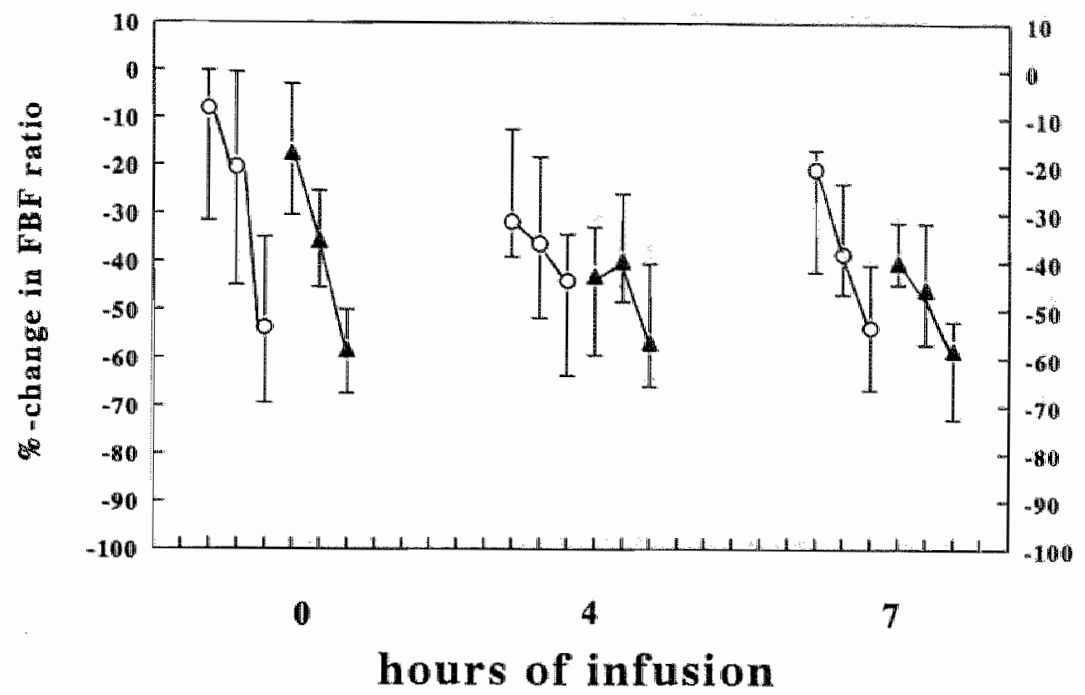

Figure 9.5: Percentage change in forearm blood flow ratio (infused:contralateral arm) $(n=12)$ du ring three cuanulative doses of noradrenaline: $0.025,0.1$, and $0.4 \mu \mathrm{g} / \mathrm{min}$, before and after 4 and 7 hours of intraarterial glucose (o) or placebo ( 4 ) infusion. Data are expressed as median and interquartile ranges. No differences were observed.

\subsection{DISCUSSION}

The results of the present study indicate that total forearm and skin microcirculatory blood flow (nutritive as well as thermoregulatory) are not affected by local hyperglycaemia $(\approx 16 \mathrm{mmol} / 1)$ for 7 hours. In addition, forearm vasoreactivity to noradrena-line was not affected by the intraarterial glucose infusion.

We used the perfused forearm model to induce local hyperglycaemia without major systemic metabolic effects. In the present model, possible vasoactive properties of glucose would lead to haemodynamic changes in the infused arm only and not in the contralateral arm, resulting in a change of the FBF or LDF ratio. The experiments were placebo-controlled to correct for possible systemic effects of the infused glucose. As demonstrated in the present study and an earlier study (18), FBF increases during the day, which is probably based on a circadian rhythm in sympathetic vasoconstrictor activity (19). In contrast, skin microcirculatory blood flow (LDF) decreases particularly in the morning, probably due to an acclimatization phenomenon (18). As in the present study FBF and LDF were measured on both the 
infused and the contralateral arm, it seems unlikely that these diurnal variations in blood flow might mask any local effect of glucose on peripheral blood flow. Surprisingly, local forearm hyperglycaemia resulted in systemic haemodynamic changes: a small increase in MAP and a diminished increase in absolute FBF and a diminished decrease in FVR, while plasma catecholamines did not change. These systemic haemodynamic changes suggest relative vasoconstriction. During the intraarterial glucose infusions C-peptide, insulin, and "systemic" glucose levels were relatively increased compared to placebo infusions. However, both insulin and C-peptide have been suggested to exert vasodilator instead of vasoconstrictor effects. Systemic infusion (intravenous) of insulin in healthy man results in increased renal blood flow and forearm blood flow $(27,28)$. Local infusion (intraarterial) of insulin seems to induce increased forearm arteriolar vasodilatation as well $(29,30)$, although other authors could not confirm these findings (31-33). Also C-peptide has been reported to have a vasodilator effect in IDDM patients (34). Finally, the changes we observed in systemic insulin and C-peptide levels were probably too small to exert a direct (local) effect on forearm vasculature. The small increase in MAP and relatively decrease in FBF during glucose might, therefore, possibly be a result of redistribution of blood (e.g. to the splanchnic area) induced by the increased levels of glucose, insulin, and/or C-peptide. As we observed small changes in systemic glucose, and C-peptide levels, higher levels of local hyperglycaemia than $16 \mathrm{mmol} / \mathrm{l}$ can not be used in this model. More-over, such extreme levels of hyperglycaemia are not very relevant for the diabetic patient.

It has been demonstrated in animals that hyperglycaemia affects the ability of blood vessels to autoregulate blood flow (10-12), which might be one of the priming mechanisms in the development of diabetic microangiopathy. The endothelial cells, which play an important role in vasoreactivity and the maintenance of vascular tone, are in particular susceptible to the "toxic" effects of glucose. Endothelial cells cultured in hyperglycaemic media show a disturbed DNA function, delayed replication, and accelerated death $(35,36)$. In addition, elevated glucose levels lead in endothelial cells to an accumulation of diacylglycerol (37), activation of protein kinase C (3739), a decrease in $\mathrm{Na}^{+}-\mathrm{K}^{+}$-ATPase activity (39-41), and an increase in free oxygen radicals (42). These intracellular changes could result in endothelial dysfunction, which may express itself in arteriolar vasodilation (10), increased blood flow and albumin permeation (11), and disturbed (endothelium dependent) vasodilator responses (10). Also increased prostaglandin production has been reported in animals $(41,42)$. However, in short-term IDDM patients increased levels of prostaglandins do not seem to play an important role in the peripheral hyperperfusion (4). Many of these vascular changes have been described also in diabetic models (43). Induction of systemic hyperglycaemia in healthy man results in both an increase and no change in leg or forearm blood flow, and renal hyperfiltration (44-46). However, as secondary hormonal changes occur during systemic hyperglycaemia, these results are difficult to compare with the present results. In the present study, we were able to induce local forearm hyperglycaemia (approximately $16 \mathrm{mmol} / \mathrm{l}$ ) for several hours, without major systemic metabolic changes. This local hyperglycaemia, for 7 hours, 
did not induce changes in forearm macro and microcirculatory blood flow of the infused arm. Although animal studies suggest that 2-5 hours of local hyperglycaemia in this range $(16 \mathrm{mmol} / \mathrm{l})$ can induce vascular haemodynamic changes $(11,12, \mathrm{JR}$ Williamson personal communication); it is possible that the level and/or duration of local hyperglycaemia was insufficient to affect the forearm vasculature. Due to possible heterogeneity in sensitivity to hyperglycaemia for different tissues, as demonstrated in the rat (47), the human forearm muscle and skin vasculature may possibly require a more severe or longer period of local hyperglycaemia to induce haemodynamic changes. The findings of the present study may even imply that human forearm muscle and skin vasculature is relative insensitive to local hyperglycaemia. The observed hyperperfusion in these tissues in short-term IDDM patients $(4,5)$ might, therefore, be the result of relatively high peripheral insulin levels or systemic effects of hyperglycaemia instead of local hyperglycaemia. In the present study only male volunteers were included to avoid possible influences of the female menstrual cycle on peripheral haemodynamics. It could be speculated that glucose-induced vascular changes can only be observed in women. However, other studies contradict this speculation (48). Finally, it seems unlikely that the glucose did not reach the vascular endothelial and/or smooth muscle cells, as the glucose uptake in these cells is predominantly insulin-independent and occurs by facilitated diffusion $(49,50)$. The fact that the venous pyruvate and lactate levels of the infused arm were unaltered after 7 hours of local hyperglycaemia suggests that no major changes in glucose metabolism of the forearm muscle tissue occurred. However, a possible increase in forearm lactate and pyruvate production might be masked by a decreased production at other sites (e.g. splanchnic area) (51).

The observed difference in LDF ratio after 7 hours of glucose or placebo infusion is probably an artefact. The LDF ratios during both glucose and placebo experiments did not change, suggesting that there is no local effect of glucose. The LDF signals of both the infused and the contralateral arm during glucose infusion and of the infused arm during placebo infusion show a similar pattern of decline of LDF during the day. These patterns resemble those of a pilot study we performed recently, and are probably the result of an acclimatization phenomenon (18). The LDF signal of the contralateral arm in the placebo experiments shows, however, a different pattern, resulting in a higher median signal at $17.30 \mathrm{~h}$. This probably causes the erroneous low LDF ratio after 7 hours placebo infusion.

The present data demonstrate that a 7-hour local hyperglycaemia does not change forearm vasoreactivity to noradrenaline in man. Animal (in vitro) studies suggest that diabetes induces enhanced vasoreactivity to noradrenaline $(13,52)$, although some could not demonstrate such an effect $(53,54)$. This effect is possibly related to a hyperglycaemia induced reduction in $\mathrm{Na}^{+}-\mathrm{K}^{+}$-ATPase activity (55). Morff (14) demonstrated that in animals the enhanced vasoreactivity to noradrenaline in diabetes is probably a short-term effect, which normalizes after 16 to 32 weeks after induction of diabetes. Indeed, vasoreactivity to noradrenaline has been reported unchanged in patients who have had uncomplicated diabetes for several years $(3,56)$. However, in long-term diabetic patients with retinopathy (57) the pressor response to noradrena- 
line was increased, and in patients with microalbuminuria (15) or autonomic neuropathy (16) vasoreactivity to noradrenaline was found to be increased.

In conclusion, in contrast to several animal studies, local hyperglycaemia (approximately $16 \mathrm{mmol} / \mathrm{l}$ ) for 7 hours does not affect forearm macro and microcirculatory blood flow or vascular reactivity to noradrenaline in man.

\section{ACKNOWLEDGMENTS}

This study was supported by grant 91.103 from the Diabetes Fonds Nederland. The authors thank Mr. Piet Claessens for excellent technical support.

\section{REFERENCES}

1. Parving H-H, Viberti GC, Keen H, Christiansen JS, Lassen NA. Hemodynamic factors in the genesis of diabetic microangiopathy. Metabolism 32:943-949, 1983.

2. Zatz R, Brenner BM. Pathogenesis of diabetic microangiopathy. The hemodynamic view. Am I Physiol 80:443-453, 1986 .

3. Calver $A$, Collier $J$, Vallance P. Inhibition and stimulation of nitric oxide synthesis in the human forearm arterial bed of patients with insulin-dependent diabetes. J Clin Invest 90:2548-2554, 1992.

4. Houben AJHM, Nieuwemhuijzen Kruseman AC, Bouhouch E, Slaaf DW, Schaper NC. Peripheral macro- and microcirculation in short-term insulin-dependent diabetes mellitus: the role of prostaglandins in early haemodynamic changes. Eur J Clin Invest (in press), 1993.

5. Houben AJHM, Schaper NC, Slaaf DW, Tangelder GJ, Nieuwenhuijzen Krusemam AC. Skin blood cell flux in insulin-dependent diabetic subjects in relation to retinopathy or incipient nephropathy. Eur J Clin Invest 22:67-72, 1992.

6. Mathiesen ER, Hilsted I, Feldt-Rasmussen B, Bonde-Petersen F, Christensen NJ, Parving HH. The effect of metabolic control on hemodynamics in short-term insulin-dependent diabetic patients. Diabetes 34:1301-1305, 1985.

7. Christiansen JS, Gammelgaard J, Tronier B, Svendsen PA, Parving HH. Kidney function and size in diabetics before and during initial insulin treatment. Kidney Int 21:683-688,1982.

8. Grunwaild JE, Brucker AJ, Schwartz SS, Braunstein SN, Baker L, Petrig BL, Riva CE. Diabetic glycemic control and retinal blood flow. Diabetes 39:602-607, 1990 .

9. Sandeman DD, Shore AC. Tooke JE. Relation of skin capillary pressure in patients with insulindependent diabetes mellitus to complications and metabolic control. New Eng J Med 327:760-764, 1992.

10. Bohlen HG, Hankins KD. Early arteriolar and capillary changes in streptozotocin-induced diabetic rats and intraperitoneal hyperglycaemic rats. Diabetologia $22: 344-348,1982$.

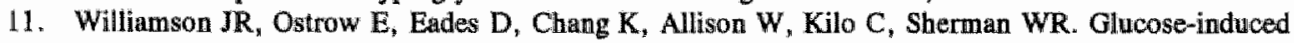
microvascular functional changes in nondiabetic rats are stereospecific and are prevented by an aldose reductasie inhibitor. J Clin Invest 85:1167-1172, 1990 .

12. Woods LL, Mizelle HL, Hall JE, Control of renal hemodynamics in hyperglycemia: possible role of tubuloglomerular feedback. Am J Physiol 252:F65-F73, 1987.

13. Friedman JJ. Vascular sensitivity and reactivity to norepinephrine in diabetes mellitus. Am J Physiol 256:H1134-H1138, 1989.

14. Morff RJ. Microvascullar reactivity to norepinephrine at different arteriolar levels and durations of streptozocin-induced diabetes. Diabetes 39:354-360, 1990. 
15. Bodmer CW, Patrick AW, Williams G. Exaggerated sensitiwity to NE-induced vasoconstriction in IDDM patients with microalbuminuria. Possible etiology and diagnostio implications. Diabetes 41:209-214, 1992.

16. Eichler HG, Blaschke TF, Kraemer FB, Ford GA, Blochl-Daum B, Hoffinan BB. Responsiveness of superficial hand weins to $\alpha$-adrenoceptor agonists in insulin-dependent diabetio patients. Clin $\mathrm{Soi}$ 82:163-168, 1992.

17. Houben AJHM, Schaper NC, Nieuwenhuijzen Kruseman AC. Acute effects of local hyperglycaimia on peripheral blood flow in man. Diab Med 10:39-43, 1993.

18. Houben AIHM, Schaper NC, Huvers FC, de Leeuw PW, Slaf DW, Nieuwenhuijjzen Kruseman AC. Diurnal variations in peripheral micro and macrocirculation in man (Abstract). Eur I Clin Invest 23 (Suppl. 1): A53, 1993.

19. Panza JA, Epstein SE, Quyyumi AA. Circadian variation in vascular tone and its relation to $\alpha$ sympathetic vasoconstrictor actiwity. N Eng J Med 325:986-990, 1991.

20. Slaaf DW, Tangelder GJ, Reneman RS, Jager K, Bollinger A. A versatile incident illuminator for intravital microscopy. Int J Microcirc Clin Exp 6:391-397, 1987.

21. Slaaf DW, Arts T, Jeurens TIM, Tangelder CJ, Reneman RS. Electronic measurement of red blood cell velocity and volume flow in microvessels. In: Investigative microtechniques in medicine and biology. Vol. 1, Chayen J and Bitensky L (eds.). New York: Marcel Dekker, Inc, 1984.

22. Caspary $L$, Creutzig A, Alexander $K$. Biological zero in laser Doppler fluxmetry. Int I Microcirc Clin Exp 7:367-371, 1988.

23. Whitney RJ. The measurement of volume changes in human limbs. I Physiol 121:1-27, 1953 .

24. Cooper KE, Edholm OG, Mottram RF. The blood flow in skin and muscle of the human forearm. $J$ Physiol 128:258-267, 1955.

25. Van Der Hoorn FAJ, Boomsma F, Man in 't Veld AJ, Schalekamp MADH. Determination of catecholamines in human plasma by high-performance liquid chromatography: comparison between a new method with fluorescence detection and an established method with electrochemical detection. J Chromatogr 487*17-28, 1989.

26. Greenfield ADM, Patterson GC. Reactions of the blood vessels of the human forearm to increase in transmural pressure. J Physiol 125:508-524, 1954.

27. Stenvinkel P, Blinder $J$, Alvestrand A. Effects of unsulin on renal haemodynamics and the proximal and distal tubuiar sodium handling in healthy subjects. Diabetologia 35:1042-1048, 1992.

28. Anderson EA, Hoffman RP, Balon TW, Sinkley CA, Mark AL. Hyperinsulinemia produces both sympathetic neural activation and vasodilation in normal humans. J Clin Invest 87:2246-2252, 1991.

29. Creager MA, Liang CS, Coffman JD. Beta adrenergic-mediated vasodilator response to insulin in the thuman forearm. J Pharmacol Exp Ther 235:709-714, 1985.

30. Louard RJ, Fryburg DA, Gelfand RA, Barrett EJ. Insulin sensitivity of protein and glucose metabolism in human forearn skeletal muscle. J Clin lnvest $90: 2348-2354,1992$.

31. Yki-Jarvinen $H$, Young AA, Lamkin C, Foley JE. Kinetics of glucose dispowal in whole body and across the forearm in man. $J$ Clin Invest 79:1713-1719, 1987.

32. Laakso M, Edelman SV, Brechtel $G$, Baron AD. Decreased effect of insulin to stimulate skeletal muscle blood flow in obese man. $J$ Clin Invest 85:1844-1852, 1990.

33. Natali A, Buzzigoli G, Taddei S, Santoro D, Cerri M, Pedrinelli R, Ferrannini E. Effeots of insulin on hemodynamics and metabolism in human forearm. Diabetes $39: 490-500,1990$.

34. Johansson BL, Linde B, Wahren J. Effects of C-peptide on blood flow, capillary diffusion capacity and glucose utilization in the exercising forearm of type I (insulin-dependent) diabetio patients. Diabetologia 35:1151-1158, 1992.

35. Lorenzi $\mathbf{M}$, Cagliero $\mathbf{E}_{p}$ Toledo $\mathbf{S}$. Glucose toxicity for human endothelial cells in culture. Diabetes 34:621-627, 1985.

36. Lorenzi M, Montisano DF, Toledo $\mathrm{S}$, Barrieux A. High glucose induces DNA damage in culltured human endothelial cells. $J$ Clin Invest 77:322-325, 1986.

37. Wolf BA, Williamson JR, Easom RA, Chang K, Sherman WR, Turk J. Diacyliglycerol accumulation and microvascular abnormalities induced by elevated glucose lewels. J Clin Invest 87:31.38, 1991. 
38. Tesfamariaun B, Brown ML, Cohen RA. Dlewated glucose impairs endothelium-dependent relaxation by actiwating protein kinase $C$. J Clin Invest $87: 1643-1648,1991$.

39. Lee TS, MacGregor LC, Fluharty SJ, King GL. Differential regulation of protein kinase C and $(\mathrm{Na}, \mathrm{K}$ ) -adenosine triphosphate activities by elewated glucose levels in retinal capillary endothelial cells. J Clin Invest 83:90-94, 1989.

40. Simmons $\mathrm{DA}$, Winegrad A.I. Mechanism of glucose-induced $\left(\mathrm{Na}^{*}, \mathrm{~K}^{+}\right)$-ATPase inhibition in aortic wall of rabbits. Diabetologia 32:402,408, 1989.

41. Yorek MA, Stefani MR, Moore SA. Acute and chronic exposure of mouse cerebral microvessel endothelial cells to inereased concentrations of glucose and galactose: effect on myo-inositol metabolism, $\mathrm{PGE}_{2}$ symthesis, and $\mathrm{Na}^{*} / \mathrm{K}^{+}$-ATPase transport activity. Metabolism 40:347-358, 1991.

42. Tesfamariam B, Cohen RA. Free radicals mediate endothelial cell dysfunction caused by elevated glucose Am J Physiol 263:H321-H326, 1992.

43. Pieper GM, Grosis GJ. Endothelial dysfunction in diabetes. In: Cardiovascular significance of endothelium-derived vasoactive factors. Rubanyi GM (ed.). Futura Pub. Co., New York, 1991.

44. Bülow J, Astrup A. Christensen NJ, Kastrup J: Blood flow in skin, subcutaneous adipose tissue and skeletal muscle in the forearm of normal man during an oral glucose load. Acta Physiol Scand $130: 657-661,1987$.

45. Laakso M, Edelman SV, Olefsky JM, Brechtel G, Wallace P, Baron AD: Kinetics of in vivo muscle insulin-mediated glucose uptake in human obesity. Diabetes 39:965-974, 1990.

46. Christiansen IS, Frandsen M, Parving HH. Effect of intravenous glucose infusion on renal function in normal man and in insulin dependent diabetics. Diabetologia 21:368-372,1981.

47. Tilton RG, Chang K, Hasan KS, Smith SR, Petrash JM, Misko TP, Moore WM, Currie MG, Corbett JA, McDaniel ML, Williamson JR. Prevention of diabetic vascular dysfunction by guanidines. Inhibition of nitric oxide synthase versus advanced glycation end-product formation. Diabetes 42:221-232, 1993.

48. Williamson JR, Rowold $E_{n}$ Chang K, Marvel J, Tomlinson M, Sherman WR, Ackermann KE, Berger RA, Kilo C. Sex steroid dependency of diabetes-induced changes in polyol metabolism, vascular permeability, and collagen cross-linking. Diabetes 35:20-27, 1986.

49. Corkey RF, Corkey BE, Gimbrone MA. Hexose transport in normall and SV40-transformed human endothelial cells in culture. I Cell Physiol 106:425-434, 1981.

50. Baron AD, Brechtel G, Wallace $P$, Edelman $S V$. Rates and tissue sites of non-insulin- and insulinmediated glucose uptake in humans. Am J Physiol 255:E769-E774, 1988.

51. Radziuk J, Inculet $\mathbb{R}$. The effects of ingested and intravenous glucose on forearm uptake of glucose and glucogenic substrate in normal man. Diabetes 32:977-981, 1983.

52. White RE, Carrier GO. Enhanced vascular $\alpha$-adrenergic neuroeffector system in diabetes: importance of calcium. Am J Physiol 255:H1036-H1042, 1988.

53. Mulhern $\mathrm{M}_{n}$ Docherty JR. Effects of experimental diabetes on the responsiveness of rat aorta. $\mathrm{Br} J$ Pharmacol 97:1007-1012, 1987.

54. Fulton DJR, Hodgson WC, Sikorski BW, King RG. Attenuated responses to endothelin-1, KCl and $\mathrm{CaCl}_{2 \times}$ but not moradrenaline, of aortae from rats with streptozotocin-induced diabetes mellitus. $\mathrm{Br}$ J Pharmacol 104:928-932, 1991 .

55. Simmons DA, Winegrad AI. Mechanisms in rabbit aorta for hyperglycaemia-induced alterations in angiotensin III and Norepinephrine effects. Diabetologia 35:725-729, 1992.

56. Halkin A, Benjamin N, Doktor HS, Todd SD, Viberti G, Ritter JM. Vascular responsiveness and cation exchange in insulindependent diabetes. Clin Sei 81:223-232, 1991.

57. Christlieb AR, Janka HU, Kraus B, Gleason RE, Icasas-Cabral EA, Aiello LM, Cabral BV, Solano A. Vascular reactivity to angiotensin II and to norepinephrine in diabetic subjects. Diabetes $25: 268$ $274,1976$. 


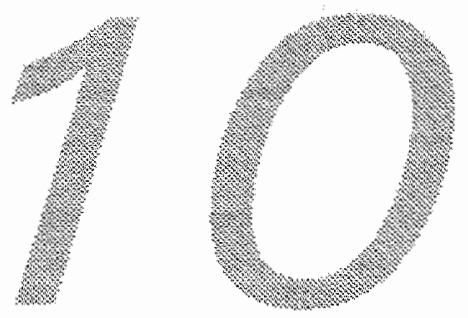

SUMMARY AND CONCLUSIONS. 


\subsection{SUMMARY}

Long-term microvascular complications, like retinopathy, nephropathy, and neuropathy are frequently observed in subjects with IDDM, and they have a great impact on morbidity and mortality. The haemodynamic hypothesis (1-3) is one of the main hypotheses explaining the pathophysiology of these late complications, besides other processes like non-enzymatic glycosylation, oxidative stress, sodium-lithium counter transport, and heparan sulphate metabolism. Early functional haemodynamic changes like increased (micro)vascular flow and pressure induce (micro)vascular sclerosis (structural changes), which results in loss of (maximal) tissue perfusion and/or loss of autoregulation. Many studies have suggested the subsequent steps of this haemodynamic hypothesis in IDDM patients, as summarized in chapter 2. The focus of this thesis is on early haemodynamic changes in IDDM patients and possible pathophysiologic mechanisms involved. As described in chapter 2, factors like subclinical sympathetic neuropathy, relative hypoxia, changes in levels of circulating vasodilator hormones (e.g. insulin) or metabolites (e.g. ketone bodies), or endothelial dysfunction (possibly as a result of chronic hyperglycaemia) may initiate and support the early haemodynamic changes.

In this thesis studies are presented on 1) the role of acclimatization and/or diurnal rhythms in the forearm and skin (micro)circulatory blood flow, 2) haemodynamic changes and maximal perfusion capacity of the skin microvasculature of short-term and long-term IDDM patients with and without different diabetic complications, 3) compliance of the forearm venous system of long-term IDDM patients and its possible involvement in the development of early nephropathy, 4) the role of prostaglandins in the early haemodynamic changes in short-term IDDM patients, and 5) effects of short-term ( 1 hour), and 6) long-term ( 7 hours) local hyperglycaemia on forearm macro- and microcirculation, and vasoreactivity to noradrenaline in healthy man.

Chapter 4 describes a study on the diurnal variations in forearm muscle blood flow and skin thermoregulatory and nutritive microcirculation. Kaneko et all (4) described already in 1968 that peripheral muscle blood flow is influenced by a circadian rhythm. However, little data are available on possible circadian variation in skin microcirculatory blood flow. As most experiments are performed between 08.00 and 18.00 hours, we studied variations in forearm muscle and skin microcirculatory blood flow in that period. The results indicate that forearm muscle blood flow increased during the day, which is in agreement with others $(4,5)$, and might be related to circadian variation in $\alpha$-sympathetic vasoconstrictor activity (5). In contrast, skin thermoregulatory blood flow decreased during the day, particularly during the first 2 to 3 hours. Skin nutritive blood flow demonstrated a similar pattern, although this decrease was not statistically significant, probably due to small numbers and large intraindividual variation. Performing the same experiments in the afternoon resulted in similar decreases in skin microcirculation during the first 2 to 3 hours, indicating that these variations in flow were due to an acclimatization phenomenon 
and not to a diurnal or circadian rhythm. The fact that the subjects (of the day-time protocol) were fasting for 12 hours at the start of the experiments does probably not explain the observed decrease in skin microcirculatory blood flow. Bennett et al (6) did not find any change in blood pressure or forearm blood flow after a 12-hour fast. However, after 48 hours of fasting muscle blood flow may increase, possibly due to decreased plasma noradrenaline levels (7). In addition, the subjects in the afternoon protocol were allowed to have a light breakfast in the morning. The observed decrease in skin microcirculatory blood flow during the first 2 to 3 hours of the experiments is probably related to the subject's physical inactive state. Physical inactivity reduces central and regional heat production and thus reduces the necessity of heat dissipation. Hence, thermoregulatory blood flow may fall. Sundberg (8) could indeed not demonstrate any variations in skin thermoregulatory perfusion during the morning in "active" subjects, coming directly from sedentary indoor work. In conclusion, distilled from the results of the studies described in this chapter it is recommendable to perform forearm blood flow measurements always on the same time of the day. Furthermore, skin microcirculatory haemodynamic measurements, in a cross-sectional study design, should be performed after a standard acclimatization period, while in a longitudinall study design such measurements should preferably be performed after a 2-3 hour period of acclimatization.

Already shortly after the onset of IDDM an increase in skin thermoregulatory and forearm (muscle) blood flow can be demonstrated, as shown in chapters 5 and 7. In chapter $\mathbf{5}$ it is described that, as long as no signs of nephropathy are present, this increased skin flow remains demonstrable in long-term IDDM patients, even in the presence of retinopathy, indicating a generalized (micro)vascular vasodilation. The findings of increased blood flow in the retima (9) and kidney (10), increased nailfold capillary pressures (11), and increased cardiac output $(12,13)$ in short-term IDDM subjects support this view of generalized vasodilatation, which remains present in long-term IDDM patients. Post-occlusive hyperaemic peak-flux is normal or increased in both short- and long-term IDDM patients, indicating no change in maximal arteriolar vasodilator capacity. Parallel to the development of diabetic nephropathy, but not retinopathy, this (micro)vascular hyperperfusion seems to deteriorate, resulting in a decreased resting skin thermoregulatory blood flow and a decreased maximal post-occlusive skin perfusion compared to short- and long-term IDDM subjects. This suggests that, besides structural vascular changes in the kidney (14), the development of diabetic nephropathy is probably representative of extrarenal structural microangiopathy. Local neurogenic control of vascular tone (i.e. precapillary resistance) does not seem to be altered in IDDM subjects with or without complications, as was tested by the veno-arteriolar reflex. These findings are not in agreement with other reports, which demonstrated an impaired veno-arteriolar reflex in both short- and long-term diabetic patients $(15,16)$. However, in these studies flow was measured in the nailfold area (which is rich of A-V shunts), while we measured flow more proximal at the dorsum of the finger. As veno-arteriolar re- 
flexes may vary at various sites of the hand (17), this may explain the differences between the observations.

As stated in the Haemodynamic hypothesis, increased pressure and flow, in combination with processes like non-enzymatic glycosylation, lead to (micro)vascular sclerosis (18-21). Skin microvascular haemodynamics are attenuated in long-term IDDM subjects with early signs of nephropathy (chapter 5). In parallel to these peripheral arteriolar vascular changes, a decrease in the visco-elastic properties of the peripheral veins could be one of the extrarenal manifestations of early diabetic nephropathy. In chapter 6 experiments are described in which we studied the compliance of forearm veins in long-term IDDM subjects with and without early nephropathy. Venous compliance was decreased in both groups of IDDM subjects to the same extent, compared to healthy control subjects. This loss of visco-elastic properties of the venous wall in the diabetic subjects could be due to structural vascular changes $(22,23,24)$ and/or increased vascular smooth muscle tone. Indeed, in IDDM subjects with incipient nephropathy or polyneuropathy hand vein reactivity to noradrenaline is increased, suggesting an increased venous tone $(25,26)$. Preliminary data (unpublished) from our lab strongly suggest that the exaggerated noradrenergic reactivity is due to a defect in the $\alpha_{2}$-adrenoceptor. However, in normoalbuminuric long-term IDDM subjects (in who we found a decreased venous compliance) this hand vein reactivity was normal $(25,26)$, which suggest that structural vascular changes rather than increased venous tone is responsible for the decreased venous compliance in these patients. In addition, venous dilatation after nitroglycerin (which relaxes vascular smooth muscle cells) was similar in the IDDM subjects and the healthy control subjects, suggesting that vascular tone was not changed in the IDDM subjects. In contrast to the observed haemodynamic changes in skin microvasculature in IDDM subjects with incipient nephropathy, possibly indicating structural microvascular changes (chapter 5), the structural vessel wall changes of the forearm veins are not related to the development of diabetic nephropathy.

It has been postulated that a loss of venous elasticity may play an important role in the development of (essential) hypertension, by increasing cardiac filling pressure and thus cardiac output (27). IDDM patients with early diabetic nephropathy (microalbuminuria) are more at risk to develop hypertension than patients without nephropathy $(28,29)$. However, as the venous compliance was decreased to the same extent in both groups of IDDM patients, other factors are probably involved in the development of hypertension in this subgroup of IDDM patients.

Many animal studies suggest that IDDM induces vascular endothelial dysfunction. Secondary to this endothelial dysfunction a disturbance of the balance of endothelium-derived vasodilator/constrictor factors may occur, leading to e.g. enhanced production of vasodilator prostaglandins. Increased production of vasodilator prostaglandins could be an important factor in the peripheral hyperperfusion as observed in short-term IDDM subjects. Various animal and human studies, however, reveal conflicting data on the changes in prostaglandin production in diabetes (see chapter 
2). In both short-term and long-term IDDM patients an increase in the vasodilator prostacyclin seems to be involved particularly in the renal hyperperfusion (30-34). To study the possible role of increased prostacyclin production in the peripheral hyperperfusion in short-term IDDM subjects, we determined forearm and skin microcirculatory blood flow before and after cyclooxygenase inhibition by ASA (chapter 7). The results indicated that the increased forearm muscle and skin thermoregulatory blood flow in short-term IDDM patients were not influenced by cyclooxygenase inhibition, suggesting that increased prostacyclin production does not play a major role in the early haemodynamic changes in IDDM. Furthermore, the results indicated that prostaglandins do not play a relevant role in the regulation of basal peripheral blood flow in normal man.

In chapters 8 and 9 the role of glucose was studied on forearm muscle and skin blood flow and vascular reactivity to noradrenaline in healthy man. Improvement of metabolic control (i.e. lowering the blood glucose level) in IDDM patients results in normalization of haemodynamic properties (see chapter 2). Moreover, artificial hyperglycaemia in healthy animals results in increased blood flow and vascular permeability within a few hours (33). This is probably due to glucose-induced changes in the intracellular milieu of the endothelial and vascular smooth muscle cells (e.g. sorbitol pathway, NADH/NAD ${ }^{+}$ratio, myoinostol uptake, DAG production, protein kinase $C$, etc.), resulting in changes in endothelial release of vasoactive factors and changes in vasoreactivity (chapter 2 ). In the experiments described in chapter 8 and 9 , we used the perfused forearm model to induce a local forearm hyperglycaemia by infusing small amounts of glucose into the brachial artery. In this way it is possible to study the local effects of hyperglycaemia on the haemodynamics of one arm without inducing any systemic changes in e.g. glucose, insulin, or glucagon levels. Furthermore, increased systemic glucose levels may act directly on the brain resulting in increased plasma levels of noradrenaline, as demonstrated recently in the rat (34). In our hands, a moderate local hyperglycaemia $(\approx 10 \mathrm{mmol} / \mathrm{l})$ of one hour duration, induced by infusion of $20 \%$ glucose into the brachial artery, resulted in an increase in forearm muscle blood flow (chapter 8), supporting the findings in experimental diabetes. This effect was not an osmotic effect, since no changes in forearm blood flow were observed after infusion of $20 \%$ mannitol. However, when a similar or even higher $(\approx 18 \mathrm{mmol} / \mathrm{l})$ local hyperglycaemia was reached by infusion of $5 \%$ glucose, no changes in muscle blood flow were observed. We feel that the effect observed during $20 \%$ glucose infusion may be due to an extremely high glucose concentration at the tip of the catheter, which was much less during $5 \%$ glucose infusion. Hence, we concluded that a short-term local hyperglycaemia (10 and $18 \mathrm{mmol} / \mathrm{l}$ ) did not affect forearm blood flow. As some animal studies indicate that possibly a longer period of hyperglycaemia is necessary to induce vascular dysfunction, we studied subsequently the effects of a 7-hour local hyperglycaemia $(\approx 16 \mathrm{mmol} / \mathrm{l})$ induced by $5 \%$ glucose on forearm and skin blood flow and (endothelium-independent) vascular reactivity to noradrenaline (chapter 9). This local hyperglycaemia for 7 hours had neither an effect on forearm and skin blood flow, nor on 
the vasoreactivity to noradrenaline. This is in contrast with findings in animal studies. It has been suggested in the rat that there is a heterogeneity in glucose sensitivity for different tissues (35). Possibly, the human forearm muscle and skin vasculature may require a more severe and/or longer period of hyperglycaemia to induce haemodynamic changes. Higher levels of local hyperglycaemia than $16 \mathrm{mmol} / \mathrm{l} \mathrm{can}$ not be used in our model without inducing systemic metabolic changes. Moreover, such extreme levels are not very relevant for the diabetic patient. Therefore, we are currently investigating whether a local hyperglycaemia $(\approx 16 \mathrm{mmol} / \mathrm{l})$ for 24 hours affects basal forearm muscle and skin haemodynamics and the endothelium dependent and independent vasoreactivity.

\subsection{CONCLUSIONS}

The results of the studies presented in this thesis allow the following conclusions:

1. Forearm (muscle) blood flow increases during the day ( 9 a.m. to 5.30 p.m.) due to a circadian rhythm. In contrast, skin thermoregulatory blood flow decreases during the day, which is probably related to acclimatization to the physically inactive state.

2. Shortly after the onset of IDDM skin thermoregulatory blood flow is increased, indicating early peripheral haemodynamic changes. This skin hyperperfusion remains present in long-term IDDM patients, even in the presence of retinopathy. However, parallel to the development of diabetic nephropathy the hyperperfusion and the maximal arteriolar dilating capacity deteriorate, which may indicate a generalized microvascular disturbance.

3. The visco-elastic properties of the peripheral venous system are decreased in IDDM patients with or without early diabetic nephropathy, probably due to structural changes in the vessel wall. In contrast to the skin microvasculature, these peripheral venous changes are not related to the development of diabetic nephropathy. Decreased venous compliance does probably not play a major role in the development of hypertension in IDDM patients with early nephropathy.

4. The increased forearm muscle and skin thermoregulatory blood flow observed in short-term IDDM patients, is not likely to be related to increased levels of endothelial prostacyclin production. Furthermore, prostaglandins are not likely to play a major role in the local regulation of basal perfusion in normal man.

5. Acute local forearm hyperglycaemia (for 1 hour), induced by $20 \%$ glucose infusion into the brachial artery with no major systemic metabolic effects, 
increases forearm (muscle) but not skin thermoregulatory blood flow. This effect is not due to hypertonicity, but is possibly related to the extremely high glucose levels at the tip of the catheter, as $5 \%$ glucose infusion, resulting in a similar hyperglycaemia, had no such an effect.

6. Local forearm hyperglycaemia (for 7 hours), induced by $5 \%$ glucose infusion (i.a.), does not affect forearm muscle and skin microcirculatory blood flow, or vascular reactivity to noradrenaline in man.

\section{REFERENCES}

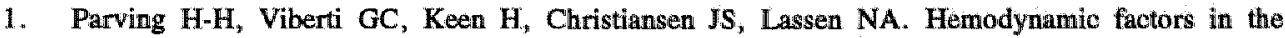
genesis of diabetic microangiopathy. Metabolism $1983 ; 32 ; 943-949$.

2. Zatz $\mathbf{R}_{y}$ Brenner BM. Pathogenesis of diabetic microangiopathy. The hemodynamic view. Am $\mathbf{J}$ Med 1986;80;443-453.

3. Tooke JE. Microvascular haemodynamics in diabetes mellitus. Clin Sci 1986;70;119-125.

4. Kaneko M, Zechman FW, Smith RE. Circadian variation in human peripheral blood flow levels and exercise responses. J Appll Physiol 1968;25;109-114.

5. Panza JA, Epstein SE, Quyyumi AA. Circadian variation in vascular tone and its relation to $\alpha$ sympathetic vasoconstrictor actiwity. N Eng J Med 1991;325;986-990.

6. Bennett $T$, Macdonald IA, Sainsbury $R$. The influence of acute starvation on the cardiovascular responses to lower body subatmospheric pressure or to standing in man. Clin Sci 1984;66;141-146.

7. Gallen IW, MacDonald IA, Mansell PI. The effect of a $48 \mathrm{~h}$ fast on the physiological responses to food ingestion in normal-weight women. Br J Nutrit 1990;63;53-64.

8. Sundberg S. Acute effects and long-term variations in skin blood flow measured with laser Doppler flowmetry. Scand J Clin Lab Invest 1984;44;341-345.

9. Kohner EM, Hamilton AM, Saunders SJ, Sutcliffe BA, Bulpitt CJ. The retinal blood flow in diabetes. Diabetologia 1975;11;27-33.

10. Christiansen JS, Gammelgaard J, Tromier B, Svendsen PA, Parving HH. Kidney function and size in diabetics before and during initial insulin treatment. Kidney Int $1982 ; 21 ; 683-688$.

11. Sandeman DD, Shore AC, Tooke JE. Relation of skin capillary pressure in patients with insulindependent diabetes mellitus to complications and metabolic control. New Eng J Med 1992;327;760764 .

12. Mathiesen ER, Hilsted J, Feldt-Rasmussen B, Bonde-Petersen F, Christensen NJ, Parving HH. The effect of metabolic control on hemodynamics in short-term insulin-dependent diabetic patients. Diabetes $1985 ; 34 ; 1301-1305$.

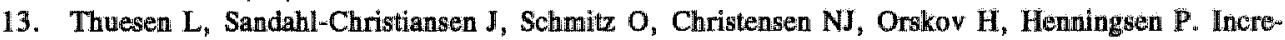
ased myocardial performance following acute hypergllycaemia in insulin-dependent diabetic patients. A consequence of increased peripheral blood flow? Scand J Clin Lab Invest 1987;47;571-579.

14. Osterby $\mathbb{R}$, Parving HH, Hommel $\mathrm{E}$, Jorgensen $\mathrm{HE}$, Lokkegaard $\mathrm{H}$. Glomerular structure and function in diabetic nephropathy. Early to advanced stages. Diabetes $1990 ; 39 ; 1057-1063$.

15. Tooke JE, Lins P-E, Ostergren J, Fagrell B. Skin microvascular autoregulatory responses in type I diabetes: the influence of duration and control. Int J Microcirc Clin Exp 1985;4;249-256.

16. Tooke JE, Ostergren J, Lins P-E, Fagrell B. Skin microvascular blood flow control in long duration diabetics with and without complications. Diab Res 1987;5;189-192.

17. Winocour PH, Mitchell WS, Gush RJ, Taylor LJ, Baker RD. Altered hand skin blood flow in type I (insulin-dependent) diabetes mellitus. Diab Med 1988;5;861-866. 
18. Kastrup J, Norgaard T, Parving $\mathbb{H H}$, Henriksen O, Lassen NA. Impaired autoregulation of blood flow in subcutaneous tissue of long-term Type I (insulim-dependent) diabetic patients with microangiopathy: an index of arteriolar dysfunction. Diabetologia $1985 ; 28 ; 711-717$.

19. Kastrup $\mathbf{J}$, Mathiesen ER, Saurbrey $N$, Norgaard T, Parving HH, Lassen NA. Effect of strict metabolic control on regulation of subcutaneous blood flow im insulin-dependent diabetic patients. Diab Med 1987;4;30-36.

20. Williamson JR, Kilo $C_{\text {. }}$ Current status of capillary basement membrame disease in diabetes mellitus. Diabetes $1977 ; 26 ; 65-73$.

21. Vracko $R$, Benditt EP. Capillary basal lamina thickening, Its relationship to endothelial cell death and replacement. J Cell Biol 1970;47;281-285.

22. Monnier VM, Vishwanath V, Frank KE, Elmets GA, Dauchot P, Kohn RR. Relation between complications of type II diabetes mellitus and collagen-linked fluorescence. N Eng I Med $1986 ; 314 ; 403-408$.

23. Brownlee M, Cerami A, Vlassara H. Advanced glycosylation end products in tissue and the biochemical basis of diabetic complications. N Eng $J$ Med 1988;318;1315-1321.

24. Dominiczak MH. The significance of the products of the Maillard (browning) reaction in diabetes. Diab Med 1991;8;505-516.

25. Bodmer CW, Patrick AW, How TV, Williams G. Exaggerated sensitivity to NE-induced vasoconstriction in IDDM patients with microalbuminuria. Possible etiology and diagnostic implications. Diabetes $1992 ; 41 ; 209-214$.

26. Eichler HG, Blaschke TF, Kreamer FB, Ford GA, Blochl-Daum B, Hoffman BB. Responsiveness of superficial hand veins to alpha-adrenoceptor agonists in insulin dependent mellitus. Clin Science $1992 ; 82 ; 163-168$.

27. Safar ME, London GM. Yenous system in essential hypertension. Clin Science 1985;69;497-504.

28. Mogensen CE, Hansen KW, Osterby R, Damsgaard EM. Blood pressure elevation versus abnormal albuminuria in the genesis and prediction of renal disease in diabetes. Diab Care $1992 ; 15 ; 1192$ 1204.

29. Norgard K, Feldt-Rasmussen B, Borch-Johnsen K, Saelan H, Deckert T. Prevalence of hypertension in type 1 (insulin dependent) diabetes mellitus. Diabetologia 1990;33;407-410.

30. Fioretto $\mathbf{P}$, Sambataro M, Cipollina MG, Dumer E, Giorato $C_{*}$ Morocutti A, Mollo F, Ben GP, Carraro A, Sacerdoti E, Brocco E, Opocher E, Nosadini R. Impaired response to angiotensin II in type I (insulin-dependent) diabetes mellitus. Role of prostaglandins and sodium-lithium countertransport activity. Diabetologia 1991;34;595-603.

31. Gambardella S, Andreani D, Cancelli A, Di Mario U, Cardamone I, Stirati G, Cinotti GA, Pugliese F. Renal hemodynamics and urinary excretion of 6-ketio-prostaglandin $F_{10 t}$ and thromboxane $B_{2}$ in newly diagnosed type I diabetic patients. Diabetes $1988 ; 37 ; 1044-1048$.

32. Berg van de BW, Nieuwentiuijzen Kruseman AC, Geel van JLC, Cornelissen $\mathbf{P}$, Mulder AW. Effect of short-term inhibition of prostaglandin synthesis on glomerular filtration rate and microalbuminuria in patients with incipient diabetic nephropahty. Neth J Med 1988;33;106-112.

33. Williamson $\mathbf{J R}$, Ostrow $\mathbf{E}$, Eades D, Chang $\mathbf{K}$, Allison W, Kilo $C$, Sherman WR. Glucose-induced microvascular functional changes in nondiabetic rats are stereospecific and are prevented by an aldose reductase inhibitor. $J$ Clin Invest $1990 ; 85 ; 1167-1172$.

34. Lovin BE, et al. Glucose increases rat plasma norepinephrine levels by direct action on the brain. Am J Physiol 1991;261;R1351-R1357.

35. Tilton RG, Chang K, Hasan $\mathbb{K S}$, Smith SR, Petrash JM, Misko TP, Moore WM, Currie MG, Corbett JA, McDaniel ML, Williamson JR. Prevention of diabetic vascular dysfunction by guanidines. Inhibition of nitric oxide synthase versus advanced glycation end-products formation. Diabetes $1993 ; 42 ; 221-232$. 


\section{SAMENVATTING}

Een groot deel patiënten met insuline-afhankelijke (type I) diabetes mellitus (IADM) zullen in de loop van de ziekte secundaire complicaties, zoals retinopathie (oogafwijkingen) en nefropathie (nierafwijkingen) ontwikkelen. Deze secundaire -microvasculaire- complicaties hebben een grote invloed op de morbiditeit en mortaliteit van deze patiënten. Een belangrijke theorie, die het ontstaan en verloop van deze complicaties verklaart, is de hemodynamische theorie. Volgens deze theorie leiden vroege hemodynamische veranderingen, zoals verhoogde capillaire doorbloeding en druk, tot het ontstaan van (micro)vasculaire sclerose (verharding van de vaatwand). Als gevolg van deze sclerose neemt de (maximale) weefsel perfusie af en verminderd het vermogen tot autoregulatie. Vele studies hebben de verschillende stappen van deze theorie aangetoond bij IADM patiënten (hoofdstuk 2). In dit proefschrift wordt met name ingegaan op de vroege hemodynamische veranderingen die optreden bij IADM patiënten en de pathofysiologische mechanismen die daarbij betrokken zijn. In hoofdstuk 2 is een overzicht gegeven van de mogelijke mechanismen/factoren die verantwoordelijk zijn voor het ontstaan en verloop van de vroege hemodynamische veranderingen: subklinische sympathische neuropathie, veranderde concentratie van circulerende vaatverwijdende hormonen (bijv. insuline, ANP, groei hormoon, histamine) of metabolieten (bijv. ketonen), endotheel dysfunction (a.g.v. chronische hyperglycemie), relatieve hypoxie.

In dit proefschrift zijn studies beschreven over 1) de invloed van acclimatisatie en/of diurnale ritmen op de onderarms- (spier) en huiddoorbloeding, 2) hemodynamische veranderingen en maximale perfusie capaciteit van de huid microcirculatie van zowel kortdurende als langdurende IADM patiënten met en zonder verschillende complicaties, 3) de compliantie van perifere venen van langdurende IADM patiënten en de mogelijke rol hiervan in het ontstaan van diabetische nefropathie, 4) de rol van vaatverwijdende prostaglandines in de vroege hemodynamische veranderingen bij kortdurende IADM patiënten en 5) de effecten van een kortdurende (1 uur) en langdurende (7 uur) lokale hyperglycemie op de onderarms macro- en microcirculatie en de vaatwandreactiviteit op noradrenaline van gezonde vrijwilligers.

In hoofdstuk 4 is een studie beschreven naar de diurnale variatie in onderarms (spier) doorbloeding en de huid (thermoregulatoire en nutritieve) microcirculatie. Reeds in 1968 werd beschreven dat de perifere spierdoorbloeding beïnvloedt wordt door een circadiaan ritme. Echter over mogelijke ritmen in huid microcirculatie is weinig bekend. Aangezien de meeste experimenten tussen 8.00 wur en 18.00 uur worden uitgevoerd, hebben wij de variatie in onderarms spier- en huiddoorbloeding in deze periode bestudeerd. De resultaten laten zien dat de onderarms spier doorbloeding toeneemt gedurende de dag, wat in overeenstemming is met wat anderen gevonden hebben. Echter de huid thermoregulatoire doorbloeding daalt gedurende de dag met name de eerste 2 à 3 uur. Een dergelijk patroon wordt ook gevolgd door de huid nutritieve doorbloeding. Wanneer soortgelijke experimenten in de middag 
worden gestart zien we een vergelijkbare daling in huiddoorbloeding gedurende de eerste 2 aे 3 uur, wat suggereert dat een dergelijke daling een gevolg is van een acclimatisatie fenomeen en niet van een diurnaal ritme. Het feit dat de proefpersonen reeds 12 uur nuchter waren aan het begin van de experimenten, speelt waarschijnlijk geen rol, angezien anderen hebben aangetoond dat pas na 48 uur vasten er een veranderde onderarms doorbloeding optreedt a.g.v. verlaagde noradrenaline spiegels. De waargenomen daling van de huid microcirculatoire doorbloeding wordt waarschijnlijk veroorzaakt door de lichamelijke inactiviteit van de proefpersoon. Als gevolg van de afgenomen activiteit, daalt de centrale en regionale warmte productie en is er dus ook minder noodzaak om lichaamswarmte kwijt te raken. Hierdoor neemt de thermoregulatoire huiddoorbloeding af. De resultaten van deze studie maken het aanbevelingswaardig om metingen van de onderarmsdoorbloeding steeds te verrichten op het zelfde tijdstip van de dag. Metingen van de huiddoorbloeding dienen in een cross-sectionele studie bij voorkeur na een standaard acclimatisatie periode te gebeuren en in een longitudinale studie na een acclimatisatie periode van 2-3 uur.

Reeds kort na het ontstaan van IADM kan een verhoogde huid- en spierdoorbloeding worden aangetoond, zoals aangetoond in hoofdstuk 5 en 7 . In hoofdstuk 5 is beschreven dat deze hyperperfusie van de huid aantoonbaar blijft in langdurende IADM patiënten, zelfs in de aanwezigheid van retinopathie, wat een algehele (micro)vasculaire vasodilatatie suggereert. Deze algehele vasodilatatie wordt ondersteund door bevindingen, zoals toegenomen netvlies- en nierdoorbloeding, toegenomen cardiac output en verhoogde capillaire druk in kortdurende kortdurende IADM patiënten. De post-occlusieve hyperimische piek-flux is normaal of toegenomen in zowel kortdurende als langdurende IADM patiënten, duidend op een onveranderde maximale arteriolaire vasodilator capaciteit. Echter parallel aan het ontstaan van diabetische nefropathie wordt een afname van de hyperperfusie en een verminderde hyperemische doorbloeding waargenomen t.o.v. kort- en langdurende IADM patiënten. Dit suggereert dat naast eerder aangetoonde structurele vasculaire veranderingen in the nier, het ontstaan van diabetische nefropathie representatief is voor structurele microangiopathie buiten de nier. De lokale neurogene regulatie van microvasculaire doorbloeding (in deze de precapillaire weerstand), getest a.h.v. de veno-arteriolaire reflex, lijkt niet veranderd te zijn in IADM patiënten met en zonder complicaties. Dit is niet in overeenstemming met bevindingen van anderen, die een verminderde veno-arteriolaire reflex aantoonden in zowel kort- als langdurende IADM patiënten. Mogelijk is dit het gevolg van het feit dat zij op een andere plaats van de vinger gemeten hebben, waar deze reflex varieert.

Zoals beschreven in de hemodynamische theorie, leidt verhoogde doorbloeding en druk, in combinatie met andere processen zoals niet-enzymatische glycosylering, tot (micro)vasculaire sclerose. De microcirculatoire doorbloeding van de huid is verminderd in IADM patiënten met beginnende nefropathie (hoofdstuk 5). Parallel aan deze perifere arteriolaire vaatveranderingen, zou een daling van de visco-elastische 
eigenschappen van perifere venen een mogelijke extrarenale manifestatie kunnen zijn van vroege diabetische nefropathie. In hoofdstuk 6 zijn studies beschreven naar de compliantie van de onderarms venen van langdurende IADM patiënten met en zonder vroege nefropathie. De veneuze compliantie was in dezelfde mate verlaagd in beide patiënten groepen t.o.v. de gezonde controle personen. Deze verminderde visco-elastische eigenschappen van de veneuze vaatwand van IADM patiënten kan het gevolg zijn van structurele vaatveranderingen en/of een toegenome tonus van het glad spierweefsel. Bij IADM patiënten met vroege nefropathie of met polyneuropathie is inderdaad een toegenome reactiviteit van de handvenen op noradrenaline aangetoond, wat een verhoogde veneuze tonus suggereert. Echter bij IADM patiënten zonder nefropathie is dit niet aangetoond, terwijl wij bij deze patiënten toch een verlaagde compliantie vonden. Bovendien bleek de veneuze dilatatie na toediening van nitroglycerine (wat de gladde spiercellen in de vaatwand relaxeert) gelijk te zijn in de diabetes patiënten en gezonden. Dit suggereert dat niet de veneuze tonus verhoogd is, maar dat structurele vaatveranderingen verantwoordelijk zijn voor de afgenomen veneuze compliantie in diabetes. In tegenstelling tot de waargenomen hemodynamische veranderingen in de huid (hoofdstuk 5), welke mogelijk structurele veranderingen van de arteriolaire microcirculatie indiceren, zijn de structurele vaatwand veranderingen van de onderarms venen niet gerelateerd aan het ontstaan van diabetische nefropathie.

Een verlies van de veneuze elasticiteit zou mogelijk een belangrijke rol kunnen in het ontstaan (essentiële) hypertensie, a.g.v. een verhoogde cardiale vullingsdruk en dus verhoogde cardiac output. IADM patiënten met vroege nefropathie (micro-albuminurie) hebben een verhoogd risico om hypertensie te ontwikkelen vergeleken met patiënten zonder nefropathie. Aangezien de veneuze compliantie in dezelfde mate verlaagd was in beide patiënten groepen, zullen waarschijnlijk andere factoren betrokken zijn bij het ontstaan van hypertensie in deze subgroep van IADM patiënten.

Vele dierstudies suggereren dat IADM vasculaire endotheel dysfunctie induceert. Secundair aan deze endotheel dysfunctie kan een veranderde productie van prostaglandines ontstaan. Een toegenome productie van vaatverwijdende prostaglandines zou een belangrijke rol kunnen spelen in de perifere hyperperfusie kort na het ontstaan van diabetes. Echter de vele humane en dier studies laten tegenstrijdige resultaten zien m.b.t. de productie van prostaglandines in IADM (zie hoofdstuk 2). Een toegenome productie van het vaatverwijdende prostacycline lijkt met name in de toegenome nierdoorbloeding van IADM patiẻnten een belangrijke rol te spelen. Om de mogelijke rol van toegenome prostacycline productie in de perifere hyperperfusie van kortdurende IADM patiënten te bestuderen, hebben we de onderarms- en de huid microcirculatoire doorbloeding gemeten voor en na cyclo-oxygenase inhibitie door infusie van ASA (hoofdstuk 7). De resultaten lieten zien dat de toegenome onderarms- (spier) en huid- (thermoregulatoire) doorbloeding van kortdurende IADM patiënten niet beïnvloed werd door cyclo-oxygenase inhibitie. Dit suggereert dat prostaglandines geen belangrijke rol spelen in de vroege hemodynamische verande- 
ringen in IADM. Bovendien duidden de resultaten erop dat prostaglandines geen relevante rol spelen in de regulatie van basale perifere doorbloeding van de mens.

In hoofdstuk 8 en 9 zijn studies beschreven naar de effecten van glucose op de onderarms- en huiddoorbloeding en de vasculaire reactiviteit op exogeen noradrenaline van gezonde vrijwilligers. Een verbetering van de metabole instelling (verlaging van de bloed glucose spiegel) van IADM patiënten resulteert in een normalisatie van de hemodynamische veranderingen (zie hoofdstuk 2). Kunstmatige hyperglycemie resulteert in gezonde dieren binnen een paar uur tot verhoogde doorbloeding en vasculaire permeabiliteit. Waarschijnlijk is dit het gevolg van door glucose geinduceerde veranderingen in het intracellulair milieu van de endotheel en/of glad spier cel (sorbitol pathway, $\mathrm{NADH} / \mathrm{NAD}^{+}$ratio, myoinositol opname, DAG productie, protein kinase $\mathrm{C}$ etc.), leidend tot verstoring van de endotheliale balans van vasoactieve factoren en/of veranderingen in vasoreactiviteit (hoofdstuk 2). In de experimenten beschreven in hoofdstuk 8 en 9 , hebben we gebruik gemaakt van het geperfundeerde onderarmsmodel om een lokale onderarms hyperglycemie te induceren m.b.v. infusie van kleine hoeveelheden glucose in de brachiaal arterie. Zo is het mogelijk om de lokale effecten van hyperglycemie op de hemodynamiek van een onderarm te bestuderen, zonder systemische veranderingen in bijv. glucose, insuline of glucagon spiegels teweeg te brengen, aangezien dit op zich ook weer hemodynamische veranderingen teweeg zou kunnen brengen. In hoofdstuk 8 staat beschreven dat een matige lokale hyperglycemie $(\approx 10 \mathrm{mmol} / \mathrm{l})$ gedurende een uur, geïnduceerd door glucose $20 \%$ infusie in de brachiaal arterie, resulteert in een verhoging van de onderarmsdoorbloeding. Dit effect was geen osmotisch effect, aangezien infusie van mannitol $20 \%$ geen effect had op de doorbloeding. Echter een soortgelijke of zelfs hogere hyperglycemie $(\approx 18 \mathrm{mmol} / \mathrm{l})$, geïnduceerd door glucose $5 \%$ infusie, had geen enkel effect op de onderarmsdoorbloeding. Naar onze mening was het effect van glucose $20 \%$ het gevolg van extreem hoge glucose concentraties rond de tip van de catheter, welke veel lager waren bij de glucose $5 \%$ infusie. Deze studie leidde dus tot de conclwsie dat een korte lokale hyperglycemie (10 en 18 mmol/1) geen elfect heeft op de onderarmsdoorbloeding. Aangezien sommige dierstudies suggereren dat een langere periode van hyperglycemie noodzakelijk is om vasculaire dysfunctie te induceren, zijn we vervolgens de effecten van een 7-uurs lokale hyperglycemie $(\approx 16 \mathrm{mmol} / \mathrm{l})$, m.b.v. glucose $5 \%$ infusie, gaan bekijken op de onderarmsen huiddoorbloeding en de (endotheel onafhankelijke) vasoreactiviteit op noradrenaline (hoofdstuk 9). Deze lokale hyperglycemie, gedurende 7 uur, had geen effect op de onderarms- of huiddoorbloeding, of op de vasoreactiviteit op noradrenaline. Dit in tegenstelling tot resultaten van dierstudies. Aangezien in de rat is aangetoond dat er een heterogeniteit bestaat in glucose gevoeligheid tussen verschillende weefsels, is het mogelijk dat de bloedwaten van de huid en spier in de onderarm een nog hogere of langere hyperglycemie nodig hebben, voordat er hemodynamische veranderingen optreden. Hogere glucose waarden dan $16 \mathrm{mmol} / \mathrm{l}$ kunnen wij in ons onderarmsmodel niet gebruiken, zonder systemische veranderingen in glucose en insuline spiegels te induceren. Bovendien zijn zulke hoge glucose waarden niet relevant voor een 
diabetes patiënt. Daarom zijn we momenteel een studie aan het verrichten naar de effecten van een 24-uurs lokale hyperglycemie op de onderarms- en huiddoorbloeding en op de endotheel afhankelijke en onafhankelijke vasoreactiviteit.

De resultaten van de in dit proefschrift gepresenteerde studies hebben tot de volgende conclusies geleid:

1. De onderarms (spier) doorbloeding stijgt gedurende de dag $(9.00$ tot 17.30 uur) als gevolg van een circadiaan ritme. De thermoregulatoire huiddoorbloeding daalt echter gedurende de dag, waarschijnlijk als gevolg van acclimatisatie aan de fysieke inactiviteit.

2. Kort na het ontstaan van IADM is de thermoregulatoire huiddoorbloeding verhoogd, wat wijst op vroege perifere hemodynamische veranderingen. Deze hyperperfusie van de huid blijft aantoonbaar in langdurende IADM patiënten, zelfs in de aanwezigheid van retinopathie. Echter parallel aan het ontstaan van diabetische nefropathie treedt er een vermindering van de hyperperfusie en de maximale arteriolaire dilatatie capaciteit op, wat mogelijk een gegeneraliseerde microvasculaire verstoring indiceert.

3. De visco-elastische eigenschappen van perifere venen zijn verlaagd in IADM patiënten met en zonder vroege nefropathie, mogelijk als gevolg van structurele vaatwand veranderingen. In tegenstelling tot arteriolaire microvasculatuur in de huid, zijn deze perifere veneuze veranderingen niet gerelateerd aan het ontstaan van diabetische nefropathie. Voorts speelt de verlaagde veneuze compliantie bij IADM patiënten met vroege nefropathie geen belangrijke rol bij het ontstaan van hypertensie.

4. De verhoogde onderarms- (spier) en thermoregulatoire huiddoorbloeding, zoals waargenomen bij kortdurende IADM patiënten, is waarschijnlijk niet gerelateerd aan verhoogde endotheliale productie van prostacycline. Prostaglandines spelen waarschijnlijk geen belangrijke rol in de lokale regulatie vab basale perifere perfusie bij de mens.

5. Acute lokale onderarmshyperglycemie (gedurende 1 uur), geïnduceerd door glucose $20 \%$ infusie in de brachiaal arterie zonder systemische metabole effecten te veroorzaken, leidt tot een stijging van de onderarms (spier) doorbloeding. Dit effect wordt niet veroorzaakt door hypertoniciteit, maar is waarschijnlijk gerelateerd aan de extreem hoge glucose concentraties aan de tip van de catheter. Infusie van glucose $5 \%$, leidend tot een vergelijkbare hyperglycemie, heeft geen effect op de onderarmsdoorbloeding.

6. Lokale onderarmshyperglycemie gedurende 7 uur, geïnduceerd door glucose $5 \%$ infusie (i.a.), heeft geen effect op de onderarms (spier) en microcirculatoire huiddoorbloeding, of op de vasoreactiviteit op noradrenaline. 


\section{TENSLOTTE..}

Bij het lezen van andere proefschriften en verslagen stuitte ik altijd weer op een cliché met ongeveer de volgende strekking: "Dit boekje en de studies die hierin beschreven staan, zouden niet mogelijk geweest zijn zonder de inzet en hulp van vele mensen". En altijd kreeg ik dan een beetje een gevoel van: hè hè, wat overdreven allemaal. Maar gaandeweg mijn AlO-schap realiseerde ik mij dat deze cliché maar al te waar was. Daarom wil ook ik op de laatste pagina's van mijn boekje een aantal mensen, in willekeurige volgorde, van harte bedanken:

Allereerst wil ik alle patiënten en vrijwilligers bedanken voor het belangeloos afstaan (gedurende enkele uren) van hun ledematen, zonder welke ik geen studiemateriaal gehad zou hebben.

Prof. dr. A.C. Nieuwenhuijzen Kruseman, die naam heb ik zo vaak moeten invullen op formulieren dat ik het nu foutloos kan. En altijd was de regel te kort, of werd het abstract daardoor te lang. Enfin, beste Arie, vooral in mijn beginperiode hebben wij veel kontakt gehad. Later werd jouw begeleidende taak voor een gedeelte overgenomen door Nicolaas. Toch bleef je altijd merkbaar op de achtergrond aanwezig en wist je net op de goede momenten de vinger op de zere plek te leggen. Een van jouw gaven is dat je ogenschijnlijk grote problemen binnen no time weet te reduceren tot kleinigheden. Dat heeft mij altijd een zeker gevoel gegeven.

De meeste uren heb ik de afgelopen vier jaar doorgebracht met Nicolaas Schaper. Een middag-besprekinkje liep meestal uit tot aan Joop van Zijl en soms ook tot diep in de nacht (blijkbaar ben je na twaalf uur 's middags op je best). Maar altijd waren deze brain storms zeer vruchtbaar (en niet te voorspellen door Erwin Krol). Jij was de stuwende kracht achter dit boekje. Altijd vond jij een positief punt, als ik het niet meer zag zitten. Bovendien blijft jouw integere persoonlijkheid voor mij een voorbeeld.

Dick Slaaf, volgens de wet een ambtenaar, maar als op iemand dit predikaat zeker niet slaat, dan ben jij dat wel. Nog nooit heb ik zo snel van iemand correcties teruggekregen als van jou. Als mijn laatste velletje door de fax naar Louisville was, rolde jouw eerste correctie al er achteraan. Een man, een man, een woord, een woord; recht door zee; altijd paraat. Meer hoef ik niet te zeggen.

In den beginne ..... was ik alleen, maar gelukkig kregen we na verloop van tijd analytische ondersteuning. Met name jij, Claudia de Haan, verzet achter de schermen enorm veel werk en je bent onmisbaar op ons lab geworden. Maar ook Paul van Es en Monique Fuss hebben hun steentjes bijgedragen aan dit boekje.

Daarnaast hebben een heel aantal studenten: Yvonne Schoon, Maureen Janssen, Eli Bouhouch, Frank Jungbauer, Niek Kessels, ieder op eigen wijze bijgedragen. 
Zonder de hulp van Lou en Serva van het Klinisch Chemisch lab en Rene en Elian van het haematologisch lab zouden een aantal studies nooit zo soepel verlopen zijn. Last but not least in dit rijtje is Piet Claessens. Zonder jouw technische ondersteuning was het lab nooit geworden wat het nu is. Altijd had je wel ergens een reserve apparaat staan, of maakte je een passend kabeltje.

Alle collegea van de werkgroep Endocrinologie en de vakgroep Interne Geneeskunde, inclusief het secretariaat (met name Lilian W., Lilian D. en Tiny W.), bedank ik voor de hulp en het creëren van een prettige werksfeer.

Ook alle microcirculanten van Fysiologie (vooral Sabrina bedankt voor het maken van sommige illustraties), Farmacologie en Heelkunde bedank ik voor hun bijdrage en de prettige sfeer tijdens congressen.

I would like to thank all the members of the Promotion Committee: Prof. Kitslaar (chairman), Prof. Reneman, Prof. Struyker Boudier, Prof. Tooke, and dr. Daemen for their comments and the approval of my manuscript.

Natuurlijk vergeet ik niet mijn paranimfen. Frank Huvers, bijna twee jaar lang een naaste collega. Jij staat altijd voor iedereen klaar, zowel op het werk als na het werk. Niets is jou teveel. Bedankt voor de hulp tijdens de experimenten en rond het organiseren van de promotie. Paul Stalmeijer gen. Schmidt, jij bent al ongeveer 16 jaar een vriend. Je bracht mij de eerste beginselen van het verkennen bij en je zorgt altijd voor de juiste sfeer. Bovendien weet jij in de vrije tijd vaak de boel goed in Brand te zetten.

Leef $\mathrm{Pa}$ en Ma. Geer höb dit alles meugelik gemaak. Iech kos altied goon en stoon boe iech wow, kos studere en aoch die paar maond tijdens ut sjrieve vaan dit book op mien aw zolderkamer, woord iech oetstekend verzörreg. Bedaank.

Leef Ineke, aoch diech zals wel un book kinne sjrieve euver de aofgelaope veer jaor. Diech höbs aoch väöl motte opoffere, mer zoonder diech waor dit neet gelök. En opins waor daor Joep, mien lekker joonk. Door häöm lierde iech te relativere. D'r is mer ein dink belangriek in ut leve: neet de carrière, mer dat ste gelökkig bis ! 


\section{LIST OF PUBLICATIONS}

\section{Papers}

B.M.L. Verburg-van Kemenade, B.G. Jenks, A.J.H.M. Houben.

Regulation of cyclic-AMP synthesis in amphibian melanotrope cells through eatecholamine and GABA receptors. Life Sci $1987 ; 40 ; 1859-1867$.

A.J.H.M. Houben, N.C. Schaper, D.W. Slaaf, G.J. Tangelder, A.C. Nieuwenhuijzen Kruseman.

Skin blood cell flux in insulin-dependent diabetic subjects in relation to retinopathy or incipient nephropathy. Eur J Clin Invest 1992;22;67-72.

A.J.H.M. Houben, N.C. Schaper, A.C. Nieuwenhuijzen Kruseman.

Acute effects of local hyperglycaemia on peripheral blood flow in man. Diabetic Medicine 1993;10;39-43.

A.J.H.M. Houben, A.C. Nieuwenhuijzen Kruseman, E. Bowhouch, D.W. Slaaf, N.C. Schaper.

Peripheral macro and microcirculation in short-term insulin-dependent diabetes mellitus: the role of prostaglandins in early haemodynamic changes. Eur J Clin Invest 1993;in press.

A.J.H.M. Houben, D.W. Slaaf, F.C. Huvers, P.W. De Leeuw, A.C. Nieuwenhuijzen Kruseman, N.C. Schaper. Diurnal variations in human forearm macro and microcirculation. (submitted).

N.C. Schaper, A.J.H.M. Houben, Y. Schoon, J. Kooman, D.W. Sleaf, A.C. Nieuwenhuijzen Kruseman. Venous compliance and the venodilatory effect of nitroglycerin in insulin-dependent diabetic patients with and without (incipient) nephropathy. (submitted).

A.J.H.M. Houben, N.C. Schaper, C.H.A. de Haan, F.C. Huvers, D.W. Slaaf, P.W. de Leeuw, A.C. Nieuwenhuijzen Kruseman. The effects of a 7-hour local hyperglycaemia on peripheral blood flow and vascular reactivity in man. (submitted).

\section{Proceedings/Abstracts}

A.J.H.M. Houben, N.C. Schaper, B.H.R. Wolffenbuttel, A.C. Nieuwenhuijzen Kruseman. Skin microcirculation in IDDM patients with incipient nephropathy. Neth J Med 1989;35;A3.

A.J.H.M. Houben, N.C. Schaper, D.W. Slaaf, A.C. Nieuwenhuijzen Kruseman. Functional changes in sikin microcirculation, assessed by laser-Doppler fluxmetry (LDF), in early stage insulin dependent diabetes mellitus (IDDM) patients. Int J Microcirc Clin Exp 1990;9;86.

A.C. Nieuwenhuijzen Kruseman, A.J.H.M. Houben, D.W. Slaaf, N.C. Schaper.

Microcirculation in different stages of type I (insulin dependent) diabetes mellitus. Diabetologia $1990 ; 33 ; \mathrm{Al} 70$.

A.J.H.M. Houben, N.C. Schaper, A.C. Nieuwenhuijzen Kruseman.

Skin microcirculation, assessed by laser-Doppler fluxmetry, in IDDM patients with and without microvascular complications. Eur I Clin Invest 1990;20;A53.

N.C. Schaper, A.J.H.M. Houben, A.C. Nieuwenhuijzen Kruseman.

Peripheral blood flow after acute cyclooxygenase inhibition in short-term insulin-dependent diabetic patients (IDDM). Diabetologia 1991;34;A135.

A.C. Nieuwenhuijzen Kruseman, A.J.H.M. Houben, N.C. Schaper. Effects of intraarterial glucose infusion on forearm blood flow. Diabetologia 1991;34;A73.

A.J.H.M. Houben, N.C. Schaper, D.W. Slaaf, A.C. Nieuwenhuijzen Kruseman. Effects of intraarterial glucose infusion on forearm blood flow. Fifth World Congres for Microciroulation, Louisville, USA, 1991, p. 39.

A.J.H.M. Houhen, N.J.G. Kessels, N.C. Schaper, A.C. Nieuwenhuijzen Kruseman.

Peripheral blood flow after acute cyclooxygenase inhibition in short-term insulin-dependent diabetic (IDDM) patients. Fitth World Congres for Microcirculation, Louisville, USA, 1991, p.38. 
N.C. Schaper, A.J.H.M. Houben, J.A.G. Wijnen, L.M.A.B. Van Bortel, A.C. Nieuwemhuijzen Kruse man. Local hyperglycemia increases regional blood flow directly in man. Diabetes 1991;40suppl1;212A.

A.J.H.M. Houben, F. Jungbauer, J.A.G. Wijnen, L.M.A.B. Van Bortel, D.W. Slaaf, A.C. Nieuwen huijzen Kruseman. Effects of local hyperglycaemia on forearm blood flow. Int J Miorocinc Clin Exp $1991 ; 10 ; 379$.

A.J.H.M. Houben, Y. Schoon, A.C. Nieuwentuijzen Kruseman, N.C. Schaper, Venous distensibility (VDIST) in insulin-dependent diabetes mellitus (IDDM) patients. Eur J Clin Invest $1992 ; 22 ; A 56$.

A.J.H.M. Houben, N.C. Schaper, D.W. Slaaf, A.C. Nieuwenhuijzen Kruseman.

The effect of acute prostaglandin inhibition on peripheral blood flow in short-term insulin-dependent diabetic (IDDM) patients. Int I Microcirc Clin Exp 1992;11;324.

A.J.H.M. Houben, N.C. Schaper, D.W. Slaaf, A.C. Nieuwenhuijzen Kruseman.

Day-time variation in peripheral micro and macrocirculation in man. Int $f$ Microcirc Clin Exp $1992 ; 11 ; 559$

N.C. Schaper, A.J.H.M. Houben, Y. Schoon, A.C. Nieuwenhuijzen Kruseman.

Increased wenous wall stiffness in type I diabetes with and without microalbuminuria. Diabetologia 1992;35-suppl 1;A162.

A.J.H.M. Houben, N.C. Schaper, A.C. Nieuwenhuijzen Kruseman, P.W. de Leeuw.

Forearm vascular reactivity to noradrenaline is decreased in the morning. Int Catecholamine Symposium, Amsterdam, 1992, p.142.

A.J.H.M. Houben, N.C. Schaper, F.C. Huvers, P.W. de Leeuw, D.W. Slaaf, A.C. Nieuwenhuijzen Kruseman. Diurnal variations in peripheral micro and macrocirculation in man. Eur $\mathbf{J}$ Clin Invest 1993;23 suppl 1;A53.

A.J.H.M. Houben, N.C. Schaper, F.C. Huvers, A.C. Nieuwénhuijzen Kruseman.

Effects of 7 hours local hyperglycaemia on forearm blood flow and vascular reactivity in man. Diabetologia 1993;36 suppl 1;A70.

F.C. Huvers, N.C. Schaper, L. Hofstra, A.J.H.M. Houben, P. Kitslaar, P.W. de Leeuw, A.C. Nieu wenhuijzen Kruseman. Venous distensibility and the venodilatatory effect of nitroglycerin are not reduced in uncomplicated non-insulin-dependent diabetes mellitus. Eur J Clin Invest $1993 ; 23$ suppl $1 ;$ A7. 


\section{CURRICULUM VITAE}

Alfonsius Josephus Hubertus Mathias (Boy) Houben werd geboren op 5 maart 1963 te Heerlen. In 1981 behaalde hij het atheneum-B diploma aan de scholengemeenschap Jeanne d'Arc te Maastricht. Datzelfde jaar startte hij met de studie Biologie (oude stijl) aan de Katholieke Universiteit Nijmegen. Het kandidaatsexamen werd in 1984 gehaald. De doctoraalfase, bestaande uit het hoofdvak Dierfysiologie (KU Nijmegen) en de bijvakken Humane Biologie ( $\mathrm{RL}$, Maastricht) en Biogeologie (KU Nijmegen), werd afgesloten in april 1988. Ter vervulling van de vervangende dienstplicht werkte hij van juni 1988 tot december 1989 bij de werkgroep Endocrinologie (hoofd: Prof. A.C. Nieuwenhuijzen Kruseman), vakgroep Interne Geneeskunde, Academisch Ziekenhuis Maastricht, met als taak het opzetten en uitvoeren van microcirculatiore metingen bij diabetes mellitus patiënten. Van december 1989 tot december 1993 was hij aangesteld als AIO bij dezelfde werkgroep voor het verrichten wan het hier beschreven promotieonderzoek. Vanaf december 1993 heeft hij een aanstelling als post-doc bij de werkgroep Nefrologie/Hypertensie (hoofd: Prof. P.W. de Leeuw), vakgroep Interne Geneeskunde, Academisch Ziekenhuis Maastricht. 
